\title{
Listening to student voices: A phenomenological investigation of the student experience of using technology for learning.
}

Judy Lymbery

\begin{abstract}
A thesis
submitted to the Victoria University of Wellington

in fulfillment of the requirements for the degree of

Master of Education
\end{abstract}

Victoria University of Wellington

2017 


\section{Abstract}

This study explored the perceptions of 8 secondary school students who self identified as heavy users of digital technology to gain insight into how the young people perceived that their school was preparing them for a future in the digital world. Much of the previous research had focused on the effects of technology on learning outcomes and the integration of technology in the classroom as identified by teachers and management. What appeared to be lacking from this previous research was the attention being paid to the student voice. The purpose of this study, therefore, was to investigate the student perceptions of using digital technologies for learning by listening to the students talking about their experiences from both at school and at home. An interpretive phenomenological approach, was selected for this study as a systematic attempt by the researcher to come into direct contact with the world of the participants, to uncover and describe the meaning and structures of their lived experiences.

The information gathered for the study was based on interviews, observation, and talking in depth with the 8 participants (four males and four females) aged between 15 and 17 years and attending a secondary school in Wellington, New Zealand. Using an interpretive phenomenological method of analysis, four key patterns were revealed that provided detail on the barriers or enablers that the participants had reported that influenced their technology use. These patterns include;

- access, not only to hardware and software but also to digital knowledge

- teacher knowledge and how they integrate this into the learning environment

- students' personal learning preferences

- developments for the future as identified by the students themselves.

A significant finding was that while schools were attempting to engage these young people with technology, little regard was taken of the students' prior 
knowledge and skills in this area. In the use of search engines, social networking and using mobile devices the students self reported skills superior to most of their teachers, but were lacking in the way in which they applied these skills to their learning. What also became apparent was the resentment some students felt at the control exercised by teachers over technology use. The students were frustrated that the teachers were preventing them from using the tools with which they were familiar and resisting the offers of support and assistance from the young people.

Underpinning modern life is the idea that advances in technology are creating societal changes that require new approaches and practices, not only in our educational establishments, but also in our work and social lives. Radical change in education is needed because our traditional school system does not meet the needs of a new generation of "tech-savvy" learners. Young people are different to all generations that have gone before because they think, behave, and learn differently as a result of continuous, pervasive exposure to modern technology. It has been claimed that education is a key arena for supporting these changes but the student participants recommended that schools and policy makers listen to the student voice, accept the need to respond to different learning preferences and allow them to use their knowledge and enthusiasm for digital technology as a tool to support teacher development. 


\section{Acknowledgements}

I wish to acknowledge all the support and encouragement that I have received from friends, family, colleagues as well as my supervisors, Dr Lex McDonald and Dr Stephen Marshall as I travelled on this extended voyage of discovery that enabled the completion of this thesis. I have likened my journey to a voyage, as I have experienced the changing winds and tides as well as the storms and calms over the time of conducting this research. I now have completed my voyage and feel safely anchored in my home port.

As with all great adventures, time must be spent in the planning and provisioning; during this time, the support I received from friends and colleagues both in New Zealand and the UK enabled me to start this trip of a lifetime. My need to feel connected to family and friends in the UK had led me to explore the use of technology as a means of communication. Following the lead of the young people that I worked with, they sparked my interest in examining the young people's use of digital technology, not only for communicating but for also learning. So, with full sails and a fair wind the journey began.

It has not all been plain sailing; at times, I faced the doldrums and was grateful to my husband, Gregg, who provided endless support, excellent meals as well as the tough talk when I was about to give it all away. You were my PFD during this trip! The long walks on the beach with my faithful companion, Jed, who never criticised but just patiently listened to my ramblings, the only dog to have worked towards a $\mathrm{PhD}$, he was important in giving me time to clear my head.

My thanks must also go to my real sailing crew, Paulie and Barbara, both academics in their own right - they knew when to ask the PhD question and, more importantly, when not to broach the subject. The young people on the crew, Muppet and Meerkat who both gave their opinions on my study that served to validate the views of the Netgen. You all gave me the time for remaining true to my love of sailing and racing throughout my voyage of discovery into the digital world.

Finally, to the participants, I will be forever in your debt. You shared your thoughts, opinions and ideas in a clear and frank manner. You provided the safe harbour when I was lost in an ocean of details, information and experiences. I have, 
through you, gained valuable insight into the world of the Netgen kids. Sincere thanks must also go to the principals and teachers from the Wellington schools that enabled the collection of rich data. 


\section{Contents}

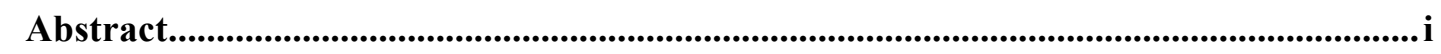

Acknowledgements ...................................................................................................................................ii

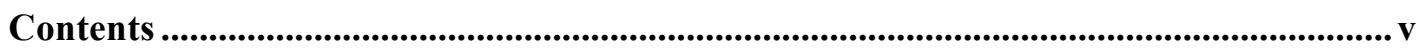

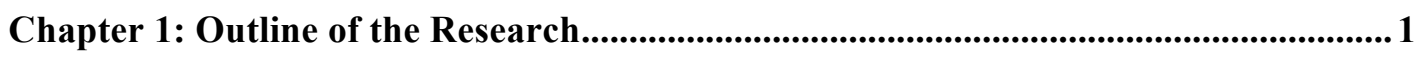

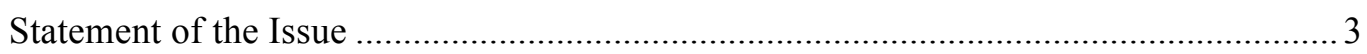

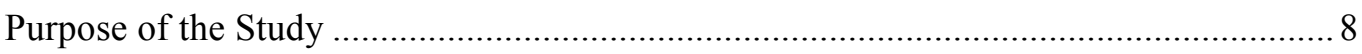

Main Research Question ........................................................................................

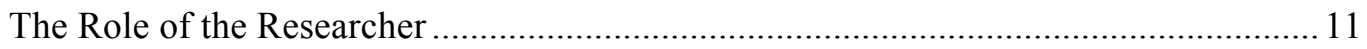

Chapter 2: Literature Review................................................................................................ 12

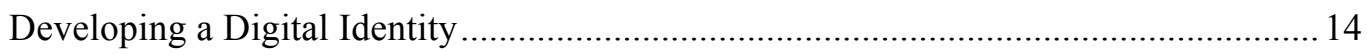

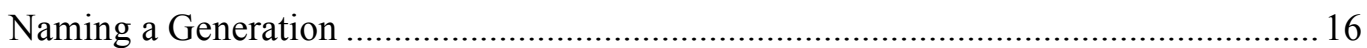

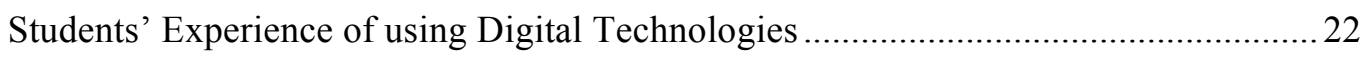

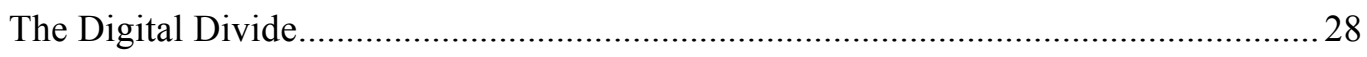

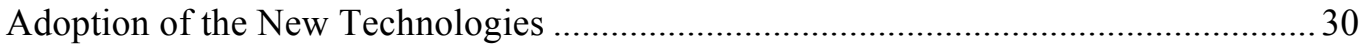

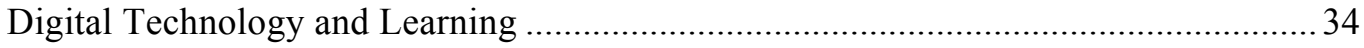

Developing Digital Pedagogy within the School System. ............................................... 41

Role of the Teacher in the Challenging Digital Age? .....................................................5 54

Assessing the Effectiveness of Technology Use in the Classroom..................................56

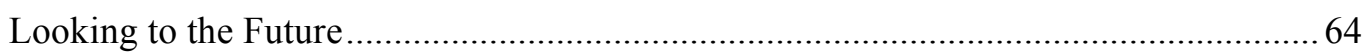

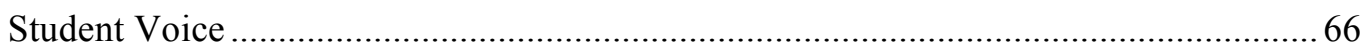

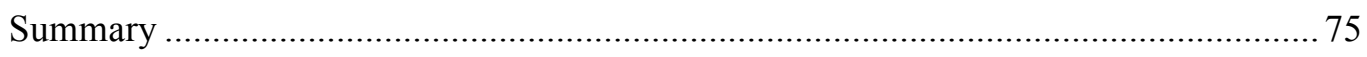

Chapter 3: Research Methodology and Design .......................................................................... 77

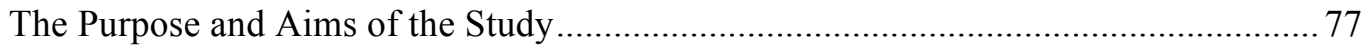

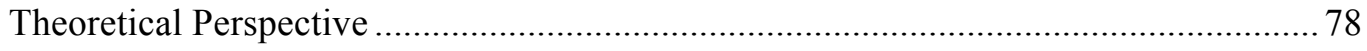

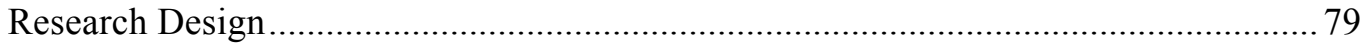

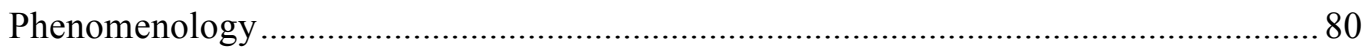

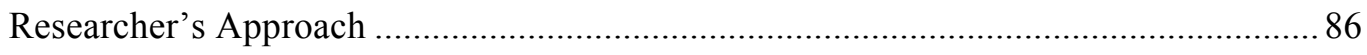

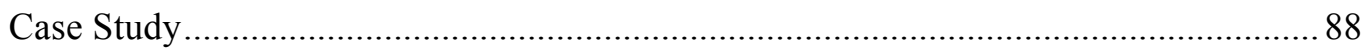

Ensuring the Quality and Reliability of Qualitative Research....................................... 91

Criteria for Judging Qualitative Research ................................................................ 92

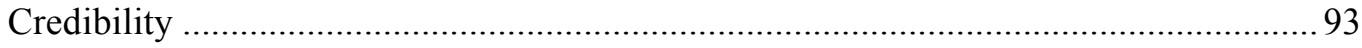

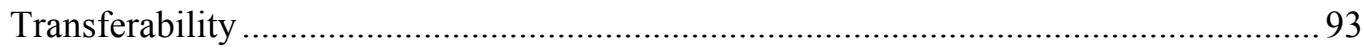




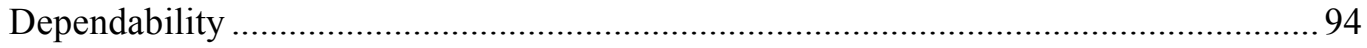

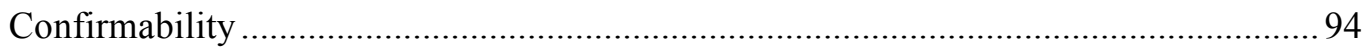

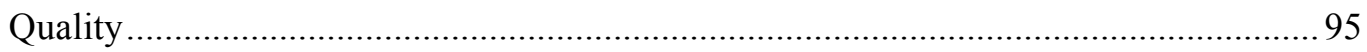

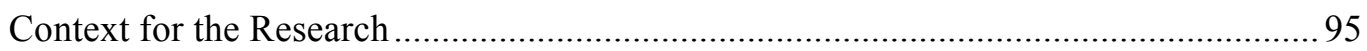

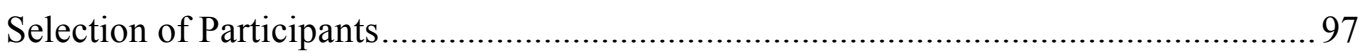

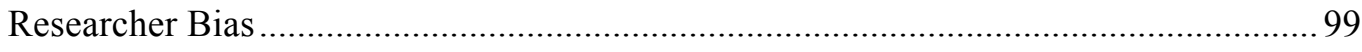

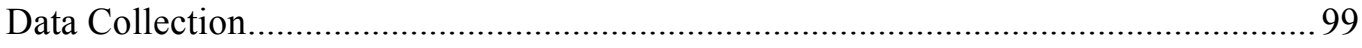

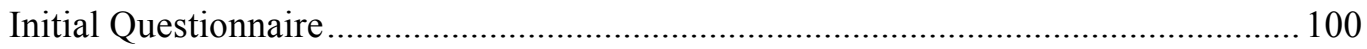

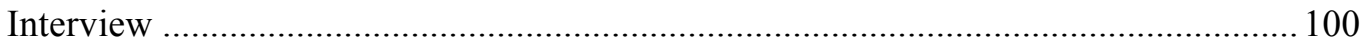

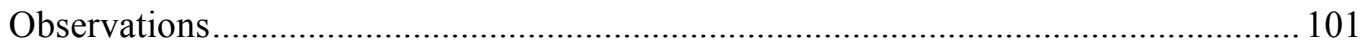

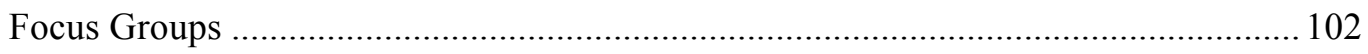

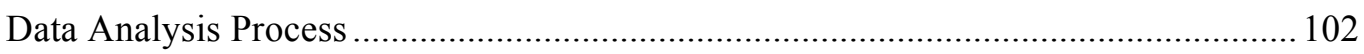

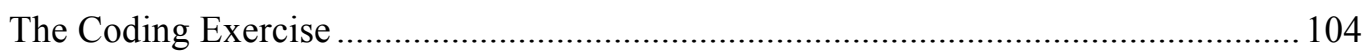

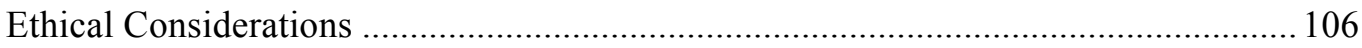

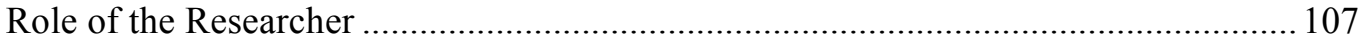

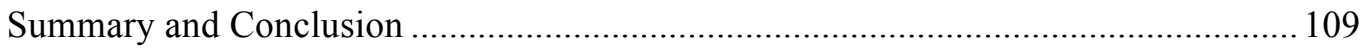

Chapter 4 Individual Case Studies.......................................................................................... 110

Participant 1.Tom.

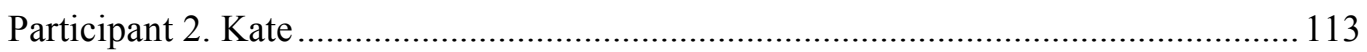

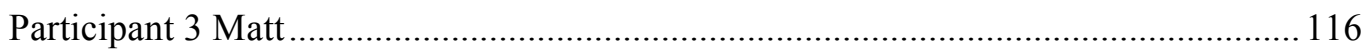

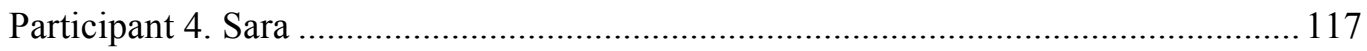

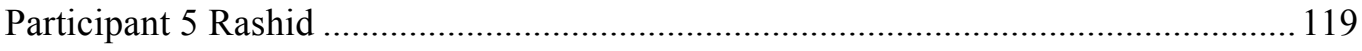

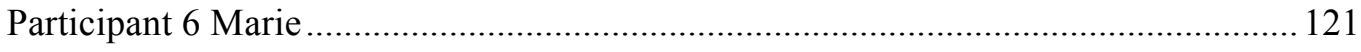

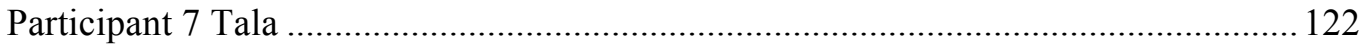

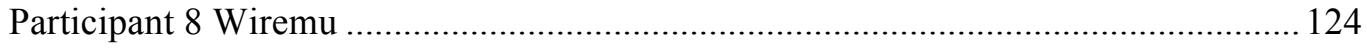

Chapter 5: Findings - Cross Case Analysis................................................................................ 126

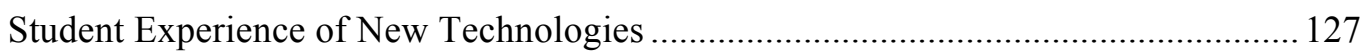

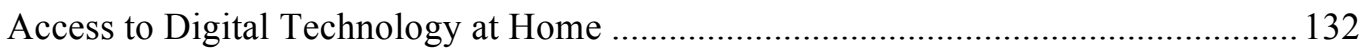

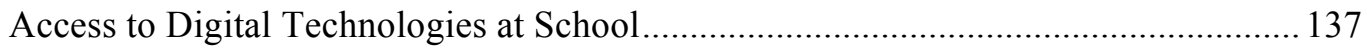

Student Perceptions of Teacher Knowledge and Capability ……................................ 151

Integration of Technology into Learning at School ................................................... 154

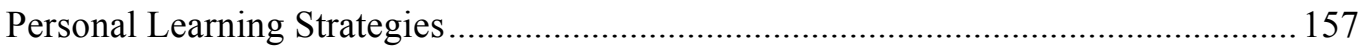

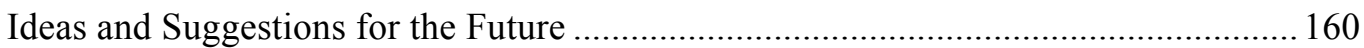

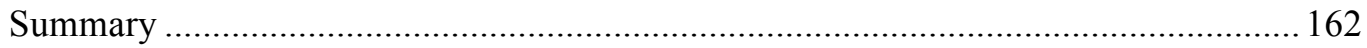


Chapter 6: Discussion of Findings.......................................................................................... 164

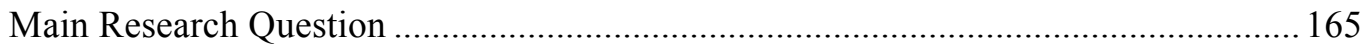

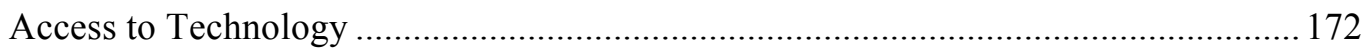

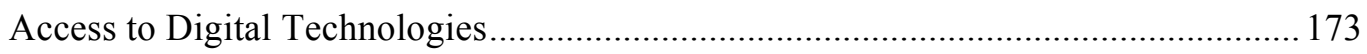

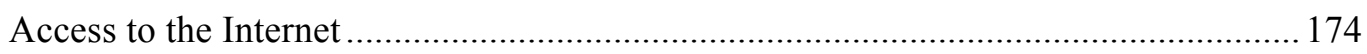

Access to Digital Devices at Home ............................................................................ 176

Access to Digital Devices at School .......................................................................... 179

Student Perceptions of Teacher Knowledge and Capability ......................................... 187

Integration of Technology into Learning at School ..................................................... 190

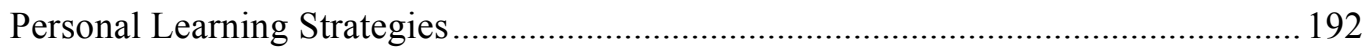

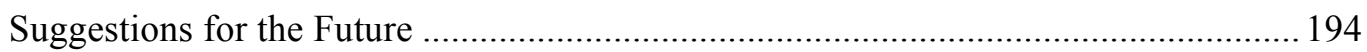

Chapter 7: Conclusion and Implications for the Future..................................................196

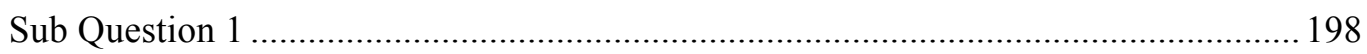

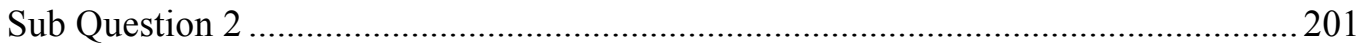

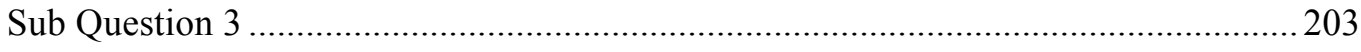

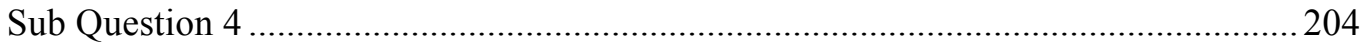

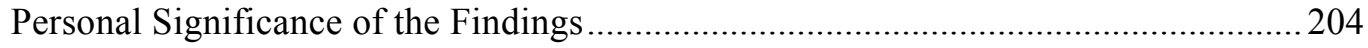

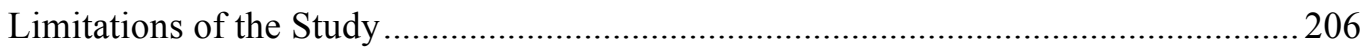

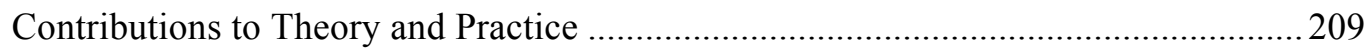

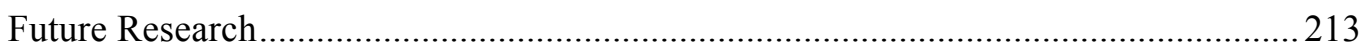

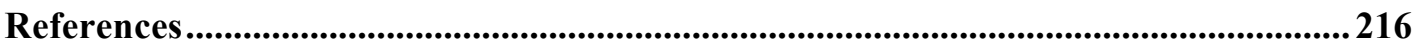

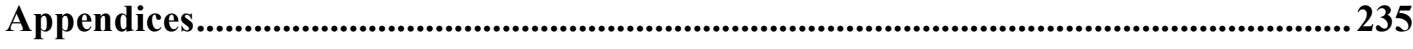

Appendix A Initial Information Technology survey............................................2236

Appendix B Participant Information sheet and Consent Form........................... 242

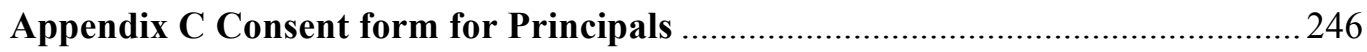

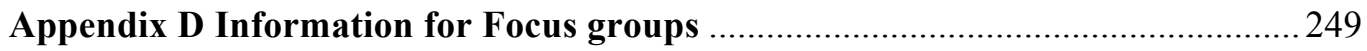

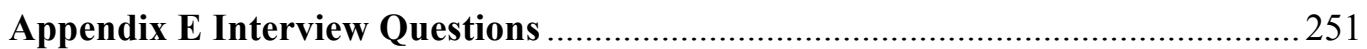

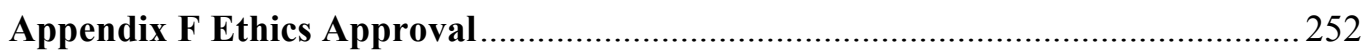




\section{Chapter 1: Outline of the Research}

Throughout New Zealand the use of educational technology in schools has been rapidly changing. This has, in part been due to the increasing availability of the hardware and the inclusion of high-speed broadband access in the schools. Technology has been affecting the way that people learn about the world and how they have communicated for hundreds of years, from the introduction of the printing press to the introduction of mobile and latterly wearable technology devices for communication. The introduction of an Internet connection into classrooms during the last twenty years has enabled some teachers to include the use of the Internet on mobile devices in their teaching. The New Zealand Information and Communications Technology Strategic Framework for Education (Ministry of Education, 2006) stated that all students should be able to access information and communications technology at school and have the opportunity to become confident and capable users of said technology. Further development and the completion of Ultrafast broadband infrastructure should see all schools being connected by 2016 . Whilst it is important to recognise that there are a diversity of views on the use and impact of ICT in the schools, the use of mobile technologies and social networking sites are an everyday feature in the lives of our young people.

Despite priority being placed on investment in the school infrastructure there are clear tensions. The pace of adoption of personal devices and social media use by students far outstrips the changes occurring in most schools. Devisive intergenerational narratives and moral panics regarding the use of technology by teenagers continues to cause concern to parents and teachers struggling to keep up with young people that are constantly discovering new technologies.

Moreover, this issue of technology use by teenagers has frequently been discussed in the media, by parents and educators and often in terms of generalities. Assumptions have been made by this older generation, that all young people are digital natives (Prensky, 2001); he describes the young people as frequent and habitual users of technology for organising their social and working lives. The terminology used by Prensky (i.e. digital natives) to describe young people assumes that all young people have expertise in using the latest devices for organising their 
lives regardless of other factors such as access to both hardware and software as well as economic factors, location and access to the Internet.

The young people of today are being described by some as significantly "different to previous generations in the way they think, in the way they access, absorb, interpret, process, and use information and, above all, in the way they view, interact, and communicate in the modern world" (Jukes \& Dosaj, 2004, p. 2). If true, this difference in the way that they think and process information has significant implications for the teaching profession. Carr (2011) and Greenfield (2014) have also argued that the Internet use may be having an effect on the structure of the human brain and this is contributing to the changing relationship between students and teachers.

Each succeeding generation has made comments about the younger generation and often concluded that the youth of the day would not succeed in life unless there was a change in their behaviour and attitude. For example, Socrates (469-399BC) noted that:

Children now love luxury, they have bad manners, contempt for authority; they show disrespect for adults, and love to talk rather than work or exercise. They no longer rise when adults enter the room. They contradict their parents, chatter in front of company, gobble down food and intimidate their teachers.

These very same comments continue to be made by parents, the media and teachers about young people in the $21^{\text {st }}$ century.

Various studies, conducted by the MacArthur Foundation - the Digital Media and Learning initiative (2005) and Pew Internet Research (Lenhart et al., 2005, 2007a, 2007b; Madden, Lenhart, Duggan, Cortesi \& Gasser 2013) and more recently Davies \& Eynon, (2013), have identified that it is during the teenage years that young people become more proficient in developing, sharing, and establishing their skills with technology. New technologies appear to meet the needs of the adolescent as they move towards independence (Davies \& Eynon, 2013). Young people appear to have the capacity to move quickly from one activity to another using multiple devices to meet their needs. Information technology is entwined into their lives and they do not see technology as something separate from themselves. 
Of course, they are also learners who require extra help with education and support for learning no matter how technologically savvy they might be.

Therefore, this study was designed to identify if a young person's perception of learning supported by technology was being provided at their school. This was to be achieved through a qualitative interpretive phenomenological case study of eight young New Zealand students and examining their digital experiences as well as how they were being prepared for a life in a digital world.

Statement of the Issue

The study examined eight student's use of digital technology, their experience of how this is used at school and at home and how they are prepared, by the school, to face the future world of work. The analysis shows that not all young people are expert technology users but have acquired varying degrees of "digital wisdom" as described by Prensky (2005b). The use of the technology, and its perceived value, varied according to school type, student age, and to a certain degree the social acceptance of the technology.

It is now more than 30 years since the first computers were introduced to schools and the American guru, Seymour Papert (1980), claimed that the computer would transform education and make schools and teachers redundant. Papert's work was based on constructivist theory that suggests that learners create mental models in order to understand the world around them and this work has its roots in Piaget's theory of constructivism. Although Papert's prediction has not been realised in full, individual schools and the New Zealand Ministry of Education have been reviewing how they function in order to include the rapidly changing digital innovations. It has been argued that technology alone cannot replace good educational practice and teachers should be adopting a more blended approach, where the technology is integrated into the educational programme.

There is no doubt that has been a slow but steady uptake of technology across all the school sectors and although the society and culture of young people today is awash with technology, it is a very broad assumption that all young people are technologically literate. Nevertheless, there is a wide range of gadgets and gizmos that form the fabric as well as the language and grammar of the young peoples' worlds, and these digital devices are having a major effect on the way that 
our lives are conducted. Pivec (2007) suggested that this plethora of digital devices has had an impact on work habits, the manner in which we communicate, our spending habits, as well as the way we entertain ourselves and it is therefore a reasonable assumption that the education system has also be affected. Although it was long before the digital revolution that Dewey (1915) was suggesting a progressive "new" approach to education, Dewey believed that experience is the best form of education and a good education system would focus on "learning by doing”. This belief is still prevalent today and, indeed, increasingly students are learning through experience in a virtual world - as well as the real world.

Vygotsky (like Dewey) suggested in Thought and Language (1986) promoted the idea that education was socially constructed and this also had a significant impact upon how learning occurs. Vygotsky believed that the basic mental functions that occur during natural development are changed into more advanced mental functioning through the child's social interaction with more experienced members of the social group. Vygotsky goes on to suggest that with help learners can perform more challenging and sophisticated tasks than they can unassisted. Using this idea and applying it to those children who are using computers from an early age, it would follow that young people are developing habits of thinking that the older generation cannot understand. On this basis, educators have a belief in the importance of scaffolding and supporting learners. Added to this is the mix of theories of the constructivists Piaget, Bruner (1966), and Jonassen (2000) and it can be understood why technology use is expanding to be used by schools to support teaching and learning activities rather than just as a tool for administration. Four years after the work of Jonassen, Siemens (2004) introduced the idea of connectivism as a learning theory for the digital age in order to explain the increasing use of technology to support the learning process. The theory of connectivism is distinct but often confused with constructivism. The theory that Siemens suggests takes into account trends in learning, the use of technology, and networks. It combines the relevant elements of a number of learning theories, social structures, and technology to create a powerful theoretical construct for learning in the digital age.

Anecdotally many people report that life has become more complex requiring them to deal with more information at a faster speed (Prensky, 2001). An 
important consideration is the response of individuals to these developments: do they adapt and embrace new technologies, or do they resist change and overlook ongoing developments? Members of the older generation have memories of how interactions were accomplished prior to the current technological developments and may adopt an apprehensive position, whereas young people appear to be embracing the new technologies and live their lives at twitch speed (Prensky, 2001).

For many of the young people attending schools today, it can be likened to living in a desert. Outside of school they are subjected to a digital world where all their communication and entertainment requirements are met rapidly - for example, they communicate via "txt speak" so as to send and receive information rapidly, and messages are rapidly sent and received through Twitter, SMS, and other messaging tools. They are bombarded with colour, sounds, and images that we cannot easily replicate in our schools and it is, therefore, not surprising that the digital natives are restless (Prensky, 2001). This restlessness, as Carr (2010) suggests, may have resulted in the brain being "rewired" by the Internet. This could explain why learners appear to be unable to focus on one activity and are struggling to learn in a one-dimensional environment (Carr, 2010). Scott McLeod (2011) has even suggested that students who have previously been identified with Attention Deficit Disorder (ADD) or Attention Deficit Hyperactivity Disorder (ADHD) are not the ones with a problem; maybe our classrooms are operating too slowly for them. This may have particular significance in New Zealand as there appears to be an increasing number of young people being medicated to control their behaviours, when a similar result could possibly be achieved by addressing the teaching styles within the classroom. In 2014, Headspace.org identified that between $3 \%$ and $5 \%$ of school aged children in New Zealand show pronounced evidence of ADHD and infers that the rapidly changing development of technology may have an influence on such individuals' propensity for restlessness.

Information technology, including the use of computers, iPad, tablets, smartphones, and the Internet, has during the past 10 years become more commonplace in homes; New Zealand has one of the highest rates of Internet access in the world. In 2002, it was ranked eighth in the Organisation for Economic Cooperation and Development (OECD) for the number of Internet users per 10,000 populations (Statistics New Zealand, 2004). By 2010 this had increased to 75\% of 
households having access to the Internet and $80 \%$ of households had a computer. Statistics NZ (2012) described Wellington and Auckland, with 85\% of homes online, as the best-connected cities in the country.

It could be argued that while changing technologies have influenced how information, entertainment, communication, and work are pursued, these developments have been slow to infiltrate schools (Buckingham, 2007). Today's students are surrounded by "new technologies" both in and outside of formal learning environments, but their relationship with them is no longer primarily formed in the school but is now flourishing within the domain of popular culture and outside of the school environment. However, while these evolving technologies have demonstrated the ability to capture the attention of young people, the innovative learning outcomes that some educators had hoped for have been a little more elusive (Williamson 2013). It appears that the computer revolution for academic purposes may have eluded some schools (Illich, 1971; Papert, 1980). This study examines the changing digital landscape for students in 2010 and seeks to discover whether the digital revolution as suggested in 1971 really passed by the schools - or has the change been more subtle?

However, although computers are now fixtures in most schools and many homes, there is a growing recognition that it is peers that have sparked young people's passion for digital media through group pressure and play more than through academic learning activities. Although the use of computer technology for learning has been criticised by some educationalists as well as the general public as a vehicle that promotes shallow learning and mindless copying and pasting there are many more positives about the Internet's contribution. Prensky (2001), for example, is enthusiastic about the use of technology and gaming for learning, Greenfield $(2009,2014)$ is more concerned about the long term effects on brain development, and Ito et al. (2010) are more accepting of technology as a well-established part of teenage culture. Many centuries ago there was already a questioning of the role of technology - for example, the use of writing was regarded as a detrimental development. Writing was viewed as a tool for "jogging the memory, not for remembering... [providing students] with the appearance of intelligence, not real intelligence...they will seem to [have] wide knowledge, when they will usually be 
ignorant" (Plato, p. 69). It appears that this type of criticism is constant with each new innovation.

Lenhart et al., (2005) indicated "reading and writing are information and communication technologies and, like all technological innovations, have been subject to reactions ranging from unquestioning enthusiasm to reactionary scepticism.”(p.3) The skills of reading and writing, however, have filtered through society over hundreds of years allowing systems to adapt gradually, whereas digital technologies have had a much more sudden impact, thus giving the students and teachers less time to assimilate and adapt to the changes. More recent studies, as reported by Pew Internet have endeavoured to illustrate how technology has affected these skills of reading and writing (Purcell. Buchanan, \& Friedrich, 2013). When considering the influence of technology upon learning, what are largely missing from the current research in this area are the voices of students themselves. An important question is "how do the students themselves perceive technology affecting their communication, learning, and socialising?" Accordingly, this current research explores this gap in the literature by enabling the student voice to be heard, as the young people discuss their own experiences.

In my work as a secondary school teacher, teaching a wide range of subjects including digital technology and information technology, and advisor for elearning, I observed that students were bringing a range of technology skills to school but were then frustrated by not being able to use these skills in schools due to a number of factors. They reported limited access to a computer and the Internet, lack of equipment, firewalls, and bandwidth problems. This frustration was highlighted for me when working with an even younger group of 7 and 8 year old students who were developing a project poster. One girl wanted to use her cell phone to take photographs to include on the poster. I enquired how she intended to get the photo onto the page and I was informed by her that she did this all the time at home, "You connect the phone to the computer, download your picture, and then you can change it if you want and then you print it out." This student then proceeded to demonstrate this on my laptop in the classroom, "cos the school don't have the right sort of computer". This student had not been taught this skill in school and when asked how she knew this she said that she just watched her mother do it. 
Although it seems that the nature of secondary education has changed little over the last 50 years, the world that the students will spend the rest of their days in has changed significantly. The challenge facing schools today is clear: schools are expected to prepare students for jobs that do not yet exist, using technologies that have not been invented, in order to solve problems that we have yet to identify. (Fisch, 2007; Jukes \& Dosaj, 2004). Jukes and Dosaj call into question the function of schools - should the priority be to develop the "workforce of the future" or to maximise the learning opportunities for the individual in order to encourage lifelong learning? In addition to this question, an important consideration must be the student's perception of the function of schooling.

\section{Purpose of the Study}

This study examines the extent to which technology entered the lives of eight young people, and the manner in which it is being used by them both in a school environment and at home. The study also examined a number of aspects of the teenagers experience with technology; including how they developed their technology skills, built social networks, used a variety of devices as well as using technology to support learning. It was also important to consider how the teachers were adapting to the use of technology and how the students percieved these changes impacting on their education at secondary school.

From prior research, it was clear that young people's use of technology in education has become an issue of growing interest. Therefore, the purpose of this qualitative, interpretive phenomenological study was to explore the lived experiences and perceptions of young people's use of technology as expressed through their own voice. This research was designed to gather data that explores the young people's perceptions of secondary schooling and how technology is being used to promote their learning. Also of interest are the issues of how students perceive schools to be meeting these challenges, of meeting the learning needs of the Netgen students now, and whether some significant changes need be made for the future. This fore-shadows some related issues: with respect to any such changes, will the students' voices be heard or will politicians, employers, or educational leaders simply decide upon the skills they think students need, and on what evidence are these policy makers making these decisions? 
In order to address these questions, there were a number of other related background issues that needed to be taken into consideration: namely, how, when, and where did the participants acquire their technological skills? Consideration of these issues contextualised the research and facilitated the inquiry and in doing so, enabled the issue to be explored in detail from the perspective of eight students.

\section{Main Research Question}

What does the personal lived experience of students using technology in their education tell us about the capability of the education system to prepare people for life in the $21^{\text {st }}$ Century?

To ensure that this question was answered adequately, the following subquestions required consideration:

1. How, when, and where did the participating students acquire their knowledge and skills in using the new technologies?

2. How can they apply their knowledge and skills to their learning?

3. How do the students perceive that teachers and schools are meeting their needs for the future?

4. Are the Net-gen students aware of any changes in teaching and learning as a consequence of their immersion in a digital society?

Each of these questions was examined in detail through the literature review and then explored in this qualitative interpretive phenomenological study involving eight senior secondary students from the Wellington region of New Zealand. It is expected that the findings from this study will add to the international literature and, thereby, support a more global perspective of the digital generation as well as assisting teachers in meeting the needs of these students. It has to be emphasised at this point that this is a snapshot in time of a rapidly changing learning environment and it may be that the students' concerns have been addressed by the subsequent developments in technology. However, it will highlight what was considered to be important factors for these eight young people at the time. There will be other students in the cohort that have identified other issues that these participants may not have considered. This is an account of the individual personal experiences of a specific phenomenon at a specific point in their educational journey. It will be an 
important outcome of this study to re-visit the topic at a later stage, interview a different cohort of students and report on any significant changes that have occurred during the time of this study and the reporting of the data.

This research project will add to a global perspective by discovering more about how the students relocate their use of technology skills from home to school use. It will highlight the barriers and enablers of the relocating process that they each experienced; while this is on a very small scale compared to the Pew Internet and American Life research (Lenhart et al., 2005), it nevertheless provides a valid record of the student perspective via the use of student voice. Furthermore, this research identifies and defines the common characteristics of the digital natives the Netgen Kids or Millennials - and investigates how these students perceive the New Zealand education system to be accommodating their learning needs within the secondary classroom through the integration of digital devices.

As indicated earlier, the use of digital technologies in education occupies a growing body of research in the field of education that has focused on student outcomes and the raising of achievement standards. However, to date there has been a limited number of research studies that have examined the issue from the perspective of the student using their voice. By taking this student voice perspective, it is expected that this research will have a number of important contributions for education. Firstly, the findings will have implications for teacher professional development programmes in schools that have limited technology resources as well as those that have more advanced resources but little teacher expertise. Secondly, while the emerging issue of technology use in schools already has implications for pre-service teacher education programmes, the results of this study will provide relevant background information for the planners and lecturers of these programmes to identify what skills the student teachers will need in their classrooms in the future.

This research is equally important for the reason that there is a paucity of literature regarding the use of technology by the young people in the secondary sector - as reported by the students themselves. This study will, therefore, contribute to knowledge, understanding, and research in this field. 
The interpretive phenomenological study used in-depth interviews and observations as well as casual conversations to allow participants to tell their stories of technology use. The use of semi-structured interviews gave ample opportunity for the student voices to be heard but further valuable information was also gained from the casual conversations after the more formal interviews. By allowing the participants to describe their own experiences, the findings of the study begin to address a gap in the literature concerning use of technology for learning as well as the transfer of skills from home to school.

As a lecturer and supporter of using digital technology for learning, I hope to use the students' views in developing my future teaching. I hope to be in a position to inform future teachers of the knowledge and skills they can expect to meet in their classrooms and working alongside the Net-gen students.

\section{The Role of the Researcher}

Prior to beginning this research, I was a teacher working with students with special learning needs at an urban secondary school in the Wellington region of New Zealand. I have had extensive experience as a classroom practitioner, head of department, and pastoral team leader, as well as the advisory role for teacher professional development in the area of gifted education and including an advisory role for ICT and e-learning. Personal professional development included a strong interest in the way that technology could be used to support the learner with special needs and this resulted in my completing a Master's qualification in education with a focus on supporting students' learning with assistive technology. It was apparent from this research that all students could benefit from using the ever-increasing technological developments in the classroom. Many of the students had the practical skills but lacked the ability to use these skills for educational purposes.

My personal skills in the use of technology for learning have developed from this interest, but few formal professional development opportunities were available. The students with whom I worked were themselves often the source of information and I worked from their interests to develop links and application of their skills to facilitate the use of these emerging technologies in the classroom for my own use as well as for other teachers. Further details of the researcher's role and potential bias are discussed in Chapter 3 as part of the methodology. 


\section{Chapter 2: Literature Review}

In this chapter I examine the literature that describes the generation of students studied in this thesis with regard to their understanding, experience, and use of digital technology. The literature explores the identifying characteristics of these young people and how they use technology both at home and within the school. I will then extend this review in order to examine how digital technology has been integrated into the school education system prior to the interviews being undertaken with the participants in 2010 and how schools have been trying to adapt and adjust to these changing technologies. The chapter will then conclude with an examination of the important changes in technology use subsequent to the interviews and other data gathering efforts. Also included in this chapter is a section on the validity of using student voice to record individual experience including a discussion of the importance of using the student voice in order to gather rich data.

My review of the literature considers the important developments of technology from the mid 90's to the present day in order to clarify the context for this study. In the latter stages of the review there will be a focus on the student perspective of the impact of digital technologies upon their formal and informal learning. It was considered important, by the researcher, to examine how technology had infiltrated the secondary schools prior to interviewing the participants to establish whether they really were part of the so called digital revolution.

One of the central problems of building student's understanding of technology use, as identified by Cranmer (2014), was how to develop young people's skills in using technology that would enhance their life transitions particularly as they moved from school into further study or into the community for future employment. Therefore, this study will reveal how eight young people in the Wellington region have experienced this phenomenon of using technology to enhance their skills and competencies for learning and future careers. The study also contributes information on the students' perspective of how schools are working towards preparing them for participation in a digital future. It is firmly grounded in what the young people are saying about using technology for learning and also as part of their everyday lives. 
Research by Davies and Eynon (2013) suggests that it is during the teenage years that young people develop, share, and build their technology repertoire that they will use for study and then later transfer these skills and knowledge into their working life, but in order to do this they require considerable support and guidance from others. This support, guidance and education that could be provided by schools appears to have been hindered by local government policy and financial constraints as education in the use of digital devices has not always been seen a priority investment for the schools.

Since the introduction of computers into schools, there has been a significant amount of research about the effects of technology on learning and on learning outcomes (Cuban, 2001, Bolstead et al 2006, Lenhart \& Madden 2007, Owen \& Moyle, 2008). Despite this research, there appears to be little evidence systematically drawing upon the learner's perspective of this phenomenon concerning young people, specifically in secondary education. A literature review conducted by Owen and Moyle (2008) indicated that seeking students' perspectives about learning with technologies had not been a common research approach at the time of this study. Apart from evaluation studies seeking students' responses to particular courses and/or approaches to learning, little research has subsequently been undertaken from the students' perspective concerning their personal use of technology for learning at secondary school.

However, unlike the school sector there have been a number of studies that have examined student experience and use of technology in the tertiary education sector, for example the research undertaken by Beetham, White and Wild (2013) in the UK. Although a limited number of items were reviewed in their report the key findings clearly illustrated the expectations that first year tertiary students had of ICT facilities that should be provided by the institution. Issues that were highlighted for the tertiary students included access to the Internet, provision of power points (to charge laptops), an adequate number of desktop computers, and open access to social media sites such as Facebook. The Beetham et al., report suggested that the students based their expectations on their prior experiences in the school setting and their experiences were both positive and negative with regard to the provision of computer access at their previous school. The students had the expectation that technology provision and support would be superior in the tertiary environment to 
that provided at secondary school level. But this does not appear to be the case; tertiary students are still experiencing the same problems as those highlighted by secondary students today.

The following section of this review of the literature will examine the way in which, the so called digital generation, has been defined. There has always been discussion and debate about this teenage period of life that is influenced by so many biological, cognitive and social changes, and so for the current generation the influence of technology is also playing a major role in these changes (Davies \& Eynon 2013).

\section{Developing a Digital Identity}

For many years now technology has played an important part in the study of development of the identity of teenagers. Their use of technology has been studied from a variety of perspectives, including developmental, social, cultural, and historical aspects (Arnett, 2013, Davis \& Eynon, 2013, Corrin et al., 2010). Technology has been an important part of the life for the teenager - for entertainment, listening to music, and watching television - and now being part of the digital revolution it appears to be no different except in the type of device being used to access the media. The generalisations regarding how the current generation interact with technology has the potential to influence how they are taught both in schools and in higher education establishments and warrants further investigation as suggested by Corrin, Lockyer, and Bennett, (2010).

In the past there was a clear pathway for the young people as they learnt to adapt to their changing role in society as they matured. However, in more recent years these traditional markers of class, family, gender, and location are becoming blurred as society has developed and as the influence of technology is felt. Arnett (2013) had suggested that there are five key uses of this new technology for adolescents. These are entertainment, identity development, coping, high sensation and the development of a youth culture. Arnett (2013) explained that these key uses are developmental in nature and apply to adolescents rather than to children or adults.

As Arnett (2013) states adolescence is a key time for identity development and the construction of identity appears to be increasingly supported by the use of 
social media sites as the young people find people they wish to emulate in the online environment (Arnett, 2013). This development of an online identity serves to show how important connection to the Internet is for the young people. They are also able to take these ideas and mix and match them in order to create their individual youth culture identity.Young people today have many more options for how they present themselves to the world; they may develop an online identity as separate from the real world, and they have many more opportunities for global contacts and often have a large number of online friends as a result of engaging in an online world (Leander, Phillips, \& Headrick Taylor, 2010). Many of these young people are staying in education longer, being financially supported by their family, and the use of the Internet means location is no longer a limiting factor in their social development as their involvement in the virtual world has become more pronounced (Buckingham, 2007, 2008; Green \& Singleton, 2009). It is important in the context of this study that these changing developmental and technological issues are examined in more detail in order to arrive at a term that best describes this cohort of young people.

A study in Britain by Valentine and Holloway (2002) illustrated how interwoven the on- and off-line identities of the young people have become. These researchers sought to engage directly with the young people, listening to their accounts of Internet use rather than relying on the voice of adults thus stressing the importance of student voice research. They also detailed in the study how the young people, aged 11-16 years were connected through common interests rather than by geographical location. Friends extended further than the local environs to have friends worldwide. The development of an online identity is seen by the young New Zealanders, as an important aspect of using the Internet, as they have access to greater resources as well as extended social circles. Their online identity appears to compensate for what they see as inadequacies in their everyday life by building on characteristics and traits that are valued by their peers (Miller, Gibson, Smith, Bell, \& Crothers 2013).

Beddington (2013) explored this issue of changing identities and the impact that this will have on UK government policy making for the next 10 years. In this report it is acknowledged that there were a number of factors that were driving this 
change and one of the most significant was the rapid pace of technological developments. Whilst these changes can be regarded as a positive move towards building social capital and wellbeing they can also contribute to social unrest and antisocial behaviour.

Another significant finding from Beddington (2013) is the need to develop digital literacy skills and to ensure that individuals have the understanding, knowledge and technical skills to manage their on-line identity. This aspect of identity management in the virtual world will need to be acknowledged by educators as they prepare their young people for the world of work. These findings from the Beddington report are also applicable to the young people living in New Zealand if they are to take their place in the global workplace of the $21^{\text {st }}$ century. The management of their online identity is crucial for the future as many employers will now conduct an online search before interviewing potential employees.

It is important for the young people to acknowledge that the online world is not entirely separate from the real world, although they do appear to be adept at switching between the two realms. Leander, Philips and Headrick Taylor (2010) suggest that young people are "using new technologies and digital media to build social connections across space-time, produce virtual places in online spaces and otherwise interrupt the spacio-temporal contours of their lives" (p. 330) to demonstrate their technology skills. The value to the young person of living in two worlds is that they can live two very separate lives, they may have the online persona of who they want to be and the person they are in the real world (Leander et al., 2010). Learning to manage these two profiles has proved problematic for some teenagers as they fail to identify the differences between the virtual world and the real world. This inability to distinghuish between the virtual and real world may account for people blaming the online gaming activities of youth for causing real life aggressive behaviours.

\section{Naming a Generation}

Throughout time there have always been recognisable generational differences; dress, language, behaviour, or cultural beliefs may differ and so it can also be assumed that there will be generational differences in the use of technology. Demographers, the media, popular culture, market researchers, and members of the 
generations themselves have frequently defined the generational differences themselves rather than by a more formal approach of using birth years (Howe \& Strauss, 2000). Thus, members of the current generation appear to have been defined by the type and the frequency of the digital media that they use rather than their year of birth. The inherent danger in this that the selected terminology is applied as a blanket term to cover all the young people within a generation. This can also lead to assumptions being made about their individual ability to effectively use digital technology.

Although there has been disagreement amongst demographers as to the range of birth years that defines particular cohorts of young people and whether this terminology is specific to North America, the Anglophone world, or people worldwide, publications from an array of academic, demographic, business, and governmental sources have used their own specific parameters for who constitutes the millennial cohort; thus, there is no specific accepted definition. The generation of students at school in the period of this study has been described as the children of Baby Boomers; they are children who were indulged by their parents and also have a high level of self-confidence in using technology (Howe \& Strauss, 2000). There is no doubt that their parents support these young people for longer periods of time than previous generations (Howe \& Strauss, 2000).

Numerous terms have been suggested to define the young people of today: from Generation Y, simply because they followed Generation X, to the use of such terms as Netgen, the Millenials, and the Internet Generation or Echo Boomers as well as the use of the term digital natives. These labels have changed over time to align with developments in, and their usage of, digital technologies. The popular press in the United States described the first truly digital generation, those individuals who have never known life without the Internet and computer technology, as "Millenials" (Howe \& Strauss, 2000). Young people, who have had lifelong access to digital technologies were also labelled as the Net Generation or $\mathrm{N}$-gen (Tapscott, 1998) or the Google generation, thus supporting the underpinning idea that they are different to previous generations in the way they live and learn due to the rapidly changing technological developments. Another name that has been suggested for the current digital generation is Generation C (Dye, 2007) with the $\mathrm{C}$ representing content, but it could also stand for creativity, consumption, or 
connected - the latter three giving a Web 2.0 and connectivist flavour to the term. These young people are likely to be familiar with computers, cell phones, dedicated games machine such as a PlayStation, or Xbox as well as Facebook, Google, and My Space (Lenhart et al., 2005). The important point is that they are familiar with, but not necessarily expert in using, all these digital devices.

Tapscott (1998) had introduced the term N-gen, a shortening of the term Net Generation, as a description of the youth of the time that he says grew up with Internet access. But it appears rather premature to call the young people of 1998 the Net Generation. In 1998, these young people might have had access to the Internet for a few years; however, they would be unlikely to have had access since their preschool years. Tapscott's research appears to be based on young people he had spoken with on a small sample of websites, his own children and, their friends. He noted that as these young people had greater access to a wide range of information via the Internet, so life would be different for them. Tapscott's book was an interesting opinion-based work that highlighted the idea of a generation that is living in differing times and gaining different skills through the use of the Internet and, while it raises some interesting issues, further research is required before it can be shown that these views apply to all the young people of the time. However, the use of the term focuses on the issue of access to technology rather than the individual's skills in using these devices. Tapscott (2009) had followed up his previous work by examining the lives of the "grown up digital" generation. This was an extension of his work from 1998 and documents the changes that occurred in technology use by the so called Net Generation. Although the study was part of a \$4 million dollar project, Tapscott (2009) acknowledges that the opinions expressed in the book are his alone. The second project did have more of a structured component than his initial work which was based on his own children and their friends. However, it still indicates that significant changes have occurred in the way in which young people are now using technology. His focus has moved from access to technology to how the young people are using the technology in everyday life.

Three years after Tapscott's initial publication, Prensky (2001) introduced the notion of the "digital native" to describe people who have grown up with access to digital technologies. But by using this term Prensky implied that there is a world that all young people share and a body of knowledge that they have all mastered. 
Prensky's theory has been questioned on a number of counts; he assumes that all students are digitally competent and capable users of the latest technological devices (Bennett et al., 2008). Prensky (2001) likened the phenomenon of being a digital native to that of operating in a first language and, therefore, the "digital immigrants" (older adults) are like second language learners.

Prensky (2001) also suggested that there needed to be a change to the education system as students have changed radically and they are no longer the people that our educational systems were designed to teach. Prensky offered the idea that, as students were digital natives being taught by the digital immigrants, this would cause a rift between the learners and their teachers.

This notion of disparity between young people and their teachers was also identified by Hood (1998). He suggested that digital native young people switch off at school as they are not being taught in a way that fits with their multi tasking, gaming, Internet, and instant messaging worlds (Prensky, 2005a, 2005b). Also, within Prensky's work he quotes a young person as stating they have to power down when in school. This suggests that the technology is switched off or removed from the learning environment for the young person. Prensky (2005a) proposed that these young people are comfortable working at twitch speed, thus identifying that life and information processing is carried out at high speed.

Whilst Prensky's idea of digital natives and digital immigrants has been a widely accepted metaphor, it does appear to lack a foundation in research and as such is open to critique. Furthermore, there has been little empirical evidence to follow up these grand claims and it is fair to assume that not all the young people are comfortable or adept at using the technology.

Although this appears to be a grand claim about a generational change and to suggest that an urgent need to change the education systems to suit the "natives" is required, the actual situation is far from clear (Bennett, Maton \& Kervin, 2008). It still seems premature to call these young people in 2001 digital natives for the following reasons: in 2001 Google was only two years old, Wikipedia had just been launched, and YouTube and Facebook did not exist. There is also little empirical evidence in the literature of this time to show that digital natives' brains are wired differently or that they have less concentration span than previous generations. As 
indicated by Carr (2010) and Greenfield (2014), it has been suggested that areas of the brain can adapt to new functions through stimulation, a process known as neuroplasticity. From evidence of neuroplasticity it has been shown that using technology does stimulate different areas of the brain than when for example reading a book (Carr, 2010, Greenfeld 2014).

Further research and reports by McNeely (2005) and Windham (2005) that depict young people as being constantly connected is beginning to provide some empirical evidence that supports a few of Prensky's generalisations. So whilst digital native is a widely used term, there are many factors that have influenced the development of young peoples' digital skills. This generalisation of all young people being "digital natives" has been used in a very general term to describe the current young people in my study. However, as this is the term most frequently applied to this generation by the general public, it will be utilised to denote the inclusion in the cohort, but not to indicate that the young people are all expert digital users.

Prensky also made the assumption that all teachers are digital immigrants, which again is clearly questionable; it may be more prudent to call the teachers "late adopters" of technology as described by Rogers, (2003). There are also an increasing number of the cohort described by Prensky as digital natives becoming teachers and being employed in all sectors of education so this should not be such an issue for the students in school today. However, the students that were participants in my research were in Year 12 in 2010 and as such there were a limited number of teachers that would fit the stereotype of the digital native.

The early work of Prensky (2001, 2005a, 2005b) has evolved to suggest that young people demonstrate varying degrees of "digital wisdom", which seems to more adequately describe some of the teenagers of today (Prensky 2009). Also the term digital divide is being used to indicate more than the "have and have not's" of digital devices and starting to focus on how the device is being used.

Research by Oblinger and Oblinger (2005) suggested that, although there are significant and measurable generational differences in both social attitudes and behaviours, these differences are mediated by the use of technology. For example, Netgen students appear to have the ability to read visual images, they are intuitive 
visual communicators, and they record their lives with photos and videos and share these on line with the world. They also seem to be comfortable moving from the virtual to the physical world. They learn better through discovery than being told, rapidly shift their attention from one task to another, and actively choose not to pay attention to things that do not interest them. They respond quickly and expect quick responses in return (Oblinger \& Oblinger, 2005). This perceived ability to read visual images puts an interesting perspective on what the schools are providing in terms of learning opportunities for these students. The chalk and talk, or transmission, model of content delivery is no longer appealing or appears to be effective with these students according to Oblinger and Oblinger (2005). For the young people of today, being connected is important and the ability to facilitate this appears to be the vital component of the technology.

Gomez (2007) suggested that the needs of an entire generation of young people - that is, those individuals who have grown up with access to the Internet and are accustomed to the entire world being only a mouse click away - are going unmet by traditional print media like books, magazines, and newspapers. Gomez (2007) stated that the young people would rather use Google than visit a library. He also suggests that they find print "boring and a waste of time" (p. 4) and that the information quickly becomes out of date and is irrelevant to the young learner who works on a "just in time" learning model. The use of Google as a valuable search engine has led to another commonly used term for the young digital technology using people, the "Google generation" - defined by Wikipedia as those born after 1993 - that uses search engines as their first port of call. Rosa, Cantrell, Hawk, and Wilson (2005, as cited in Starkey, 2012), found that $89 \%$ of college students in the US used search engines to begin an information search. The report noted, however, that their teachers and educators are also likely to use Internet searches as a starting point, and concluded that maybe rather than a "Google generation" it is a "Google era". For this reason, because the term Google Generation can refer to both students and teachers, it was not used in this study.

Therefore, for the purposes of this research, the term Netgen - as defined by Howe and Strauss (2000) and with reference to Tapscott (1998) - will be used to describe the cohort which has been in secondary education since the year 2007 . These young people have been exposed to digital technologies in varying degrees 
for both social and educational use. They are content producers and content creators as well as consumers of the content. So, for the sake of clarity, in this study the term Netgen is used throughout as a collective term to describe these digitally enabled participants and to indicate their desire to be constantly connected to the Internet. However, the term digital natives as is more commonly used by the general community, will also be included as a term to indicate this younger generation, but without assuming it automatically denotes a high and comprehensive level of technical competence.

\section{Students' Experience of using Digital Technologies}

How young people use and respond to digital technologies has been the subject of much research but, as previously stated, little information has come from the perspective of the students themselves. The popular media frequently presents a rather negative picture of young people and their use of technology. Some of the issues that have been highlighted include their addiction to online gaming, the use and misuse of social networking sites, cyber bullying, and posting of inappropriate photographs and the potential of violent videos to influence violent behaviour. However, there are also some positive comments about the manner in which young people are using technology; for example, the use of social networking sites that mobilised the student army in Christchurch after the earthquake in 2011 but this has still been reported from an observer's perspective.

In order to clarify the context of my study it is important to recognise that any research prior to 2010 would subsequently have an influence on the availability and use of technology in the classroom . One such important long term study that encompasses young people's perspectives on using technology by the Pew Internet and American Life Project (Lenhart, Madden, \& Hitlin, 2005; Lenhart \& Madden, 2007b; Lenhart et al., 2007), would be influential on the use of technology in the classroom in later years. Although the majority of these early studies still focus on the educators or policymakers' perceptions of their (young people's) technology it still provides an insight into how technolgy has infiltrated the teaching in secondary schools. Even the Teens and Technology Report (Lenhart et al., 2007) does not go into a great deal of detail about technology use from the young person's perspective, but is reported from the researchers', educators', and policymakers' 
perspectives. However, a more recent study by Corrin, Lockyer, and Bennett (2010) investigated different ways in which higher education students were using technology. The study gathered data from the students and enabled the student voice to be heard as it reports on the experience from the students' perspective albeit from a significantly older group than secondary aged students involved in my study.

Early in 2002 The Pew Internet and American Life Project commissioned research into how the Internet was being used by American 12-17 year-olds. The researchers surveyed 136 students and found that Internet using students relied on the Internet to help them navigate their way through school, and to juggle school assignments and extracurricular activities. The research identified five metaphors for the way that students use the Internet: as a virtual textbook, virtual tutor, virtual study group, virtual guidance counsellor, and virtual locker or notebook (Levin et al., 2002). The research reflected a time when students were starting to use the Internet to collaborate and learn informally beyond school. However, the study did not identify if the students' prior skills and knowledge were considered during the school implementation period.

A later study of primary and secondary school students from the United Kingdom, which included surveys and interviews, identified four categories of digital technology users amongst the young people. Green and Hannon (2007) described the students as digital pioneers, creative producers, everyday communicators, and information gatherers. It could be argued that these four categories of technology users can also be used to describe how young people are using technology in the classroom to support their learning. These categories are similar to those identified by Lenhart et al., (2002) when using the Internet.

Similary Bolstad, Gilbert, Vaughan, Darr \& Cooper, (2006) infer a number of young people in New Zealand would identify with more than one of these categories identified in the UK study. These results reflect some diversity amongst users, and the New Zealand report acknowledged that not all young people are digital enthusiasts, despite the ubiquitous use of cell phones and digital music players. However, the study also found that the students had accepted use of digital technology as part of everyday life, a tool that helped them to achieve everyday day tasks. 
The evidence of young people from the cohort studied in this research being substantial users of technology is supported by a contemporaneous study carried out by the Pew Internet and American Life Project (Lenhart, Madden, Macgill, and Smith, 2007). They found that $93 \%$ of US teens surveyed were using the Internet and by 2013 this had increased to $95 \%$. The participants in the 2007 study were 12 17 year-olds and their parents. The survey indicated that $39 \%$ of these online teens were sharing their artistic creations (artwork, photos, stories, or videos), 28\% were blogging, and 26\% mashing (mixing) content they found online into their own creations. These figures show an increase from an earlier and similar survey taken in 2004 (Lenhart \& Madden, 2005) which found teenagers accessing tools to remix and create media. This growth in sharing digital creativity reflected the increasing use of Web 2.0 tools by American secondary school students with much of this activity being used outside of the regular classroom environment. The $2013 \mathrm{New}$ Zealand census report into the increased use of the Internet in New Zealand suggests that if similar studies had been conducted in New Zealand it would be likely that a similar growth trend of online interactions would be noted throughout the period of data collection.

In 2004, Muir-Herzig undertook a study to examine the effectiveness of using digital technology with "at risk" students. He found no significant improvement in achievement when digital technologies were introduced and concluded that, in order for digital technology to be effective, technology training is needed for the teachers. This issue had also been highlighted by Cuban (2001); it is unreasonable to expect that just because the technology appears in the school the teachers have knowledge to effectively integrate the technology into the learning experience.

The Pew study also found that $89 \%$ of the teens thought that digital technologies made their life easier, suggesting/indicating that this would be a motivation for on-going use both now in school and for work in the future (Lenhart et al., 2007a). However, there was little evidence demonstrating how the students transferred these skills acquired out of school to their learning, or whether the educators were using the students' experiences with technology to facilitate learning within the classroom (Lenhart et al., 2007b). 
During the period of this study there was a rapidly increasing adoption of mobile digital technologies - such as mobile phones, iPods, and tablets such as the iPad - fast becoming the digital devices most frequently used by teenagers (Madden et al., 2013). There are $78 \%$ of US teenagers using mobile devices to access the Internet and almost $47 \%$ are using a Smartphone. This increase in mobile usage by New Zealand teenagers is also evident in the census information from Statistics New Zealand (2013). Whilst it has been recognised by teachers and parents that cell phones are used for micro-coordination - organising meetings, transport arrangements, and social events with family and friends - they are not always being used for educational purposes. The majority of students in New Zealand secondary schools have access to a cell phone and with the introduction of the Smartphone these students now have a very powerful learning device in their pocket. Access to this powerful device is frequently blocked by school policies that prevent the use of a mobile phone during school hours.

Colmar Brunton interviewed more than 600 New Zealand children aged between 6 and 13 years of age and their primary caregivers for the Broadcasting Standards Authority (BSA, 2008). The study identified that $99 \%$ of these children watched TV programmes, $84 \%$ played computer or video games, $62 \%$ used the Internet, and $42 \%$ used a cell phone. BSA Chief Executive Dominic Sheehan said;

Not surprisingly, the research reveals that children are interacting with new media, like cell phones, MP3 players and the Internet, in high numbers. However, there are marked inequalities in access to new media, with Pacific and Maori children, in particular, falling behind Asian and Pakeha children. (p.7)

The New Zealand's Broadcasting Standards Authority (BSA) report found that nearly half of the country's children (42\%) use a mobile phone as their main communication device. The BSA report, (2008) is pertinent to my study as the children surveyed in 2008 form part of the cohort taking part in my research. This percentage of young people using mobile devices is destined to increase and further research for the Pew Internet, Teens and Technology report indicates that by 2013 they expected $74 \%$ of American teens will be using mobile technology. The increasing use of mobile technology is also evident in New Zealand schools as indicated by Ministry of Education initiatives to increase the connectivity for 
schools with the roll out of the Ultrafast Broadband project starting in 2011 and aiming to have all schools connected by 2016 .

The BSA (2008) report also found that New Zealand children were shrewd media users and that, while there has been a rapid growth of media devices in homes in the past decade, television has remained the main form of entertainment for most families, although more than half of the respondents in the BSA (2008) study reported having used the Internet for entertainment. However, this report also noted that $89 \%$ of Asian children and $77 \%$ of Pakeha children that used a computer at home had access to the Internet for entertainment purposes compared with just $53 \%$ of Maori children and $38 \%$ of Pacific children.

By comparison, a study carried out in the UK 4 years earlier, of mobile phone use amongst 11-16 year-olds reported that students tended to get phones when they began secondary school (Vincent, 2004) as compared to the New Zealand. Students who tend to have access to a phone at a much earlier age, $42 \%$ of 6-13 year olds. The findings of these reports indicate significant differences between the situation in the UK and in New Zealand existed at the time of this study. The major difference being the way that students use their phones for communication. New Zealand teenagers tended to text friends using text language, rarely using their phone to talk, which contrasted with UK teenagers who use voice calls. This may well have been due to the difference in pricing of the mobile service between the two countries.

Mobile phones have become an important digital technology for New Zealand teenagers during the period of this study, not only as a communication device but as a calendar, note taking and information seeking device, but the use of mobile phones for learning in schools has not been extensively reported apart from some innovative but small scale pilot schemes. In one such project, a teacher from Howick College in New Zealand has made significant use of cell phone technology in the teaching of geography. This project was part of the Ministry of Education approved study of cell phone use, (m-learning) project carried out in New Zealand during 2010. Evidence of this successful Ministry of Education project may be a factor in the increasing use of mobile phones in the classroom as a learning device. 
An earlier New Zealand study, "Zooming in on Learning in the Digital Age" (Zilda), Bolstad, Gilbert, Vaughan, Darr and Cooper (2006), asked young people to visually present their ideas about learning in the Digital Age. One of the significant findings of the Zilda study was the diversity of young people's interests in making use of digital technologies in their personal lives. Young people also had different priorities for using the technology. These findings are important to consider when reviewing "digital generation" literature, as they imply that the young people think and act in particular ways due to their early experiences of digital technologies. A second finding was that many of the young people found it very difficult to articulate what it meant to be "learning in the Digital Age". The students in the Zilda (Bolstad et al., 2006) survey were asked to make a digital presentation about their experiences of digital technology, but the information that was obtained did not give sufficient detail to allow any generalisation of those findings.

The findings of Bolstad et al., (2006) research however, do align with the contemporary study by the Pew Internet and American Life Project data (Lenhart et al., 2005, 2007) which examined teens' use of the Internet and social media, which also found diversity of use amongst the users. Further research in this area would help to get an understanding of the connection between students using digital technologies both in formal and informal settings and in their learning for the future. The need for further research is also included in a later report from the World Internet Survey (Gibson, Miller, Smith, Bell \& Crothers, 2013) supporting the need for a change in focus from the number of people using the Internet to focus on how and what they are using it for. This would enable a more detailed understanding of the link between the technology and learning.

The Zilda report (Bolstad et al., 2006) also noted that not all young people have access to digital technologies when away from the formal learning setting of the school, but as shown by the 2013 census data this number is decreasing, as is the number of people who are using a dial up connection as opposed to broadband. This change in connection type has had a considerable influence on the adoption of digital technology by schools and the development of an e-learning environment. The other big change is occuring is the type of device that is being used to connect to the Internet. There is an increase in the number of mobile devices being used and there is frequently more than one device per family. The change has been 
influenced by the New Zealand Government's Ultra-Fast Broadband (UFB) initiative as well as increased demand by consumers, and has had the effect of diminishing the perceived digital divide amongst the population.

Information from Statistics New Zealand (2007), obtained during the 2005 census, showed an increasing number of homes had computers and broadband access during the period of this study. The major change in information and communication technology in recent years, as shown by Statistics New Zealand, is in how and where people are accessing the Internet. In 2009, it was desktop computers dominating over two thirds of New Zealand homes. More recently, the most common way people connect to the Internet is via laptops, with other mobile devices (Smartphones, tablets) are not far behind. The census data from 2013 also indicates that there are an increasing number of homes that have multiple devices that are Internet capable. But this is not just about replacing types of technology; there are more types of devices available to connect with, and the cost of hardware and Internet connection is becoming more affordable to the majority of families.

\section{The Digital Divide}

Information that was gained from a Pew Internet and American Life Project conducted by Levin, Arafeh, Lenhart and Rainie, (2002) concluded that the digital divide was due not only to lack of access to hardware, but also to the lack of digital knowledge. The Levin et al., (2002) study reported that students believed that teachers required further professional development in order to be able to effectively integrate technology into the classroom. The technology included computers, the Internet, as well as the availability of mobile devices and the digital knowledge that was deemed necessary included how to operate the variety of devices that were available. Although within New Zealand steps have been taken to reduce the access to hardware issue for students, there is still much work to be done in ensuring that people have access to the digital knowledge that they require for learning or employment. Therefore, the lack of access should be considered to include the competencies and skills that are required to participate in the wider online environment. There still remains the question of how people will gain these competencies (of computer and Internet literacy) if they are not taught in school. 
Research by Jenkins, Clinton, Purushotma, Robinson and Weigel, (2007) into teens' use of search engines (digital knowledge) found that the students' critical skills in accessing and evaluating information were not well developed. When put into context, however, the research found this was not only a feature of the young people, but that their teachers also lacked the tenacity and skills for conducting effective online searches. This lack of digital knowledge is also evident in New Zealand schools as an increasing amount of hardware, computers, tablets, laptops, and interactive whiteboards have appeared in many schools but there was a lack of teacher professional development during the period studied that would have ensured effective use of the hardware (Brown, 2004; Underwood, 2009).

The Pew Internet research ( Lenhart et al., 2007) suggests that more could be done to improve students' digital knowledge rather than just making the technology available to all. A report funded by the MacArthur Foundation, Living and Learning with New Media (Ito et al., 2009) aimed to challenge the thinking about the digital divide, from lack of access to technology to developing the competencies and skills of the students to enable participation in a Web 2.0 environment. Spitzer (2015), a German neuroscientist has questioned this "dumping" of technology into the classroom without professional development opportunities for the teachers as being a waste of public money. This perspective had also been highlighted much earlier by Cuban (2001) in his book 'Oversold and Underused' and it appears that little has changed over nearly two decades. There are still devices being supplied to schools without the necessary professional development to ensure that it is integrated into the teaching in the classroom.

Therefore to summarise this section, the suggestion that young people have sophisticated technology skills that the current education system is not fully equipped to support and develop has been documented by Prensky (2001, 2005a), Gomez (2007) and Underwood (2009). There appears to have been inconsistency amongst researchers as they seek to address this, but, as pointed out by Gomez and Underwood many of the arguments which report improved student achievement and innovative use of computers have been based on limited research detail and anecdotal instances and so lack empirical evidence. There is also a paucity of empirical evidence to support the suggestion that easier and cheaper access to the 
Internet has enhanced academic achievement levels amongst young people as illustrated by the Pew Internet studies during the last decade.

\section{Adoption of the New Technologies}

The adoption of technology for teaching and learning has proved challenging for some secondary schools and teachers. Research by Moser (2007) identified three of the most common issues experienced by teachers. These issues include the time commitment required to implement a new technology frequently outweighed the educational benefits of the technology tool, the prior knowledge and experience of the teacher to use the said technology effectively and the lack of ability to select technology that was relevant to the learning experience. A follow up project by Moser (2014) confirms that little appears to have changed for the regular classroom teacher and investment by institutions into the professional development opportunities should be continued if educational environments are to take advantage of the ongoing adoption of the latest digital devices for learning and teaching.

Rogers $(1995,2003)$ describes a model of the process of adoption in his book, Diffusion of Innovations and whilst the process of adopting new innovations has been studied for over 30 years, research from a broad variety of disciplines has used this model as a framework. This theory of diffusion is a widely used theoretical framework in the area of technology diffusion and adoption and is appropriate for investigating the adoption of technology in educational environments. In early editions of Roger's book, he uses the following terminology to describe the adoption of an innovation: awareness, interest, evaluation, trial, and adoption. However, in later editions of the text, Rogers changes the terminology of the five stages to: knowledge, persuasion, decision, implementation, and confirmation. The following table summarises the five different stages of technology adoption that could influence the changing habits of technology use by both teachers and students. 
Table 2.1 Five stages of the technology adoption process (Adapted from Rogers 1995 p. 169)

\begin{tabular}{|l|l|}
\hline Stage & \multicolumn{1}{|c|}{ Meaning } \\
\hline Knowledge & $\begin{array}{l}\text { The individual is made aware of the innovation, but is only aware } \\
\text { of its existence and has not explored the usefulness of the } \\
\text { innovation. }\end{array}$ \\
\hline Persuasion & $\begin{array}{l}\text { By now the individual is beginning to explore how the } \\
\text { innovation may be of use to them. This may come from the } \\
\text { recommendation of peers or from teachers as a requirement to } \\
\text { complete a task. }\end{array}$ \\
\hline Decision & $\begin{array}{l}\text { The individual is now faced with making the decision of whether } \\
\text { the innovation would be of value and may begin to learn how to } \\
\text { use the technology. }\end{array}$ \\
\hline Implementation & $\begin{array}{l}\text { In this stage the individual employs the innovation to a varying } \\
\text { degree depending on the situation. During this stage, the } \\
\text { individual determines the usefulness of the innovation and may } \\
\text { search for further information about it. }\end{array}$ \\
\hline Confirmation & $\begin{array}{l}\text { In this stage, the individual completes his/her decision to } \\
\text { continue using the innovation. The decision will be supported by } \\
\text { their peers as they continue to use and share information. }\end{array}$ \\
\hline
\end{tabular}

Rogers' (1995) study also suggested that there are four main elements that influence the spread of any innovation. These four elements are:

- the innovation itself

- the manner in which the information gets passed from person to person

- the time it takes for the innovation to be "adopted", and

- the system within which these elements are operating.

Under the right conditions a new innovation will spread through a learning community by this process of diffusion. It typically begins at a slow rate, gathering momentum until most of the community has adopted the innovation and then the rate 
slows again. Rogers has illustrated this as a normal distribution curve as shown in the diagram below.

Figure 2.1 Stages in the adoption of an innovation (Adapted from Rogers, 1995)

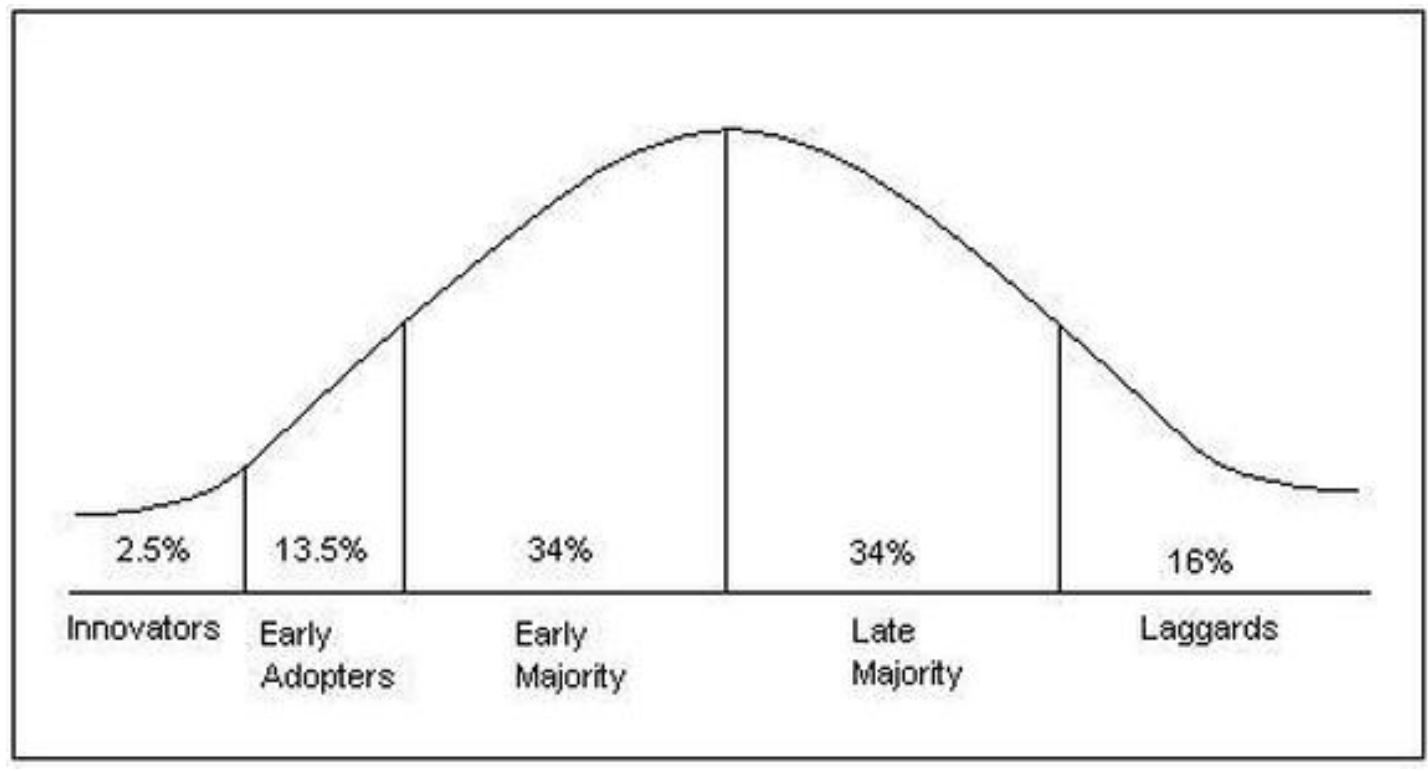

It is also important to note that this process of technology adoption may not occur at the smooth rate as Rogers has indicated in this graph. Depending on the popularity or the ease of use of the technological innovation adoption may occur at a faster or slower rate.

A study of the use of technology in New Zealand schools by Johnson, Kazakov and Svehla (2005) used a model of technology adoption that was developed by Knezek and Christensen (1999). This model is similar to the Rogers model of technology adoption and can also be applied to students use as well as teacher use. In the same study (i.e., Johnson et al., 2005), secondary school principals were asked if the integration of ICT was making major improvements to the quality of curriculum delivery in their schools, to which $76 \%$ of the 138 respondents stated that it was making a difference. The principals had rated the majority of staff at level four or above on the six point scale in terms of their ability to integrate technology into their teaching. The question was very broad and likely to be interpreted in different ways by different principals and, as those responding to the questionnaire are likely to have supported the financing and use of computers in their schools, there was likely to be some bias in the answers. The researchers included results from a similar survey carried out in 2001 in which $52 \%$ of 
secondary school principals had said that ICT was making major improvements to the quality of curriculum delivery; the change in the results over time may negate the bias caused by the vested interest. This study did not examine how teachers were using digital technologies and did not attempt to evaluate the effectiveness beyond reporting on principals' perceptions and students per computer ratios (4:1 in 2005 as compared with 10:1 in 1995). As previously identified, the presence of digital technology within a school does not automatically ensure efficient or effective use or indeed improved learning outcomes.

Knezek and Christensen's (1999) model infered that learning was neat and ordered and that the teacher be the technical expert. However, when Web 2.0 applications are applied to technology use it becomes apparent that the stages suggested by Knezek and Christensen are unlikely to be sequential or present when teachers adopt the new technologies. Many of the teachers are still at the lower end of the scale with regard to their personal use of the computer whilst students are frequently observed as being higher on the same scale (Christensen \& Knezek, 2001). Research into the manner of integrated use of digital technologies in teaching and learning has tended to centre on the more experienced teachers who have established pedagogical practices. These established pedagogical practises may preclude the development of a digital pedagogical style.

Similar to Rogers' model, the Knezek and Christensen model has six stages that are arranged in a hierarchical format. A table below sets out these six stages along with a brief description of each stage.

Table 2.2 Knezek and Christensen model of technology adoption.

\begin{tabular}{|l|l|}
\hline Stage & Definition \\
\hline Awareness & $\begin{array}{l}\text { The individuals are aware of ICT but have not used } \\
\text { or are avoiding use of technology }\end{array}$ \\
\hline Learning the process & $\begin{array}{l}\text { Learning the basics, experiencing frustration and } \\
\text { lacking confidence }\end{array}$ \\
\hline $\begin{array}{c}\text { Understanding application of the process } \\
\text { and }\end{array}$ & $\begin{array}{l}\text { Understanding ICT use and able to identify tasks } \\
\text { for which it may be suitable }\end{array}$ \\
\hline
\end{tabular}




\begin{tabular}{|l|l|}
\hline $\begin{array}{l}\text { Familiarity } \\
\text { confidence }\end{array}$ and & $\begin{array}{l}\text { User is gaining confidence and beginning to } \\
\text { explore other applications }\end{array}$ \\
\hline $\begin{array}{l}\text { Adaptation to other } \\
\text { contexts }\end{array}$ & $\begin{array}{l}\text { Computer is becoming a tool, rather than } \\
\text { technology; can be used in numerous situations in } \\
\text { an appropriate manner }\end{array}$ \\
\hline $\begin{array}{l}\text { Creative application to } \\
\text { new contexts }\end{array}$ & $\begin{array}{l}\text { The tools can be used in creative ways in numerous } \\
\text { different situations. }\end{array}$ \\
\hline
\end{tabular}

As illustrated in the Table 2.2, the Knezek and Christensen model suggests that adoption of technology is a linear and hierarchical process but evidence from research by Davis and Eynon (2014) supports the idea that young people do not develop their skills in this linear fashion but tend to work on a trial and error approach in order to develop their confidence rather than reading instructions or following a pre-determined plan of learning.

\section{Digital Technology and Learning}

In the past, education had been easy to define. It consisted of a set of accepted literacy skills, a definable body of knowledge, and the pedagogies for teaching those skills to students who were arranged in straight rows within the confines of a classroom (Tapscott, 2009). But now many educators question whether this is relevant to the students of the $21^{\text {st }}$ Century.

Educators have been aware for many years that students show a preference for certain learning strategies over others and this is becoming more evident in our classrooms as more and more technology becomes available (Bolstad \& Gilbert, 2012). Papert (1982) suggested that technology had the capacity to change classroom learning as students have the ability to access essentially unlimited quantities of information that could enable them to learn whatever they wanted to know. Although not all schools and classrooms have taken up this opportunity it could be that unlimited information led Jukes (2010) to coin the term "infowhelm" to describe the overwhelming amount of information that was now available to the learners. Jukes (2010) also highlighted the importance of providing the young 
people with critical media literacy skills to enable them to make sense of this mass of information.

Teachers also face the challenge of changing their notions about teaching and learning in order to adapt to this rapidly advancing technology wave. Teachers are struggling to redefine what it is to be educated, to reinvent the classroom, and to redefine what it means to be a teacher and a student in this challenging environment of unlimited access to information.

As the world of digital technology use is moving through a period of exponential change people have responded to this by attempting to ignore, filter, or to block out the changing technology (Jukes \& Dosaj, 2004). Jukes reminds us that because of the educational impact of the computer, the Internet, and what young people doing with the new technologies is of critical importance for the future, attention should focus on what are our young people doing with these "new" technologies" rather than just the affordances of the technologies themselves.

Teachers need to be examining their practice in order to incorporate the technology skills that the young people are bringing to the learning environment as well as consideration of their mode of learning. Jukes et al., (2010) states "if we continue to teach the same old way, we will completely miss connecting with our students" (p. 47). It was also suggested that it is not only the older teachers that struggle to accept the changing learning preferences of the Netgen students but also the younger, newly qualified teachers as they have spent so much of their learning based on $20^{\text {th }}$ century thinking and exposed to a traditional didactic style of teaching. These younger teachers are reverting to a style that was comfortable for them as learners. As young people are now needing more than content knowledge; they need to be able to process and apply the knowledge they have as well as create new knowledge therefore changes to the learning environment were required. During the course of this research it appears that there have been small changes in the way that schools have attempted to accommodate these changing learning preferences of the young people. Evidence of these changes have included, opportunities for increased professional development for the teachers, changes to the school infrastructure to include "modern learning environments", and upgrading of school hardware and software. 
In 2005, the first of the true Netgen students entered the secondary education system. This was the generation that had grown up with the Internet, computers, cell phones, mobile gaming, and rapid access to information. These learners, according to Prensky (2005a), showed unique characteristics in their learning styles that challenged the existing pedagogy. Students still want to learn but in a very different way to their predecessors. This cohort operates at "twitch speed" according to Prensky (2005b). The Netgen accept as normal that they'll have instantaneous access to information, goods, and services at the click of a mouse. They expect to be able to communicate with anyone or anything at anytime, anywhere, day or night.

Such expectations have led to the death of patience and the emergence of a society increasingly expecting, wanting, and demanding instant gratification (Jukes, McCain, \& Crockett, 2010). This may be one of the reasons why educators appear to find it more difficult to engage students with print material. Reading, for example, is a delayed gratification medium while TV, video games, and the Web are immediate gratification media. What is becoming abundantly clear to educators is that Netgen students are fundamentally different types of learners than most of their teachers. These Netgen students demand access to tools that let them network with their peers or anyone or anything else they choose to interact with - and for them, it is second nature to multi task. They expect, want, and need tools that provide hyperlinks and instantaneous random access that allow them to connect everyone and everything to everyone and everything else simultaneously for instant gratification. As a result, teachers are looking to technology to provide the instant feedback and visually appealing media for the students with a limited regard for the impact it may have on learning.

The following table summarises these differences between the students in the classroom and some of their teachers. It is noticeable from further investigation of these student and teacher expectations that there is much to be done if the needs of both parties are to be addressed. 
Table 2.3 Differences between Netgen learners and their Teachers

\begin{tabular}{|l|l|}
\hline Netgen Learners & Teachers \\
\hline Desire quick access to information & Controlled, slow release of information \\
\hline Using multimedia sources & $\begin{array}{l}\text { Using limited, usually text based sources } \\
\text { and to content required for the "test" }\end{array}$ \\
\hline $\begin{array}{l}\text { Working with others on co-operative tasks } \\
\text { useful }\end{array}$ & Expect students to work independently \\
\hline Expect instant gratification & Learning for the test or assessment activity \\
\hline
\end{tabular}

Friedman (2006) suggested that the introduction of digital technologies and the Internet have "flattened the world" and this has resulted in equalising the opportunities for young people to participate in the global market and communicate across the world with other people. This advancement has put considerable pressure on schools and teachers to prepare their students for this knowledge economy and globalisation. Friedman's underpinning rationale for including digital technologies in schools is the fear of being left behind economically - of losing market dominance - in a global economy. However, this should not be the sole reason for making sure that the young New Zealanders are not left behind in the digital revolution.

Whilst there have been mixed reviews about the benefits of using technology for learning, Oblinger (2008) has illustrated through her research that when technology is used effectively to support pedagogy, students may well achieve the learning objectives faster, learn materials more quickly and at a deeper level, and are more interactive and experiential during their learning process than when technology is not used. In this case, effective use of the technology is defined as using it to create learning opportunities that expand student collaboration, and integrating the technology into student learning and actively engaging students. 
However, earlier research (Cuban, 2001; Oppenheimer, 1997) reported that there has been little or no effect on the achievement levels of the students. This diversity of views on the advantages and disadvantages has continued to be debated by educators during the last 15 years and as yet no definitive conclusion has been reached. There were a huge number of positives and negatives points raised pertaining to the inclusion of technology in education. Technology and education are a great combination if used together with a right reason and vision. This importance of incorporating technology for learning has been illustrated through further research by Celik and Keskin (2009). They compared student learning outcomes for a set of learning objectives taught with "instructional" technology to student learning outcomes for the same set of learning objectives being taught without instructional technology. It was noted that the effective use of instructional technology decreased the amount of teaching time needed for students to learn a set of learning objectives. However, this research did not take into account the mediating effect of a classroom teacher.

A Becta study investigated the use of ICT in UK schools and its effect on teaching and learning. This study undertaken by Somekh, Underwood, Convery, Dillon, Jarvis, and Lewin, (2007) supported claims for enhanced learning outcomes for students who had been using technology for learning. The study used quantitative methodologies to illustrate that improved student outcomes had been achieved in a variety of learning areas. They found that national test outcomes had "improved beyond expectations" (Somekh, et al., 2007, p. 6). However, this impact was greater in primary schools than in secondary schools. A later study by Sheehan and Nillas (2010) examined the integration of technology in secondary mathematics classrooms and this study illustrated that when students were users of technology, they were more engaged in learning and attained higher levels of mathematical understanding. The authors report that technology use could help students to manipulate and link different representations and to focus on concepts rather than calculations.

A further study considered the effects of technology integration in middle schools (Shapley, Sheehan, Maloney, \& Caranikas-Walker, 2011) and it was found that the teaching of technology had a positive effect on students' technology skills and understanding. Although they did not find any statistically significant 
improvement in either reading or mathematics, there were consistent positive effects across the study in the ability to use technology. A review of the effect of technology use in European schools found that there were improvements in primary schools in the home language (e.g., English) and science. There was also evidence for improvement in mathematics when the use of technology was over a longer period of time than the other subject areas (Balanskat, Blamire, \& Kefaia, 2006). A New Zealand research project by Falloon (2010) also found that students are more engaged and motivated in their learning when using technology. Falloon also highlighted evidence in his study that using technology had increased the interaction between student and teacher.

As Bennett and Maton (2010) point out, in the same year that iPads were launched, "there is a significant lack of consensus over what effects digital technology is actually having on young people" (p. 322). They also stated that, "the advent of new technology always raises questions and claims about how it can be used effectively in education" (p. 325). Judging by the resources invested by major technology providers, Apple and Microsoft, to sell their products in the educational marketplace, it could be implied that the use of digital devices that students use to access information and social networks is not a trend that will decline but how to improve their effective use for learning still requires further debate.

In his book Information Anxiety, Wurman (1989) estimated that high school students had spent 10,000 hours playing video games, 20,000 hours watching TV, and over 20,000 hours talking on the phone, not to mention countless hours listening to music, surfing the Web, and using Instant Messenger, chat rooms, and email. But, he claims, at the same time, they have only spent 5,000 hours reading printed text and 11,000 hours attending school. As reported by Oblinger (2008), educators globally have expressed concerns that the education standards have been falling due to the increasing amount of time young people are engaging with the digital world. This contrasts with the expected improved learning outcomes espoused by other researchers at the time.

Adams (1999) observed that our attitude to technology was determined by the age at which we first encounter it. He suggested that everything that was in the world when one was born was just regarded as normal, anything that gets invented 
before you are thirty is an exciting innovation and possibly a career can follow from it, and, finally, anything that is invented after your thirties is against the natural order of the world but when it has existed for ten years or so it turns out to be acceptable. Noted computer scientist Alan Kay (cited in Tapscott, 2009), father of the modern Windows user interface, once observed, "Technology is only for people who are born before it was invented" (p. 19). Adams and Kay's insights provide a possible model for understanding the mixture of attitudes, knowledge, and response to technology that is apparent in schools today.

However, teenagers have embraced this new digital world with great enthusiasm, responding eagerly to its invitation to share ideas, contribute content, and otherwise place their stamp on a system that they themselves create and manage (Ito et al., 2010). This enthusiasm for the use of the latest technology appears to be much more advanced for personal use rather than using the technology for educational purposes. According to Harwood and Asal (2007), teenagers are "insightful, honest and knowledgeable on the subject of school technology" (p. 27), because as far as they are concerned it has always been available for their use. Young people have not simply adopted digital media into their lives; they have internalised it.

According to Devaney (2008), one of the key factors in keeping a country competitive in the global economy is preparing students for careers in science and technology. However, this is proving difficult for schools to achieve as there are rapid changes taking place in this area. One of the main issues with the education system at the time of this study appears to be one of relevancy according to Jukes et al., (2010). There appeared to be a gap between what was learned in the classroom and what was needed for today's workforce. According to Jukes et al. (2010), the school curriculum was extremely theoretical and needed to become more attuned with higher-level thinking and in order to achieve this; teachers need to move towards a more practical curriculum. The learners need to be able to apply the knowledge that they have acquired to a variety of real life situations.

Today's educators have to be aware that those students who are starting school this year will be entering the work force around 2030. Clearly, the educators are unable to accurately predict the type of work force that will be required or even 
the skills that will be needed by that time; this potentially compromises their ability to support students to become lifelong learners and develop the skills to find and interpret the information they require in order to become valuable members of that workforce.

The New Zealand Ministry of Education (2007) had attempted to address this situation by producing a National Curriculum (NZC) document that identifies some of the $21^{\text {st }}$ Century skills and suggests how schools may choose to implement these skills. This Ministry of Education document identifies several key areas that form the vision statement for developing education for $21^{\text {st }}$ Century learners. These four key areas, as indicated in table 2.3, should be supporting each school in providing learning experiences that will develop the future leaders of our country. But it is left to each individual school as to how they apply this vision.

Table 2.4. $21^{\text {st }}$ Century skills, (Ministry of Education, 2007. p. 8)

\begin{tabular}{|c|c|}
\hline Confident & Actively involved \\
\hline Positive in their own identity & Participants in a range of life contexts \\
\hline Motivated and reliable & Contributors to the well-being of \\
\hline Resourceful & New Zealand - social, cultural, \\
\hline Enterprising and entrepreneurial & economic, and environmental \\
\hline \multicolumn{2}{|l|}{ Resilient } \\
\hline Connected & Lifelong learners \\
\hline Able to relate well to others & Literate and numerate \\
\hline Effective users of communication tools & Critical and creative thinkers \\
\hline Connected to the land and environment & Active seekers, users, and creators of \\
\hline Members of communities & knowledge \\
\hline International citizens & Informed decision makers \\
\hline
\end{tabular}

Developing Digital Pedagogy within the School System.

In 1989 the Education Act changed the way that schools in New Zealand were governed; this resulted in an increase of community and local decision making 
and less central government control. Each school, under the guidance of the board of trustees, was able to make the decision about how to devolve the bulk grant for curriculum and learning support. The purchase of digital technologies, support for the technologies, and teacher professional learning became a function of the boards of trustees who governed individual schools. This change in funding of schools coincided with an era of a quasi-marketing of the school system, where marketing and the image of schools became a priority for some boards of trustees and the ratio of computers to students was included in marketing information as a desirable feature of a school. In New Zealand, the 1990s became a time when secondary schools were very image aware, sometimes consciously marketing themselves in terms of the ratio of computers to students - figures which could be misleading if administration computers were included.

The introduction of technology was initially seen as a management tool for school administration and teacher planning. It was then included in classroom learning with the introduction of data projectors, interactive whiteboards, and computers and, more recently, the students bringing their own Internet capable devices. This introduction of digital technologies has led to a need for the development of new understandings and knowledge about schooling, teaching, and learning in the digital age (Starkey, 2012).

From a review of ICT and pedagogy, Cox et al. (2004) identified what was considered effective pedagogical practices. This list included the need for teachers to:

- understand the relationship between a range of ICT resources and the concepts, processes and skills in their subject;

- use their subject expertise to select appropriate ICT resources which will help them meet the specific learning objectives; this includes subject-specific software as well as more generic resources;

- be aware of the potential of ICT resources both in terms of their contribution to pupils' presentation skills, and their role in challenging pupils' thinking and extending their learning in a subject; 
- develop confidence in using a range of ICT resources, via frequent practice and use beyond one or two familiar applications;

- appreciate that some uses of ICT will change the ways in which knowledge is represented, and the way the subject is presented to and engages pupils;

- know how to prepare and plan lessons where ICT is used in ways which will challenge pupils' understanding and promote greater thinking and reflection;

- recognise which kinds of class organisation will be most effective for particular learning tasks with ICT, for example, when pupils should work on their own, how working in pairs and groups should be organised, and when to use ICT for whole-class teaching. (Cox et al., 2004, p. 4)

All the above factors indicate that the teachers have to understand the need for technological inclusion in their teaching and how to adapt their pedagogical knowledge to achieve this. How this understanding occurs can depend on a number of factors, including the school management, priority of ICT integration, and the professional learning opportunities available for teachers. The analysis shows that the students were motivated due to the effective teaching practices of the teachers as they used ICT in the learning programmes. These results align with the findings of Cox et al. (2004) who noted in their review of literature that ICT makes a difference to learning when it is accompanied by effective teaching practice.

In 2012 the Ministry of Education reference group began to examine the $21^{\text {st }}$ century learning environment and the need to develop digital literacy skills for all learners. This reference group agreed that all young learners should have the opportunity to achieve better learning outcomes no matter how diverse their background may be, then a system wide change to the educational environment would be required. As digital technologies are playing an increasing role in the development of the $21^{\text {st }}$ century environment it is important that we equip all students with the necessary skills to thrive in such a digitally driven world. 
Alongside the development of digital literacy there needs to be attention paid to the development of a digital pedagogy. Digital pedagogy is about much more than simply teaching about or with digital technologies. Digital pedagogy recognises that there are fundamental changes in the way learning is occurring, and responds in ways that value knowledge and understanding about effective teaching. Application of a digital pedagogy is evidenced by effective teaching in a context where learning is ubiquitous, where learners have agency over their learning, and where knowledge and understandings arise through the connections that are made in a network of provision (MOE, 2014).

The digital technologies and software that are most commonly available for use in schools are of three types: those that are designed for the business world but also used in schools, those which have a subject specific application, and those that are designed specifically for use in schools. Thus, at the start of the Digital Age the digital technologies that were available and accessible to schools may not be ideal for the socio-cultural context of a classroom. As young people and educators have input into the development of technologies and software, a greater range, more suited to learning at secondary school and in the Digital Age, is beginning to emerge and Web 2.0 tools and networks are taking a more prominent role in today's schools.

The American longitudinal study, Teens and Technology (Lenhart et al., 2005) and later, the World Internet Project (Crothers, Gibson, Smith, Bell \& Miller, 2014) found that secondary school students used a range of digital technologies including computers, laptops, tablets, cell phones, MP3 players, iPods, and iPads. The studies noted that the students were familiar with the Internet, diverse in their attitudes to digital technologies, and that they would use a mobile phone to keep in touch with friends and family. Furthermore, some of the young people would be involved in online gaming, instant chat, or social networking, finding information, downloading music or sharing creative products with others. Students may also use their devices to join social networks such as Bebo, Myspace, and Facebook where they share information online. This evidence has been used by the New Zealand Ministry of Education (2014) in forming future development of a digital learning environment for the $21^{\text {st }}$ century. 
These claims, of increasing use of technology by students and teachers are supported by data from the 2013 Census Information released by Statistics New Zealand illustrating that New Zealand young people are following an international trend in becoming prolific users of digital technologies. Data from Statistics New Zealand (2013) show that in 2012:

- 4 out of 5 New Zealand homes had access to the Internet.

- Two-thirds of rural households had a broadband connection.

- $40 \%$ of households were using more than one device to access the Internet.

- Laptops were the most popular means of accessing the Internet in more than two-thirds of households.

- One-third of households accessed the Internet via a mobile phone.

This is an increase in all aspects of technology use in the home over the last three years and is in a similar proportion to that of the US and the UK. This heightened awareness of technology use by young people has not always been matched by the schools' leaders with integration of technology for learning taking place at a much slower rate. While this could be explained in part by the changes in school funding, the development of the New Zealand curriculum documents by the Ministry of Education and increased professional development opportunities for teachers. In order to understand why this integration of technology into the secondary school has been so sluggish we need to consider the past.

Although digital technologies such as computers and calculators have been available in schools since the 1970s (Cuban, 2001), the literature of the late 1990s highlighted a growing concern about the value of using computers in schools. The assumptions about the benefits of using computers in schools for advancing learning was being questioned at the time by educational experts such as Oppenheimer (1997) and Cuban (2001). Policymakers and some supporters of information communication technologies had expected the teachers to quickly change their pedagogy to incorporate the introduction of digital media and the Internet into their classrooms rather than the reverse. Oppenheimer (1997) expressed concern at the US government's desire to increase computer ratios and computer use in schools at the expense of learning arts and physical education, a trend that was followed by New Zealand schools several years later. He noted that 
in examples of research which reported improved student achievement and innovative use of computers, the studies themselves were anecdotal rather than research based and that it was the teachers' pedagogical approach that was behind improved student learning rather than the use of the digital technologies. Furthermore, the opinions he gathered were those of the administrators and teachers who were perhaps trying to justify the inclusion of digital technology in the curriculum and the associated high financial outlay that was occurring.

When Cuban (2001) compared the introduction of computers in schools with previous innovations, he found that the process of change in the schools was taking decades rather than a few months or years. The research undertaken in the early 2000 s tended to focus on if teachers were using digital technologies in their teaching and the factors that were helping or preventing their use of them. Student learning, as a result of this use was not examined and student prior learning, knowledge, and skills were not considered. It was not until much later that research attention changed to look at how the students are using the technology and whether this is having any effect on student achievement levels.

There are a number of other studies (Lai, 2005; Sime \& Priestly, 2005) that identify teacher-reported issues which prevent, inhibit, enable, or encourage the use of digital technologies in their teaching practice. Sime and Priestley (2005) had identified four categories of factors that predicted whether teachers would integrate digital technologies into their teaching. These include resources available (access to both hardware and software), personal experience of digital technology, their beliefs, and the context of the integration opportunities. It is interesting to note that these studies focussed on the teachers' ICT needs rather than the students' needs. These findings also supported the views of Lai (2005) and Cowie et al. (2008) indicating that little appeared to be changing in the way that teachers viewed technology integration in the classroom.

Further investigation by Cuban (2001) had suggested that teachers were adapting computer use to fit with their traditional practices rather than adapting the way they teach to take account of the opportunities offered by computers. But by 2012, a pro technology debate was suggesting that: "digital devices let students learn at their own pace, teach skills needed in the modern economy and hold the attention of a generation weaned on gadgets" (Selwyn, 2012 as cited in Davies and 
Eynon 2013 p.85). The Khan Academy is an example of using technology to provide online learning materials. This approach has been marketed on the Khan website as "personalised and individual learning support", but is no different from the didactic pedagogy that students experience in their regular classroom. It is only personalised in that students can access anytime, anywhere and may appeal to the young people's desire to use technology for learning.

Previously, Cuban (2001) had suggested that access to reliable digital technologies was the biggest barrier to use in the classroom, arguing that if the technology was believed to be unreliable, secondary teachers with 25 to 30 students to keep engaged and motivated would choose not to use it. Cuban had found little evidence of resistance by teachers to using digital technology. He found that many used it extensively to prepare their work, to communicate with parents and maintain records, and to carry out research; however, they did not have students using digital technologies extensively or in a way that showed a change in the way that students were learning. If there was a lack of immediate technical support or assistance for teachers to solve problems with the technology then they were also discouraged from using computers for teaching and learning. He also found that where teachers were using digital technologies it was to enhance their existing teaching practices; therefore, teachers would only consider using digital technologies which they perceived as enhancing their existing or desired teaching practice. There was little evidence of teachers adopting a digital pedagogy at this stage.

Lai (2005) examined a number of barriers that New Zealand teachers encounter when using digital technologies. These barriers include the school itself and the culture of that school, the leadership and management of the school, professional development opportunities, and technical support as well as the allimportant access to hardware and the Internet. The teachers were concerned about the lack of support within the school for integrating these new tools in their teaching. Whilst Lai's study focused on beliefs about ICT rather than pedagogical beliefs about learning and teaching, it provided some clues as to why teachers were encountering problems using technology in the classroom. In a later study of teacher use of laptops in New Zealand, it was found that lack of support was still an important criterion for teachers when attempting to use digital technologies (Cowie et al., 2008). The support that the teachers valued ranged from messages given by 
the principal about the value of digital technologies in the teaching and learning process, professional learning available, collegial support, as well as "just in time" technical support.

However, by 2008, 100\% of New Zealand secondary schools had Internet access and 93\% of them had broadband access (Johnson, Lynch \& Kazakov, 2008). Although access to the Internet was possible, it was not always a reliable connection and not available in every classroom; currently, however, continual improvements are taking place, mostly through government funding that has enabled upgrading of the school networks. Thus, the issue of unreliability of classroom connectivity as a perceived barrier to teachers and for students should be decreasing. By 2008 most New Zealand teachers had access to laptops (Cowie et al., 2008) and all secondary schools had computers students could access and some schools had access to digital video cameras and data projectors. However, there is a difference between schools having the digital hardware and teachers being able to use these with their students.

During the last 10 years and most significantly since the interviews with the participants in this study, there has been an increase in both software and hardware designed specifically for educational purposes. One significant development has been the introduction of tablets and most notably the iPad with its thousands of Apps into the New Zealand classrooms. Several schools in New Zealand - primary and secondary schools in both rural and urban areas have introduced a tablet computer as a requirement for each student or have instigated a 1:1 programme for a whole class. This has also significantly improved access to technology for a number of students but as yet there is still little evidence that learning outcomes have increased or that there has been a significant change in the teachers' pedagogical skills to integrate technology into the learning environment.

As early as 1998, Hood suggested that schools were stuck in the $20^{\text {th }}$ Century whilst students have rushed into the $21^{\text {st }}$ Century. This was also an observation made by Prensky (2005a) who noted that schools were struggling to update their teaching practices to meet the changing needs of the students. He is reported as saying that "teachers are still doing many things the 'old way' and not recognising that the students of today are learning differently" (p. 9). They (the students) are so different that teachers can no longer use $20^{\text {th }}$ Century knowledge or 
their teacher training as a guide to what is an appropriate programme for the current students. The way in which digital technology has evolved has influenced both teachers' and students' attitudes to their use. Both teachers and students have developed their own individual methods of using technology in an educational setting. There was also a shift in international thinking about education in a time when there was massive social, economic, and technological change taking place. Policy makers were beginning to question the role of education in this fast changing environment (Bolstad \& Gilbert 2012).

Research by Cox et al. (2004) carried out in England during 2003 identified the approach by which teachers were using technology in the classroom. Through this study, Cox et al. (2004) identified three broad categories of use including an integrated approach, an enhancement, and a complementary approach to the integration process. Cox et al. (2004 as cited in Starkey, 2012), reviewed studies on the use of digital technologies and student attainment and concluded that digital technologies only enhance student achievement when combined with effective teaching practices. This review by Cox reflected the changing beliefs on how digital technologies were being used to enhance student learning.

The integrated approach, as identified by Cox (2004), included deliberate planning to use technology within the subject area to increase the learning of particular concepts and skills. The planning was essential in order to raise the achievement levels of the students. The teachers used digital technologies to present information, ideas, and concepts to the students; this included teachers developing paper-based resources using word processing software as well as using a range of presentation tools. The presentation tools included PowerPoint presentations and Internet-based information and multimedia presentations via a data projector or interactive whiteboard. This approach was by far the most common used by teachers in the UK study. It is also the most common approach taken by secondary teachers in the Wellington schools involved in my study.

The use of specialist programmes and technologies for specific purposes in the different curriculum areas formed part of the enhancement approach. It included the use of Logo in mathematics or technology, and simulation activities in the social sciences, music software for both performance and composition, and the inclusion of specific drawing and design software being introduced into the art and 
technology curriculum. But it also contributed to the mainly didactic approach from the teacher and did allow a little more student involvement to make connections across geographical spaces, between information sources, media, and ideas. There are fewer examples of this in the literature which is not surprising as the tools for this to occur have only recently become widely available in schools, for example the use of Skype and video conferencing and a reliable fast network connection. At the same time, there is an increasing amount of reliable information available through the Internet which has coincided with a growing trend towards the use of inquiry-based learning, particularly in the social sciences and sciences in secondary school. The use of the Internet may well have increased, but the students still need to be taught how to use the information in a critical manner and respect the copyright implications of using online information.

The variety of approaches as referred to in the previous section reflect the different ways in which teachers had attempted to incorporate digital technologies into their existing practice. The first two approaches appear to be similar in that they both enhance the existing teaching practice and lead to a didactic teaching style, but do attempt to address the increased success of the students learning. The third approach is using digital technologies as part of the management and organisation of the teaching and learning process, but it may not have the desired effect of raising learning outcomes. To use digital technologies in these different ways does require teachers and students to be using digital technologies creatively and collaboratively and developing a distinctive digital pedagogy.

In a review carried out in New Zealand by the Education Review Office (ERO, 2005a) that examined e-learning in secondary schools, the researchers examined 48 schools during 2004 and concluded that while teaching programmes that incorporated e-learning had generally increased student motivation and enjoyment of learning, the extent to which e-learning was embedded in teaching practice and supported students' learning goals was limited. The way that the evaluators measured effectiveness was by focusing on critical thinking and information literacy, but the report did not clearly explain how this was measured and did not report on whether the level of achievement had been enhanced through the use of technology. The increase in student motivation and engagement may 
have been short-lived and then waned as the novelty factor of using technology wore off.

All the evidence about student learning and technology had led Siemens (2004) to suggest that a new learning theory was required for the $21^{\text {st }}$ Century learners. His theory of connectivism considers how people, organisations, and technology can work together to construct knowledge. The contributors of the knowledge are building on ideas that have emerged since the introduction of digital information via the Internet; an example of this is the initial development of Wikipedia, the online collection of knowledge that can be added to and altered by anybody. The literature and research on this theory is somewhat limited as connectivism as a learning theory is relatively new. However, the development of the theory itself has been collaborative and open to anyone to contribute whilst digital technologies have been used extensively to construct and develop the knowledge of this theory.

Siemens (2004) has described connectivism as:

The integration of principles explored by chaos, network, and complexity and self-organization theories. Learning is a process that occurs within nebulous environments of shifting core elements - not entirely under the control of the individual. Learning (defined as actionable knowledge) can reside outside of ourselves (within an organization or a database), is focused on connecting specialized information sets, and the connections that enable us to learn more are more important than our current state of knowing. (paragraph 21)

This theory of connectivism can be related to the perceived learning preferences of the Netgen students. They appear to be able to make sense of the chaos by using their networking skills; perhaps teachers should also be exploring the ideas of how, by utilising Siemens' theory of connectivism, they too can make sense of the chaos and the enormous amount of information that is available to the students. The abundance of information and ideas available at an individual's fingertips through the Internet can be overwhelming and is frequently described as infowhelm (Jukes et al., 2010). In order to address this issue of infowhelm both teachers and students must develop more sophisticated media literacy skills. It will be important that 
students develop critical thinking skills in order to navigate their way through the enormous amount of available information.

Becta (2008) carried out a study of about 1200 British teachers in 2007 and found that one third reported sometimes or often using IT to help students to be creative, with $16 \%$ sometimes or often using ICT to help learners to work with others. A challenge identified in this UK review was developing the use of technology from enhancing and enriching learning to extending and empowering it, and developing a broader repertoire of teacher skills. In a report to the Ministry of Education of New Zealand teachers' use of laptops, Cowie et al., (2008) found that $60 \%$ of the teachers used their laptops with data projectors and the most prevalent use of the laptop and peripherals was to present visual material as part of the content to the class. Teachers who used their laptops during lessons to present multimedia materials reported that this engaged students both creatively and critically in their learning, although there is little evidence to support how they made this decision. It was suggested by Cowie et al. (2008) that students were likely to find the range of visual media more engaging than either simply listening to a teacher standing by a board and talking or by making notes themselves.

The way that digital technologies are used in schools has been found to be causing a rift between formal (at school) and informal (outside of the school environment) learning. The report by Becta (2008) had suggested that when the learner is at school they are placed in a passive role, whereas when using technology in an informal setting such as at home the learner is in a more active role. There is now much more emphasis being placed on the out of school learning with teachers embracing the idea of a "flipped classroom" whereby the learning of content takes place away from school and the classroom becomes an opportunity to apply the skills and knowledge they have learnt at home, and seek support from a teacher, if needed, to explain any problems. However, this flipped approach does depend upon the students having access to the technology when away from school. However, when referring back to the New Zealand census data for 2013, this access to technology out of school does not appear to be a problem for many students, with $95 \%$ of the population having access to the Internet via a number of different devices. So in terms of harnessing the power of technology the use of a "flipped classroom" would appear to be appropriate for the New Zealand environment. 
While research does exist concerning the teachers' pedagogy and the way that they integrate computers in schools (Kitchen, Finch \& Sinclair 2007), it does tend to focus on examining how students search for information on the web, or how students learn to use different types of software. It has been noted that the students' expertise at using collaboration tools, such as social media, instant messaging, and blogs, skills that they have acquired away from school, far exceeds that of the teachers. This has meant that students do not always want to use digital technologies in classrooms in the way that teachers may intend. In some cases, this mismatch of understanding of the use of technology has had the effect of teachers blocking the students' use of technology and the students being unwilling to use what they see as outdated software. This can be clearly illustrated by teachers' reluctance to utilise the cell phone in the classroom as a learning tool, as evidenced by the number of schools that have brought in a cell phone policy that enforces students to turn off the device during class time.

Furthermore, the Kitchen et al. (2007) study found that use of digital technologies can differ between the different subject areas that the students are studying at school. The researchers reported that geography teachers were more likely to use Internet-based resources, whilst music and English teachers were unlikely to use presentation tools, however the music, science, and mathematics teachers were more likely to use subject specific software. It is also evident from the New Zealand Ministry of Education, "Software for Learning" website that many more digital resources are being developed and implemented in the primary school than the secondary school. Previous to the Kitchen et al. (2007) study, Ofsted (2005) in the UK also found a variation in the way that digital technologies were used, noting that good application of ICT was seen in design and technology, languages, and art curriculum areas. But the definition of "good" application was not made clear to the reader.

The Ministry of Education is bringing many new technological opportunities into the schools that will impact on both the teaching and learning activities. As well as ensuring that all schools will have UFB by the end of 2016, the connected classrooms will offer greater opportunities for teachers and students to access resources both locally and globally. Schools are using digital devices such as laptops, iPad and tablets to quickly, easily and cheaply connect students with a huge 
and ever-growing number of educational tools and resources and subject-matter experts via the Internet. The teachers are also becoming more proficient in using these online networks and resources through the implementation of in service professional development programmes that have been supported by the Ministry of Education.

Students are using digital technologies to connect with other students across the country and across the world both from home as well as during school time, and they are able to engage in learning in areas that are of personal interest and expertise. The increase in connectivity has also enabled parents, families and whanau to develop stronger connections with schools using digital services like social networks, websites and online surveys.

\section{Role of the Teacher in the Challenging Digital Age?}

Do teachers really need to change how they teach? Two issues are particularly relevant in considering this:

1. How are current methods of teaching suiting the Netgen learners and

2. Are schools and teachers still relevant and appropriate in preparing today's students for tomorrow's jobs?

Children have always acquired basic skills, from communicating, to looking after themselves, to becoming independent and self-sufficient from the adults with which they come into contact. This had all been done with parents, caregivers and teachers fully aware of what the future offered and what job prospects would be available. Nothing really changed that much during the 19th Century. Then the 20th Century turned that all upside down, and future prospects started changing on a daily basis. The 21 st Century has not only continued that trend of new ways of working with new tools, but also new ways of thinking. The problem for teachers is that they must try to prepare students, without possibly knowing what type of employment will be available to them (Jukes et al., 2010).

There can be a novelty factor which increases motivation of learners when digital technologies are first introduced as identified in the research by Falloon (2004). However, earlier research by Moss et al. (2002) had suggested that when 
the purpose of digital technology use for learning is underpinned with effective pedagogy, a decline in student motivation can be reduced. In a study into the motivational effect of ICT on pupils carried out in the UK, Passey, Rogers, Machell and McHugh (2004) found that students and teachers involved in the study felt that access to ICT and resources had reached a level where ICT could be applied to the curriculum and the curriculum purpose could be supported by ICT. All except one secondary school teacher interviewed thought that ICT positively enhanced the range of teaching approaches that could be used. The approaches described involvement using presentation software and downloading information from the Internet. However, it did not include the students working together to produce content when away from the classroom, although this research took place at a time when Web 2.0 tools were only in their early stages of development. It appeared that the students were motivated as a result of the increased auditory, visual, and kinaesthetic stimulation that was a result of the teacher using presentation software and hardware, and motivated by the improvements to the quality of their work in terms of writing, appearance, and presentation. Being able to develop drafts and get formative feedback and knowing the end point or aim of the learning was a factor which students reported improved the quality of work and motivation. Sharing these aims of learning, giving focussed individual formative feedback to learners, and having fast-paced lessons with high expectations of the students have been found to be effective teaching practices. These results align with the findings of Cox et al. (2004) who noted in their review of literature that ICT makes a difference to learning when it is accompanied by effective teaching practice.

Prior to the work of Cox et al. (2004) and Passey et al. (2004), Roschelle, Pea, Hoadley, Gordin, and Means (2000) had examined in more specific terms how computer technology had been used to motivate learners. The research of Roschelle et al. found that active engagement and working collaboratively in groups was important to Netgen learners. Frequent interaction with both teachers and peers, and gaining feedback and connections to real world contexts appeared to enhance how young people learn while using computer based applications. A study by Falloon (2004) had also analysed the impact of a digital classroom environment on the social, cognitive, and affective elements of student learning. Falloon showed that the positive impacts of digital technology use resulted from sound teaching practice 
as well as the novelty factor, as students saw the use of computers as play rather than real work. In this study the students had a stronger preference for using computers at the start of the year than later in the year as the novelty factor wore off. This could also be the result of the student skill level which had increased and they were no longer satisfied with simplistic use of the technology.

Development in education policy in New Zealand (Ministry of Education, 2006) has embraced the suggestion that using technology has the ability to transform education. At the centre of this strategy document is the belief that the appropriate use of technology will have an effect of moving education from a transmission, behaviourist model towards a constructivist, student centred one that can meet the demands of a contemporary workplace and society. The Future focused report from 2014 continues this theme of developing the teachers skills of technology use in the learning environment and states that "we must equip our students with the knowledge, capabilities and values essential to particiate fully and safely in a digital world" (p.9).

Therefore, in summary of this section, it is noted that the literature identifies that in order for technology to be effectively employed in an integrated manner teachers need to reflect upon their pedagogical beliefs. The technology skills of the students also need to be challenged and fully integrated into the learning experience in order to maintain their interest and motivation for learning.

\section{Assessing the Effectiveness of Technology Use in the Classroom}

Examining the effectiveness of learning using digital technologies has been approached in a number of different ways in the previous decade, with most studies reporting on student behaviours such as observed engagement rather than learning achievements. Measurement of the effectiveness of learning in a connectivist learning environment would need to include ideas about knowledge in the Digital Age, including critical thinking, connections, collaboration, and creating knowledge. Any measure of effective use of digital technologies in Digital Age schooling should be underpinned by a view of knowledge that is relevant to the digital era. Ideas about "knowledge" appear to be changing from something that is found in the heads of individuals or in books, to something that is not fixed, is 
debatable, accessible through a range of mediums, and created through networks, connections and collaboration (Bereiter, 2002; Gilbert, 2005; Siemens, 2006).

Jonassen, Peck, and Wilson (2000) discussed the use of computers as a learning tool, stressing that digital technologies promote meaningful learning only when learners are engaged in construction of knowledge, collaboration, and reflection. To engage in this meaningful learning, the learners would have to have connections to other learners or people with whom they could converse, collaborate, and gain authentication. These people could be within the schooling community or, using Web 2.0 technologies ideas, they could be beyond the school environment. As well as providing access to the digital environment it is vital that robust tools are developed to assess the effectiveness of the learning taking place through the use of these digital tools.

In a study of effectiveness of digital technology use in Tennessee (Lowther et al., 2008), programme effectiveness was measured by direct classroom observations, surveys, student performance assessments, focus groups, and student achievement analysis. Observers used a rubric of meaningfulness of computer activities and examined how computers were being used, noting cooperative learning, project-based learning, higher level questions, experiential hands-on activities, independent inquiry, student discussion, or when students were producers or creators of content. The researchers were then able to report that there was a change in pedagogical practice as illustrated by a less transmission style of teaching and more student centred behaviour. Although measuring the ways in which digital technologies are being used in the teaching and learning process could be of use in determining effectiveness, the link between the use and the learning has to be explicit.

The lack of a clear link may also account for the reduced motivation of students during the course of their study as suggested by Falloon (2004). Falloon determined that digital technologies can have a short- or long-term motivating effect on learners. There can be a novelty factor which increases motivation when digital technologies are first introduced to learners. This motivation will be temporary when learning is focused on the technological aspects rather than the learning aspects of a digital technology. Where the purpose of digital technology use is underpinned with effective pedagogy, the longer-term decline in motivation 
is reduced according to Moss et al., (2002). As previously alluded to, the study by Roschelle et al. (2000) suggested that computer technology could be used to motivate learners. It was identified in the research that active engagement with the learning materials, participation in groups for collaborative study, frequent interaction with both peers and teachers, gaining feedback, and linking to realworld contexts enhanced the motivation and achievement outcomes for the students, thus providing more evidence for increasing the use of computer based applications to aid learning in the classroom for all young people.

Although the study of learning using digital technologies has been approached in a number of different ways, many of these studies reported on changes in student behaviour rather than the change in learning outcomes. For example, behaviours that were reported were, engagement with the learning materials, motivation of students, and perseverance with learning tasks. For example, in a study into the motivational effect of ICT on pupils, Passey et al. (2004) used a sample of 17 schools across the United Kingdom. They found that students and teachers involved in the study felt that access to ICT and resources had reached a level where ICT could be applied to the curriculum and the curriculum purpose could be supported by ICT. Teachers from these 17 United Kingdom schools almost unanimously agreed that ICT positively enhanced the range of pedagogical approaches that could be used. The approaches involved using presentation software, such as PowerPoint and downloading information from the Internet. It appears that the students were motivated as a result of the auditory, visual, and kinesthetic stimulation resulting from working with Web 1.0 and presentation software and hardware.

The students also appeared to be motivated by the improvements to the quality of their work in terms of writing, appearance, and presentation. Being able to develop drafts and get formative feedback and knowing the end point or aim of the learning was a factor that students reported, improved the quality of work and motivation. Sharing the aims of learning, giving focused individual formative feedback to learners, and having fast-paced lessons with high expectations of the students have been found to be effective teaching practices as supported by AltonLee, (2003) and were also reported to be motivational in the research by Passey et al. (2004). 
Despite this growing body of literature that examined the effectiveness of the use of digital technologies in schools, interpretation of the term "effective use" varies. In the study by Hernández-Ramos (2005), the focus was on the frequency of use of digital technology by the teachers. Whilst the aim of the study was to focus on the level of technology use, the results reported how some teachers had designed project based activities using technology. The results, however, did not report any significant detail on the effectiveness of technology use. Another study undertaken by Ofsted (2005) reported observing "good application" of ICT in design and technology, languages, and art. Most frequently, the good application identified was in regard to such topics as presentational work including web page construction, web related research, revision, and accessing information from the Internet.

Heppell (1999) had previously argued that the ways in which we assess learning using digital technologies is problematic as the measures are constructed through a transmission teaching pedagogy. However, measuring student learning based on traditional achievement measures is unlikely to take account of the way that students learn in a connected world or apply the use of digital technologies to construct knowledge, and so is an invalid measure as indicated by Loveless, (2002). For example, when Larry Cuban (2001) examined the use of computers in Silicon Valley, he reported an unexpected outcome: "In the schools we studied, we found no clear and substantial evidence of students increasing their academic achievement as a result of using information technologies" (p. 133).

The use of information technologies has also been reported to have a negative effect on students' level of achievement. This negative relationship was found in a US study by Wenglinski, (1998) which compared the frequency of computer use with school achievement, although the study also indicated that certain uses of technology were found to have positive effects. The final conclusion that can be drawn from this study was that how the digital technology is used is more important than the frequency.

It could be that if different measurements were taken, the effect of computer use may have been different. It is therefore clear, that the link between digital technologies and student performance is complex. The later research by Lowther et al. (2008) included gathering student achievement data in two levels of standardised tests. Analysis showed that the students taking part in the programme, which had 
digital technologies and support, performed as well as or better than the control students in most, but not all, of the tests. While this suggests that the introduction of digital technologies and associated support did not make a significant difference to student achievement, it does depend on whether what was being measured as effectiveness was compatible with the aims of integrating digital technologies into the teaching and learning process. The students observed spent more time learning through student centred studies and cooperative learning activities, which may have benefits in other areas of development not measured directly in the tests.

In a study, where presentation software, Internet access, support, and professional learning were put into clusters of schools in poor neighborhoods in England, there was a resulting increase in achievement at the primary level and minimal change at the secondary level (Somekh et al., 2007). Another key finding from Somekh's report suggested that the effective use of presentation software led to greater interaction between students and teacher, which according to Roschelle et al., (2000) was an important motivational factor for student learning. The use of a system of digital attendance keeping improved attendance rates at school and the use of an electronic system for recording behavioural issues also led to improvement in attendance. These factors - attendance and positive behaviour are pre-requisites for effective learning (Somekh et al., 2007).

In their review of the literature, Cox et al. (2004) found that, as with most teaching, lessons that are poorly planned or executed lead to unfocussed students and limited learning. Within the complex context of learning at school, it is difficult for researchers to unpick the teaching from teaching tools. It appears from the work of Cox et al. (2004) that it is the teacher rather than the type of technology that influences the effectiveness of digital technology use in the classroom. It tends to be those teachers who demonstrate exemplary practice within their schools that are more successful when integrating technology into the learning experience. Given the diverse nature of schools and the variety of the management and organisational structures that are required to support such practice, it is unlikely that exemplary practice would be found across the whole school. However, the review by Cox et al. (2004) of the use of ICT in the classroom, also found that there had been a positive effect on attainment in almost all national curricular subjects in English schools with specific uses of technology. These studies support the importance of including 
digital technology across the curriculum as well as across the different schooling sectors.

In order to engage in an investigation of how teachers were integrating technology into the classroom the SAMR model (Puentedura, 2013), has been used. This model supports and enables teachers to design, develop, and infuse digital learning experiences that utilize technology. The goal is for the teacher to transform learning experiences so they result in higher levels of achievement for students. This model has four stages to identify the implementation of technology as shown in the following diagram.

Figure 2.2 The SAMR model of technology integration

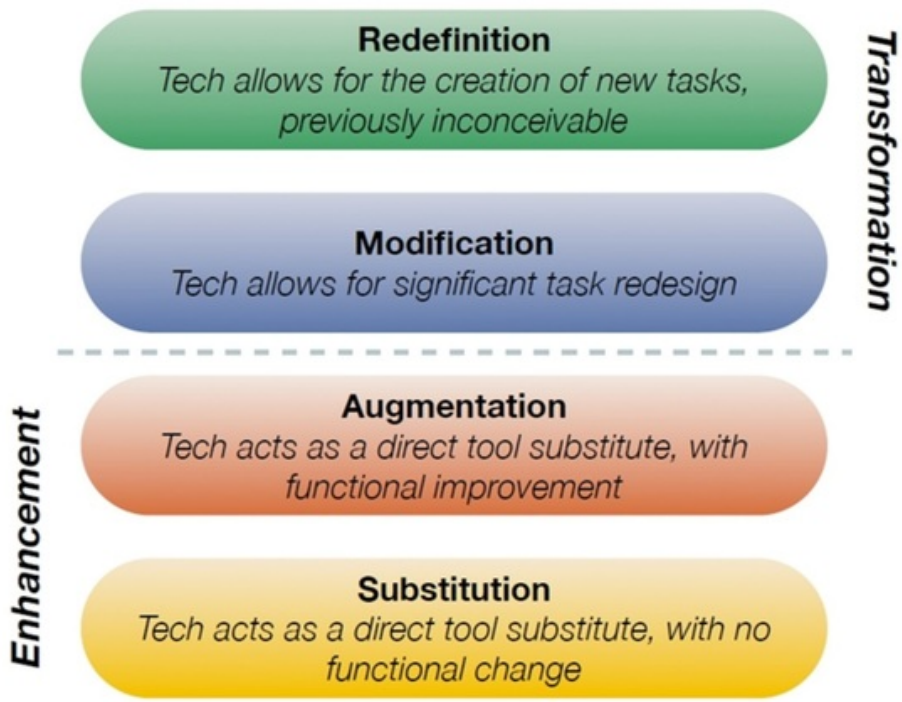

Image the creation of Dr. Ruben Puentedura, Ph.D. http://www.hippasus.com/rrpweblog/

When introducing technology to the classroom, teachers initially use the tools as substitution for an activity that they have used previously. For example, a teacher may use a PowerPoint presentation instead of writing notes on a whiteboard or providing the learners with a worksheet. There has been no change in the teaching style and little or no interaction with the material being taught from the students. As the teacher becomes more confident with the type and use of the technology then it will enable them to develop a digital pedagogy. Students will be introduced to learning tasks that previously would not have been possible within the regular classroom without the use of technology. 
The students in the class may not be able to comment on the development of a digital pedagogy, but they will be aware and able to identify changes in the teachers practice. Therefore, the use of the SAMR model not only enables teachers to plan effective use of technology but also allows students to recognize change in the way that content is delivered and the type of learning activities that become available due to the use of technology.

However, not all studies reported in this review, do show this positive, motivating effects of using technology for learning. For example, a study of at-risk students in an English school carried out by Muir-Herzig (2004) found no improvement in their achievement following the integration of digital technologies in their classrooms This illustrates that it is not just about the technology tools but the way in which those tools are used within the classroom for learning purposes.

Another element that has been identified as particularly important in Digital Age learning is the use of critical thinking. This change in the approach to learning has been caused by the easy access to a wide range of information. The relatively speedy access to this wide range of information means that the user needs the ability to critically evaluate the validity, authenticity, and value of information being accessed. In the past, the library, a book, or an expert (e.g., a teacher) were consulted, and the value or validity was unlikely to be questioned (Rowlands et al., 2008). Therefore, it can be seen that critical thinking is an important aspect of learning and an essential skill when using digital technologies. The development of a students ability to think critically may well be a future measurement of the effectiveness of using technology for learning.

In 2006, a report was commissioned by the New Zealand Ministry of Education to examine the evidence, from both an international and national perspective, of the influence of e-learning in New Zealand schools. The report defined e-learning as "Learning and teaching that is facilitated by or supported through the smart use of information and communication technologies" (Ministry of Education 2006, p. 2). The findings contained within this report suggest that although there are numerous claims about the benefits of technology use for the learners, there is little empirical data to support such a claim and much of the evidence is anecdotal. In New Zealand, the Ministry of Education (2006) viewed new technologies as a vehicle that would transform education for the young people. 
In the ICT Strategic Framework for Education (Ministry of Education, 2006) it was proposed that the appropriate use of technology would move education from a transmission, behaviourist model towards a constructivist and more student centered approach able to meet the demands of a contemporary workplace and society, which emphasises self-directedness, lifelong learning, communication, and collaboration skills.

An earlier review, carried out in New Zealand by the Education Review Office (ERO, 2005a) looked at e-learning at 48 secondary schools. The researchers concluded that while teaching programmes that incorporated e-learning generally increased student motivation and enjoyment of learning, the extent to which elearning was embedded in teaching practice and supported students' learning goals was limited. The way that the evaluators measured effectiveness was by focusing on critical thinking and information literacy, but the report did not explain how this was measured. Some studies have reported that when this increased motivation is combined with effective teaching, students have been able to achieve more than when technology is not used.

The effect that digital technology has on education appears to depend on how the technology is used. Some authors have researched how digital technologies are used as a basis of effectiveness, though where this has occurred, the definition of effectiveness is not clear as reported in the previous section. Most frequently, the good application of technology tools included such items as presentational work including web page construction, web-related research, revision, and accessing information from the Internet. However, this list does not include a focus on collaboration or knowledge building or evidence of developing critical thinking skills that illustrates the effectiveness of technology. It is not sufficient to provide a tool if the students or teachers do not know what it is for or how to use it. However, just having them available in a teaching space may encourage the building of relationships between students and teachers as they work together in learning how to best use these tools. While many of our young people may be expert in using social networking and mobile tools for social purposes, they are still beginners in terms of engaging with these devices in an educational situation.

This area of study into the effectiveness of using technology for learning has continued to be debated German neuroscientist Spitzer (2015) making comment on 
the OECD report states that there is growing evidence to suggest that computer technology in schools is of no educational benefit. He goes on to suggest that in order for deeper learning to occur content requires deeper mental processing such as occurs when information is obtained from books or journals. Notes that are handwritten rather than typed are better committed to long term memory. Spitzer also goes on to suggest that the use of digital media poses risks and serious side effects when used in educational settings as students tend to be more engaged in distracting activities that are offered by mobile computing and wireless access to the internet.

Therefore, the reported effectiveness of technology can also be dependent on research participants' perceptions of the way learning should occur. It is therefore only natural that students would judge the effective use of digital technology in a very different way to their teachers. The students' perspective tends to focus on the enjoyment, satisfaction and relevance of the material whilst their teachers will be expecting higher levels of engagement and achievement. There is currently a lack of research which suggests a way of measuring effective use of digital technologies in a connectivist learning environment with the research findings about effectiveness being presented through the researcher's perspective about teaching, learning, and the nature of schooling. This study will focus on the students' perspective of learning with the use of digital technologies, as expressed through the use of their words.

Looking to the Future

To ensure that New Zealand schools keep pace with the global economy the Ministry of Education has developed a discussion document that is looking forward to New Zealand education in 2025, where the ideas are to "lead with pedagogy, accelerate with technology". They are currently consulting with schools to ensure that the technology developments will enhance better learning outcomes for all students. They are currently supporting this through,

- Providing teachers and principals with leased laptops through the TELA scheme

- Providing funding for software

- Providing professional development and information for schools 
- Helping teachers to connect and network with each other online with the Virtual Learning Network

- Developing digital resources for schools such as e-books

- Assisting schools to become digital hubs for their communities

- Providing on-going support to schools free of

- Working with Network for Learning (N4L) as they rollout the governmentfunded Managed Network internet service to schools and provide Pond as a digital hub for teachers seeking educational resources

- Providing schools with online tools that support teaching and learning and tools that assist with student assessment such as e-asTTle

In summary, the above discussion indicates that during the course of this investigation, teachers and government departments, both in New Zealand and the UK are attempting to implement a programme of increasing integration of technology into the classroom. This has had a mixed reception and the challenge appears to be how to assess the effectiveness of the technology use. Should it be measured by the increasing number of digital devices available, the increased perception of student motivation and engagement, or should it be by rising levels of achievement?

A number of studies on the use of digital technologies in secondary schools report on whether teachers are using digital technologies, identify the barriers and issues for teachers using digital technologies, and/or describe how digital technologies are being used, but there is little evidence to demonstrate that student prior knowledge or learning needs have been taken into account. During the early years of schooling there was an increasing involvement of digital technology for learning being made available for student use but as reported by these young people it was not available to all. Also, there is a paucity of information regarding how these digital technology skills are relevant to the future careers of the Netgen students or whether there is a significant increase in learning outcomes. 


\section{Student Voice}

In this section I discuss major research and pedagogical practice trends in student voice by discussing how definitions, discourses, purposes and practices have developed and evolved as researchers and educators have worked to include voice in their work. The terminology "pupil voice" as used in the United Kingdom and Australia, and "student voice" as in the United States and Canada, emerged from what is generally considered the first wave of student voice work, during the 1990s and early 2000s (Fielding, 2004). This terminology "student/pupil voice" describes how young people give their input to what happens within the school and classroom that will impact on their learning. Student is a term used to signify learners within an educational context and the term voice functions as a marker to refer to the perspectives of a particular social group (Thomson, 2011). Whilst there have been a number of studies (including, Beetham \& White 2014 and Jefferies \& Hyde 2009) pertaining to the use of technology by tertiary students through the medium of student voice, there is little evidence of this approach from school-aged students.

The intention of the issue is for the young people to know that their expertise, opinions and ideas are valued across all aspects of school life. The use of this terminology implies a worldview, stance or standpoint unique to that particular group. Therefore, student voice research refers to the perspectives of students as part of a larger social group.

Historically school aged students have been excluded from educational design, debate and decision-making on the basis that they lacked the capacity and maturity necessary to understand their best interests. However, counter-arguments for the inclusion of school students in this traditionally adult domain can be linked to a number of predominant discourses. Discourse being defined as a limited number of statements that are referred to repeatedly around a particular concept. These statements, linked to each other, provide the grounds for what represents 'truth' in that context for this group of young people.

Educators and policy makers rarely invite students to contribute to educational debate, design and decision-making. Instead, educational decisions and pedagogical initiatives deemed to be in the best interests of students are implemented most commonly without student input or influence. Where students 
have been consulted about their experiences of aspects of schooling, this has occurred largely once educators and policy makers have made significant decisions. This prevailing adult-centric approach is predicated on an historic societal view of children and young people as being immature and lacking rationality. However, a different sociology of childhood (James \& Prout, 1990) has emerged that challenges children and young people's passive positioning and counter-positions them as active social actors with viable and unique insights to contribute in their own interests. Simply consulting students for their views is a commonplace but with a minimal enactment of student voice (Bahou, 2011) because, typically, it does not come with influence on decisions that are taken next (Lundy, 2007). Increasingly researchers and educators are exploring research and pedagogical design initiatives where students contribute as co-researchers and partners alongside adult researchers and educators (Thomson \& Gunter, 2007).

In moving from the $20^{\text {th }}$ Century to the $21^{\text {st }}$ Century there has been a move away from the $19^{\text {th }}$ and $20^{\text {th }}$ Century "children should be seen and not heard" perceptions of childhood towards more child-centred dialogue (Lodge, 2008). However, in many schools, expectations about the young people's attitudes and behaviours are still shaped by an "ideology of immaturity" (Flutter \& Ruddock, 2004 , p. 225) that characterised the earlier centuries. This ideology is based on an assumption that children lack the maturity to be involved in decision-making regarding their future. The exclusion of young people from the processes of discussion and decision-making has failed to recognise the young people's ability for resourcefulness, inventiveness, initiative, and their ability to reflect on issues that affect their learning.

The term, "student voice", as described by Fielding (2009) is "a portmanteau term": the terms student voice, pupil voice, and learner voice are often used to indicate the same perspective and they have been used in that way within this study. This work was most fully investigated by scholars such as Jean Rudduck and Julia Flutter, who worked on several longitudinal studies of students' perspectives on schooling. Throughout their study, "student voice" and "pupil voice" aimed to signal not only the literal sound of students' words as they began to inform educational planning, research, and reform but also the collective 
contribution of diverse students' presence, participation, and power in those processes.

The importance of listening to 'student voice' permeates all levels of education including the teachers, administrators and researchers working together with young people. Examples of this working together include students participating in small groups in classroom conversations to students being involved in curriculum design, responding to research questions, establishing school rules and policies. Student voice is an important factor to consider when conducting research as student achievement and engagement appears to increase when students have more ownership of their school community. It is therefore important to remember that what students have to say matters in how learning occurs, these young people have untapped expertise and knowledge that can bring renewed relevance and authenticity to classrooms and school reform, if they are given the opportunity to express themselves. Students also benefit from opportunities to practice the problem solving, leadership and creative thinking required to participate in a decision-making learning community according to Flutter and Rudduck (2004).

Another key element of student voice signals important shifts in both teacher and student roles. A key dimension of student voice research and pedagogy that has been identified is a change in status for students. This change in status was to position them as educational decision-makers alongside teachers, however, despite years of student voice research and pedagogical practice, this change in student status has remained problematic. By creating an environment for students to be more active participants in the learning process, more innovative teaching practices emerge (Fielding, 2004) as both teachers and students become more comfortable sharing opinions and ideas, thus involving students in a change process should become a routine part of practice. As Thomson argues, "voice" is inherently concerned with questions of power and knowledge, with how decisions are made, who is included and excluded and who is advantaged and disadvantaged as a result (Thomson, 2011, p. 21). The significance of it needs to be more clearly acknowledged in the daily practice of teaching and learning. Fullan, (1991) suggested that one over-arching question summarises the focus of student voice research and practice: "what would happen if we treated the student as someone 
whose opinion mattered?" (p.170). This question has been addressed throughout this study and has resulted in a depth of description of personal experience being shared with the researcher.

In the New Zealand context student voice literature emerged largely in the early 2000 s and this was linked to children's rights debates. Some countries articulate a shared vision for student voice in educational research and practice, and others have no such unifying vision. For instance, according to the New Zealand Ministry of Education website: The New Zealand Curriculum (Ministry of Education, 2007) articulated a shared vision of "Young people who will be confident, connected, actively involved, lifelong learners" (page 8). Moreover, the New Zealand Curriculum (Ministry of Education, 2007) can be seen to promote student voice in a number of ways as it defines dimensions of effective pedagogy by stating that students learn best when teachers:

- Create a supportive learning environment;

- Encourage reflective thought and action;

- Enhance the relevance of new learning;

- Facilitate shared learning;

- Make connections to prior learning and experience;

- Provide sufficient opportunities to learn; and

- Inquire into the teaching-learning relationship.

(Ministry of Education, 2007, p. 34)

By addressing these different dimensions it was suggested that it would lead teachers to using more inquiry learning and e-learning to make relevant links between home and the school curriculum. Teachers were encouraged to find out from students what is important in their learning. The curriculum document also promoted five key competencies, and when these were taken into account students would develop as confident, connected, and actively involved lifelong learners.

However, the students from their vantage point were more ambivalent in their evaluation of these same actions. Although they appreciated having a say in deciding aspects of the classroom programme, they identified pedagogical decision-making as a clear responsibility for teachers who they perceived were professionally trained for this responsibility. Implications from this approach suggest that building student 
influence in classrooms, as a means to elevate their status as governance partners with teachers is necessary. Research needs to look beyond the classroom to bring taken-for-granted elements of school culture expectations, and how these constrain classroom possibilities for action, into the student voice agenda. Teachers and researchers need also to consider how their conceptions of student voice are imposed within the context of compulsory classwork on students.

The approach to research with older (tertiary) students has expanded to include a revision of roles, structures, and processes to support students developing the capacities they need to be research collaborators and leaders. When researchers translate themselves into partners with students in the research process, they are no longer the distanced, authoritative, sole authors of the meaning derived from qualitative research approaches such as observations of and interviews with students (Cook-Sather, 2012). The research begins to shift from research on to research with students.

Research with students has "adults and youth working together to share in the planning and decision making in their endeavours" (Mitra, 2007, p. 731). Issues of power, inclusion, representation, and critical awareness that permeate student voice in educational research make this work fraught with ethical considerations. The experience of investigating others is always bound up with complexities of identity, previous experiences that inform current lenses, and the partial nature of any representation as well as perception (McKenzie, 2014). This is no less true in relation to the participation of children and young people in educational research, and continually engaging in forms of translation, particularly of what one discerns and how one represents it (Cook-Sather, 2012), is an important aspect of this work. Representations of what is generated through the research process have seen a shift toward greater inclusion of student voices, both as "expert witnesses" (Rudduck, 1999) and as co-authors.

The young people involved in Taylor, Smith and Gollop's (2008) research that explored 14 and 15 year olds understanding of "citizenship" found that students valued voice opportunities for the purposes of gaining respect and "the right to "have a say", "to be given opportunities to discuss issues", "to be respected like an adult", "to be listened to" (p. 204). They noted "New Zealand children see themselves as active agents in society, rather than just being acted upon by society" (p. 207). 
A number of school-level student voice projects in New Zealand have focused around advocating the value and authenticity of students' views on their learning. In the middle school and secondary-school domains New Zealand researchers (Bourke \& Loveridge, 2014; Kane \& Maw, 2005; Nelson \& Christensen, 2009; Nelson et al., 2008) have investigated the role students can play in improving teachers' practice (student voice as enhanced learning discourse). Nelson and Christensen (2009) used student voice to explore the perceptions held by students about themselves as learners and their experience of school. The students' teachers were involved as the audience for the students to communicate their perspectives so that teachers' enhanced understanding of the needs of these students might inform and improve their pedagogy and relationships with these students. Teachers utilised these student perceptions to inform their classroom planning and to consider issues relevant to students through staff development sessions.to promote student voice within classroom-based pedagogical and curriculum decision-making.

Not only does it make good educational sense to incorporate the student voice but it is also considered to be a right of an individual. For example, the U.N. Convention on the Rights of the Child (1989) included children's right to be heard as one of its four basic principles. Therefore, it should be of high importance to teachers and the policy makers who are responsible for planning the educational future for the young people to hear what they consider important to their future. Schools have moved slowly in changing their practice; many people have a belief that this is more evident in the area of secondary education where they feel constrained by external forces demanding examination success in the traditional subject areas of literacy, mathematics, and sciences and the temporal constraints of timetables.

There is no doubt that academic skills are important but other competencies are also being required by employers of the young people. The young people have access to a wide range of information via the Internet but frequently lack the skills of critical thinking, and problem solving and the ability to work in a collaborative manner. The students themselves have spoken up about the need to include more "Digital Age skills" in their educational programme. Student voice is important because presenting the research focus from the individual stance and using the voice of the participants as far as possible, the research comes alive. It is my belief that, although some schools have successfully moved from blackboard to whiteboard to smart-board use, they have been less successful in recognising that young people are 
maturing at an increasingly younger age and they have the capacity to be fully involved in the decision making processes concerning their future.

Fielding (2009) has stated that it was important to emphasise the words, suggestions, and critique provided by the students as being of value in order to develop a positive relationship between student and researcher. It was considered important to listen to student opinions and respect their rights to contribute and participate in decision making. For the students, respecting their opinions and valuing their contributions towards effecting change was important. However, as Robinson and Taylor (2007) note, the term "voice" should be used with caution; voice encompasses much more than the speech of the speaker. Adults who recognise these limitations also acknowledge that the term is a composite notion and note that voice has been used to describe a multitude of actions and non-verbal cues (Robinson \& Taylor, 2007).

There are three definitions of learner voice that are particularly relevant to this study. Firstly, the definition of student voice as expounded by Rudd, Colligan and Naik (2007) maintains that student voice is about: "Empowering learners by providing appropriate ways of listening to their concerns, interests and needs in order to develop educational experiences better suited to those individuals." (p.8) Secondly, the suggestion by Johnson (2004,) is that learner voice is about considering the perspectives and ideas of learners, respecting what everyone has to say, taking risks, sharing, listening, engaging, and working together in partnership. Finally, Fielding (2009) refers to student voice as the practice of "Listening purposefully and respectfully to young people in the context of formal schooling" (p.2). The application of these three definitions of student voice to the study of the use of digital technology appears to be absent from current research; the students have been given little opportunity to report on their experience. It is important for the future of technology integration that, by working together, students and teachers will be better placed to use the technology to enhance learning.

Halsey, Murfield, Harland and Lord, (2007) argue that there are considerable advantages to schools and other educational institutions when the voices of young people are listened to. These advantages are recognised as being of benefit to improving the services that are provided to the students, decisions on spending and the purchase of specialised equipment, and providing greater democracy for the 
learners. Including the young person in the discussion also has a secondary benefit of improving the social and communication skills of the young person as well as improving self-esteem when teachers consult them and value their input.

The student group are the main stakeholders in the work of schools and educational institutions, yet there has been little research listening to the student voice in relation to learning with technology. Students have shown throughout time that they are perceptive thinkers and are aware of what is happening in their learning environments and what improvements could be made. This generation of students is acknowledged as being "digital natives" and the "Netgen" due to their familiarity with technology and the variety of technologies that are a normal part of their lives. Owen and Moyle (2008) suggested that it is time to bring together student understandings of technologies with the wisdom of teachers to jointly construct learning futures and synthesise the best of both sets of experiences.

The literature (Fielding 2009; Robinson \& Taylor 2007) identified that there was a strong argument for involving and consulting young people about their learning. It enabled recognition of their maturity and desire to be treated in an adult way, the importance of feeling "respected" and listened to in school both as individuals and as a group. Providing links to real world learning opportunities, as identified by a student group, has been shown to improve both motivation and engagement with learning that ultimately leads to improving learning outcomes. Schools are now finding that utilising meaningful student involvement can be a powerful and effective force for gathering information about ideas for school improvement, and for increasing students' commitment to their own achievement as well as to school goals, thereby making schools, in turn, more responsive to the characteristics and needs of their students. This meaningful student involvement in reporting on the experience validates the unique perspectives, insights, and needs of the students and engages them in shaping their own educational experiences.

However, there is no guarantee that changes that occur from listening to the student voice within the school system will ensure that the students will engage in the educational process. If students are to engage with the school and learning process, then there needs to be consideration of student opinion to identify a productive pedagogy that truly motivates and engages them in learning. This direct investigation of student opinions, according to Fletcher (2003), is currently missing 
from the literature and there is little known about how school students think about their own learning, particularly in relation to technological innovation in learning environments. Therefore, using student voice to discover school students' perceptions of technology integration, of the teachers' skill and knowledge of a variety of applications, and of the cultural and social circumstances through which this is occurring will significantly add to the body of knowledge about learning with digital technology in school environments. Consulting the young people directly is one way of doing this; being consulted can help students feel that they are respected as individuals, that their opinions are valuable, and that they are being treated in an adult way.

Furthermore, the literature, (Fielding 2009; Robinson \& Taylor 2007) suggests that young people who are at risk of disengaging from school may become more involved if they think that they are valued by the school. Fletcher (2003) suggested that by seeking the perspective and valuing the experience of each individual student, meaningful involvement can help to end educational discrimination. Schools where students are consulted and involved in the planning and decision making process appear to be places that have built a strong sense of inclusive membership, where differences among students are accepted, and where opportunities for discussion and support are made available for those students who find learning a struggle. This would also help to bridge the gap between minority, low-income, and underserved students and mainstream student populations in engagement with school. Students can influence school changes by providing thoughtful and reliable information about ways to make schooling more engaging and effective for all. For this consultation to be genuine the students need to be sure that schools are really interested in what they have to say, that their views will be given careful consideration, and that they will also receive feedback on what they have said and some explanation of any decisions taken as a result of the consultation. The consultation should be guided by the desire to hear that what the young people have to say is genuine, that the topic is not trivial, and that the purpose of the consultation is explained to the young people. Students need to understand the purpose of the data collection and what the data will be used for so that they are confident that expressing a sincerely held opinion, or describing a feeling or an experience will not disadvantage them. Previous research on the way 
that young people use digital technology had focussed on what media they used and how much time they spent using it. But it must be emphasised that the researchers in the past have not always asked the young school students for this information.

Fletcher (2003) believed that seeking and valuing the students' perspective was important in distinguishing between tokenism and the development of the student-adult partnership in creating effective learning environments. It is possible to develop this partnership approach by using methods such as surveys, focus groups, and interviews to gain information about the learning needs, preferences, and experiences of individual students (Howard, 2003; Rudduck \& Flutter, 1996). Therefore, by using a student voice approach that incorporates many different methods of gathering information, a valid picture of technology use by this small group of secondary age students will provide valid data for this research.

\section{Summary}

This chapter has outlined a broad depiction of technology use in schools around the world before 2010 and some of the significant changes that have occurred to date. As expected, there are a variety of views and perspectives as to the value that technology has contributed to the learning environment and the learning outcomes.

Despite the assertions of the early adopters and critics of the new technology, uptake by schools has been considerably slower than expected. The literature has illustrated that technology in the classroom is merely a tool for learning just like a teacher assistant, a textbook, a library, or even a desk. The research also suggests that learning should not be about the digital tools but the way in which the students and teachers are using the tools to support that learning. Through inviting and then encouraging exploration, students and teachers have the opportunity to explore computer software. Some students and teachers are more relaxed about taking these initial risks than others and often actively support more reluctant students (and staff) to take experimental risks with technology. As a result, schools are at very different stages in their knowledge, understanding and the integration of technology into the classroom. The literature review has also identified that school leadership is an important factor for successful technology integration. Leaders must believe that modern technology is a necessity and through 
those beliefs, encourage teachers to be sufficiently and competently trained and supported to use technology in their everyday planning, programming, and assessments of student learning.

As Davies and Eynon (2013) have indicated, the most significant indicator of increasing technology use has been the refinement and access to the Internet. Young people appear to be constantly connected via their Smartphones or increasingly through a small mobile device such as an iPad or other tablet. The latest census information for New Zealand has shown a marked increase in the number of homes that have an Internet connection and that it is accessed via a number of different devices. This increasing accessibility to information from global sources must now be integrated into the young people's education so that they can develop skills to become successful $21^{\text {st }}$ Century digital citizens. However, as Spitzer (2015) comments, we need to be aware of some of the serious risks that technology use presents to the young people of today.

This literature review indicates that there is a need to investigate the effective use of technology for learning as perceived and reported by the young people involved. Despite the assumptions that have been made about the Netgen or digital natives by the older generation there are a number of these young people who do not have the ability or access to the technology to enable them to use it effectively for their learning. The main barrier to this appears to be that the voices of the young people are not being heard, therefore this study will enable the views and experiences of the young people to be acknowledged as they continue to develop their personal skills. 


\section{Chapter 3: Research Methodology and Design}

This study was undertaken to investigate the Netgen students' perceptions of the educational systems' ability to prepare them for a future role in the $21^{\text {st }}$ century workforce with regard to their knowledge, understanding and use of digital technologies. In undertaking this it was important to consider their prior knowledge, understanding and use of digital technologies. This chapter outlines the purpose, aims, and the research methodology that were used for the study and a particular focus is the rationale for selecting a qualitative, interpretative phenomenological, multiple case study as the preferred means of studying this phenomenon.

This section also includes an examination of issues that are relevant to the researcher's role, trustworthiness, and credibility within the relevant field. Also included are details of the data collection methods, interviews, observations, and focus groups, and the method of analysis of the collected data. Ethical issues for both the participants and the researcher are outlined and the chapter concludes with a discussion of the overall research process.

The Purpose and Aims of the Study

Keogh (1999) suggests that valuable research begins when the researcher identifies a problem or issue in which they have a personal interest. In this study, the researcher's interest was driven by her experience of working alongside students who demonstrated significant technology skills but who were unable to take advantage of such skills within the classroom environment in order to support their learning. This is particularly important because the use of digital technology appeared to be the students' preferred mode of accessing, producing, and presenting information. The researcher also observed that as a result of students often being denied permission to use and have access to technology at school, combined with the teachers' lack of understanding of the technology that was available, the students reported the work being "boring" and "not relevant" in relation to their future. Green and Hannon (2007) suggest that this perception can cause some students to opt out of learning and, in some cases, out of school completely. Therefore, the aim of this study was to examine the Netgen students' perceptions of 
the educational system's ability to prepare them for a role in the workforce of the $21^{\text {st }}$ Century with regard to their knowledge, understanding, and use of digital technology.

\section{Theoretical Perspective}

Within the last two decades, there have been rapid and significant changes in understanding and thinking about education and learning. For example in Connectivism: A Learning Theory for the Digital Age, George Siemens (2004) argues that technology has changed the way we learn. He suggests that connectivism is a useful learning theory for the digital age because it seeks to describe how students who use personalised, online and collaborative tools learn in different ways to those who do not employ these strategies. Although there are critics of this theory who suggest that Siemens has overlooked some significant issues such as reflection, learning from failures, error detection and correction, and inquiry. However, these critics agree that it can provide a framework for proposing a learning theory for the $21^{\text {st }}$ century. The value of connectivism places the responsibility firmly on the students to develop their own personalized learning tools, learning environments and communities where they can share their individual knowledge and skills. However, in many schools this approach to learning is potentially constrained by the school timetable and curriculum.

A crucial point of the theory of connectivism is that the connections that make it possible for us to learn in the future are more relevant than the sets of knowledge we know individually in the present. Siemens (2004) goes on to explain how digital technology tends to complicate or expose the limitations of the learning theories of the past and indicates that the focus should be more on developing a digital pedagogy. It is implied that technologies can, to some degree and in certain contexts, replace know-how with know-where-to-look. Indeed, the theory of connectivism suggests that through the use of digital technology there is more to learning than memorisation. This notion of memorisation has been criticised however. For example, Carr (2010) asks the question "is Google making us stupid?" by providing the place to look for the "answer" rather than the need to learn or remember the answer and then to apply the knowledge to a different situation. 


\section{Research Design}

Considering the underlying approach is connectivism, a constructivist paradigm using an interpretive phenomenological approach utilising multiple case studies was adopted for this study. This facilitates the examination of social interactions from the participants' perspectives using their voices in order to obtain their understanding of the phenomenon in question. In other words, the sources of data for this phenomenological investigation were the participant's perceptions of the situation as explained in their own words, and perhaps manifested in their behaviour within the situation. Social constructivism argues that educators should be aware of the skills, knowledge and experiences that the learners have when they arrive in class. The teacher must view the student within a context of what they can do and what they already know in order to create an effective learning environment. This approach is also consistent with the phenomenological perspective, which takes human interpretation of the situation as the starting point for developing knowledge about the social world (Prasad, 2005).

As this study was designed to understand and investigate in detail the participants' perspectives on how they were using technology to assist their learning consideration of a learning theory that was relevant to these $21^{\text {st }}$ Century learners became an important focus. Thus, the researcher's choice of strategy of inquiry was situated within a constructivist paradigm, based on the belief that individuals come to know what has happened partly in terms of what others reveal as their experience through their stories - that is, that knowledge is socially constructed (Janesick, 2000). Indeed, qualitative researchers assume that there are multiple realities and that the world is a function of personal interactions and perceptions. Furthermore, the manner in which most people come to understand their experiences is through the use of words. Therefore, the use of a qualitative paradigm that is primarily concerned with the participants' perspectives and how they make meaning of that experience provides data for the researcher in the form of their words.

The research approach was influenced in particular by an interest in, and the wish to gain a greater understanding of how the selected participants perceived the school support for their learning through the use of technology. The approach selected was not intended to propose a solution to an issue, nor was it intended to imply all students encountered the same experience. As a result, a number of 
different approaches were initially identified and the relative merits of each approach considered. Finally, after careful analysis (refer below) a qualitative and student centred phenomenological approach that focused on the participants' experiences and ensured that the "stories" were recorded in detail was selected.

Creswell (2007) describes five different types of qualitative research traditions - narrative, grounded theory, case study, ethnography, and phenomenological - each needs to be considered in relation to the purpose of the study. Refer to Table 3.1 below for the major attributes of each of these five traditions and the essential reasons why the phenomenological approach was adopted.

Table 3.1: Types of Qualitative Research Traditions (Creswell, 2007)

\begin{tabular}{|c|c|}
\hline Type of Qualitative Tradition & Main Attributes \\
\hline Narrative & $\begin{array}{l}\text { Reports on the life of a single individual in } \\
\text { detail. }\end{array}$ \\
\hline Grounded Theory & $\begin{array}{l}\text { Moves beyond just describing or reporting } \\
\text { and attempts to generate or determine a new } \\
\text { theory }\end{array}$ \\
\hline Case Study & $\begin{array}{l}\text { Focuses on one or more cases within a } \\
\text { bounded system }\end{array}$ \\
\hline Ethnography & Focuses on an entire cultural group \\
\hline Phenomenological & $\begin{array}{l}\text { Describes the lived experience of several } \\
\text { individuals focusing on a concept or } \\
\text { phenomenon. It does not attempt to provide } \\
\text { solutions or generalisations from the } \\
\text { findings. }\end{array}$ \\
\hline
\end{tabular}

As indicated above, when bearing in mind how this study would proceed, consideration of the relative attributes of each of these five different traditions was taken into account before making a final selection of phenomenology.

\section{Phenomenology}

This tradition was judged to be the most appropriate to study the phenomenon of digital technology use by the Netgen students for two main reasons. Firstly, phenomenology is concerned with lived experience and, through the 
participants' narrative, seeks to reveal the essence of the phenomenon. Secondly, it enables the examination of the experience as it is occurring for the individuals (Creswell, 2007). Whilst these lived experiences may be mundane for the participant, when they are examined in detail they can reveal meaning that may not be obvious to the participant.

Each of the five differing qualitative research traditions (Table 3.1), have value but phenomenology was important for this study because it begins with an experience or condition and, through the narration of participants of either a shared single incident or shared condition, investigates the effects and perceptions of that experience: "Phenomenologists distinguish phenomena, the perceptions or appearances from the point of view of a human" (Willis, 2007, p. 53). Simply put, the phenomenological method interprets an experience or fact by listening to the different stories of the participants; furthermore, the method examines the phenomena through the subjective eyes of the participants and through the words of the participants. As Willis (2007) explains: "Phenomenology is focused on the subjectivity of reality, continually pointing out the need to understand how humans view themselves and the world around them" (p. 53). The phenomenon that is being studied is not limited to historical events or extended time frames. This study, for example, is a snapshot in time of students' perceptions of the current situation as it is occurring for them.

As the intent of a phenomenological study is to study participants, viewing them as people who interpret the world and their experiences and who construct personal understandings of these experiences, this methodology enables the gathering of rich data (Pring, 2004, as cited in Hopwood, 2004). This perspective therefore supports the purpose of this study - to understand and describe in depth the phenomenon of how the participants' uses of technology have influenced the way in which they, the Netgen, prefer to approach learning, and to arrive at the essence (Husserl, 1969; Moustakas, 1994 as cited in Cilesiz, 2009) of these experiences. The inquiry was framed around the perspective of the students so the research question adopted was "What does the personal lived experience of students using technology in their education tell us about the capability of the education system to prepare people for life in the $21^{\text {st }}$ Century."

By taking this phenomenological perspective, this study attempts to uncover 
and describe the essential nature of the digital experience for 8 young people. It was never the intent to find a solution to issues these young people shared, instead, it was hoped through the sharing of the young people's stories, others may begin to understand and appreciate the enablers and barriers to using technology for the young people. It was important that the student voice was heard in the telling of their experiences.

Accordingly, understanding of the student perspective via a case study research strategy was also employed. Multiple data collection methods, both formal and informal were utilised in order to provide detailed information about the student experience. The data was then subjected to a thematic data analysis in order to extract the prominent issues - each was considered as an individual case and the data were subjected to two stages of analysis: case specific and cross case analysis.

The structured methods of data collection included a questionnaire and an interview whilst the informal data was to be obtained through focus group discussions and casual anecdotal, personal conversations with the participants as well as observations in the school setting. In some of the school settings the teachers also willingly talked about their experiences of using technology for teaching. These teacher comments served to confirm certain aspects of the participants' experiences. The observations and teacher experiences were considered as supplementary to the questionnaire, interviews and conversations as primacy in phenomenological research is the experience as expressed by the participants.

In many ways, the use of an interpretive phenomenological approach respects the legitimacy of the participants by ensuring that their views are clearly stated and understood by the researcher. There are potential dangers in adopting this approach, as the participant's interpretation does not necessarily equate with reality or truth (Willis, 2007). This is, however, the very substance of phenomenology and is at the same time its strength. Whilst adopting an interpretative phenomenological approach for the analysis, the researcher was conscious that any interpretation of the digital natives' life world through their stories and recollections may not necessarily correspond with the participants' or the reader's understanding of the experience cited. Therefore, while the researcher shared some reflective understanding of the 
young people's stories, it is important to acknowledge that the participants' description of their school and home experiences remained the primary focus.

Given that it was the voices of the participants that were important in relation to the previous discussion of methodologies, the researcher concluded that the topic was best interpreted via a constructivist perspective using an interpretive phenomenological paradigm utilising multiple case studies.

Firstly, it was the most suitable approach because the context of the research was concerned with both formal and informal use of digital technologies that had influenced the way these students approached learning with technology. Secondly, it had influenced the way these students approach learning with technology in school, as reported by the students themselves. Thirdly, the approach was selected as it empowers the participants to be voicing their views. It was expected that more valuable, in-depth data would be obtained from this research approach than one based on a quantitative approach which would be better for examining specific issues.

In consideration of all this and acknowledging phenomenology as a philosophy that focuses on the lived experience and a methodology that studies people's experience of a social phenomenon, this made it an appropriate choice for this study. It was a study that built upon an epistemology that sees knowledge as being socially constructed and a theory that views learners as active constructors of that knowledge; therefore, the phenomenological approach as detailed was deemed appropriate for this study. It was a study that built upon an epistemology that sees knowledge as being socially constructed and a theory that views learners as active constructors of that knowledge; therefore, the phenomenological approach as detailed was deemed appropriate for this study.

Phenomenology offers the researcher a qualitative method of inquiry that can be applied to a multitude of experiences. However, phenomenology also offers the researcher the ability to examine the cumulative experience of participants as they relate to a single point in time. In phenomenology the shared experience of a single life event, be the event lengthy or a matter of seconds it is the focal point of the research, not the event itself. For example, research conclusions do not investigate the Christchurch earthquake as a phenomenon, but rather the experiences of the 
participants as they experienced that phenomenon; the investigation of those individual experiences in turn, allows a deeper understanding of the phenomenon. "The focus is thus on understanding from the perspective of the person or persons being studied" (Willis, 2007, p. 107).

For this research, the focus was on the students' experiences of the use of technology specifically for learning, not just the use of technology. This style of investigation was made explicit in writing up of single case studies that represented in-depth examinations of the lived experience of a single person an approach as noted by Smith (2010). More commonly interpretative phenomenological analysis involves the detailed analytic treatment of each case followed by the search for patterns across the cases. Where this is done, studies are concerned with the balance of convergence and divergence within the sample, not only presenting both shared themes but also pointing to the particular way in which these themes play out for individuals.

Phenomenology is a philosophy that was introduced by Edmund Husserl (1859-1938) at the beginning of the Twentieth Century, around the same time as psychology as a discipline was being founded. Although the philosophy has changed over time, many of Husserl's ideas have remained pivotal especially the key idea that phenomenology was defined as a process that allowed the viewing of an event or experience as perceived by those involved in that experience. It was seen as a means of "describing" the experience rather than the invention of a theory to explain the phenomenon. An important element to Husserl was the understanding of the "essence" or true nature of the experience as perceived and explained by the participants. Initially, although phenomenology was viewed as a philosophy rather than a research methodology, it has given rise to a style of research that aims to gain a deep understanding of the participants' perceptions of the phenomenon. Thus Giorgi (1997) describes the phenomenological methodological approach as one that seeks to describe the lived experience as it occurs for the participants and, therefore, attempts to uncover the meanings within this everyday experience.

In contemporary times, phenomenology includes transcendental, existential, and hermeneutic traditions (Audi, 2001; Schwandt, 1997) and, as a consequence of the development of these different traditions, the concept of phenomenology is best described as a movement rather than a single approach. Moustakas (1994) described 
transcendental, or psychological, phenomenology as focusing more on the actual experiences of the participants and less on the interpretations of the researcher. Heidegger (as cited in Smith, 2013) explained existential phenomenology as a way of conducting oneself in the world whilst van Manen (1990) identified hermeneutic phenomenology as focusing on the lived experiences of research participants and interpreting the "texts" of their lives (p.4). As can be ascertained therefore one of the strengths of a phenomenological research approach, was the flexibility and adaptability of phenomenology (Garza, 2007).

This interpretive phenomenological approach, was selected for this study as it is a systematic attempt by the researcher to come into direct contact with the world of the participants, to uncover and describe the meaning and structures of their lived experiences, and to arrive at a deeper understanding of the nature or meaning of everyday mundane experience of the phenomenon under study (Lauer, 1965; van Manen, 1990, as cited in Cilesiz, 2009). The participants described firsthand the events that they experienced and the researcher interpreted the deeper meaning of these experiences. This phenomenological methods approach is consistent with a range of studies that have been used extensively to study learning in a variety of contexts, (Baytak, Tarman, \& Ayas, 2011; Cilesiz, 2009; Tuttle, 2012). This research was in part guided by these earlier studies. It is also important to signal to other researchers in the field of education that phenomenology is a challenging, rigorous methodology that has the potential to be enriching and transformative in terms of shaping practice. Good research is not all about numbers, hypotheses and measuring change. Creswell (1988) states: "Qualitative inquiry represents a legitimate model of social and human science exploration without apology or comparisons to quantitative research. Good models of qualitative inquiry demonstrate rigor, difficulty, and time-consuming nature of this approach." (p. 9

One model of phenomenology as advanced by Willis (2007) sees phenomenology as just one part of qualitative or interpretive research, where there is an emphasis on different aspects of an in-depth understanding of the phenomenon. He suggests that researchers need to ascertain how people perceive themselves and the world around them and through this approach he believes phenomenology has immense value for the researcher. It was not the intention of this study to develop theories about student learning through the use of digital 
technology, but rather to present the experiences of using digital technologies (the essence) for learning as perceived by a small group of secondary school students. The essence is the condition or quality of an experience commonly shared by the participants; it is what makes the experience what it is (Moustakas, 1994; van Manen 1990). In order to arrive at this essence, a multi method approach to data collection was employed, including questionnaires, interviews, observation, and focus groups.

Although the researcher was the main instrument for data collection and analysis, it was mediated through the researchers' personal perceptions and knowledge in order to present an understanding of the participants' world. As Glesne (1999) notes, the researcher is a translator of culture, trying to understand the world of the interviewee, and to make a meaningful interpretation of the data. It is important, therefore, to acknowledge that, as with all research that requires interpretation, this research was filtered through the researcher's own experiences and events that have shaped her thoughts, beliefs, and values. However, "by being aware of forces that help shape your interpretations, you can challenge some, while simply acknowledging others" (Glesne, 1999, p. 158). Moustakas (1994) suggests that by suspending one's natural standpoint and preconceptions of the phenomenon, the data analysis will be free from supposition and this can be achieved by using a disciplined and systematic effort.

\section{Researcher's Approach}

The researcher utilised a hermeneutic/interpretive approach in this phenomenological research, attempting to interpret the experiences of the research participants as they described their technology experiences. Table 3.2 is a representation of van Manen's (1990) qualitative tradition of phenomenology as related to the steps that were taken by this researcher in accordance with the same qualitative tradition. 
Table 3.2: Phenomenology Model and Researcher Actions (van Manen, 1990).

\begin{tabular}{|c|c|}
\hline Preparing to Collect Data Model & Researcher Actions \\
\hline Formulate the question & $\begin{array}{l}\text { Discussion held with Year } 12 \text { students } \\
\text { to focus the main research question and } \\
\text { shape the sampling method. Trialled } \\
\text { the questions with another group of } \\
\text { year } 12 \text { students. Checked for } \\
\text { consistency of quality responses. Make } \\
\text { any required changes and prepare final } \\
\text { questionnaire. }\end{array}$ \\
\hline $\begin{array}{l}\text { Conduct literature review and } \\
\text { determine the nature of study }\end{array}$ & $\begin{array}{l}\text { Literature review was conducted to } \\
\text { determine gaps in the research. Data } \\
\text { describing the lived experiences of } \\
\text { students who were using technology } \\
\text { for both formal and informal learning } \\
\text { were lacking. }\end{array}$ \\
\hline $\begin{array}{l}\text { Develop criteria for selecting } \\
\text { participants }\end{array}$ & $\begin{array}{l}\text { Purposeful sampling method was used } \\
\text { to select participants who were known } \\
\text { to use digital technology both at home } \\
\text { and in school. They were not } \\
\text { considered representative of the Year } \\
12 \text { cohort. }\end{array}$ \\
\hline $\begin{array}{l}\text { Develop instructions and guiding } \\
\text { questions for phenomenological } \\
\text { interview }\end{array}$ & $\begin{array}{l}\text { An interview guide (Appendix E) was } \\
\text { prepared, which ensured that similar } \\
\text { questions were asked of all } \\
\text { participants, thus giving an opportunity } \\
\text { to compare the experiences across each } \\
\text { case. }\end{array}$ \\
\hline
\end{tabular}




\begin{tabular}{|c|c|}
\hline Collecting Data Model & Researcher Actions \\
\hline $\begin{array}{l}\text { Engage in the "epoche process" to assist in } \\
\text { creating an atmosphere and developing } \\
\text { rapport for conducting the interview }\end{array}$ & $\begin{array}{l}\text { Engaged in epoche by leaving biases } \\
\text { behind, focusing on only what the } \\
\text { participants were describing as their } \\
\text { personal experiences. Prior } \\
\text { knowledge and understanding of the } \\
\text { phenomenon were set-aside during } \\
\text { the interviews. }\end{array}$ \\
\hline Bracket the question & $\begin{array}{l}\text { Due to personal interest in the } \\
\text { phenomenon being studied, } \\
\text { experiences and personal biases were } \\
\text { bracketed to enable participants to } \\
\text { express their personal views without } \\
\text { intervention from the researcher. }\end{array}$ \\
\hline
\end{tabular}

\section{Case Study}

In this current study a phenomenological approach was adopted but utilised a multiple case study in reporting the data. Case study methods have been widely used in educational research that relates to both perceptions and experiences of participants. Case study is a methodological approach that involves systematically gathering enough information about a particular person or group and situation to permit the researcher to effectively understand how the subject operates or functions (Berg, 2004). A case study approach is employed when a "how", "who", "why", or "what" question is being asked, or when the focus is on a real-life phenomenon within a real-life context, or about a contemporary set of events over which the investigator has little or no control (Yin, 1994). This researcher was significantly influenced by the reported experiences of students using Internet cafes in Turkey (Cilesiz, 2009), a case study approach that also used a phenomenological methodology. 
Merriam (1998) describes four characteristics that are the essential components of a qualitative case study. These characteristics are outlined below and specific reference is made to how they apply to the current study:

a) Particularistic - where the case study focuses on a particular event, situation, or phenomenon. It can examine a particular instance but illuminate a general issue. In relation to this study, the phenomenon being investigated is the use of technology by the students and the impact on the way that the Netgen students learn and their future employability.

b) Descriptive - the end product of the case study is a rich description of the phenomenon under study. The data in this study were collected via one to one interviews and discussion with focus groups on the topic. The data were then used to describe the "experiences" of the student using their own words.

c) Heuristic - the case study illuminates the researcher's understanding and brings about discovery of new meaning of the phenomenon under study. It is anticipated that the data obtained in this study will be used to inform practice as well as helping teachers to support the learning of the $21^{\text {st }}$ Century students.

d) Inductive - data are grounded in the context itself, and inductive reasoning leads to discovery of new relationships and understanding rather than a verification of predetermined hypotheses. As previously explained, my own personal experiences and perspectives will mediate the data analysis but these perceptions may well be challenged by the participants' comments.

This research falls within this general description of a multiple case study in that it is exploring a particular contemporary issue (the use of digital technologies) in a real-life situation (informal learning out of the classroom as well as formal learning within school). A case study may be intrinsic (the researcher wants better understanding of a particular case), instrumental (the case is supportive and facilitates our understanding of something else) or collective (an instrumental study extended to several cases) (Merriam, 1998). This study contains both intrinsic and collective methodologies; each participant is viewed as an individual case. In this particular study the "cases" were eight students from a selection of year 12 students who attended secondary schools in the Wellington region and who had participated in an initial questionnaire concerning the use of ICT in school. 
Although this research is primarily qualitative, the methods incorporate both qualitative and quantitative data collection and analysis modes. Patton (2001) stated that using both qualitative and quantitative data, with their varying strengths and weaknesses, could be combined to clarify complementary aspects of the same phenomenon. By collecting initial data from a large group of secondary students it was possible to quantify the ownership of technological equipment (cell phones, computers, iPad, tablets, and netbooks) across a range of socio- economic groups. It was also possible to view how these students viewed their personal expertise in using a variety of types of software and hardware. This means of data collection enabled the researcher to identify individuals that had a wide range of technological experiences and could be involved in further interviews and focus groups.

A multiple case study approach was the complementary methodology selected as it allowed the research to focus on the complex forces and relationships that impact on the participant within the context of the school and home environment in which they are learning. Furthermore, the information gathered in a multiple case study approach allows the reporting of complex, dynamic, and unfolding interactions or events, human relationships and other factors in unique situations. The depth of the personalised and contextual detail gathered from the case studies allowed analysis of the complexities of relationships, context, skills experiences, and beliefs of each of the case study participants. It has been suggested by Cohen, Manion and Morrison, (2000) that case studies can penetrate situations in ways that are not always accessible through numerical analysis.

Case studies not only provide depth for as Yin (1994) noted using multiple case studies increases the ability to generalise the findings, thus adding validity to the research. By using multiple case studies to explore the research questions across eight cases the researcher was able to ascertain patterns, replication, or contradictions of the findings within this group. However, there was no suggestion or attempt on behalf of the researcher to generalise these findings across a larger population - this is not the purpose of a phenomenological study. The detail of only these eight students' experiences within the complexities of the school and home context is the focus of this research, hence the purpose of using case studies is as Stake (2006) puts it: "the real business of case study is particularisation, not generalisation'(p. 8) future research endeavours could provide generalisation data. 
Ensuring the Quality and Reliability of Qualitative Research.

Understanding phenomena, rather than generalisation of findings is a key feature of qualitative research. It is "any kind of research that produces findings not arrived at by means of statistical procedures or other means of quantification" (Strauss \& Corbin, 1990, p. 17) and, instead, is the kind of research that produces findings arrived from real-world settings where the phenomenon of interest unfolds naturally. Patton (2001) describes qualitative research as a methodology similar to one that uses a naturalistic approach that seeks to understand phenomena in real world settings. Unlike quantitative researchers who seek causal determination, prediction, and generalisation of findings, qualitative researchers seek instead illumination, understanding, and transferability to similar situations (Hoepfl, 1997).

In relation to the qualitative research paradigm, researchers are now reconsidering the use of the terms validity and reliability that are more commonly found in quantitative research. It is important however to consider what these constructs mean in relation to this particular qualitative study. Furthermore, it is also important to consider how triangulation, as used in quantitative research to test the reliability and validity, is necessary to be incorporated in qualitative studies. Therefore, these terms - reliability, validity, and triangulation - have been redefined in order to reflect the multiple ways of establishing the truth as Golafshani (2003) suggested as this reflects the qualitative approach.

Qualitative researchers have in the past tended to reject rigid validity and reliability measurements that are routinely accepted by quantitative researchers (Golafshani, 2003; Trochim, 2006) and indicated that the quantitative definitions of validity and reliability do not apply to qualitative research. They suggest that the measurement and replication required by a quantitative definition of reliability are not relevant in qualitative studies as the intent of qualitative research is to find understanding using induction, not measurement methods and deduction. Creswell (2007) states that in quantitative research, reliability is the consistency of measurement of results over time, and validity is a determination of whether the research measured that, which was intended to be measured. Golafshani (2003) expounded that when quantitative researchers consider research validity and 
reliability, they are usually referring to research that is credible, which is related to the ability and effort of the researcher. A good qualitative study can help us "understand a situation that would otherwise be enigmatic or confusing" (Eisner, 1991, p. 58).

\section{Criteria for Judging Qualitative Research}

In consideration of the need to reconceptualise the quantitative terms reliability and validity a number of guidelines and methods have been identified to establish and ensure the trustworthiness of a qualitative inquiry and hence dealing with issues of validity and reliability. These focus on the study's credibility, transferability, dependability, and confirmability (Denzin \& Lincoln, 2000). Therefore, Guba and Lincoln (cited in Trochim, 2006) proposed four criteria for judging the trustworthiness of qualitative research and suggested these as an alternative to more traditional quantitatively oriented criteria. They also suggest that their four criteria (shown in Table 3.3) better reflect the underlying assumptions involved in qualitative research.

Table 3.3: Criteria for Judging Qualitative Research (Guba \& Lincoln, 2003)

\begin{tabular}{|l|l|}
\hline $\begin{array}{c}\text { Traditional Criteria for Judging } \\
\text { Quantitative Research }\end{array}$ & $\begin{array}{l}\text { Alternative Criteria for Judging } \\
\text { Qualitative Research }\end{array}$ \\
\hline Internal validity & Credibility \\
\hline External validity & Transferability \\
\hline Reliability & Dependability \\
\hline Objectivity & Confirmability \\
\hline
\end{tabular}

However, there has been considerable debate about the value and legitimacy of this alternative set of standards for judging qualitative research (Golafshami, 2003). Quantitative researchers have criticised the alternative criteria as just a relabelling of the very successful quantitative criteria in order to establish greater legitimacy for qualitative research. Therefore, a deeper understanding of the quantitative criteria would show that they are not limited to quantitative research alone and can be applied equally to qualitative data. It is claimed that research 
inherently assumes that there is some reality that is being observed and can be observed with greater or less accuracy or validity.

Golafshami (2003) suggested that a measurement for reliability in qualitative studies is "quality" and that good quality qualitative research stems from a thorough description of the whole process, whilst Stenbacka (1999) noted previously that if the purpose of a qualitative study was to generate a social understanding of "another person's reality based on a specified problem area . . . the understanding of the phenomenon is valid if the informant is part of the problem area and given an opportunity to speak freely" (p. 552). A qualitative study should, therefore, involve the use of a structured and rigorous process that follows high standards of credibility, transferability, dependability, and confirmability (Denzin \& Lincoln, 2003).

\section{Credibility}

Credibility is essential to establish that the qualitative results are believable (Denzin \& Lincoln, 2003). The criterion for establishing credibility involves ensuring that the results of qualitative research are credible or believable from the perspective of the participant in the research. Credibility also involves the believability of the researcher's conclusions. As the purpose of qualitative research is to describe or understand the phenomena of interest from the participant's perspective, only participants can legitimately judge the credibility of the results. The researcher should maintain ethical and quality professionalism by bracketing personal beliefs, opinions, and values. Thus, it is important when interpreting the data that the researcher avoids bias within that interpretation.

The data collected in this study were reviewed by a third party to ensure that the researcher's interpretation of the participants words is without bias and not influenced by the researcher's personal opinion or values. Each participant was also asked to review the information gathered through the interview and any observations that were undertaken.

\section{Transferability}

According to Lincoln and Guba (1985), transferability in qualitative inquiry refers to providing such a "thick" description that others may be able to transfer the 
conclusions to another group of participants or context. The authors point out that from a qualitative perspective, transferability is primarily the responsibility of the person doing the generalising. The qualitative researcher can enhance transferability by ensuring that a detailed description of the research context has been made. Then the person who wishes to transfer (or relate) the results to a different context is fully aware of the degree of transferability. Although transferability may be limited, it will enable the research results to be used to further investigate the phenomenon in other settings (Lincoln \& Guba, 1985). Although a small sample size is being used for this study, the context of the research is described in detail later in this chapter and could, therefore, be used to replicate the study.

\section{Dependability}

Dependability involves the consistency of the results across researchers and over time (Lincoln \& Guba, 1985). The traditional quantitative view of reliability is based on the assumption that the research can be replicated or repeated. It is concerned with whether the same results would occur when observing the same event again. In contrast, the idea of dependability emphasises the requirement for the researcher to account for the ever-changing context within which research occurs. The researcher is responsible for describing the changes that occur in the setting and how these changes affect the way that they approach the study. For this study, the researcher's aim was to have an accurate representation of an individual's subjective experiences rather than anything that might be replicated. The researcher was aware of how quickly the circumstances and context of this research were changing. It is acknowledged that it would be difficult to replicate this study as it was dependent on the participants' personal experience of the phenomenon and their reaction to that would depend on how they interpreted that experience and also how they recounted it for the purposes of the study.

\section{Confirmability}

Qualitative research tends to assume that each researcher brings a unique perspective to the study. Confirmability, according to Lincoln and Guba (as cited in Denzin \& Lincoln, 2003) refers to the degree to which the results can be confirmed or supported by others. Confirmability involves whether the findings of the study 
are reflective of the participants' perspectives. In this case, the researcher practiced continual bracketing, resolving to set aside theories, research presuppositions, or ready-made interpretations.

A number of strategies can be employed for enhancing confirmability, viz.,

- The researcher can document the procedures for checking and rechecking the data throughout the study.

- Another researcher can take a "devil's advocate" role with respect to the results, and this process can be documented.

- The researcher can actively search for and describe negative instances that contradict prior observations.

- And, after the study, one can conduct a data audit that examines the data collection and analysis procedures and makes judgments about the potential for bias or distortion.

In this study the devil's advocate role was adopted by the researcher as well as constant checking of the interpretation of the data with a third party.

\section{Quality}

Another means of enhancing the value of this phenomenological study was a strategy to draw the reader into the information that has been obtained, so enabling them to "see" the phenomenon through the eyes of another person. Polkinghorne (1983, as cited in Pietersen, 2002) suggests that for this to occur that the research should embrace the following four qualities - vividness, accuracy, richness, and elegance - within the writing. These qualities will be evident in this study through the recording of the participants' experiences in the results and findings section.

\section{Context for the Research}

Within the urban Wellington region there was a large pool of potential participants for this research, but interviewing adolescents presented the researcher with some unique difficulties. The major difficulty was finding an appropriate time period for the interviewing and subsequent observation of the students. The year 12 students were focused on their internal assessments and final examinations for 
National Certificate of Educational Achievement (NCEA) during this time and teachers were reluctant for them to lose their focus by being involved in this study. The participants were also on examination leave and attendance at regular classes was sporadic. There was the added pressure of teacher professional development programmes that were occurring in the schools and several teachers identified this as an area of stress for them in their teaching. These issues were taken into account by the researcher who needed to adopt a flexible approach to making appointments with the participants and confirming with the school that the timing was not going to interfere with other planned events.

A number of strategies were adopted to overcome the problems presented when interviewing adolescents. Firstly, indicating to them that their voice was important was a useful strategy. Eder and Fingerson (2002) encourage the interviewing of adolescents and state, "One clear reason for interviewing youthful respondents is to allow them to give voice to their own interpretations and thoughts rather than rely solely on our adult interpretations of their lives" (p. 181). For example, rather than forming views on what students' experiences are and what they mean to them, it is important that information is sought directly from them and then identify how they interpret the messages they receive through their experiences at school. Sandt (1999) identified an important factor in adolescent interviewing as being the audience with whom their stories were to be shared. Therefore, it was important in this research that the students' voice was heard and their views were to be valued.

General guidelines for interviewing adolescents call for the interview to be in a safe and familiar setting with few distractions, to keep to age-appropriate times, to choose clear and simple language, and to be deliberate with attending behaviours (Sandt, 1999). The researcher used these guidelines in order to obtain authentic data. Also the interviews were held in a familiar environment which, in most cases, was the students' own school, a setting very familiar and appropriate for the topic. Questions that were asked in the interview were simple, open-ended, and free of suggestions and this enabled the students to take the conversation in the direction of their choice. These questions were used to guide the discussion if necessary and not all questions were asked in each interview. 
Another issue to be considered was the manner of the interview as research findings concerning multiple interviews with the same participant are mixed (Docherty \& Sandelowski, 1999). Some researchers have claimed that giving the participants several opportunities often has the effect of increasing their memories (Poole \& White, 1991); others have advocated for group interviewing (Eder \& Fingerson, 2002); and others for individual interviewing (Rubin \& Rubin, 2005). The advocates for individual interviewing have claimed that adolescents are likely to be influenced by their peers in a group interview; therefore, this option of multiple interviews was not considered for this study. However, the participants were encouraged to contact the researcher via email if they wished to contribute further detail to their individual interview.

Consequently, single, individual in-depth interviews were employed in this study with students being given the option to participate in a focus group within their own school at a later stage. The aim of the focus group was for students to form a small group of no more than five members, and to allow them to discuss the issue with the researcher being present as an observer within the group. This general discussion would allow the researcher to confirm the experiences of the participant. There would be one participant being observed within the group of their peers from the same school. None of the participants chose to be part of a focus group.

\section{Selection of Participants}

Stones (1988) provided important criteria for the selection of participants in phenomenological studies. He suggested that participants should:

1) have experiences relating to the phenomenon being researched,

2) be verbally fluent and able to communicate their feelings, thoughts and perceptions, and

3) have a sense of commitment to the research.

(p. 150)

The first of these criteria were met as all eight participants had been attending secondary school in the Wellington region for at least 3 years. For the second criterion, reliance was placed on each student's willingness and interest in the project and confidence in being able to articulate their feelings, thoughts, and 
perceptions about the topic. It was also clear that the third criterion would be met, as all participation would be voluntary. Proof of the participants' commitment to the research was borne out by their willingness to be available for interviews, their punctuality at interviews, and their candid reports of the issue as they saw it.

The participants for this research were selected from secondary schools within the urban area of Wellington, New Zealand. The variation between the selected participants included different secondary schools (decile rating, culture, size, geographical location), and student experiences, beliefs, and attitudes that they brought to the learning environment.

New Zealand schools are assigned a decile rating that describes the extent to which they draw students from low socio-economic communities. A decile rating of 1 indicates a school is one of $10 \%$ with the highest proportion of students drawn from the lowest socio-economic communities. A decile rating of 10 indicates a school is one of $10 \%$ that have the lowest proportion of students drawn from low socio-economic communities. A School's decile rating is devised from national census data and updated every five years. Decile status is linked to government funding to state and state- integrated schools. The lower the school's decile rating, the more funding it receives. A school's decile rating is in no way linked to an assessment of the quality of education it provides (Ministry of Education, 2013). The participants were selected from schools with a range of decile ratings from the urban Wellington region.

The participants for this research were selected using purposeful sampling because "information-rich cases... from which one can learn a great deal about issues of central importance to the purpose of the inquiry" was desired (Patton, 2001, p. 230). Cohen et al. (2000) also define purposeful sampling as sampling for a specific purpose and picking a group who fit a profile. In this study, students from the same cohort, (Year 12), who were confident and familiar with the use of digital technologies and keen to share their experience of using digital technologies for learning, were selected. The aim was to select six to eight participants from the volunteers who had participated in a class survey that indicated their technology experience. A total of 17 students volunteered to become participants in future discussions and interviews from approximately 250 students who participated in the initial survey. Subsequently, after a meeting with each of the students, 8 were 
chosen. Of those who withdrew there was one male student who did not have access to a computer at home as it was his father's work laptop. Discussion with the other students indicated they did not have the necessary expertise to be included in the final group but they were willing to partake in a focus group and casual conversations. These students withdrew their consent to be part of the interview for the study.

\section{Researcher Bias}

There is a wealth of literature available on the ways to limit the impact of the researcher on the quality of data gathered during the interactive interview (for example, Cohen, Manion, \& Morrison, 2000; Terre Blanche \& Durrheim, 2002). Seidman (1991) also contends that "rather than decrying the fact that the instrument used to gather data affects this process, ... the human interviewer can be a marvellously smart, adaptable, flexible instrument who can respond to situations with skill, tact, and understanding" (p. 16). Whilst agreeing with Seidman, a further aspect of the interviewing process that was of critical importance was the "meaning" embedded in the responses of the participants to the researcher's questions, that is, the so-called meaning that emerges as the interview unfolded. The prompts that were given constantly provided the interaction with new energy and direction. In the ideal phenomenological interview, the researcher aims to provoke, through possibly only one or two significant questions and sporadic prompts and requests for clarification, a narrative-style response to the phenomenon under study. The ideal phenomenological interviewee describes, unselfconsciously and fluently, her/his experiences by descriptions and behaviours. As such a phenomenological researcher works from the premise that normally what one expresses in speech is what one thinks and believes about the experience.

\section{Data Collection}

For each of the research questions in this study, there were at least three different sources of data including initial questionnaire, individual interviews, and observations. 


\section{Initial Questionnaire}

The initial questionnaire was designed to develop a general picture of the participants' cohort and also to identify potential participants for future interview. The questions were designed to generate data relating to home and school use of technology, the type of equipment available, and assess the students' competence in using the technology.

The data collected from this initial questionnaire was used to identify and select participants to continue through to the interview stage of the study. Whilst some interesting quantitative data was obtained from this questionnaire it was not intended to be included in this study. A copy of the questionnaire can be found in the Appendix A.

\section{Interview}

The purpose of the interview was to explore the beliefs and understanding of the use of digital technologies in the participants' learning. Open-ended semistructured interviews were used for gathering this data from the participants about their experiences. As recommended by Yin (2003), open-ended interviews were selected for this topic as this allows the participants to freely express their thoughts without being tied to formal questioning. Interview questions were developed to align with the research questions. The formulation of these questions was guided by the general questionnaire used previously and the questions were used as prompts to keep the participants on track with their "story". The questions were designed as a starting point for the participants to describe their experience of using technology for learning.

The following outlines the steps taken in the planning and execution of the interviews in order to maximise the generation of rich data from each interview. These guidelines were suggested by Kvale (1996).

1. The time and the venue for interviews were agreed by the participant.

2. Prior to the commencement of the interview the purpose of the research and the interview was outlined in the introductory information sheet that was provided to the participants. ( Appendix B) 
3. The interviews were designed to be semi-structured with key guiding questions/prompts prepared and peer reviewed in advance. A written copy of the questions was used by the interviewer at each face-to-face interview to help guide the participants when talking about their experiences.

4. The interviewer checked that all the ideas from prompts were explored before moving on to another question. Gentle, open, and sensitive prompting and questioning enabled the participants to say what they wanted to say in its entirety and in their own time and way.

5. As the interviews were semi-structured, there was no specific time limit, just a guide for how long they would take. The listed questions were used when necessary, then participants were allowed as much time as they needed to answer each question.

6. There was an opportunity for the interviewer to interpret and question the participant in order to clarify and confirm the interviewee's statements. Additional questions were also allowed for in order to seek further information on points of interest to the research, or clarification of a statement made.

7. Each interview was audio recorded. This allowed the interviewer to concentrate on actively listening to the participant's answers during the interview. Digital recording was chosen for ease of data management and transcription.

\section{Observations}

Throughout the course of the study the researcher took the opportunity to observe the participants during the school day. This enabled confirmation of the data collected from the questionnaire and the interview and any discrepancies could be followed up with the student at a later stage. It was also an opportunity to observe how the teachers were accommodating these digitally able students within the classroom. These observations were conducted with the approval and consent of the school principal, class teacher and the participant. During the course of these observations teachers frequently offered suggestions and asked for advice on improving their use of technology. With their permission some of these comments have been included in the findings chapter. 


\section{Focus Groups}

The focus group was an unstructured opportunity for the participants to discuss with their peers digital experiences. The researcher would attend these discussions and collect field notes that were to be discussed with the participants at a later stage. These discussion groups would form a valuable opportunity to check on the participants' interview information as well as to support other casual conversations. It later transpired that the students did not want to meet in groups, but preferred to have informal conversations with the researcher on an individual basis.

\section{Data Analysis Process}

During the course of this research, it was noted that a number of the teachers in the participants' schools were or had recently undertaken professional development in the use of technology and technology integration. It was ascertained that the schools were all at different stages of maturity (e-maturity) in their implementation of learning with technology, and this was evidenced in the students' reports of their experience. In some respects this proved an advantage during the data collection period as the participants reported that they considered that their opinions were included in the change of teacher technology use. The participants remarked that their voices were being heard.

Smith and Osborn (2003) suggested that finding the meaning is central to the research if the researcher is to understand the content and complexity of that meaning. They argued that the researcher must be engaged in an interpretative relationship with the data that have been gathered:

While one is attempting to capture and do justice to the meanings of the respondents to learn about their mental and social world, those meanings are not transparently available - they must be obtained through a sustained engagement with the text and a process of interpretation. (p. 64)

A number of different researchers (Bogdan \& Biklen, 2007; Miles \& Huberman, 1994; Wolcott, 1994) have suggested guidelines for the analysis of qualitative data with some specifically for phenomenological research (Grbich, 2007; Moustakas, 1994). The analysis of the text and the observational data that is 
collected presents a formidable task to enable the researcher to get to the essence of the phenomenon that is being studied. In this study the general principles of qualitative data analysis as suggested by Bogdan and Biklen (1992), Miles and Huberman (1994), and Wolcott (1994) as cited in Creswell (1998) were considered as appropriate approaches to follow. It is suggested that: "the researcher...analyses the data by reducing the information to significant statements or quotes and combines the statements into themes" (Creswell, 2007, p. 60). From these themes the researcher "develops a textural description... what the participants experienced and a structural description...how they experienced it in terms of conditions, situations or context" (Creswell, 2007, p. 60). The combination of textural and structural description "conveys an overall essence of the experience (Creswell, 2007, p. 60).

These suggestions were used to produce the following eight steps using Creswell's (1994) framework as systematic process of analysing textual data. The researcher chose to follow these steps in order to analyse the data.

1. The first phase involved reading through all the interview data and making notes to get a sense of the whole, then to "organize and prepare the data for analysis" (Creswell, 2007, p. 191). An attempt was also made at this point to identify key issues raised in the interviews.

2. Focus was then placed on the underlying meaning of the data and detailed notes on the key ideas were recorded.

3. A list of topics that were identified was then grouped together. The topics were separated into major topics, minor topics, and orphans (outliers). Clear patterns and themes began to emerge.

4. Short codes were developed for each topic, and then the data was re-read and codes were assigned to appropriate sections.

5. During the grouping process related topics were categorised, and descriptive wording for the category names was assigned.

6. The data were then grouped based on their assigned category.

7. Then major themes were identified from the initial categories.

8. Finally, the original data was revisited to check for cross theme information. 


\section{The Coding Exercise}

The analysis began with a detailed content analysis that used a coding process. According to Creswell (2007), "coding is the process of organizing material into 'chunks' before bringing meaning to those 'chunks'... It involves... segmenting sentences (or paragraphs)... into categories and labelling those categories with a term" (p. 192). Merriam (1998), however, offers an alternative definition of coding: "nothing more than assigning some sort of shorthand designation to various aspects of your data so that you can easily retrieve specific pieces of the data" (p. 164), and Trochim (2001) defines it as "a process for categorizing qualitative data and describing the implications and details of these categories" (p. 160). Despite these differences all agree that coding is a means of breaking down the participant's narrative into key points. According to Merriam (1998), these categories (codes) should reflect the purpose of the research and be extensive and mutually exclusive, whilst Glesne (1999) explains coding as "a progressive process of sorting and defining those scraps of collected data... that are applicable to your research purpose" (p. 135).

The results of the coding process were used to identify patterns and ultimately "generate... themes for analysis" (Creswell, 2007, p. 193). These patterns then served as the basis for the discussion of the findings of the study. Finally, the researcher made an interpretation as to the meaning of the findings. The researcher was now beginning to theorise, and taking a step toward developing a narrative that explained some aspects of technology use in schools and outside of the classroom environment and this enabled the researcher to draw inferences about future research and actions. In this respect the researcher's role in the study was to build from the data to broad themes, and then to a deeper understanding of the phenomenon. As Merriam (1998) had pointed out, "data collection and analysis is a simultaneous activity in qualitative research" (p. 151), and "data that have been analysed while being collected are... illuminating" (p. 162). It was important to conduct an analysis of the data as soon as possible after collection in order to check the meaning and correct interpretation of that information. Due to school 
examinations and the possibility that they would not return to school after these examinations, the participants were only available for a limited time.

It was prudent to manage the data processing manually rather than using computer software as the researcher could link the observational data and casual conversations, recorded as field notes, with the participants' interview responses. After coding all the data, the field notes for each participant were reviewed and any additional information was coded.

Verbatim quotes from the participants' interviews were utilised to illustrate each theme and to write descriptive explanations of these experiences. Finally, the data were summarised and meaning from both single examples and aggregated themes was collated. This enabled overall meaning to emerge from this collection of stories, examples, and themes. Table 3.4 overleaf illustrates some of the codes that were generated during the data analysis process.

Table 3.4. A selection of some of the codes that were generated from the interview data.

\begin{tabular}{|l|l|l|l|l|l|}
\hline Space & Connection & Blocked sites & Games & Homework & Research \\
\hline Hardware & Video & IM & Sharing & $\begin{array}{l}\text { Teacher } \\
\text { attitude }\end{array}$ & $\begin{array}{l}\text { Cooperative } \\
\text { working }\end{array}$ \\
\hline Software & $\begin{array}{l}\text { Interesting } \\
\text { topics }\end{array}$ & $\begin{array}{l}\text { Relevant to } \\
\text { work }\end{array}$ & $\begin{array}{l}\text { Global } \\
\text { contacts }\end{array}$ & $\begin{array}{l}\text { Student } \\
\text { support }\end{array}$ & $\begin{array}{l}\text { Rules and } \\
\text { regulations }\end{array}$ \\
\hline $\begin{array}{l}\text { Modern } \\
\text { technology }\end{array}$ & BYOD & Investigation & $\begin{array}{l}\text { Ability } \\
\text { level }\end{array}$ & Confidence & Home access \\
\hline $\begin{array}{l}\text { School } \\
\text { access }\end{array}$ & Teacher PD & Legal use & $\begin{array}{l}\text { Social } \\
\text { networks }\end{array}$ & $\begin{array}{l}\text { Learning } \\
\text { style }\end{array}$ & $\begin{array}{l}\text { Producers of } \\
\text { content }\end{array}$ \\
\hline
\end{tabular}

From such codes seven patterns emerged that illustrated the students' perceptions of using technology for learning and highlighting some of the challenges that the participants faced when attempting to utilise their technological skills in the school setting.

These patterns are shown in Table 3.5, along with a brief description of each item. 
Table 3.5 Patterns identified from the data.

\begin{tabular}{|l|l|}
\hline Pattern & Description of Pattern \\
\hline Access to digital technologies at school & $\begin{array}{l}\text { References to the access to computer } \\
\text { facilities at school. }\end{array}$ \\
\hline Access to digital technologies at home & $\begin{array}{l}\text { References to computing facilities at } \\
\text { home or away from school. }\end{array}$ \\
\hline $\begin{array}{l}\text { Student perceptions of teacher } \\
\text { knowledge and capability }\end{array}$ & $\begin{array}{l}\text { Students perceptions of the skills, } \\
\text { knowledge, and capability their } \\
\text { teachers have in the use of technology. }\end{array}$ \\
\hline $\begin{array}{l}\text { Integration of technology into learning } \\
\text { at school }\end{array}$ & $\begin{array}{l}\text { Examples of how the teachers' teaching } \\
\text { style may be changing and how } \\
\text { teachers are using technology in the } \\
\text { classroom. }\end{array}$ \\
\hline Personal learning strategies & $\begin{array}{l}\text { Mention of the strategies that students } \\
\text { prefer to use when learning new skills } \\
\text { or material content. }\end{array}$ \\
\hline $\begin{array}{l}\text { Suggestions for future development, } \\
\text { positive and negative }\end{array}$ & $\begin{array}{l}\text { Any ideas or criticism that students } \\
\text { may have for changing the present } \\
\text { situation regarding technology use in } \\
\text { schools. }\end{array}$ \\
\hline Orphans/Outliers & $\begin{array}{l}\text { Any detail relevant to the topic that } \\
\text { does not fit into main patterns. Further } \\
\text { analysis may result in a new category } \\
\text { being established. }\end{array}$ \\
\hline
\end{tabular}

The data that formed these patterns were then reviewed and related to the overall themes. The data obtained from the student interview, discussion, and the field notes made during the observation were revisited during a subsequent analysis of the data to enable cross referencing of the patterns. Two main themes emerged and were categorised as those factors that either enable or constrict the use of digital technologies for learning for the Netgen students.

\section{Ethical Considerations}

It was important that confidentiality was maintained throughout the research so that the individuals and their schools could not be identified in the final report. All participants were asked to choose a pseudonym for themselves, and the schools 
were named alphabetically. Each participant signed a consent form that was discussed with them at the start of the study. The consent process was explained in detail to the participants who were also given the opportunity to withdraw from the study at any stage and assured that, if they did so, all information about them would be destroyed. Each school principal was also asked to sign a consent form allowing the researcher access to the school and the participants. A copy of these forms is available in Appendix C.

Application was also made to the Victoria University Ethics Committee and approval of the committee was gained before the data collection began. The approval code number is Ethics application SEPP/2009/40: RM 16731 and a copy of the approval is available in Appendix F.

\section{Role of the Researcher}

It is important to reiterate here my role as the researcher in order to counter any bias that may become evident in the research findings. Prior to beginning this research I was a teacher working with students with special learning needs at an urban secondary school in the Wellington region of New Zealand. I have had extensive experience as a classroom practitioner, head of department, and pastoral team leader, as well as in the advisory role for teacher professional development in the area of Gifted Education, ICT and e-learning. My initial teacher training in the United Kingdom had prepared me for secondary school teaching with strong subject expertise in Physical Education and Social Sciences, but equipped me with limited skills or understanding of how students learn. This lack of knowledge convinced me that I still had much to learn about the art of teaching and so I resumed part time study for a degree in education, with a focus on the areas of psychology and learning disability. It was during this study that I became interested in the area of educational technology - albeit the use of film and audio resources as learning materials. Computers were appearing in the workplace and in schools as administrative tools, but little attention was being directed towards their use as a learning tool.

Further study that culminated in a Master's degree involved an investigation into how technology could enable access to the regular curriculum for people with a 
disability. During this time there was an increasing number of computing opportunities for students interested in programming developing in the secondary schools, and computer science was becoming popular in higher education institutions. Despite this, there was still little opportunity for teachers to integrate the use of computers into the regular classroom. However, it was soon apparent from my Master's research that all students, not only those with an identified learning disability, could benefit from using the ever-increasing technological developments in the classroom. From my experience in the classroom I knew that many of the students had the practical skills but lacked the ability to use these skills for educational purposes. My Master's study found evidence that the learning institutions had knowledge of the technology but due to financial constraints, little application of the technology was occurring. A secondary barrier to the use of the technology was lack of experience and individual technical skills of the academic staff members.

During the time I was studying for my Master's degree I moved into the realm of special education and was working as a teacher in an all age school for students with high needs. It was interesting to note the different approach to technology use in this type of school. Every opportunity was taken to enable the young people to have control over everyday activities through the use of touch screen device and a variety of switches that could control music playback or a simple speech generating devices. Furthermore, within this environment there was extensive technology support available for the teachers and the support staff to upskill and learn more about the equipment available. This encouraged me to follow up on opportunities to extend my personal knowledge of some of the devices available for enabling access to the curriculum.

Shortly after this time I relocated to New Zealand and became aware of how little technology was being made available either to students with disabilities or to students in the regular classroom. After beginning work in a Wellington secondary school I became involved in a project run by the Ministry of Education, DigiOps, examining the introduction of student learning management systems. This project culminated in the development of MindSpring, in collaboration with Microsoft NZ and Unisys, in promoting the use of a learning management system in schools. 
From this position an opportunity became available to work in School Support Services as an e-learning advisor based at Victoria University.

My personal skills in the use of technology for learning have developed from this interest, although few formal professional development opportunities were available. The students that I worked with were, themselves, often the source of information and I worked from their interests to develop links and application of their skills to facilitate the use of these emerging technologies in the classroom for my own use as well as for other teachers. This $\mathrm{PhD}$ study arose from my interest in understanding how the learners in schools perceive the changing use of digital technologies. If I had to acknowledge any bias it would be related to my belief in the value of using technology as a learning aid noting that it is not about the tools but the way in which they are used to encourage and support learning.

\section{Summary and Conclusion}

This chapter has outlined the research methodology selected for this research project, and explained the justification for this. To gain a greater understanding of the school experience, as perceived by the young people I selected a qualitative, interpretive phenomenological approach using multiple case studies. Interpretive phenomenology was selected because it aims to acquire information and understanding of the phenomenon as experienced by the participants and interpreted by the researcher. However, as explained in this chapter, these interpretations of the experiences can be influenced by researcher bias and their experience of the phenomenon. I have explained how I intended to limit this bias to achieve a true report from the participants. This chapter has also described and discussed the data collection and data analysis processes that was undertaken in order to facilitate this process. 


\section{Chapter 4 Individual Case Studies}

This chapter presents the data that was obtained for each participant and it provides the context from which each participant drew upon his or her personal experiences. All eight participants involved in this study met the criteria of being a Year 12 student, attending a secondary school in the Wellington region for at least 3 years and considered themselves to be "expert" technology users. However, the initial survey that they completed identified that there are significant differences in their individual home and school situations that may have led them to forming this unique opinion about their technology skills.

Each individual profile contains a description of the second meeting between the young person and the researcher. The first meeting was a group session to complete the initial questionnaire and identify possible participants for the interview stage. The second meeting was an individual interview that enabled the participants to talk about their unique situation. These interviews were guided by the questions detailed in Appendix E. However, it should be noted that not all participants required the use of these prompting questions. The profiles detailed below, describe the researcher's observations of the individual and are, therefore, written in the first person. The researcher understands that this is her impression of the young people and is therefore subjective; she recognises that her feelings may be influenced by bias based on her own previous experiences and prejudices. It is important for the analysis that the researcher makes visible and acknowledges her own biases as she attempts to ascertain the meaning behind the young people's stories.

Therefore, in the following section, I provide a summary of the background information that was gathered during the interviews and the less formal conversations that occurred with each participant. This information was developed in the first stage of the data analysis in order to provide a holistic view of each participant using the criteria suggested by Smith (2011). It provides a context for the more detailed findings that support the emerging themes as reported on in Chapter 5. 
Participant 1.Tom.

Tom was a 16 -year-old student who attended a state, single sex high decile school in the Wellington region. His school was described as offering a balanced, challenging academic and co-curricular programme. The school has high expectations for all students and its mission is to inspire students to develop their talents, to reach well beyond the ordinary, to acquire a life-long passion for learning, and to become productive citizens who appreciate the importance of service, leadership and traditional values in a changing world. Tom has identified that there are some drawbacks to his education due to attending this school. He reported that some teachers were slow to adopt $21^{\text {st }}$ century teaching approaches, this he felt was due to the traditional values and beliefs that were held by the school leaders and the classroom teachers.

Tom stated that his school could do more to support his interest in computers. He had identified a future for himself in the technology industry and wanted the school to teach more programming rather than just using computers for information sharing. During the interview he was able to justify his comments about the need for changes at school by providing concrete examples of how this could be achieved. From Tom's perspective he wanted teachers to undergo more professional development so that they learnt the "new ways of teaching" and he wanted a more robust network that all students could access. He was very willing to demonstrate his skills and knowledge to me as an individual but was reluctant to take part in a wider forum of discussion such as a focus group or provide details electronically. He was concerned that his teachers didn't like him and would not approve of him reporting on them. He was assured that all information that he provided would not be disclosed to his teachers and he would not be identified in the study by his real name.

However, in contrast to the school experience Tom described his home as being "technology rich" and he had unlimited access to technology tools. His father was very encouraging of his son's interest and involvement with computers and provided support and instruction when required. For Tom, educational uses of computers were less important than his need to master computer coding and 
programming skills - "writing his own apps" was how he described his interest. He stated that as a result of his activities, mainly at home and through the support of his father, he has become one of the most knowledgeable individuals amongst his peer group and his peers seek him out for his computer knowledge and skills. These skills make him feel confident and socially competent. His teachers described this attitude of confidence as one that sometimes appeared as arrogance, especially when teachers asked for his advice or assistance.

He was very confident in his own knowledge and skills in using computers and was optimistic about having future job security in a technology related position. He associated working in the technology industry as being a high earning role and perceives himself to be a good fit for this type of position; this reflected his feelings of superiority and entitlement. Tom emphasized that these are earned selfaccomplishments; he expressed the view that school has done little to support his interest in the development of his personal technology skills. Thus, all the resources spent toward educational uses of computers at home, with the support of his father, he believed were well justified as investment in the future.

Tom conveyed a constant desire for progress as well as an ambition to obtain superior technology skills that would enable him to be competitive in the working environment. He was keen to support his peers with their computer problems but demonstrated a more negative attitude towards supporting teachers with their technology problems. Whilst attributing a high level of significance to his home experiences of technology, Tom felt very differently about school. His experiences of educational uses of computers at school had been a frustrating experience. His responses to questions regarding computer use for learning were met with indifference. He was recorded as saying that "using technology was a quick and easy way to complete homework tasks" before he moved on to follow his own interests. He thought that school should be leading the way forward if they are to prepare the young people for the future workforce.

He supplemented his formal schooling by learning about topics that he described as being useful for the future when at home. "You just work it out for yourself ...... click on stuff and see what happens". This reflected a view that selfeducation at home via the Internet and YouTube would enable an alternative path 
that would allow Tom to achieve his goals. He also stated that as teachers were becoming more proficient in using multimedia resources they should be helping the students to learn to use them effectively. He was aware that the majority of students in his class did have access to computers at home, but that did not indicate that they knew how to use them.

His earliest recollection of using a computer was to play games at home using an $\mathrm{X}$ box rather than a $\mathrm{PC}$, he was unable to recall a time when there was no access to technology at home and he was always encouraged to use it, with the support of his father and self investigation " trial and error" approach. He made a clear distinction between using a computer for finding information and using game based equipment for games. He saw the computer as a tool to assist with his schoolwork and supporting his desire to learn about topics outside of the school curriculum.

The overall impression gained during the interview was of a confident young man who had well-developed technical skills and a strong desire to use these tools to further his career in the technology industry. He was critical of the schools attempt to integrate the use of digital technology into the classroom and had strong ideas of what could and should be done by the teachers.

\section{Participant 2. Kate}

Kate was a quietly spoken young lady who attended a state, single sex school in the high decile range within the urban area of Wellington. The school was described as a college that would prepare young women to go out into the world as independent thinkers with respect for themselves and others, the confidence to accept and respond to challenges, and an enduring passion for learning. During the interview Kate was confident in expressing her views on personal experiences of using technology both at home and at school and was keen to demonstrate how she and her fellow students were trying to adapt to learning in the digital environment. She explained her use of digital technology as "using the computer ...... we can have up to date information". Kate went on to explain how this was important for her future; she felt the need to be current with her knowledge of events around the world. She used technology for developing social networks and her phone was of 
high importance. Kate was disappointed that school did not allow students to use cellphones during the day and suggested that if the teachers made their lessons interesting then students would not feel the need to engage in social use of their phones when in class.

In common with the other participants Kate reported that she had learnt most of her computer skills at home and with the support of family and friends. She had an older sister who has helped her as they shared use of the family computer. Kate reported that her school was trying to integrate technology into the classroom and teachers were being given help to develop their technology skills. The school was using senior students who were "good at using computers" to help the teachers set this up in the classroom. Kate recognised that some teachers "have tried to learn, we have some really smart students at school who have been running classes for the teachers who want help. I think some of the teachers think they are too old to learn the latest gadgets and would rather use the text books and just PowerPoint for their lessons."

She said that the school had limited access to different types of software and the teachers most popular and most used application was PowerPoint. "We are only allowed to use Power point at school, there are other tools that I like too, like Prezi”. Kate later added that there was more opportunity to watch informational videos that were available from YouTube during lessons. Enjoyment of learning and having 'fun' was important to Kate; technology use would improve this aspect of school for her. "If I was a teacher I would make learning fun, using iPad, phones and iPods."

The computer, in Kate's home, was in the family room and she said her mother watches what she is doing on Facebook. She had discussed with her mother about privacy and Internet safety and Kate considered that she is a responsible computer user. Although Kate had confirmed that her mother watches what she does on the computer and they had discussed the need for "being safe online" she had never been removed from the computer for inappropriate use. Kate stated that she was:

Allowed about an hour every day to use the computer at home, I try and do my homework first, and then use leftover time to play games or go on 
Facebook. I have a Facebook account, but my parents are my friends, they watch what I do and are concerned about me being 'safe' on line. My use of the computer at home depends on my parents; they think that I waste my time playing games when I should be doing my homework.

Kate reported that using a computer when working at home had helped her, as she was able to contact her peers for assistance and support with homework tasks.

If I am doing homework I usually work in my bedroom and will text my friends if I need help. Our computer is in the family room so if I need to use it for homework I can't Facebook or play games, as my mother will tell me off. But when my schoolwork is done I can use it then. Sometimes I will type a piece of work or if we have a project to do I will use the Internet rather than books to find the information.

For the future Kate would like to see "everybody to have some sort of computer, like an iPad or tablet. Laptops are too big to carry about - you would have lots of data so you wouldn't have to worry about the network going slow. You would use your iPad for everything, making video calls, texting, taking photos, watching films and TV programmes whenever and wherever you want." Although she was not so sure that a personal digital device should be part of essential school equipment due to the high cost that some families may incur.

The barriers that Kate identified that have impacted on her ability to use technology for learning were: lack of opportunity to use her device of preference and teachers' lack of knowledge in how to use technology for teaching. But she was quick to qualify this statement and say that some teachers are making an effort to keep up with the current computer trends and were experimenting with allowing students to do homework on the computer and then "email to the teacher".

Kate also suggested that if the teachers were more interested in using technology in the classroom, then the students would probably be more interested in their subjects. She did not consider that a computer or Internet access was an essential part of learning, but it did provide access to a wider range of information. 
Matt was a Year 12 student who attended a state co-educational high decile school in the Wellington region. This school aims to provide a stimulating environment that offers opportunity, diversity and a strong sense of community for both students and staff. He has attended this school since Year 9 and is confident of obtaining University entrance next year when he hopes to study for a degree in computer science. Matt lives with slightly older parents than the norm, but he appeared to have great family support from the extended family. Matt presented as being mature for his age and had given great thought to his future in a digital age. As he currently lives some distance from the school and as such does not have many school friends close by he has used social networking sites and text messaging to keep in contact with school friends. Matt was a self-confessed "computer geek", who relied on the computer and Internet for his social life. He played a number of different online games and hoped to make a career from his interest in all things computing.

Matt stated that he had a preference for independent learning; so using a computer to gain information was crucial to his success. He made good use of instructional videos available on YouTube to help not only with school-based tasks but his own interests in developing computing skills. "I use the help when I need to work out how to do something in a document, but you can learn about all sorts of stuff from YouTube videos, not just for schoolwork". He enjoyed playing on line computer games and had acquired additional hardware for his personal computer in order to do this. He had little supervision on his computer use at home from his parents - "they didn't understand computers and didn't want to. I can spend all day and night playing online games if I want to".

However, the close supervision on computer use at school was proving frustrating for Matt. He commented that the computer rooms are always locked or another class was using them. The school boasts 6 computer suites, pods of computers and tablets for student use but access to them is limited.

... we can't go on the computers and play games and waste our time. The computers should be open so we can use them at any time. Maybe the teachers are worried that they (the computers) might get stolen or broken if 
the rooms are left open.

Given this lack of access to computers at school, he felt that there were considerable barriers to his learning. This frustration was also evident in Matt's comments about potential interesting websites being blocked. He talked about the fact that he should be able to access all the sites he was interested in using, but did appear to understand why this blocking was put in place by the school administrators. Whilst Matt agreed that there needed to be some sort of filtering system he stated, "if students were taught to use the Internet in a responsible manner then some of these rules could be relaxed". He could see the point of blocking Facebook during lesson time but during lunchtime he believed that it should be available. Again he felt that some of the problems that occurred were because students "did not understand the meaning of privacy and were posting personal information for the world to see".

Matt was really frustrated with the lack of access to computers and the Internet, he was quick to blame the school and the teachers for this issue. "We need to have better access to the Internet and teachers need to have a better understanding of how to use the technology we have". He reported that the school was not supporting him to learn the skills he required for his future career. He was hoping to study computer science at University but considered that the school was not giving him the opportunity to extend his computer skills whilst at school. He wanted to learn more about programming but "I know more about it than the teacher, I just use online tutorials."

\section{Participant 4. Sara}

Sara attends an independent high decile school that has special character that is supported by a religious education programme, assemblies and services where respect for spirituality and different beliefs is encouraged. It is reported that the girls in the school are destined to become confident, principled women who can make a difference in world. I met with Sara during lunchtime to discuss her continuing in this project, although she wasn't very confident in personal use of the computer she wanted to talk about some of the barriers to her use of her laptop at school. She wanted other teachers and students to be made aware of the problems 
that she was having and wanted to know what could be done to alleviate these. The details that Sara provided were very relevant to my study, so she was selected as a participant.

Sara spoke freely of her problems in using her personal laptop for school. She told me that "she had her own laptop, but they (the school administrators) won't let me connect to school network". Sara had been given a laptop to use for her schoolwork through Group Special Education funding as she had a disability that prevented her from handwriting for long periods. However, the school was not happy about letting her access the school network with her personal machine, as it was deemed a security threat to the network was the reason given. As a result of this, Sara did not always bring her laptop to school- "it is heavy to carry and the battery does not last all day". It did mean that some of her schoolwork was not completed, which meant that she spent time at home finishing off this work. She had asked the teachers if they would email her the PowerPoint's that were used in lessons so that she could add further details to them. The teachers indicated they were unable to do this in advance of the class but two teachers had tried to make them available after the lesson. Thus this inability to use the school network, and receive lesson details in advance outweighed the advantages of having a laptop, and was a barrier to Sara making effective use of it.

However, Sara had made extensive use of her laptop to make social connections from home, "I use Facebook to keep in touch with friends, we sometimes discuss school work but it's more like what we are doing or going to do at the weekend". When Sara was asked about using Facebook as a means of communicating with her teachers she replied very strongly; "eeeew, no way would I want my teachers as my friends on Facebook". Sara was more interested in using technology for social reasons than for study, "I like using Facebook, chatting to friends that I don't see at school and it has games I can play when I am bored. I am not sure it helps my learning".

When Sara was asked about how teachers were using computers in their teaching her reply was, "I think some of the older teachers are scared to use a computer." Sara's opinion that teachers were scared to use a computer was reflected in other students' remarks too, but she did explain at some length that; 
"My teachers have tried to help me use my laptop but sometimes the school rules mean we can't use it how we want to. It won't connect to the school network so I can't use the Internet and the teacher does not know how to fix that. Why do some schools have technicians to do this and my school doesn't? How do teachers learn this? I end up not using my laptop."

However, Sara thought her school was trying "really hard to make sure that the teachers were learning to use computers" in the classroom; "not just the internet for doing project work", but encouraging the teachers to try out using blogs and wikis and different ways of presenting their work. She suggested that as "more and more people have computers and the internet at home so schools need to keep up to date too".

Sara also commented that "we can use a calculator in maths, so why not a cellphone to look up information in other subjects". For many students the cell phone is much more than just a communication device and for Sara it would mean that she did not have to carry a heavy laptop to school.

\section{Participant 5 Rashid}

Rashid attends a co-educational state secondary school of approximately 1500 students, which falls into the medium decile range. The students that attend this school are drawn largely from the local area which itself has a broad socio-economic mix and in that sense, it is a microcosm of New Zealand society. The school aimed to develop students' intellectual abilities, personal maturity and social responsibility in an educational environment that promotes achievement, resilience, self-esteem and service. Rashid described himself as a keen user of digital technology but "not in the geek category" and was able to talk clearly about how his school was embracing the use of technology in the classroom. He described the use of technology as being the way of the future, everybody needs to know how to use a computer and be able to access the Internet.

His earliest memory of using a computer at school was during his primary years when it was simply used for publishing their writing - it was being used as a typewriter. Like other participants Rashid's home use of technology was for entertainment "I had an old Gameboy", but now he has greater access to a number of different digital devices both for use at school and at home. 
An important issue for Rashid was the use of his Smartphone at school. He was very critical of the school's policy on use of cell phones, especially for finding information when there was no access to a computer during class time. He wanted to connect his phone to the school Wi-Fi, but access in his school was in limited areas. However, there were plans for a network upgrade to take place during the coming year that may alleviate this issue for Rashid. He considered that this lack of network coverage was a barrier to his learning.

Rashid was critical of his teachers' expectations when using a cell phone.

"Teachers think you are texting whenever you use your phone - what is the point of having these tools if you have to leave it in your bag during lessons". He had not really considered how the teachers could manage this problem of inappropriate use of cellphones but felt that it was unreasonable for year 12 students to have access to the Internet blocked. However, he also gave several examples of when teachers had allowed use of cellphones in class. These included, taking photographs of work in progress, or posting questions and answers to a blog. When asked if their teachers would set online homework Rashid said that his English teacher regularly set homework that required access to the Internet. He thought that it was unfair as not everybody in the class had their own computer at home but nobody complained, "They all managed to find a way to do it".

Rashid also acknowledged that some of his teachers were making an effort to try and incorporate the use of computer skills in their lessons. He highlighted his English teacher's interest and enthusiasm for using computers. "My English teacher is quite good with technology, we write blogs and make our own wikis and he showed us Prezi". The English department had acquired a small number of computers that were accessible during class time. The teacher also used an interactive whiteboard and made frequent use of video and collaborative tools such as wikis and blogs with the students. This enthusiasm of the teacher in using technology was important to Rashid was important in helping him develop his personal technology skills. 
Maria attends a multicultural co-educational secondary school with a roll of around 1100 students that includes a number of International students from Europe, South America and Asia. It is a school with a strong tradition in academic achievement, sport, cultural activities and the performing arts. Although Marie appeared to be a shy individual she spoke freely about the wide variety of subjects that the school offers for the students as well as an extensive extra-curricular programme offers all students the opportunity to represent the school, follow a passion and develop their own interests. She explained that she didn't like speaking out in class and had few friends at school.

During the last 5 years Maria's school has been committed to developing a more up to date learning environment, and an important feature of this was to ensure that full advantage was taken of the changing world of technology. Student use of digital devices in the classroom was becoming more and more common where students are able connect and collaborate with other students and their teachers. They are also able to conduct research and explore new ideas and knowledge as well as make notes and manage their information in order to develop and present their ideas and learning through presentation tools. Marie expected these changes to help all students learn new skills and be able to use digital devices more competently. She also said it was going to be too late for her to get much benefit from this, as she would be leaving school before it was all finished.

Marie was keen to explain that her school was "getting new, really fast computers, this will make it easier for everyone to use the computers for their work." She believed that the school was making a real effort to support the students to become better learners and also that the school acknowledged that not everybody had a computer at home that could be used. Marie talked about the lack of computer knowledge of some of her teachers and offered her help when required. "I sometimes help the teachers when they don't know how to get the computer or projector to work. I can show them how to use video as well'". She appeared to be proud of her 'geek' status amongst her close friends.

Marie discussed her use of technology at home, when she uses alternative 
software to that available in school. "I use Photoshop at home for editing my photos but we don't have that at school. I use it to change pictures and make them look funny". Marie had acquired skills of editing photographs to meet her need of being able to share information with family and friends, and this learning had occurred at home and with the support of online tutorials. She cited her main reason for using a computer at school was to find information for projects and assignments. But when asked about her strategy for finding information she just adopted a low level Google key word search and then copied the information she needed into a word document for printing at a later stage. Marie reported having a laptop at home that she was able to access, it was her mothers work machine, but she was able to use it on occasions, but "only for doing homework". She also had access to a PC but has to share this with her 2 younger sisters. Marie also has a cell phone for her personal use and uses this to text her friends, usually for social reasons rather than educational reasons.

\section{Participant 7 Tala}

Tala was the oldest child from a Samoan family living in the Wellington region. She attended multi-cultural, state co-educational school with approximately 850 students. This college was a low decile college that aims to meet the needs of the diverse community through providing a safe and creative learning environment. Tala spoke proudly of her school and emphasized that teachers were always willing to help the students. However she did highlight some areas where she thought that the school could do better.

When talking about the technology that was available to Tala at school she commented that at her school the computers were "very old and slow" and it was frustrating having to wait for Internet pages to load. "When you try to $\log$ on in the library you can wait for, like- 10 minutes for the computer to start up, this means you only have about 5 minutes to do your research before the next person has their turn".

She indicated this was frustrating as the class had to share a limited number of computers and the teacher had to reserve the library space weeks in advance to give the students the opportunity to engage in research online. The majority of the school computers were in three classrooms that were used for computing lessons. 
Another aspect of school computing that Tala found frustrating was the limit placed on the amount of material that they could download. She felt that it was insufficient for her needs and she had to finish work at home. This too was fraught with problems, as she had to share the home computer with her siblings. She commented that this limit had been set up to, "stop the young kids wasting their time by downloading pictures and music, but we are more sensible and need a bigger limit to complete our projects". Tala suggested that the school should be doing more to keep up to date but realized that the school did not have much money to spend on computers. Supervision of student use of the computers was also very rigid at this school, rooms were locked and access to social media sites was blocked on all computers. There was little evidence of a wireless network, except for teacher use in the staffroom and workroom areas.

In commenting upon how they used computers at school the only mention of 'games' was the use of educational drill and practice activities such as Mavis Beacon typing games. Tala spoke of a competition that was held in her Text and Information Management class at year 9, where they were given time at the end of the lesson to play these games and a weekly chart of high scores was kept and displayed in the classroom. Tala was not sure how this had helped her learning with the support of technology but did say that it had helped her to learn to type. Tala had identified a number of positive attributes of using computers for learning,

"There are so many ways that a computer can help you learn - you can get neat writing by typing, it helps check your spelling and you can watch films and TV programmes too. We can learn stuff that even the teachers don't know about - pity they can't do our exams too."

Tala said she had learnt her technology skills at home, mostly from her younger siblings as they had more opportunity to use a computer at their primary and intermediate school. But the major drawback of using the home computer was the sharing with other children in the family.

For Tala the main barriers to using computers for learning was access to a digital device and the time it takes to access the Internet on school computers. For the future she was keen to see the school upgraded and teachers to be more receptive to using a digital device in the classroom. 


\section{Participant 8 Wiremu}

Wiremu is a 16-year-old Maori boy who attended a low decile coeducational secondary school in one of the outlying suburbs of Wellington. This school was quite small, about 650 students, and had a high percentage of Maori students on the role. The school has changed and grown over the last five years and now offers a wider range of subjects to meet the community needs. Wiremu was very chatty and was keen to tell stories about his experiences, both positive and negative, of using computers at school. This was the most entertaining interview as I listened to his recall of his learning at school. He was also keen to share how he managed to learn his technology skills through game playing and the use of a friend's computer. He was a very likeable character that was happy to lead the discussion and offered some interesting insights to using a computer within the restrictive school environment. His introduction to computers came through playing online games with a friend "as we didn't have a computer at home" and at primary school. He told tales of how he was able to manipulate the class time so that he could have more time on the computer and even at secondary school he proved to be a challenging individual for the computer department.

Wiremu's school had been part of a laptop initiative had equipped a number of senior science students with a personal laptop and at the end of the project these laptops had been set up as an additional classroom resource. This resource room was not well treated by the students and subsequently access was limited as the machines were taken away for repair. Part of Wiremu's charm was his ability to describe these situations where he was the hero of the day, for example, "When one of my teachers found the site he wanted to use for a lesson was blocked, I was able to help the teacher to get around the block by using my 'hacking' skills."

The insights gained from Wiremu about the teachers' inability to use a computer for teaching was also revealing. He explained that the teachers were scared of the computer and didn't know how to use it; they didn't want to be shown up by the students who had the superior skills and knowledge. Those that did use technology only used PowerPoint or used videos in the classroom. Although he did admit that this was changing and now they had a Smart board in the maths classroom and "the teacher was good at using that". 
At home the technology used was the television and two different dedicated games machines, an Xbox and a PlayStation. It was not until Wiremu started Year 12 did they get a computer at home but he did have access to a cellphone that he used for organising his social life.

This chapter has provided an insight into the eight individual cases; it illustrates the context within which the young people were experiencing digital technologies and how this background has influenced their responses to the main research question. It was found that there were a number of commonalities of experience such as the limited access to both hardware and software in the school setting, the supervision of Internet use as well as the lack of opportunity to use their own mobile devices. The following chapter examines the themes, similarities, and differences across the eight cases as described above and draws out the barriers and enabling factors as described by the young people. 


\section{Chapter 5: Findings - Cross Case Analysis}

Chapter 5 further describes the findings of the research - it emphasizes the voices of the participants and draws on the data gathered from all phases of the project. In order to answer the main research question and the four sub questions relating to the students experience of technology use for learning it is structured by linking to the key patterns identified through the individual case data analysis as well as comparing across the eight case studies. As previously indicated, information from the participants was collected via interviews, statements from a questionnaire, and field notes gathered from the casual conversations with the participants. The participants' words are significant as they offer insight into their personal experiences of using technology for learning and leisure purposes. When considering the information gathered from the participants, it was important to view this alongside background information concerning the individual and the secondary school that they attended as detailed in the previous chapter.

The participants in this study can be identified as a cultural sub-set of the Netgen as they had self-identified with a high skill set and knowledge of digital technologies which may not be representative of their peers from similar backgrounds. This self-identification was provided by details from the initial questionnaire and follow up questioning during the interviews as well as the informal conversations held with the participants.

As the purpose of this study was to gain an in-depth understanding of the lived experiences of eight high school students' use of digital technology, with a secondary purpose to find out how the students perceive that their schools supported them with this particular style of learning. This information was obtained through a qualitative, interpretive phenomenological study using multiple case studies. The data was collected through in-depth interviews as well as observations at school and has been analysed using the coding system referred to in the methodology section. The resulting analysis provided a number of patterns that came together to provide a thematic understanding of the data. These patterns were:

- Access to digital technologies at home

- Access to digital technologies at school 
- Student perceptions of teacher knowledge and capability

- Integration of technology into learning at school

- Personal learning strategies; and

- Suggestions for future development (both positive and negative).

Each of these patterns was further analysed across the eight individual case studies through a cross case analysis, in order to identify the significant factors that had influenced the participant's educational experience of using digital technology. As a result of this cross case analysis two main themes emerged - "barriers" and "enablers" to the use of digital technology for learning as experienced by the participants. Further investigation of these two main themes has continued throughout the following sections where the participants have clearly explained how they have adapted their learning approach in an attempt to overcome these barriers.

\section{Student Experience of New Technologies}

The interviews with the participants identified two different perspectives about the term "new technologies". Firstly, they talked about the types of hardware and software that they used most frequently, and, secondly, how they used these resources and networks to enhance their learning and social lives. During the initial stages of the individual interviews with the eight participants they were asked about their first experience of using digital technologies. The participants had interpreted the phrase digital technologies to mean using a computer of one type or another. The responses included using a PC or a Mac and also included the use of dedicated games machines such as a PlayStation, Xbox, or Gameboy. The responses were varied but the predominant use of the technology was for playing games, either on a PC or, more likely, via a dedicated game machine such as a PlayStation. The participants described this experience as being "fun" rather than an educational experience. When following up on this theme of using technology for entertainment the participants related experiences of streaming videos and listening to music using the computer or an iPod. Many of these activities took place at home and usually in isolation. 
As can be seen from the table below, the participants had access to a wide range of digital devices for their use both at school and at home.

Table 5.1 Digital devices available to the participants at school and home.

\begin{tabular}{|c|c|c|}
\hline Participant & Hardware at school & Hardware at Home \\
\hline Rashid & $\begin{array}{l}\text { Desktop computer both } \\
\text { PC and Mac, printer }\end{array}$ & $\begin{array}{l}\text { Gameboy, } \\
\text { Computer, mobile } \\
\text { phone }\end{array}$ \\
\hline Wiremu & $\begin{array}{l}\text { Desktop, laptop, } \\
\text { printer, Smart board }\end{array}$ & $\begin{array}{l}\text { Computer, Xbox, } \\
\text { PlayStation, mobile } \\
\text { phone }\end{array}$ \\
\hline Matt & Desktop, Printer, laptop & $\begin{array}{l}\text { Computer, } \\
\text { PlayStation printer, } \\
\text { joystick, speakers, } \\
\text { camera, mobile } \\
\text { phone, webcam }\end{array}$ \\
\hline Sara & Desktop & $\begin{array}{l}\text { Personal laptop, } \\
\text { mobile phone }\end{array}$ \\
\hline Marie & Desktop, & $\begin{array}{l}\text { Computer, laptop, } \\
\text { mobile phone, printer }\end{array}$ \\
\hline Tom & Desktop, & $\begin{array}{l}\text { Desktop, laptop, } \\
\text { PlayStation, Xbox, } \\
\text { smartphone, printer, } \\
\text { digital camera, } \\
\text { webcam }\end{array}$ \\
\hline Kate & Desktop, laptop, & $\begin{array}{l}\text { Computer, } \\
\text { smartphone }\end{array}$ \\
\hline Tala & Desktop, laptop, & $\begin{array}{l}\text { Computer, } \\
\text { PlayStation, mobile } \\
\text { phone }\end{array}$ \\
\hline
\end{tabular}


Further investigation into the way that the students were really using the technology, both at school and at home, continued throughout the interviews through a number of follow up questions as detailed in Appendix E. It is important to note that not all questions were asked of all participants but used as prompts when required.

Researcher: When did you first begin using digital technologies and what did you use it for?

Tom: I can't remember when I first used a computer; we have always had computers at home. I think I probably started playing games - we had an Xbox at home too. There wasn't much chance at school to play games.

The initial introduction to technology for most of the participants came through the use of games and six participants reported their first contact was at home but for Sara and Wiremu it was at school or at a home of a friend.

Sara: I think I might have used my first computer at school; we had spelling games we could play. They were pretty boring games.

Tala: We had a PlayStation at home before we got a real computer, so games was the first thing I learnt about. I did not know much about computers until I went to High School; we had TIM (Text and Information Management) classes where we learnt to type and word processing and finding information for projects. We weren't allowed to use the computers for games, I mean, not real games.

Rashid: At primary school we had a computer in the classroom, we used it for publishing our writing. But I did have an old Gameboy that I played with at home.

Wiremu: Playing games at my friend's house, we did not have a game machine at home or a computer. I remember at primary school we used to take the ball out of the mouse when the teacher made us come off the computer, we used to hide them so nobody else could use the computer. The teacher used to get really mad. 
From this early experience of playing simple computer games the participants had basic computer skills when they arrived at High School. These basic skills also included a simple fault finding process; they were able to check cabling and knew how to turn on the computer and check the monitor was operational. A follow up question asked the participants how they learnt to use the computer: five out of the eight said that friends were their teachers, or that older and sometimes younger siblings had helped them at home. Only one participant, Tom, said that his father had helped him to learn about computers. It was interesting to note that none of the participants said that they learnt to use a computer through lessons at school. Mostly they adopted a trial and error approach before they asked for assistance. It was also obvious from the conversations that Tom and Matt spent longer trying to work things out for themselves than the girls in the group. The girls appeared to use a more conservative approach and would ask friends rather than experiment or try out ideas.

The information gained from the participants illustrated the importance of technology for entertainment rather than the use of technology for learning, although at a later stage in the interview, the students were able to relate learning to their game play. The young people were able to offer a coherent picture of how all these things fit together in their lives, and their very clear feelings about what they gain from the technologies they used in their own time. They described very straightforward sets of functions that their own technologies allow them to carry out: talking to friends, interacting with other people, communicating with friends/family, chatting, listening to music, playing games, watching movies, watching video clips, revision, fun. One participant (Marie) spoke, strikingly, of using technologies as a means of "making friends":

Marie: I don't like talking in class or meeting new people, so using the computer to ask questions or talk to other people is much easier for me.

I don't have many friends at school but I have people I talk to online.

When Marie was asked about online safety she was unsure how talking to people online could be perceived as being problematic. She hadn't considered that they would not be who they described themselves to be. This area of safety on line was then discussed in some detail with Marie at a later stage in the interview. 
The following comments from the participants support the view that the most common usage of digital technology by these young people was for entertainment:

Matt: I mostly like using games consoles and computers, Xbox 360, talking to mates and playing games together - music, buying things.

Tom: I use a computer for finding information, and games consoles for games, PlayStation to play games.

Kate: My phone to text, to find out what my friends are doing.

Rashid: Computer for messages, Facebook, Bebo, music, watching films, mobile for talking to mates, computer for email, instant messaging - music.

Most of these activities were conducted alone and at home, so the computer or cellphone were a means of social contact when it was not possible to meet face to face.

The following section presents the data from the interviews that identify further differences between using digital technology at home and whilst at school.

Through their responses to the following question, each of the eight participants confirmed that the use of a computer was an important part of their learning experience.

Researcher: "Can you give me an example of how using the computer has helped you to learn?"

Matt: I like learning on my own, I can use my own computer at home to find out information about topics that I am interested in. I can get up to date information. I don't have to wait for the teacher to answer my questions.

Matt went on to explain how he enjoyed following up on topics he was interested in when away from school and when he could, "use his own computer and not have everything blocked."

Tom, however, was far more concerned about how quickly he could complete school tasks and then use the computer for his own interests. 
Tom: It is a quick way to find out answers to our homework questions, except when using school computers.... They can be a bit slow at times. I am not sure it has helped me to learn, but I know how to find out stuff.

Kate, Marie, and Tala were concerned with having up to date information, stating that having to look up information in textbooks was "boring". "I think using the computer means we can have up to date information." (Kate) "You can stay up to date." (Tala)

Sara explained that presentation of her work was important so using a computer was really helpful to her:

Sara: Using the computer has helped me with my writing - it looks better when I type. This means the teachers can read my work, so I can get better marks.

Rashid had identified that being familiar with technology was crucial to his future employment prospects:

Rashid: It's the way of the future! Everybody needs to know how to use a computer - school could do a better job of teaching us how to do this.

Connecting with a range of people, sharing information, and learning more about what is occurring worldwide was important to Wiremu and Marie:

Wiremu: We can watch videos and learn about stuff we can't find in New Zealand. I can get information about music and sport. Learn more about what is happening in the world.

Marie: I like being able to share my work with other people. Share photos and family news as well.

\section{Access to Digital Technology at Home}

A section of the interview focused on the participants' use of digital technology at home. The participants were asked about the type of hardware that they could use at home and for examples of how they used the equipment. In particular, the researcher was interested in whether there was any similarity with the 
technology that they encountered at school and how they were able to transfer their learning from home to school.

Family composition and family economic status appeared to play an important part in the students' responses in this section. Initial responses from the participants indicated that they had their own computer for use at home. Further questioning resulted in eliciting the fact this was not the case, the computer had to be shared with siblings and in one case the student was using her mother's laptop, a machine associated with her place of employment, to complete her homework. A summary of the students' family background is detailed in Table 5.2.

Table 5.2 Participants family composition

\begin{tabular}{|l|l|}
\hline Participant & Number of Siblings \\
\hline Rashid & 1 younger sister \\
\hline Wiremu & $\begin{array}{l}1 \text { older brother, a younger brother and } \\
\text { sister }\end{array}$ \\
\hline Matt & None \\
\hline Sara & 1 older brother \\
\hline Marie & 2 younger sisters \\
\hline Tom & 1 younger sister \\
\hline Kate & 1 younger sister \\
\hline Tala & 2 younger sisters, 2 younger brothers \\
\hline
\end{tabular}

The participants were consulted on the various types of technology that they had access to at home, see Table 5.1. There was considerable variation within the group - from Wiremu, who had a PlayStation and a computer with Internet capability, to Tom who reported almost every device possible: "desktop computers, laptop, Smartphone, iPod, printer, webcam, external hard drive and several games 
machines". While Tom did confess that he did not own any of these devices, as they were part of his father's work equipment, he did have an understanding of how the equipment could be used, and was keen to share his expertise with anybody who showed any interest. The rest of the participants had a phone that was Internet capable, and either a laptop or family desktop computer with a broadband connection and the ability to print documents. The sophistication of the printer appeared to depend on its purpose; this varied from a basic black and white printer to a device that was capable of printing colour photographs. It was also interesting to note that, until prompted, none of the students listed a television as a technology item, although several participants had identified that watching television was one of their leisure activities.

The participants gave a variety of responses to the question about frequency of use of the computer at home. These ranged from Tala saying, "not a lot", to Tom expressing that he used a computer every day, while Matt replied "twenty four seven if I can". These statements led to further discussion with the participants as to the reasons why they had given these responses. Tala's main reason was that it was the family computer at home and, as she had siblings who also wanted to use it, she was limited in the amount of time that the computer was available. When this was discussed in more detail she divulged that her siblings wanted to use the computer for playing games. She felt that her schoolwork should take preference, but the family computer was for "sharing" so she had to wait for her turn, often quite late at night when the younger children had gone to bed:

Researcher: Matt, why do you want to spend so much time using the computer?

Matt: I live away from my friends so I can only talk to them online after school, I like playing computer games, you know those team shooting type of games, so I need to be able to talk to my teammates.

Researcher: Would you say that most of your time at home is spent on the computer; do you watch TV at all?

Matt: The computer is in my bedroom, so when I am supposed to be doing my homework I get distracted and go online to see what is happening in the game. Sometimes I use the computer for homework 
but usually just playing games. I sometimes watch TV with my parents, but mostly I use the computer. I can watch TV programmes on my computer as well.

Tom felt that he had to be permanently connected to the Internet, "not for all that Facebook stuff', but his passion was for online gaming and he was interested in programming and liked "writing apps".

Kate stated that she was:

Allowed about an hour every day to use the computer at home. I try and do my homework first, and then use leftover time to play games or go on Facebook. I have a Facebook account, but my parents are my [Facebook] friends; they watch what I do and are concerned about me being "safe" online. My use of the computer at home depends on my parents. They think that I waste my time playing games when I should be doing my homework.

The computer in Kate's home is in the family room and she said that her mother watches what she is doing on Facebook. She has had discussions with her mother about privacy and Internet safety and Kate considers that she is a responsible computer user.

The participants cited carrying out homework activities as the main reason for needing computer and Internet access at home. This was becoming more important too as they approached senior examination requirements. Marie described doing homework from books as "boring as you have to just sit and read". The participants had begun to prioritize their computer use to include greater time spent on study rather than on games and entertainment. However, they still tended to multi task, listening to music and texting or chatting to friends online when completing homework tasks.

All the participants mentioned that their main use of their free time on the computer whilst at home was for games and chatting to friends. Marie reported having a laptop at home as well as a PC; while the laptop was her mother's work machine she was able to use it on occasions, but "only for doing homework". In order to keep in contact with her friends Marie uses her cell phone and texts her friends. 
All eight of the participants agreed that they had learnt most of their computer skills by themselves with help from their friends or family. Tala explained that when she was in years 9 and 10 they had ICT lessons at school but they did "boring stuff, like word processing and learnt how to make a spreadsheet". It only became fun when they could make posters or play typing games. Matt reported that he had to, "learn by himself, as nobody in my family had any idea. I got a basic computer as a birthday present when I was younger".

Only one participant, Tom, had undertaken a course or training programme that was organised outside of school. This was a school holiday programme run by a computer software company, but aimed at adults. He was allowed to attend because of his father's position at the company organising the course. Family members were also a significant source of assistance, not always the adults but older and sometimes younger siblings. Tala mentioned that she often asked her younger siblings for help as they used the computers at school more frequently than she was able to.

Two of the participants, Matt and Rashid, reported having used online help when faced with a technical problem. They obtained the information they required by watching a YouTube video:

Rashid: Sometimes you can find answers to computing questions by going online or watching a YouTube video. I learnt about using Prezi from watching the tutorials.

Matt: I use the help when I need to work out how to do something in a document, but you can learn about all sorts of stuff from YouTube videos, not just for schoolwork.

Other participants said that they had accessed online "cheat sheets" for help with gaming problems - that is, how to get past a certain character and move to the next level. All the participants agreed that they had learnt more about using computers from family and friends than they had at school.

After the comments made by the participants about the regulation of computer use at school, it was worthy of note that there was little or no regulation of computer use at home. Although Kate had confirmed that her mother watches what she does on the computer and that they had discussed the need for "being safe 
online", she had never been removed from the computer. Matt had no limits imposed on him at home; according to Matt, the only child of older parents, "they don't understand computers and don't want to. I can spend all day and night playing online games if I want to".

We discussed how this lack of regulation affected Matt's schoolwork and his health. He was not aware of any issues; he claimed his work at school was not suffering, and he was still getting good grades. He said that he was doing sufficient work to maintain his grades. It was interesting to note, however, that he was not involved in any after school activities and did not appear to have any friends his own age in his local area. He also held a part time job after school and on the weekends, using his earnings to support his gaming and to buy new "gadgets". He was also saving money to buy a car for when he went to university.

From the discussion with the participants it was apparent that using the technology from home was more accessible. All the participants had Internet access and the opportunity to engage in the use of social networking and technology for entertainment. But there was little control over the amount of time that they spent using the computer or the type of material that they were accessing. This lack of regulation and supervision of computer use at home may well contribute to the frustration of using digital devices in school. But a major enabler of development of technology skills was the ability to learn at home.

\section{Access to Digital Technologies at School}

Technology can be a powerful learning tool that, when effectively integrated into a challenging curriculum, improves learning and helps to achieve educational goals. A purpose of technology use at school is to support teaching and learning; when the participants were asked about how their learning strategies had developed through the use of technology, all eight of them agreed that technology had affected their learning experience in some way. This was expressed as access to "up to date information" and enabling "written work to be neatly presented" as well as a focus on the speed of completing homework tasks. Negative comments were also included such as "I get distracted easily when on line", and "it can be frustrating when you get too much information" and "the computers are very slow". 
It was also important to acknowledge that the participants in this study attended schools that had different decile rankings, a factor that may influence their responses. In order to maintain the security and anonymity of the schools each is referred to as a low, medium, or high decile school. The decile rating 1 to 3 is Low 4 to 6 Medium and 7 to 10 are High decile. This ranking is an important factor to consider when the participants are talking about their school experiences. The researcher also observed that the high decile schools had better quality hardware and a more stable Internet connection. The same high decile schools also appeared to have a superior technical support system than the lower decile schools involved in this study. For example, it was noted by the researcher that a high decile school had a dedicated IT professional whose role was to provide technical support to the school and maintain the network.

Table 5.3 Decile Rating of Schools for each participant

\begin{tabular}{|l|l|}
\hline Participant & Decile Range \\
\hline Rashid & Medium \\
\hline Wiremu & Low \\
\hline Matt & High \\
\hline Sara & High \\
\hline Marie & Medium \\
\hline Tom & High \\
\hline Kate & High \\
\hline Tala & Low \\
\hline
\end{tabular}

An expectation by the higher decile schools was that the students had access to a personal technology device to assist with their studies when away from the school site. There also appeared to be the expectation that parents, caregivers as 
well as the students would be able to take advantage of the online access to the school website and the student learning management system. Lower decile schools were providing a similar, but more limited service. The lower decile schools were still in the process of setting up a school website that was interactive and a student learning management system to enable them to deliver on line content for students. The school administrators rather than individual teachers usually carried out the use of email contact and text messaging to parents. It was also noted by the researcher that the higher decile schools had a more sophisticated technical support system. The lower decile schools did not have a dedicated technical support person; the teacher responsible for ICT carried out this work.

Access to digital technology in the schools was mostly problematic for the participants. When they were asked about their use of technology in school their initial responses gave a very negative view of technology use in the school, in particular they indicated how difficult it was to access a computer during class time and even more difficult to use the computers during their free time. Wiremu, from a low decile school, complained, "There are not enough computers for the whole class to use at the same time". Matt, from a high decile school, commented that the computer rooms are always locked or another class was using them.

Researcher: Why do you think the rooms are kept locked?

Matt: So that we can't go on the computers and play games and waste our time. The computers should be open so we can use them at any time. Maybe the teachers are worried that they (the computers) might get stolen or broken if the rooms are left open.

Researcher: How do you feel about this?

Matt: Some of the others (students) will not use them in a sensible way. They just want to download music or pictures, so I suppose that is the reason why they are kept locked.

As Matt was unable to get frequent access to his preferred mode of technology was perceived by him to be a considerable barrier to his learning.

In commenting upon how they used computers at school, the only mention of "games" was the use of educational drill and practice activities such as Mavis Beacon typing games. Tala spoke of a competition that was held in her TIM (Text 
and Information Management) class at year 9, where they were given time at the end of the lesson to play these games and a weekly chart of high scores was kept and displayed in the classroom:

Researcher: How did you feel about the scores being posted on the classroom wall?

Tala: At first I wasn't too sure it was a good idea.

Researcher: Why was that?

Tala: Because I was always going to be on the bottom and be last. But then the teacher changed it to only show the top ten people - that was much better.

Researcher: Did you feel that you were learning when you were playing these games?

Tala: They were all typing games, so I suppose that we were learning to type faster. I did not think they were learning games when I was in year 9, but now maybe they did help with learning to type.

In this instance the technology was not being integrated into the learning experience but being used as a reward for completion of other work, although it was related to the learning of a specific skill. So this could be interpreted as an important part of developing digital skills - an enabler.

Another major use of school computers as reported by the participants was accessing the Internet to look up information and they were frustrated that they did not have the access to the computers that they required that would enable them to complete research work. Several of the participants claimed the use of the Internet for research as a reason for needing a computer and Internet access at home:

Marie: I like to use the computers to search for information for doing schoolwork. It is interesting to discover new places to get information much quicker than having to use the library and look in books. Using the Internet helps me to get my work done quickly.

Matt: I have to do my research at home, not enough computers in the library for everyone to use. 
Rashid: It is easier to use the Internet when I am at home. I don't have to wait so long.

Another reason that the students found carrying out research at school was problematic was their inefficient research strategies. The majority of them just typed a phrase into the Google search box and then used the first few results as the basis for their work. A study by Jenkins, Clinton, Purushotma, Robinson and Weigel, (2007) had also identified poor research strategies as a problem for young learners. It would have been of benefit to these students to have some clear search strategies explained to them. If they became efficient users of search strategies then they would not have to wait for an extended period of time to use the school computers. This poor use of effective search strategies has been identified as a barrier to the student learning. Teachers need the skills and knowledge to be able to guide their students in developing these important critical media literacy skills.

Both Sara and Kate mentioned that they had used the school computers for taking tests but found it difficult to concentrate on constructing their answers because of the noise in the room other students typing. Kate felt that she could not write detailed answers within the time allowed, as she was "too slow at typing". Both girls acknowledged that for a student who found writing difficult or if the writing was difficult to read then the option to be able to type could help with their learning. Kate was more concerned about the time it took to type, so suggested that if they had to type their answers then may be "extra time could be allowed". Sara and Kate also identified the issue of marking work on line could help the teacher as the computer could mark multiple-choice questions.

At one of the high decile schools the students were expected to follow learning materials and school notices on-line. This was an issue for students who could not gain easy access to computers at school if they did not have a personal Internet capable device. This particular school had invested time in creating an interactive school web page which enabled parents to find out about school events and even homework that had been set for their child.

Tom had indicated that it was "not fair" for students who did not have access to a computer at home to expect them to be up to date with their work. He was sure that as more and more schools were starting to use technology to access 
class information, school notices, assignments and online tests and exams, it would become important to open up access to computers during the school day. This issue of gaining access to computers during out of class time was mentioned by all of the participants. They claimed that it placed pressure on them to find an alternative means of accessing computer time. Wiremu said that he would go to a friend's house and they would work together on their homework, whilst Matt reported that he would leave school during the day to go home and finish his project work on his own computer.

Each of the participants' schools had computer labs where computing lessons were held; these lessons focused on skill development and programming rather than the use of technology for learning across the curriculum. This was usually in a classroom setting with desktop computers but the participants related how difficult it was to gain access to these learning spaces if they were not in a computing class. It was also difficult for non-computing teachers to get access to these facilities due to timetable constraints and a booking system. However, a mid decile school was working towards providing small computer pods, six to eight computers in a small workroom, for the students to use. This took the form of placing between eight and ten networked computers in a classroom or study area that students were able to use on an individual basis. One low decile school that had previously been involved in a laptop initiative had equipped a room with a class set of laptop machines. This had proved problematic as the laptops were old and were easily damaged through misuse by individuals. Wiremu offered a solution to this issue: "let students use their own computers, laptops, or cell phones during school time". He proposed that if people had their own equipment they would look after it, whereas if it was school equipment they were not too concerned about misuse.

One of the high decile schools in the study was in the process of introducing a requirement that all students had their own laptop, tablet, or iPad as part of their stationery requirement. Discussion with the participants about this initiative provoked a mixed response. Kate, from a high decile school, commented that, "not all families could afford to do this; they might have 2 or 3 children attending the school". Matt, also from a high decile school, made the suggestion that "a school could buy the iPad and then lend it to the student". He also identified problems with this approach: "maybe the students wouldn't take care of the iPad and would they 
be allowed to take them home?" The participants felt strongly that if the school was making these demands then they should help the students to use the technology in a responsible manner.

Rashid was quite happy to bring his own device to use at school but expected the school to pay for his data usage. His "own device" was a Smartphone on which he could access the Internet, but he wanted to be able to connect to the school network. Unfortunately, his school did not have full wireless coverage and the areas in which he was working had limited connectivity. The issue of poor wireless connectivity was a barrier to using "bring your own device" (BYOD) devices within the school environment for Rashid.

The students recognised this (BYOD) strategy as one possible answer to the shortage of computers in schools but also acknowledged the financial pressure it may place on families. Two participants noted that some schools were using their access to computers as a marketing tool and believed that this was inappropriate and not entirely accurate. One computer for every 10 students often took into account the laptops belonging to the teachers, as well as office machines that were not available for student use. Tala, low decile school, commented that at her school the computers were "very old and slow" and it was frustrating having to wait for Internet pages to load:

Tala: When you try to $\log$ on in the library you can wait for, like, 10 minutes for the computer to start up; this means you only have about 5 minutes to do your research before the next person has their turn.

She indicated this sharing of computers was frustrating and that the teacher had to reserve the library space weeks in advance to give the students the opportunity to engage in research online. Another issue highlighted by this participant was the Internet usage allowance which, when used, prevented the students from using the Internet until the following week. She suggested that this had been set up:

Tala: to stop the young kids wasting their time by downloading pictures and music, but we are more sensible and need a bigger limit to complete our projects. 
Tala also went on to explain that it was frustrating to have a small download limit when they had so many projects to complete for NCEA, and that she had often used up her allowance by the middle of the week, leaving her no option but to do her work at home on her family computer, which she also had to share with her siblings. When asked why she needed computer access for her work she explained:

Tala: If teachers want our work typed, then the school needs to get more, better computers. It was the only way to find out information that was up to date".

Marie (mid decile) was keen to explain that her school was:

Marie: getting new, really fast computers, this will make it easier for everyone to use the computers for their work

She believed that the school was making a real effort to help them become better learners, and that the school acknowledged that not everybody had a computer at home that could be used. Marie explained:

Marie: I sometimes help the teachers when they don't know how to get the computer or projector to work. I can show them how to use video as well.

She was quite proud of her "geek" status amongst her friends.

The participants also expressed the opinion that they would use the Internet to access information and conduct "research". Tom suggested:

Tom: As more teachers are providing online learning materials, creating multimedia presentations, using e-books, and using video in the classroom. It is only time before everybody will need their own computer.

As schools are becoming more proficient in their use of technology and are using learning management systems as well as using technology for administrative purposes, it is becoming more essential for students and their teachers to need a stable networked environment.

Whilst the students have shown an appreciation for these changes, they are still very critical of the teachers" "control" of their technology use. For example, Rashid asked, "Why can't I use my cell phone to access the Internet?" He was 
concerned that he could not use his phone to record his homework, check the time, or consult a diary to find out when his projects had to be submitted:

Rashid: Teachers think you are texting whenever you use your phone.

What is the point of having these tools if you have to leave it in your bag during lessons? They don't say that about your pen or exercise book or textbook.

When asked for suggestions about how to overcome this barrier to his learning, he explained that:

The young kids would not use their phones in a responsible way so everybody had to suffer. Not everybody is into cyber bullying.

He had no real answer to the problem and thought the school should identify a better solution to manage the situation rather than just banning cell phones in the classroom. He also explained the myriad of uses he made of his phone - taking photos, keeping notes, as a watch, listening to his music as well as communicating with friends - "but not in lessons!"

In one of the other high decile schools, the students were actively encouraged to use their cell phones during lessons, but only for learning purposes. If the students were not "on task" then the phones had to be put away and books used as a resource. It was evident from observation in this school that most of the class had an Internet capable phone and those that did not were encouraged to work with a person who did. All of the participants identified that the increasing use of a phone was an enabling factor for their learning at school.

While the teachers at Rashid's school had expressed reservations about allowing cell phones in the classroom they were prepared to make exceptions. From my discussion with the teachers in this school, some of them reported that the cell phone was a distraction; the students were always texting and not getting on with their work. Another teacher said that, despite the school having a no cell phone policy, he was able to get the students to use their phones for taking photographs of classwork and then posting to the class blog. This teacher also used the camera feature of his own phone to record stages of a student's design project. This banning of mobile phones extended to the other mobile devices such as iPods and tablets, which students were bringing to this school. By the innovative actions of this 
teacher it was identified by Rashid as another means of enabling the use of digital devices for learning.

As the use of mobile devices in schools is gradually becoming more acceptable, some schools are beginning to relax the "no cell phone in class" ruling as teachers begin to appreciate the learning opportunities that they offer. Sara commented "we can use a calculator in maths, so why not a cell phone to look up information in other subjects". For many students the cell phone is much more than just a communication device. Five out of the eight participants in this study had a cell phone that was capable of accessing the Internet; they used the device to record homework, as a calculator, and as a provider of information via Google. Students also used the camera and video functions to record classwork. Although teachers were still quite skeptical of the use of cell phones, they did say that the majority of students in the class did not use them for texting friends during class time. There were still heavy penalties in place in all schools in this study for misuse of a phone during class time. When the participants were asked about their use of cell phones in class, Kate replied, “make your lessons interesting, then I won't need to text my friends". Kate felt strongly that it was the teachers' "fault" that students misused their cell phones in class.

Sara reported that she had her own laptop, "but they won't let me connect to school network". As she had a physical disability that prevented her from handwriting for long periods, Sara had been given a laptop to use for her schoolwork through Group Special Education funding. The school, however, was not happy about letting her access the school network with her personal machine, claiming that it posed a security threat to the network.

This inability to use the school network was a barrier to Sara making effective use of her laptop. Another barrier to her use of the laptop was the fact that it was heavy and quickly lost its charge. As a result of this Sara did not always bring her laptop to school, saying, "It is heavy to carry and the battery does not last all day".

Matt identified another barrier to the students' use of technology in school, saying, and "All the best sites are blocked". When asked to explain what he meant 
by the "best sites" he explained that he couldn't use YouTube or Facebook and “other video sites are blocked as well and we can't play games".

Researcher: Why do you think that the school blocks these sites?

Matt: Maybe it was not ok to be doing this (downloading personal interest material) during lesson time but it should be ok at lunch break. Researcher: If everybody was trying to download videos and music at school do you think that this might have an effect on the download speed?

Matt: It would make the network go slow, that's for sure.

Researcher: Why do you need to do this at school?

Matt: Because I get told off by my dad for going over our limit at home. He says it costs too much.

Researcher: So what about the limit for school and who is paying for that?

Matt: We don't have a limit at school or pay for our Internet time.

The researcher then revealed to Matt that the school did, in fact, have to pay for Internet use. Matt then agreed that it was probably "a good idea that access to some sites is blocked".

During their interviews, all the other participants made a mention of blocked sites and download limits. In one of the low decile schools there appeared to be strict filters applied to all Internet searches. Tala reported that her Internet access at school had been removed because she had been "looking for information about sexually transmitted diseases for her PE and Health project". In this school it appeared that the technician responsible for maintaining the network was making decisions about what the students could and could not access on their school account. This filtering system was creating a barrier for Tala to use the Internet for effective research.

Whilst Matt agreed that there needed to be some sort of filtering system, he stated, "if students were taught to use the Internet in a responsible manner then some of these rules could be relaxed". He could see the point of blocking Facebook 
during lesson time but he believed that it should be available during lunchtime. Again, he felt that some of the problems that occurred were because students "did not understand the meaning of privacy and were posting personal information for the world to see".

This blocking of sites, such as YouTube and Flickr, has created a barrier for teachers as well as students to access the learning resources that they want to use. For example, when a teacher tried to use video in their lesson and the site was blocked, Wiremu related that:

When one of my teachers found the site he wanted to use for a lesson blocked, I was able to help the teacher to get around the block by using my 'hacking' skills.

As Tom had been given special privileges on his school account, being given the same permissions as a staff member, he was able to advise and support those teachers in enabling filters to be refined. Wiremu reported that he had been asked to help the school technician to stop students hacking the system; that is, he was asked to show how he got around the filters so that the technician could then tighten up the system.

The students expressed strong opinions about the software tools that they use at home and how the school system is unable to support these. For example:

Tom: I am really interested in writing Apps and programming but don't get the chance to do this much at school.

Marie: I use Photoshop at home for editing my photos but we don't have that at school. I use it to change pictures and make them look funny.

Rashid: Making music is good fun on the computer; I can be a whole band! But can't do that at school.

Kate: We are only allowed to use PowerPoint at school; there are other tools that I like too, like Prezi.

Matt: Pretty boring computing at school.

During the classroom observations of the participants, these digital learners demonstrated how they are incorporating online tools and resources from their 
personal lives into their school activities. For example, the students used texting with their friends to collaborate on a project or assessment from home in order to continue the face-to-face work from the classroom. Marie and Sara used Facebook to collaborate with peers on school assignments:

Marie: When I am at home I chat to my friends about my homework, sometimes we use text but mostly Facebook.

Sara: I use Facebook to keep in touch with friends. We sometimes discuss school work but it's more like what we are doing or going to do at the weekend.

Kate: I would like to use Facebook more but my mum doesn't like me doing this.

None of the participants in this survey indicated that they would text or Facebook the teacher for help with homework, but two said that they knew people who did text the teacher or communicate with them via Facebook when they were away from school:

Sara: Eeeew, no way would I want my teachers as my friends on Facebook.

Matt: I would email them if I had to or might use online chat if it was really important. I do know people that are friends with teachers on Facebook. It is a bit different when you are older, I have friends at uni that text and use Facebook with their teachers.

It appears from these comments that these particular students would prefer to keep home and school events separate.

One of the mid decile schools had integrated Moodle as a learning management system (LMS) during the time of this study and the students were able to submit their homework to the teacher using Google Docs. Rashid did not see this as communicating with his teacher out of school time but more as an opportunity for quick feedback on his work. He had the expectation that if he submitted his work late in the evening, then the teacher would reply immediately: "that's why we use computers, isn't it?" He was not concerned that the teacher may have other responsibilities out of school time. 
Tom appeared to have superior computing skills and knowledge when compared to the other students in this study. His father was involved in the IT business and had encouraged him to extend his skills and knowledge and hoped he would to go on to University to follow a degree programme in computer science. He always took his own laptop into class and was able to access the school network. Special privileges were given to him and he could frequently be found working with the technical staff building the school website and sorting out network issues. However, two of Tom's teachers had commented on his "arrogant" attitude during lesson time when he was not allowed to use his laptop. When asked about this, he commented that these teachers "did not use technology and did not want anyone else to either". After the researcher had a further discussion with these teachers, they agreed that they were not very comfortable with using computers themselves so it was easier to stop everybody using them in class.

Tom was also very keen to demonstrate his skills and share his knowledge with his peers; he was able to demonstrate alternative software to the usual Word and PowerPoint and began to build up a student support group in the school. He had developed his own website and ran a weekly blog to answer questions about using technology and supporting students with online gaming.

When asked how they used computers at school, all the participants said that doing research was probably the most important task. Wiremu was concerned with "searching for information"; Matt commented, "to research things"; Sara was "finding information for projects"; Marie included a wider range of uses including "tests, schoolwork, homework, and research"; while the feedback from Tom was "taking part in this project". Kate reported that her "writing looks better when it is typed up".

When asked if their teachers set online homework, Rashid said that his English teacher regularly set homework that required online capability. He thought that it was a little unfair as not everybody in the class had their own computer at home but acknowledged that nobody complained; "they all managed to find a way to do it". The other students suggested that their teachers did not want online work because students might work together or copy others work. Tom suggested that, "if the teacher used Google Docs then he could see who was doing the work and who 
was just copying. But this would rely on the teacher's expertise in using Google docs."

From the participants' comments on their use of technology at school, then, it becomes clear that there are many barriers to overcome in order to achieve equality of access to the hardware. These issues of access appear to be common across all deciles. However, the decile rating may have an impact on the way in which the school addresses the problem of limited access. The higher decile rated schools appeared to have better technical support and a more robust wireless network. These schools were involved in teacher professional development programmes to support the development of technology integration.

\section{Student Perceptions of Teacher Knowledge and Capability}

Throughout the interviews the participants made reference to the teachers' use of technology in their teaching. Whilst not all the comments were complimentary, the underlying message from the students was for their teachers to increase their personal knowledge and understanding of how the technology could support their learning:

Matt: We need to have better access to the Internet and teachers need to have a better understanding of how to use the technology we have.

Matt was really frustrated with the lack of access to computers and the Internet, and he was quick to blame the school and the teachers for this issue. He reported that the school was not supporting him to learn the skills he required for his future career. He was hoping to study computer science at university but considered that the school was not giving him the opportunity to extend his computer skills at school. He wanted to learn more about programming but, "I know more about it than the teacher. I just use online tutorials."

Rashid acknowledged that some of his teachers were making an effort to try to incorporate the use of computer skills in their lessons. He highlighted his English teacher's interest and enthusiasm for using computers:

Rashid: My English teacher is quite good with technology. We write blogs and make our own wikis and he showed us Prezi. 
The English department had acquired a small number of computers that were accessible during class time. The teacher also used an interactive whiteboard and made frequent use of video and collaborative tools such as wikis and blogs with the students;

Tom: Schools need to catch up with the real world! Give us a chance to show what we know and can do with computers. We use Google Docs to share work with one teacher.

Although Tom attended a high decile school, he considered that the school was still offering limited computing opportunities to the students. He acknowledged that the school had a plan to upgrade the facilities and the network but was frustrated at the pace of the upgrading and that his teachers were not keen to learn "new stuff".

At Kate's school there was a programme of professional development for teachers, which was run by senior students. A few of the teachers had taken the opportunity to get involved and were transferring their learning to the classroom.

Kate: We have a group of students who help the teachers with their technology problems; they will show the teachers how to fix things themselves. Some of my teachers have been to computing classes to learn more. The young teachers are the best.

Sara: I think some of the older teachers are scared to use a computer.

Sara's opinion that teachers were scared to use a computer was reflected in other students' remarks too; Tala, for example, explained how one of her teachers did not want to have the responsibility of his own laptop in case it got broken. The only evidence she had that this teacher used a computer was that worksheets had been typed and then printed out for the class, whereas previously the teacher had written questions on the whiteboard for students to answer: "We have to look up the answers in our textbook, when we could use the Internet".

Wiremu's comment, "They don't want us (the students) to show them up", is also quite revealing about the way that the students perceive teachers' reluctance to use technology.

A follow up question was posed to the participants to discover if they had any suggestions as to how the teachers might become more proficient in their use of 
computer technology. The following responses illustrate the understanding of the problem by these year 12 students.

Tom was quite dismissive of the issue: "if they don't know how to use a computer they should either learn fast or get a different job - technology is the future!" Kate, on the other hand, recognised that some teachers:

.....have tried to learn. We have some really smart students at school who have been running classes for the teachers who want help. I think some of the teachers think they are too old to learn the latest gadgets and would rather use the text books and just PowerPoint for their lessons.

Matt had offered to help one of his teachers, in return for being allowed extra time to use school computers:

Matt: The teacher started a computer club to try and help students make videos and use the computers for editing, but he did not know much about it himself so me and a couple of mates gave him a hand to set it up.

Rashid explained how they had had "a man" visit the school to talk about using games for learning:

He told us how in Scotland they were using computer games in class that was cool. He made us think about some of the games we play at home and how we could learn stuff by playing them. The teachers liked this idea and tried it out with some of the year 9 classes. We were allowed to help the teachers with this. Some of the teachers had never played the game so it was fun beating them all the time. If the teachers could play the game they could use it in their class too.

Rashid went on to suggest that if teachers made the learning fun the students would help them with their computer skills, "but some teachers don't like us telling them what to do".

Sara's comment:

My teachers have tried to help me use my laptop but sometimes the school rules mean we can't use it how we want to. It won't connect to 
the school network so I can't use the Internet and the teacher does not know how to fix that. Why do some schools have technicians to do this and my school doesn't? How do teachers learn this? I end up not using my laptop.

It was apparent that some of the schools are providing professional development for the teachers but other schools expect the teachers to do this in their own time and without any professional guidance. If the teacher is not committed to integrating the technology into the learning then there is little time for the students to develop personal skills. Tom agreed: "the teachers should learn more about using computers so they can teach the students".

Clearly, this area of teacher skill and expertise has provided a major barrier for some students in developing their computing skills. Other students have successfully supported the teachers and at the same time learnt more about computing and technology use themselves by using online resources, video clips, and tutorials. The participants agreed that teachers need time and encouragement to develop their knowledge, and support to seek help when necessary.

\section{Integration of Technology into Learning at School}

Students can be active learners who use technology responsibly to solve problems, develop critical thinking skills, and communicate ideas whilst teachers can integrate technology across the curriculum where appropriate to enhance instruction and assessment of student learning. In several of the schools involved in this study the teachers were able to take advantage of staff development programmes that were designed to improve teaching and learning with technology and this had not gone un- noticed by the participants.

The participants were asked how they perceived the integration of technology into their classrooms was developing. Rashid noted:

My younger sister uses an iPad at her school (intermediate), but I am not allowed at high school - how fair is that?

He went on to add:

At high school we have to focus on NCEA so there is no time for the teachers to teach us about computers as well. 
For Rashid it was important that the school took the responsibility for teaching him about computers and how he could use the technology to assist with his learning. It appeared to him that there was more opportunity to use technology in the Intermediate school than at High school when the focus was placed on success in examinations. However, according to Kate, it was more about enjoyment of learning and having "fun". She believed that technology use would improve this aspect of school:

If I was a teacher I would make learning fun, using iPad, phones and iPods - let everyone bring their own. I think the teachers need to have some time to learn about computers too.

It is noted here that Kate appears to link using computers with having fun rather than just learning. Other students reported that the integration of technology into their school was changing. Wiremu, for example, mentioned, "I think it is getting better. Maybe computers are cheaper now so schools can afford to buy more". If the school had more computers this would relieve some of the access issues for Wiremu. Sara, on the other hand suggested, "as more and more people have computers and the Internet at home so schools need to keep up to date too".

However, the participants were unable to make any suggestions about how this keeping up to date might occur other than having more computers and maybe letting students bring their own device. Overall the participants appeared to take little regard of what was happening in terms of updating their own school systems.

Regarding the participants' future employability, Matt was concerned that:

Almost every job means you need to know something about using a computer, sending emails and stuff, so schools should teach that too. Some people need to know more about being good users of the Internet so that we don't get nasty rumours spreading, or videos going viral on YouTube.

It was important for Matt that people were made aware of the dangers of posting inappropriate material on websites such as YouTube or social networking sites as they would be "there for ever". Matt was concerned that this would affect his future employment opportunities or even prevents other people from going on to university. 
Tala identified a number of positive attributes of using computers for learning:

There are so many ways that a computer can help you learn - you can get neat writing by typing, it helps check your spelling and you can watch films and TV programmes too. We can learn stuff that even the teachers don't know about - pity they (the computer) can't do our exams too.

The students who have younger siblings reported that there seems to be better use of computers in the junior classrooms than at college level. Tala suggested that it must be more difficult for teachers at secondary schools as:

We have NCEA exams so the teachers have to teach us how to get the credits, rather than use technology to produce interesting and fun lessons. Tala also said, we watch videos of experiments in science instead of doing them ourselves. I would like to do them myself because I learn more when I do it myself.

Wiremu noted: "every teacher has learnt to do PowerPoint - it is really boring, they just put notes onto PowerPoint and we have to copy them down". He suggested that the teachers thought they were being clever to use PowerPoint but they were really no different to the notes they wrote on the whiteboard or the worksheets that they used to give out. In contrast to this, Wiremu said, "My maths teacher uses a Smart board. He is really good at using that, he makes maths interesting. We have videos and maths games to play. That's how it should be".

Tom was very critical about the time it took for teachers to adopt any new ideas, indicating that he felt his school was very traditional in its approach to integrating technology into the classroom:

Tom: We have a teacher whose job is to teach the teachers and run the network but not all the teachers listen to him. He is slowly trying to change the school systems and bring it up to date but not every teacher is so keen to do this. I guess they just don't like change. But the jobs in the future mean we need very different skills from when they went to school. 
Sara thought her school was trying really hard to make sure that the teachers were learning to use computers in the classroom - "not just the Internet for doing project work", but encouraging the teachers to try out using blogs and wikis and different ways of presenting their work:

Sara: We can make a video or a poster using Glogster or use Prezi instead of PowerPoint. We can use some of our own ideas as well. It is good to see the teachers changing their rules about using cell phones too.

This section indicates that after more probing questioning during the interviews and follow up discussions, the students began to talk about the changes they had noticed occurring in their schools. Despite their initial comments about how "useless and disinterested" teachers were in using technology, the participants were beginning to acknowledge that some teachers were making considerable efforts in improving their personal use of technology. These changes were noticeable in both in their personal skills as well as using the technology as a teaching tool.

\section{Personal Learning Strategies}

The participants were asked to think about how technology had influenced the way in which they were learning new information and skills. Had their personal preferences for the way in which they learnt new information changed as they were introduced to new technology?

Matt: When I am doing serious schoolwork I still like to work in a quiet space and I will write down the information I want to remember. Sometimes I draw pictures to help me remember stuff - you can't do that well on a computer. I sometimes use Inspiration for brainstorming. If the work isn't too hard I will have my computer on and will talk with some guys. But mostly schoolwork is done on my own.

Another participant found that using technology had helped her when working at home as she was able to contact her peers for assistance:

Kate: If I am doing homework I usually work in my bedroom and will text my friends if I need help. Our computer is in the family room so if 
I need to use it for homework I can't Facebook or play games, as my mother will tell me off. But when my schoolwork is done I can use it then. Sometimes I will type a piece of work or, if we have a project to do, I will use the Internet rather than books.

Wiremu was not a great user of the computer for schoolwork: "I don't use the computer for much except play games when I am not at school". Marie liked "being able to have lots of things going on when I am doing my homework, listening to music, chatting to friends as well as doing homework".

Tom was keen to tell of his computing expertise: "I helped my dad to build our home computer". Tom was really interested in programming and writing "apps"; saying computing lessons at school were boring. Tom had quite a different approach to using technology at home to the other students; his aim was to complete homework as quickly as possible so he could indulge in his passion:

I can get information faster when using the computer, you can copy from pages and not have to write everything yourself. The teachers say you should not do this, but it means I can do my work quicker and then do what I want with my computer time. I will take more time with those subjects I am really interested in and do some extra reading online.

Tala's opinion was that the using of technology had changed the amount of work that she had to complete at school in order to pass her exams:

I think using the computer has made schoolwork harder. You have to do more for yourself. Before, the teachers just told you the answers and you had to write it down and remember it. Now, we have to find our own answers and you don't always know if it is right or not.

Sara was more interested in using technology for social reasons than for study:

I like using Facebook, chatting to friends that I don't see at school and it has games I can play when I am bored. I am not sure it helps my learning but I can type quite fast now - and I have learnt how to quickly change windows when my parents come into the room - (laughs....) 
The majority of the participants had not really considered how technology may change the way they learn, being more concerned with the relevancy of the material they were learning. They just saw the computer as another tool. An interesting discussion took place when the researcher talked about how different schools were using technology for learning and how classes were being placed online so that students could access them anytime from anywhere.

Tom thought about this suggestion and decided it would suit his learning style: "you mean I could do my schoolwork from home whenever I wanted to". Wiremu also thought this was "cool, I can stay in bed and do my school work later".

Matt was not so convinced:

It would be easy to be distracted and never get around to doing your work, and it would all be homework. I think I would learn more if I had to go to school and work in the classroom. How would you get help if you did not understand something?

The girls from the high decile schools said they would "prefer to go to class so they could work with their friends". Kate suggested that her mother "would be checking on her all the time to make sure she was working and not wasting time on Facebook or something".

When the students were asked about the type of work that they did for homework when the teacher was expecting them to use a computer, a variety of responses was made:

Kate: We have to use Excel to put graphs into our work for science and sometimes for maths.

Tala: I sometimes use PowerPoint when I have to give a talk in English. Marie: Mostly it is just using Word to type up some notes. I use Google to find the information; copy and paste then mix it up a bit to make it my own.

It appears that although most of these students have better options and ideas for presenting their work, they stick to the low level activities, using simple software 
that the teacher has asked for. However, they do agree that having access to the Internet has real benefits for learning at school.

Ideas and Suggestions for the Future

During the interview the participants were encouraged to consider how they saw the future of technology developing in their lifetime. What would they be expecting to be able to use the latest gadget to do for them? The ideas that they suggested were very creative but when considering how fast technology is changing it could be a real possibility to expect these changes in the next 5 to10 years. The participants expressed a range of opinions as shown below:

Kate: I would like everybody to have some sort of computer, like an iPad or tablet. Laptops are too big to carry about - you would have lots of data so you wouldn't have to worry about the network going slow. You would use your iPad for everything, making video calls, texting, taking photos, watching films and TV programmes whenever you wanted.

Wiremu: A big as screen so that you can watch films and play games.

Tom: Have everything controlled by computers; even your car could drive itself. Everybody would have their home connected so that you need never go out - shop online, have food delivered, the lighting and heating would all be controlled by sensors linked to your computer.

Tala: A computer that would take my exams for me - I hate taking exams; I get so nervous that I can't remember anything I have learnt. I could just ask the computer the question and it will tell me the answer. If the computer could speak then I wouldn't have to learn to type or spell either.

Matt: It would be cool to be permanently connected to the Internet with a computer that is so small nobody can see you using it. People would think that you are real smart because you could answer any question about any topic quick as.... Maybe with a small earphone that fits right inside your ear, or a display linked to your glasses. 
Sara: I would like technology to be used to help people, people who have a disability.

Marie: I am not sure. I think a computer can do everything I would want to use it for... it might cause more health problems if we used it too much. People have told me that using a cell phone can cause brain damage because of the radiation. We really don't know the long-term effects of using a computer. What if we only text friends, maybe we will forget how to talk! So I am quite happy with what I do at the moment.

Rashid: I like gaming, so a better games machine would be good - with more realistic graphics, maybe we can have motion effects as well as just sound. Some of the graphics may be too much for young children so they would need to be R18.

There was a real focus on life outside of school and use of technology for entertainment by the participants, but little mention of work or career options that would involve the use of technology except from two participants, Matt and Tom. Follow up questions by the researcher probed to find out how these two participants perceived that their school was preparing them for the future as regards their use of technology.

Both of these young men, Matt and Tom, were keen to pursue a career in the technology industry. Tom was keen to develop his own software development business but stated that school did not offer him the type of course where he could learn about programming. Tom reported that most of his learning about programming was achieved through accessing online courses from home. He had also attended workshops during school holidays.

Matt, on the other hand, was keen to pursue a university education and obtain a degree in computer science. The school he attended had given him a basic introduction to programming skills, but similar to Tom, the majority of his learning had come from independent study conducted at home. Both participants agreed that their individual schools could do more to interest students in pursuing a career in the technology arena. It was important to these two participants that they learnt 
more about how a computer works rather than just being a user of the technology. The school focus on being a "user" was causing a barrier to their learning.

Wiremu was quite happy being a user of the technology. He was not interested in the understanding of how the technology "worked"; he just wanted to be able to use it for "playing games and googling stuff". Therefore, he was of the opinion that the school was doing "ok" in meeting his needs. Kate had identified her needs from school as being that of enabling her to use search engines to find the information she needed to complete her schoolwork. She was also concerned about how to "stay safe" when on line. Kate suggested that her school could do more to teach people about the dangers of sharing information and how to avoid cyber bullying. She was satisfied with the amount of support she received from teachers in using a computer for completing tasks but would like to learn more about different applications.

On the whole each of the participants considered that their school was making an effort to up skill and encourage the teachers to try out new ideas but they recognised that not all teachers were keen to do this. A consensus amongst the participants was to "let us help", "we know more than some teachers", "trust us" and we can work together.

\section{Summary}

This chapter has drawn together the main findings from the eight participants that support the six patterns that were identified during the data analysis process. These patterns led to the identification of both "barriers and enablers" that affect the way in which the Netgen students are using technology for learning and leisure. The major barrier for the students was "access", including access to the technology, both hardware and software, and access to "digital knowledge". The participants, apart from Wiremu, were critical of the way in which their school hinders access to the technologies that they perceive as essential to their future learning and potential career options.

In the following chapter the information collected from the participants has been subjected to further interpretation and analysis. These findings are linked to the literature review and other international research that supports the findings and then the main research question is considered. From the findings, suggestions will 
be made to address the issues that are highlighted by the participants that would remove the barriers that currently prevent them from effectively using technology to support their learning. It is important to reiterate at this point that it is a discussion of the student experience at a specific point in time and they would not be aware or influenced by any changes that have occurred since the time of the data collection. 


\section{Chapter 6: Discussion of Findings}

The purpose of this study was to gain an in-depth understanding of the lived experiences of eight secondary school students who were self-identified as heavy users of digital technology and how they perceived their schools were preparing them for the future. The research examined their experience via a questionnaire that indicated that they were avid users of digital technology, both at school and at home. The strength of the study was that the voices of the key players were used.

Accordingly, this chapter will draw together the information gathered from the interviews and the discussion with the participants to answer the main research question as well as the four supplementary questions. It begins by re-iterating the main question and then proceeds to explain how and why the participants were using technology for learning. The chapter concludes with suggestions of how changes to the current school system could remove some of the barriers that the participants identified as well as suggesting further areas for research.

However, while these participants had self-identified as "heavy" users of digital technology, it became evident during the data-gathering phase - interviews, conversations, discussion, and observation of them within the school environment that they were not all "experts" in the use of these technologies. It transpired that the participants had based their responses to the questionnaire on how much time they spent using digital devices, rather than on how they were using digital technology. Nevertheless, reporting their expertise of technology use provided the researcher with valuable data for answering the research questions.

In the past, research into the value and benefits that technology could add to school learning and achievement had focused on the perspective of classroom teachers, educators, and administrative people, but little was recorded from the student perspective. Therefore, this study was designed to give the school students an opportunity to express their views and concerns on living and learning in a digital world and to reflect on how the school was preparing them for the digital future.

A qualitative approach was used in this study because a key assumption of qualitative design is that the researcher is interested in "Meaning-how people 
make sense of their lives, experiences, and their structures of the world" (Creswell, 1994, p. 145). Through the semi-structured interviews and subsequent follow up conversations with eight young people, all of whom had different experiences with using technology for learning, I sought the meaning behind their experiences when using technology in their learning practices. An interpretative phenomenological approach allowed me to search for a deep understanding of the process of adopting digital technology for completing learning tasks and assessments as well as using digital media in their social lives. It was important to me to find out from the students how they perceived the school to be supporting or hindering their preferred approach to the use of digital technology for learning.

In the next section, using the four main theories, (i.e. Knezek \& Christensen, 1999, Rogers, 2003, Steele \& Brown, 1995 and Puentedura 2013), as alluded to in the literature review, I discuss implications for each pattern as they illustrate both the barriers and enablers for the participants in order to further their use of these new learning tools. Although the results of this study cannot be generalised to larger populations, the individual experiences described by the participants provides rich detail for those who want to understand the lived experiences of the young people's current technological practices. It is also important to recognize that as the technology environment is changing rapidly this study will only provide a snapshot of the participants' perspectives of these changes at a specific period of time. The participants' experiences, as told in their own words and interpreted with the categories and themes described in the previous chapter, were used to respond to the research questions.

\section{Main Research Question}

What does the personal lived experience of students using technology in their education tell us about the capability of the education system to prepare people for life in the $21^{\text {st }}$ Century?

This main question was subsequently divided to include the following four aspects for investigation:

1. How, when, and where did these students acquire their knowledge and skills in using the new technologies? 
2. How do the students perceive that the teachers and schools are meeting their needs for the future?

3. Are the Netgen students aware of any changes in teaching and learning as a consequence of their immersion in a digital society?

4. How can they apply their knowledge and skills to their learning?

During the analysis of the data from the interviews and field notes, six patterns emerged as being crucial to the participants' experiences. These patterns are listed below.

- Access to digital technologies at home

- Access to digital technologies at school

- Student perceptions of teacher knowledge and capability

- Integration of technology into learning at school

- Personal learning strategies and

- Suggestions for future development.

These six patterns will be discussed in further detail in the following sections as they are linked to the research questions. My attention became focused on the variables that either hindered or enabled a student to adopt the latest technology tools for learning, as reported by the students themselves. The variables that were taken into account were the experiences of the student, their teachers, and family as well as the social and economic variables that may have affected their adoption of the technology. It was also important that the students' perception of how the school and their teachers were responding to the increasing amount of digital content that they were accessing was taken into account. The data was gathered through interviews, conversations, discussion, and observation of the students within the school environment. This data was then examined through the lens of different theories as identified in the literature review to assist with the facilitation of understanding.

These theories included Steele and Brown's (1995) Adolescent Media Practice model alongside Rogers' $(1995,2003)$ Theory of Innovation, and the Knezek and Christensen $(1999,2001)$ Stages of Adoption model and latterly the SAMR model as proposed by Puentedura (2013). Whilst these theories have been adopted as a means of exploring the data, they do not always explain the student's 
experience or the type of experience during the learning process. Also, these theories do not adequately explain the individual factors that may hinder or enable the participants' decision or ability to adopt the latest technological practice. There are a number of different social and cognitive aspects that have shaped the participants' ability to adopt different technology tools. However, these theories do go some way towards explaining the differences between the ways in which the Netgen students and their teachers use digital devices for finding information and sharing this in a collaborative manner.

For example, the study by Livingstone and Helsper (2007) as identified in the literature review, suggested that there were a number of factors that were instrumental in influencing the young persons' use of digital technology. To reiterate the main factors, they suggested that opportunity to use technology increases with age, girls aged between 9 and 15 use a wider variety of tools than boys at the same age. Boys don't tend to make wider use of the Internet until 16- 19 years of age. The participants within my study made reference to their own particular reasons for selecting the tools that they adopted. For the majority of the participants gaming was the initial introduction to using technology. These games were for mostly for entertainment, except for Tala who had confirmed that she learnt to type by playing Mavis Beacon typing games at school. As identified in the literature review, entertainment was a key use of media by adolescents (Arnett 2013) and this was confirmed by the participants in this study. The playing of games was also the participants' introduction to using technology.

There is a perceived need, amongst the younger generation that they have to have the latest and most up to date gadget in order to be part of the "in crowd". This need for the latest gadget can also be explained through the work of Arnett (2013) as young people are developing a youth culture identity and to be part of that group there is a need for a common theme. This desire to be part of the group extends to other areas such as clothing, music genre and even a use of language. Matt and Sara reported this desire for the latest technology tool from both a positive and a negative perspective. Sara was concerned this "need" would place financial stress on the families, while Matt considered it was important to his future to be using the latest, most up to date equipment. 
In order to ascertain how these gadgets have been adopted by the younger generation I refer to Rogers $(1995,2003)$ theory as described in the literature review, that indicates that an innovation was adopted through a five-step process. In this case the innovation would be the use of the latest technology equipment that the participants were using to facilitate their learning.

The participants experiences are reflected in the five stages of accepting a new innovation be it a new smartphone or a software application. To recap, the stages of the process include - knowledge, persuasion, decision, implementation, and confirmation - and when the innovation was adopted, it spread via various communication channels, either by the student sharing with their peers both in the formal environment of the school or more likely during their out of school activity. Two examples of this process of adoption of an innovation are summarised in the following table 6.1 .

Table 6.1 Examples of adoption of an innovation.

\begin{tabular}{|l|l|l|}
\hline Stage & Example 1 & Example 2 \\
\hline Knowledge & $\begin{array}{l}\text { Tala was introduced to typing } \\
\text { skill games at school. }\end{array}$ & $\begin{array}{l}\text { Matt was interested in video } \\
\text { editing. He knew that there } \\
\text { would be information online } \\
\text { available on how to do this. }\end{array}$ \\
\hline Persuasion & $\begin{array}{l}\text { During class time she began to } \\
\text { explore the different aspects of } \\
\text { the game. }\end{array}$ & $\begin{array}{l}\text { He researched the Internet (at } \\
\text { home) for information on } \\
\text { how to do this. His personal } \\
\text { interest was driving his } \\
\text { interest. }\end{array}$ \\
\hline Decision & $\begin{array}{l}\text { The decision to continue with } \\
\text { involvement in the game was } \\
\text { supported by the introduction of } \\
\text { a competition within the class. }\end{array}$ & $\begin{array}{l}\text { He discovered several options } \\
\text { and then proceeded to select } \\
\text { the one that that would meet } \\
\text { his needs. }\end{array}$ \\
\hline Implementation & $\begin{array}{l}\text { Tala continued to use this game } \\
\text { when she realised that it }\end{array}$ \\
using different tools he finally \\
\hline
\end{tabular}




\begin{tabular}{|l|l|l|}
\hline & $\begin{array}{l}\text { contributed to the development } \\
\text { of her typing skills. }\end{array}$ & $\begin{array}{l}\text { found one that was easy to } \\
\text { use, he continued to find out } \\
\text { more about the tool by } \\
\text { conducting further research. }\end{array}$ \\
\hline Confirmation & $\begin{array}{l}\text { Continued use of the game was } \\
\text { reinforced by the improvement } \\
\text { of her skills and seeing the } \\
\text { progress reported to the class. }\end{array}$ & $\begin{array}{l}\text { He was able to support } \\
\text { teachers and peers to use this } \\
\text { tool via the school computer } \\
\text { club. }\end{array}$ \\
\hline
\end{tabular}

This theory of diffusion of an innovation may also explain the rapid rise in the use of Facebook by adolescents, as it appealed to their use of technology for developing social connections. Eveland (1986) had evaluated diffusion of innovations from a strictly phenomenological perspective, which is very different than the other perspectives. He suggested that technology is just information, and it only exists to the degree that people can make use of it.

It was evident from the interviews with the participants that they have been aware of these four elements during their developing use of technology. The innovation is the changing use of technology for learning; the means of sharing knowledge of the innovation takes place within formal and informal learning environments and can be peer-to-peer and adult to young person. The innovation may be the latest Smartphone, iPad, tablet, or specific software. The time that it takes for the young person to reach the implementation phase is determined by personal usefulness and the financial cost of the hardware and software.

The information gathered from the participants was also examined through the lens of the Adolescent Media Practice model (Steele \& Brown, 1995). This model takes a "practice" perspective, which means that it focuses on how the young people are using digital technology in everyday activities. This theoretical framework was developed by Steele and Brown in order to understand what motivates teenagers to select one media source over another. The model also investigates the factors that support their selection. The Media Practice Model emphasises the need for constant interaction between the teenagers and the type of technology they select. This is illustrated by the seemingly constant need to be 
"connected" either through having a reliable and easily accessible Internet connection or a more personal mobile Internet capable device such as a Smartphone.

As Davis and Eynon (2013) have confirmed it is during adolescence that young people are forming and developing their individual identities and are using a variety of media devices. The desire to be "connected" suggests that it is the teenagers' individual characteristics, environment, and daily routines that allow the technology to have stronger or weaker effects on them (Steele \& Brown, 1995). There is, however, circularity to the Media Practise model, which illustrates how young people develop their identity through the type of media they adopt while the technology requirements are continually changing as the participants', needs change. The model also suggests that young people will select their technology according to their lived experiences and will choose to either incorporate or dismiss it according to their current needs; in this respect, it is similar to the Rogers (1995) model and serves to endorse the comments made by the participants in this study. For example, Tom was exposed to a wider variety of technology devices in his home, but found the experience at school very limiting. Matt was left to explore different devices on his own at home and followed his own interests using YouTube and Google for advice and support. Tom and Matt continued to use the tools that best met their needs at that particular moment in time, they continued to develop their use as and when their needs changed.

Statements from Rashid, Tom and Matt have indicated that they have superior technical know-how than some of their teachers but they did not have the skills to use this knowledge to support their learning. They relied on the teachers' pedagogical understanding to include the technology in their learning. Tom in particular was only keen to complete his work as fast as possible so he could then pursue his own interests. The digital tools were not being used in a way to enhance his deeper learning of content, more as a means of shallow and superficial learning.

From the details obtained from the participants for my study, the six stages of Knezek and Christensen's (1999) model of technology adoption can be clearly ascertained. As detailed in the chart below, each participant can be placed towards the higher end of the adoption scale. From the data gathered in the initial questionnaire, all the participants had placed themselves at the top of this scale but 
following further discussion during the interview; the researcher adjusted their positions so that they more accurately reflected their ability to use technology in school. It was evident that the participants had based their understanding of proficiency of technology use on the amount of time that they spent on using the technology. For example, Matt's comment of spending "24/7” using computers was intended to indicate that he was proficient in using that particular software or hardware but from further discussion with Matt it appears that it was based on the personal assumption that he was an expert user and other students sought him out to give them assistance.

Table 6.2 shows the adjusted positions for the participants on the Knezek and Christensen model.

Table 6.2 Level of adoption of technology by participants

\begin{tabular}{|c|c|c|}
\hline Stage & Definition & Participant \\
\hline Awareness & $\begin{array}{l}\text { They are aware of ICT but have } \\
\text { not used or are avoiding use of } \\
\text { technology }\end{array}$ & \\
\hline $\begin{array}{l}\text { Learning the } \\
\text { process }\end{array}$ & $\begin{array}{l}\text { Learning the basics, } \\
\text { experiencing frustration and } \\
\text { lacking confidence }\end{array}$ & \\
\hline $\begin{array}{l}\text { Understanding } \\
\text { and application } \\
\text { of the process }\end{array}$ & $\begin{array}{l}\text { Understanding ICT use and able } \\
\text { to identify tasks for which it may } \\
\text { be suitable }\end{array}$ & Wiremu \\
\hline $\begin{array}{l}\text { Familiarity and } \\
\text { confidence }\end{array}$ & $\begin{array}{l}\text { User is gaining confidence and } \\
\text { beginning to explore other } \\
\text { applications }\end{array}$ & $\begin{array}{l}\text { Sara } \\
\text { Tala }\end{array}$ \\
\hline $\begin{array}{l}\text { Adaptation to } \\
\text { other contexts }\end{array}$ & $\begin{array}{l}\text { Computer is becoming a tool, } \\
\text { rather than technology; can be } \\
\text { used in numerous situations in an } \\
\text { appropriate manner }\end{array}$ & $\begin{array}{l}\text { Rashid } \\
\text { Kate } \\
\text { Marie }\end{array}$ \\
\hline $\begin{array}{l}\text { Creative } \\
\text { application to } \\
\text { new contexts }\end{array}$ & $\begin{array}{l}\text { The tools can be used in creative } \\
\text { ways in numerous different } \\
\text { situations. }\end{array}$ & $\begin{array}{l}\text { Tom } \\
\text { Matt }\end{array}$ \\
\hline
\end{tabular}

The participants were able to identify teaching strategies and activities used by their teacher and the researcher was able to align these with the SAMR model. The participants gave no indication that they understood the word pedagogy, but talked 
in terms of what their teachers did in the classroom. The SAMR model was used as a means of identifying the changing teacher practice and using the students' words and examples the level of integration was ascertained.

\section{Access to Technology}

The digital divide is mentioned almost daily in educational technology discussions: it may prevent students from receiving a technology-rich education that can help them compete on a global scale; it may mean that some students receive benefits that others do not; and it can be frustrating for teachers as they try to ensure an equitable and robust education for all students. According to many experts (Levin et al., 2002, Ito et al., 2009) the definition of "digital divide" has changed to involve more than who owns a computer and who does not. Several of the comments made by the participants, also concerned this digital divide. From their perspective it was not wholly explained in terms of economics but also people making a choice based on social, cultural, and religious views about whether to use technology. For example, parental views on appropriate technology use had influenced the student use of certain types of software, for example Kate's comment about the supervision from her mother on the use of Facebook. The participants also cited legislation as a barrier to the suitability of some of the software/games to which the students had access for example the R18 rating on games that appears to be ignored by some users. This legislation also included the individual school's Internet policy and teacher control of cell phone usage in the classroom.

During the time of the individual interviews, it was remarkable to see how self-confident the young people were in talking about their uses of technology. The participants did not struggle for information to share, and were easily able to give detailed reports on the different kinds of technologies they use and how they acquired this knowledge. The participants reported very different reasons for using similar technologies to meet their purpose, be it learning or entertainment. This was particularly evident in the area of social communication and their knowledge of "cyber safety". Some of these differences had their roots in the home where technology was managed by parents, and others from their activities at school that were controlled by school policies. 
However, a major issue for all students interviewed in this study was that of access, not just access to hardware but also access to technological knowledge and, most importantly, access to the Internet. In several cases the students offered solutions to overcome these difficulties and these are discussed in more detail in the following sections.

\section{Access to Digital Technologies}

Access was a topic of concern to the participants; they spoke about lack of computers, the strict filtering of websites, and the out-dated software that was available at school. Three main issues were identified from the information provided by the participants: these include access to computing devices, the capability and compatibility of the device with the school network, and access to broadband and the Internet. This lack of access to the latest technology can also be considered as a lack of access to "digital knowledge" that prevents the students from fully engaging in the digital world. Thomas Friedman (2006) has been encouraging people to think differently about our world and how we interact with each other. Friedman consistently indicates new skill sets that are required for anyone who wants to not only survive but also truly thrive in the hyper-connected world that is life in the 21 st century.

In relation to the need for ongoing skill development participants suggested that school could do more to educate students in the use of these "digital tools". As illustrated by the comments below:

Rashid: It's the way of the future! Everybody needs to know how to use a computer - school could do a better job of teaching us how to do this.

And Matt's comment about rooms being locked,

Matt: So that we can't go on the computers and play games and waste our time. The computers should be open so we can use them at any time.

But some schools do not prioritise the acquisition of sufficient appropriate technology (hardware and software) for their classrooms. The reasons for insufficient technology in a school are many; for example, having to prioritise funding, poor technical advice and support, and lack of interest from the teaching community. Some staff members, though, believe that the burden of paying for 
technological advancements remains with the Ministry of Education and that using fund raising dollars to buy technology gives the wrong message to the Government and the public. The Ministry of Education need to invest in the people as well as providing the hardware for the school.

Furthermore, some teachers are afraid or unwilling to learn more about how to use technology with their students, regardless of the needs of the students. However, the Ministry of Education is developing a managed Network 4Learning that aims to provide quality fast connections, uncapped data, and online filtering and network security services by grouping schools together. This initiative of supporting Ultra -Fast Broadband (UFB) access should enable all school to have a reliable high quality Internet connection by 2016 and provide a range of rich educational content for students in the geographical region covered by this research.

Access to the Internet

All the participants reported that access to the Internet was important to them for completing classroom tasks. Matt was so frustrated with the poor access and speed that he would truant in order to complete his work. The blocking of sites was one problem that all students questioned and in some of the schools there did not appear to be any logical reason for the sites blocked. In Tala's school a weekly data allowance, that was quickly used up and this became a barrier to learning.

Tala suggested that if students were given encouragement to use a fixed data allowance in a sensible way then they could all have better access to online materials, whilst Matt had suggested that if people were taught to be responsible digital users this would alleviate the need to have strict filters and blocked sites. When the participants were questioned on how schools could manage this, they were united in their response that school management and teachers needs to learn more about technology in order to teach the students. The interviews revealed a general naivety about the need for cyber safety; although Kate reported that her parents were very supportive in this they were not experts, so she had to just learn by trial and error and Matt had expressed his concerns and the impact careless use of social networking could have on his future. Sara was ambivalent about this issue and Marie also seemed unconcerned about developing an online presence. 
Our children and youth are immersed in technologies that give them opportunities that no previous generation has enjoyed and the question that arises is how schools will respond. Will their response be to legislate, by introducing rules and usage policies or will they educate by helping the young people to make good choices and learn to keep themselves safe on line. Brown and Steele (1995) and Davis and Eynon (2013) indicated that developing their own identity through personal experience of media use is an important part of adolescent behaviour. The adolescent either accepts or rejects the experience according to how it suits their purpose. If a more experienced person does not guide the adolescent in this learning process then they may adopt unacceptable behaviours. The schools' reaction to this unacceptable behaviour was usually to block access to web sites or limit the time available for students to use computers with little explanation for their decision. Both Matt and Tala spoke about the effect that blocking websites had had on their ability to complete research projects at school.

Addressing the "out of school" equity gap is important; this may mean ensuring that schools are able to give their students' reliable broadband access and technological devices to use in the classroom. All participants in this study had access to some form of Internet connection at home, through either a desktop, or laptop, or a smartphone and several identified the poor quality of the Internet connection at school as a reason they did not use technology at school. "Having to wait for web pages to load was frustrating for students, especially if they had to share a computer during class time" (Tala). Enabling access to the Internet away from school would allow the participants to access and use educational resources with more frequency. Wiremu described a quite creative approach to how he managed online activities before he had Internet access at home. He would work with a friend on collaborative projects or would stay after school to use the school library computers. His preferred option was to work with a friend, "cos he could help me with the hard stuff', although he did admit to getting off track with schoolwork when working with a friend. They tended to view YouTube videos and engage in on line games.

Two of the schools involved in this study were developing a system where parents could access the school website for details on daily events and homework 
tasks for their teenager, so access to the Internet was important for the success of this home/school partnership. One of the low decile schools in the study was trialling a system of texting parents rather than using the Internet to inform them of any school related problems such as truancy. This difference in technology use may be the result of a misguided notion that the families from low decile schools do not have the Internet or the technology with which to access this. However, as the next section indicates, an increasing number of New Zealand families are now connected to the Internet at home.

From this discussion it can be ascertained therefore that, although access to hardware and software was a major concern to these participants they had managed to acquire a number of computing skills that enabled basic use of a computer. The most common use of the computer was for playing games and searching for information on topics for homework or for personal interest. The strategies they employed for learning how to access online information was based on a trial and error approach, with only Tom identifying any structured learning of computing skills when away from school. Matt's approach was "You just pick it up, work it out for yourself, try it out and see what happens". The learning of skills in school was varied, Tala had received instruction during Year 9 but unless they chose to follow a "computing" course they were left to learn the skills for research and presentation on their own. As pointed out by Davis and Eynon (2013) as teenagers move through secondary education systems schools appear to lose their credibility as a source of computer expertise and students turn to their peers or on line communities of shared interest. As Marie reported, "at school they try and teach you Excel and Word, not useful stuff like research skills".

\section{Access to Digital Devices at Home}

In 2012, four out of five New Zealand homes had access to the Internet; this had increased by 5\% since 2009 (Statistics NZ, 2013). According to this NZ Statistics survey, the greatest increase in connectivity had occurred in the urban areas of Wellington and Auckland. All the participants in this study at the time of the study (2010) had an Internet connection at home although the quality of the connection and the speed were reported as variable. It was of high importance to the students that they had this access at home in order to support their schoolwork and 
for entertainment. Further information from the students suggests that the Internet also played an important role in their social life; it was important for chatting with friends and for sharing information and photographs of themselves. The boys also reported that an Internet connection was important for entertainment, which included the playing of online games and watching films and television programmes. The girls said that the Internet was important for social media use as well as finding information for school projects.

The biggest change in the manner in which students access to the Internet outside of the formal school time has come through the introduction of Smartphones, as now approximately one-third of households access the Internet via a mobile phone, up 26\% since 2009 (Statistics NZ, 2013). It was also interesting to note that $40 \%$ of households nationally were using more than one device to access the Internet - this figure has doubled since 2009. The most popular means of accessing the Internet in more than two-thirds of households was via a laptop; this has also changed since the previous survey in 2009 when a desktop PC was top of the list (Statistics NZ, 2013). The participants in my study had access to a desktop, laptop, and mobile devices for use at school and at home, including several Smartphones.

Once the participants became adept at using a particular technology at home, they were increasingly able to expand that usage or look for other technologies that may be effective in improving their learning. An example of this was Matt and his involvement in using video editing tools and detailed in Table 6.1. Technology adoption at home led to technology frustrations at school. Participants who demonstrated a high degree of technology knowledge that was developed outside of the school environment reported the need to "power down", as suggested by Puttnam (2007) during school time. The evidence from the participants suggests that their knowledge and expertise at using software and hardware exceeded that of most of their teachers and, as a result, they became frustrated with the outdated skills of the teacher. The Tech Angels approach (MOE. 2005), where students were supporting teachers' technology skill development was being trialed in two of the schools in an attempt to improve this situation. Rashid had identified some problems with this approach, "teachers didn't want to learn how to use the 
computer, and they just want us to do it for them". Tom had also been critisised by his teachers for being less than helpful in this situation.

The students had developed personal skills such as calendaring for example, recording homework tasks on their phone, communication, and organisation of learning materials at home and were attempting to share these with their teachers who were from an older generation. The knowledge and skills they gained through using technology at home often influenced the technology used by their family, as siblings were likely to adopt similar technology for communication, learning, and entertainment purposes. It was also evident from the participants' responses that the knowledge and skills brought home by younger siblings was helping to shape the participants' technology use both at home and in school. All the participants indicated that they "learnt" their technology skills at home through a trial and error method, supported by their peers, parents and siblings. Rashid commented that his younger sister was being introduced to far more interesting technology applications at her school than he had access to at college. She was able to help him with some of the technology issues that he encountered when at home.

In terms of hardware that was available at home, not only did the participants mention devices - computers, laptops, Xboxes, other dedicated game machines, and mobile phones - but also other ways that technology impacted on their lives. They talked of watching TV programmes by streaming them on the Internet (Matt and Tom) and listening to their music via online radio stations. They were able to download, re-mix, and share their music (Rashid) and video, photo favorites with their friends (Kate, Sara and Marie). They also gave the impression that the building up of a personal technology infrastructure was an important part of conducting their own lives. Tom, Matt, and Sara talked freely about how they could "multi task", listening to music whilst doing homework and texting or contributing to online discussions on Facebook. Although the literature and current research has identified that multi tasking is not an effective or efficient process, this did not appear to influence the decisions of the participants to study in this manner (Lenhart et al., 2005).

Their choices of websites did show a common pattern of favorite choices: not only did they talk of Facebook, YouTube, Google, Wikipedia, and Yahoo, but also of online games, World of Warcraft, Sims and other popular entertainment type 
games, although the censorship ratings indicated not all were suitable for this age group. When they were asked to name any technologies they disliked, little emerged apart from Marie and Sara stating a dislike for playing shooting games or other violent games on the Xbox or PlayStation.

Another factor that was beginning to impact on home technology devices was the desire of some schools for students having their own personal digital device for use when at school. Two of the schools involved in this study had implemented a BYOD initiative for junior classes as part of a stationary requirement. This was causing concern with the participants, especially those from the low decile schools, about the affordability and the risk of loss or theft of the device.

Overall, the participants regarded a reliable and fast broadband connection at home as necessary, not only for educational reasons but also for their own personal development of technology skills. The use of social networking sites and the ability to find current information was rated of high importance, well above the need for word processing or spreadsheets. The participants made little use of online shopping, except for Matt, or the ability to manage financial affairs online but this may be due to their age rather than their need to use this type of service. However, they did indicate that their parents made use of these online facilities, and thus the need for broadband access at home became a family issue rather than just for educational reasons.

\section{Access to Digital Devices at School}

The focus here was on students who had access to a personal computing device that they could use to advance their learning and who were encouraged by the school to use these devices. This may be a desktop PC, laptop, or a handheld device that is Internet capable. For the participants in this research, not only was access to a device important, but also access to the Internet was a prime requirement for both their study and entertainment needs. Two of the girls in the study had used the Internet requirement for homework as a means of convincing their parents of the need to acquire a computer or Internet capable device for home use.

Access to the Internet was considered a vital component of using a computer by all the participants; they reported that it was important to allow them to keep up 
to date with information, learn more about a topic than their teacher, and enable research of topics that they were interested in by communicating with "experts". For example, the participants suggested and had evidence of occasions when a student could email the author of a book they were studying; they could conduct an interview with a student in another country; or discuss a science project with a university staff member. The students considered these activities of value as, "my teacher doesn't know everything" (Sara).

Differences between home and school use had previously been identified in the Becta Report (Somekh et al., 2007). This report highlighted the fact that students use technology in a passive mode when at school, but are seen to be more active users in the less formal environment of home. This certainly was the case for all the participants in this study when they reported their activities of creating and sharing photographs, music, and other items with friends and family when at home. Yet when at school they were limited to using word processing and basic presentation tools.

Other students may not have technology in their homes or have access only when the digital device or Internet is available at school. Therefore, it is vital that educational facilities prioritise the purchase of, and access to, technology for students in order to raise the achievement levels. The use of technology has the ability to offer equal access to learning materials. For example, some students do not possess sufficient reading skills to decode print in their textbooks and software like Kurzweil or Dragon Dictate, text-to-voice programmes, can be utilised to remove that barrier. The software, if the student is savvy enough and willing, can allow for independent access to readings that they would never normally be able to comprehend, unless a paired reading opportunity existed or the text passage was recorded prior to the lesson. This type of equipment needs to be in every classroom but often it is available only through special education services or a centrally located room away from where that student might be learning their lesson. Sara had experience of using text to voice software but indicated that the time taken to train the software was not always the best use of her time. So despite this being an option to remove a barrier to her learning it was adding to an already stressful situation. 
This had prompted her to stop using voice recognition software completely and occasionally uses her laptop to record notes.

However, further development in the text to speech software has also meant that this barrier can be removed. An example of this is the use of Siri on an i-phone, or using Google voice search tools as well as the use of voice to control computer games. There has also been significant development in the use of video messaging and the use of voice messages. Teachers can give verbal feedback on student work by using Voice thread or similar tools. But as the participants pointed out, the teachers need to learn how to use these tools.

The participants' story of technology use, at school, was not altogether negative; they also gave positive examples of how specific teachers were encouraging and enabling of the use of technology in the classroom. All of the participants reported that using technology was enjoyable and helpful in various aspects of the curriculum, depending on individual teachers. Tom, in particular, was very critical of two of his teachers who had made no effort to integrate technology into their teaching and had refused to let students use it as well. Rogers (2003) would have described these teachers as being at the knowledge stage of adoption; that is, just beginning to discover technology and therefore not confident in sharing this knowledge. According to Tom, these teachers were not confident in their own skills, and this was why they were not prepared to allow the students to use the technology. Rashid, on the other hand, described his English teacher at being at the other end of the scale, at the implementation and confirmation stage (Rogers, 2003), both encouraging all students to become involved and comfortable in integrating technology into his teaching. Rashid's teacher was competent in using blogs, wikis, and Google docs and so had no issues or concerns in sharing this knowledge with the students. The English teacher was using technology at the more complex level as identified by Puentedura's SAMR model. The teacher adopted a digital pedagogy and they were using technology to modify a common classroom task of recording information through the use of technology. The teacher was a competent user of the tools and so was able to support the students learning through their use of these tools. 
Participants reported several instances of teachers trying out new ideas in order to engage the students. These included using PowerPoint, Prezi, YouTube video clips, making movies in English class, making music, and allowing Internet searches for project information. When examined through the SAMR model it is possible to see evidence of changing teacher practice as detailed in the following table.

Table 6.3 Examples of SAMR activity as identified by students.

\begin{tabular}{|l|l|l|}
\hline $\begin{array}{l}\text { Activity as identified } \\
\text { by participant }\end{array}$ & SAMR indicator & Explanation \\
\hline $\begin{array}{l}\text { PowerPoint - to } \\
\text { share } \\
\text { information }\end{array}$ & Substitution & $\begin{array}{l}\text { Displaying information instead of } \\
\text { writing on whiteboard }\end{array}$ \\
\hline $\begin{array}{l}\text { Taking an online test } \\
\text { using Google docs }\end{array}$ & Augmentation & $\begin{array}{l}\text { Making the use of immediate feedback } \\
\text { that may promote further learning }\end{array}$ \\
\hline $\begin{array}{l}\text { Writing an essay, } \\
\text { “expert" in real time. }\end{array}$ & Modification & $\begin{array}{l}\text { Enabling a common task to be quickly } \\
\text { edited by multiple users, and including } \\
\text { illustrations, maps and diagrams. }\end{array}$ \\
\hline
\end{tabular}

Despite the concerns of the participants over the poor availability of technology, they did express their appreciation of any efforts made by their teachers to provide digital resources and opportunities at their school. The UK government agency, Becta (2003), had claimed that a key benefit to using ICT in school was an increase in learner independence and self-motivation for study and thus by the schools providing increased access to the Internet would enable students to achieve this. In this study, such independence and motivation is reflected in the participants' use of the Internet for research projects, particularly when working at home.

At Tom's school there was a major professional development project being undertaken to up skill the teachers and for the school to become recognised as a 
"Google school". All the teachers were offered the opportunity to undergo professional development that would enable them to become more proficient at integrating the suite of Google tools into their classroom. Whilst at Rashid's school another professional development initiative was the introduction of a learning management system (LMS). This LMS was designed to allow teachers, parents, and student to access the online learning materials both from within and outside of school hours. Both Tom and Rashid recognised that these initiatives had the potential to enhance their personal access to technology whilst at school. However, much of the up skilling of the teachers relied on them spending time refining and consolidating the new skills. Kate, Sara, and Marie recognised the importance of this investment of teacher time, as they also felt that students would benefit from more technologically proficient teachers.

However, other participants, Tala, Matt, and Wiremu, identified several additional barriers that prevent students from using technology at school. These include: lack of computers, important websites being blocked, prohibited use of student-owned mobile devices (BYOD), and not being able to access social media sites. The teachers at these schools had attempted to justify these barriers by citing lack of funds, student safety, and inappropriate use of the computers by the students. The "inappropriate use" appeared to be associated with downloading music and videos as well as looking at "inappropriate material". The participants, however, had expressed concern that teachers' lack of competency in using technology was preventing them from accessing technology at school. This issue of teacher competency will be discussed in a later section.

In one of the mid decile schools, the use of personal devices for learning was becoming more common, although participants did not always agree with the school on this initiative. Again, the objections raised were mostly related to financial concerns and issues of security of the expensive devices when taken to school. However, Wiremu argued "students might take greater care of their own device than a school owned computer". But Sara was concerned that if "everybody had to bring their own device many families would not be able to afford it". Rashid was quite happy to use his personal device at school, but wanted to be able to connect to the school network instead of having to use his own data allowance for schoolwork. All the students in this study said they would use their own mobile 
devices in school, and six out of the participants reported that they had a device that they would use if they were allowed.

The most significant barrier for the students appeared to be the school policy on the use of cell phones or other personal devices being used to access the school network. The students said they considered that mobile devices would help their learning by allowing them to take notes and record work in progress using the camera function on their device. They would be able to search for information via the Internet and, as one student reported, "We can text an expert, when the teacher doesn't know the answer". Further discussion with Wiremu about who was the "expert" led to the understanding that "we can search the Internet or just Google the answer". These suggestions from the participants indicated that they had a better understanding than their teachers about how technology could support their learning but did not support the assumption that they were effective users of that technology. When asked about their research strategy, the majority of the students responded with "just Google it". They had little knowledge of other search engines or how to conduct an advanced search. Also, there was little understanding of how the search engine collated the results of the search. Both Tom and Matt had shown a little more understanding of searching the Internet, but these strategies tended to be for topics of their own choosing rather than responding to school study.

As the participants began to participate in external examinations, they reported more positive experiences of how the technology was beginning to influence their learning. In the schools that had developed an online learning environment, the students were able to access learning materials to support examination preparation. But none of these fairly isolated positive instances hide the fact that the general experience of technology use in schools failed to impress the young people themselves. They demonstrated frustration about the way that "Everything is blocked!" (Tala) and their advice for better ICT experiences in school was always unequivocal: "Don't be so petty by blocking websites like game websites" (Matt); "let's use more websites" (Sara); "faster loading computers, unblock some pictures" (Marie); "take away the filters" (Tom); "do better projects" (Kate). If their experiences of using ICT in lessons were of frustration, they found the experience of trying to extend their out of school use into their free time in 
school really disappointing, wishing constantly that they had the opportunity to "text each other, listen to music and be able to use texting" (Rashid).

Overall, the young people involved in this study did not represent marginalised technology users who do exist alongside the more privileged young people. Due to the nature of this research, this was a deliberate decision of the researcher in the selection of the participants. Just one participant expressed concerns about not being part of the "tech in-crowd". It appeared to be the case that the school was not doing much to alleviate this person's negative experience of learning to use digital technology at school. But for the most part the picture was of young people fairly happy to build technologies into their lives and to use those technology skills for learning, albeit on their own terms of use.

From the participant interviews it was noted that the majority of their technical skill acquisition had occurred outside of the formal learning environment of school. They had relied on family and friends to show them how to accomplish certain tasks using a computer, although Tala reported having Text Information Management classes when she was a Year 9 student, and that it was this class that enabled her to acquire basic word processing skills that she was later able to practise at home. Tom had received significant support from his father, who was employed in an ICT business, and Tom demonstrated superior technical skills compared to the other students in the study. Tom was more interested in programming and designing games than using the basic office suite of software. He considered that his school was not doing enough to support $21^{\text {st }}$ Century learners, and that they were not being taught the skills that they needed for the future. Tom wanted to learn more about different computer applications and how they operated rather than just being a user of a computer.

Compatibility between Home and School

It was important to the students that the hardware and software that they were familiar with should be compatible with the systems that they met in school. As students appear to be developing their computing knowledge away from the formal setting of a classroom, it is vital that as the participants experience newer versions of software and tools at home they should be compatible with school 
systems. This was a key aspect for both Tom and Matt who found that the school systems lagged well behind the technology that they had access to at home. While they felt that this posed a significant barrier to their learning, both these students appeared to understand that the reason for schools lagging behind was related to funding, possibly combined with reluctance by some teachers to change the ways in which they teach. Tom was extremely critical of some of the teachers at his high decile school that he perceived to be too slow in adopting the new technology. Clearly, today's students are experiencing a mismatch in terms of the way teachers and students use digital tools in the classroom and the way they use them at home. All eight participants agreed that school should be taking a greater role in preparing them with technology skills that would enable them to find employment in the future.

The participants' mention of a digital divide between access to digital devices at school and from home became an important focus and was perceived as both a barrier and enabler for some students. The PISA data from 2012 showed that the availability of the Internet and access to computers (including handheld digital devices) was present in all most all homes and New Zealand was represented towards the top of the table. Although the majority of home use devices are used to access services offered on the Internet, such as messaging, video and voice calls, chat and web based services such as shopping and banking, many of these can support both formal and informal learning opportunities. These educational resources, such as multimedia and encyclopaedias offer a substantial resource for education but only if an Internet connection is available from within the home.

As students today freely communicate through personal handheld technology as naturally as previous generations used land lines but, unlike that of previous generations, this technology is portable and individual connectivity to all things is important to the young people. Therefore, it can be reasonably argued that any attempt to control students' use of technology, rather than to integrate it with learning, is short-sighted. However, the successful integration of personal computing devices into the classroom will require adaptation of pedagogy and school policy. There will also have to be investment in infrastructure as well as professional development for teachers if this is to be successful. Participants 
demonstrated a clear awareness of the need for this investment in infrastructure as well as professional development for teachers if this is to be successful, a point identified by six of them, so concurring with a study by Davies and Eynon (2013).

The students in the study had not been permitted to use cell phones or personal electronic devices in school due to the risk of distraction in the classroom and the perceived security risks to the school network. However, as technology has advanced, the cell phone now accompanies nearly all daily activity for the young people. To see a high school or middle school student without a cell phone that has greater computing capacities than an early PC would be a rare occurrence.

Wiremu made the suggestion that if students each had their own Internet capable device then some of the issues of in class as well as out of class access could be resolved. However, this could pose additional problems for the school network administrator, such as compatibility, security of the network, and providing for those students who did not have their own device. Rashid also made this suggestion, but a barrier he identified was that not all areas of the school had wireless access. The teachers at his school were discussing how they could control the use of a wireless network by the students. An important issue was after-school access: would the school have to shut this down at the end of the school day and at weekends and would this also impact on teacher use of the network? To date, this issue has not been fully resolved in this particular school, and more students are bringing their own device and using them in the classroom with the approval of individual teachers.

\section{Student Perceptions of Teacher Knowledge and Capability}

When the students were asked about how their teachers were using technology, several of them showed an understanding of the difficulties that their teachers faced. There is a perception held by the participants that there is a difference between the way that they want to use technology in school and the manner in which the teachers are using technology, an issue highlighted and supported by the Pew Internet Project (Lenhart et al., 2007).

A point that was mentioned by all the participants was the teachers' interest, or lack of it, in using technology in their lessons. The teachers who were using 
technology had included PowerPoint presentations and use of video clips from YouTube in their lessons, one teacher had set up a class blog, a music teacher was using Garage Band, but the main use was as a means of presenting information to the students via a data projector. These findings from the participants are consistent with the comments made by Kitchen et al. (2007), that the technology use by the students frequently exceeds the knowledge of technology use by teachers. This appears to be more pronounced in secondary schools as these schools tend to be focussed on content delivery for the purpose of external examinations and teachers perceive less opportunity to work in a collaborative manner.

Furthermore, there are teachers who have the knowledge and understanding of technology but who have chosen not to integrate this into personal classroom practise for a variety of reasons. The participants suggested one of the reasons that teachers do not include technology use in their lessons was their lack of knowledge or confidence with personal use of digital devices or a particular application. Another reason that was suggested by a participant was to do with a perceived equity issue, not all students may have access to the technology required when away from school, and therefore teachers were reluctant to set homework that entailed the use of the Internet. However, Wiremu had shown that he had a solution to this issue by working with a friend or staying after school to use the library computers. The participants all strongly believe that the use of the Internet supports their learning both at home and when at school.

Although, in contrast to the results from Kitchen et al. (2007) who had stated that English teachers were less likely to use presentation tools, Rashid's experience was the opposite. His English teacher was making excellent use of a variety of technology tools such as PowerPoint and Prezi for presentation and the students were developing wikis and blogs to record their learning. Music at Rashid's school was also beginning to use Garage Band as a means of students producing their own music.

The school that Rashid attended had a professional development programme for teachers that was aimed at up skilling and encouraging the use of a student learning management system. The teachers were being introduced to working in an online environment, placing learning materials on line and enabling the students to work from home. This professional development was taking place during the time 
of this study and may have influenced the events that Rashid was reporting. He made the comment that "some teachers don't even use email, they have a laptop but it is kept in the cupboard. I have never seen Mr R use his laptop”. This school also experienced issues with classroom connectivity and it may well be that the teacher to whom Rashid was referring to did not have Internet access in his classroom.

Another participant, Sara, had been given a laptop via a special needs funding grant that would ameliorate the effects of her disability. However, she reported several major issues concerning use of this laptop. Sara was concerned that the teachers did not understand why she needed to be connected to the school network and she felt that it was lack of trust that was preventing her access. Also, connecting to the school network was a problem, the school had a policy of not allowing student computers to be connected to the network. Other reasons that were cited were reasons of safety; having cables across the room was not appropriate, not all the classrooms had physical Internet ports, and Sara really needed to connect to a power source when using the computer. Sara also questioned the technical support that was available to the teachers. The justification for this lack of connection was that the technical support person was not sure how to manage this issue. This was proving to be a barrier to this student's learning, Sara had received the laptop but there was no technical advice and support available that would enable her to use it effectively.

However, Sara had an answer to this problem; rather than using a laptop that was heavy and lost power rapidly, a smaller tablet or iPad or a cell phone with Internet capability would be more successful. This would give Sara access to tools such as a calculator, and online dictionary, access to information, and the ability to "ask an expert", as well as being able to use an audio recorder in the class or to take notes on the device. The advantages of the smaller device were that it would be much lighter to carry and the battery life would last the whole day. Sara also commented on the fact that her teachers had not been given any advice about how they could assist Sara with integrating the use of the laptop into her learning. She had asked teachers if they could email her with her homework or give her notes, in advance of the lesson but her teachers appeared reluctant to do this. 
In an attempt to upskill the teachers' use of technology for teaching, schools in New Zealand had adopted a scheme of making laptops available for teachers. The report by Cowie et al. (2008) illustrated that many schools had taken up this opportunity but $60 \%$ of the teachers were using their laptop with a data projector as their main use. The participants have confirmed that little appears to have changed in this area; teachers are still tending to use the laptop as an administrative tool, taking the roll, or producing worksheets that are then printed out, and the ubiquitous PowerPoint. There has also been a number of subsequent initiatives aimed at supporting teachers develop personal technology skills. These include the Network for Learning (N4L) project, the development of an e-learning community within TKI, and professional development programmes supported with Ministry of Education funding. However, these later initiatives were not in place during the interview stage of my research and as such the participants made no comment on them.

The general consensus of opinion from the participants on the teachers using technology in their class was that they could do more to accommodate the needs of the Netgen learners. Teachers need to become more proficient in their personal use of technology and to allow the young people to share with them their knowledge of the latest applications. The majority of the young people in this study had suggested "work-arounds" that would overcome these issues, but for whatever reason the schools were not prepared to accommodate these digital learners.

\section{Integration of Technology into Learning at School}

As highlighted in the literature review, some schools have offered a limited service in terms of access to technology. When digital technology first began to appear in schools there was an emphasis on teachers using technology tools initially for administrative purposes and acquiring basic technology skills. However, the focus has now moved towards an emphasis on pedagogy and the technology tools being integrated into the learning environment. Technology is a rapidly changing part of the world, and how that impacts the way people learn is still unclear despite a number of research projects (Becta, 2003; Green \& Hannon, 2007; Lenhart \& Madden, 2007). A study by Davies and Eynon (2013) has attempted to provide a more balanced perspective on the relationship between teenagers and technology in 
their everyday life. In the past, content has traditionally been the focus of preservice teacher training but now, as content is extremely accessible because of technology, the focus has moved towards changing pedagogy (Starkey, 2012). The introduction of technology into schools has forced some teachers to look more closely at their pedagogy and make it a priority in planning for teaching. But, as these pedagogical ideas develop, it is difficult to envisage learning theories without considering learning in a world dominated by technology.

If a learner has access to the technology it may reduce the need to "learn and remember" as the answer can always be found on Google (Jenkins, Clinton, Purushotma, Robinson \& Weigel, 2007; Windham, 2005). This viewpoint was supported by the participants in this study as they justified the use of the Internet to "ask an expert" when they did not know an answer and it was also the starting point for any research both by students and their teachers. According to Jukes et al. (2010), society is experiencing a state of "infowhelm", and people are in danger of having access to too much information and little knowledge of how to think critically about this information. So, when the participants were asked about how their school was integrating technology it was not surprising to discover a variety of degrees of technological capability. Tom suggested that his teachers did not want him to use the Internet to find information because "it would show how little they (the teacher) knew about a topic". If a student were to challenge teacher's personal knowledge of a topic, this could be seen as undermining the teachers' confidence and ability to be an effective teacher.

The participants were also quick to acknowledge when their teachers were attempting to integrate the technology despite a perceived lack of technology skills. Both Rashid and Kate talked about how their schools were attempting to support the teachers' learning. Both these schools had run professional development programmes for their staff and were contemplating the idea of using students to support and "teach the teachers" (Rashid). This idea had been very successfully implemented in a Wellington school as the Tech Angels Project (Ministry of Education, 2005).

Integrating students' personal technology skills into the learning environment has potential for great benefit but, as the participants themselves 
identified, also poses risk and management challenges for the schools. The students in this study were using both their own hardware, mainly for home use, as well as that provided by the school. It has been suggested by Davies and Eynon (2013) that the supporting role of technology in learning will only grow and tend to become seamless. But in order for technology to become seamless, the teachers need to understand the impact of that technology upon learning. They need to be confident and capable of using a variety of digital tools that will engage and motivate their learners to engage in independent learning. However, the teachers will only reach a level of fully integrating technology into their classroom by immersing themselves in technologies that foster sharing, collaboration, and innovation, but for some teachers, the suggestion of sharing and collaboration in the classroom amounts to "cheating".

In this section it has been indicated by the participants, that they demonstrated a concerned understanding of the issues faced by their teachers when attempting to use technology in their teaching. They had suggestions regarding improvements and changes the teachers could make but felt that their voice was not always considered by school leaders. Two of the participants (Tom and Kate) had been involved in teacher workshops and school initiatives to promote teacher capability, whilst Matt and Wiremu had taken a more casual role in helping teachers with a specific problem. All the participants have the expectation that in the future "new, young" teachers would be better able to accommodate the integration of technology into their teaching.

\section{Personal Learning Strategies}

Despite Prensky (2001) and Tapscott (2009) suggesting that all young people are experts in using digital technology, even within this small sample there is diversity in skill, knowledge and understanding amongst the participants. However, in spite of this assumption, that all young people are experts in using digital technology, schools have slowly begun to use technology to supplement learning and forge links between home and school in an online environment. It is also quite noticeable that the primary schools have embraced the new technologies far more rapidly than the secondary sector. Rashid supported this perspective during discussion about his use of technology at home and how his younger sister (at 
intermediate school) was able to solve some of his technical issues. Rashid also made the comment that his sister had greater access to a wide variety of software programmes at her school.

The participants provided details of how they preferred to learn; for example, Tala reported her dissatisfaction with watching videos of science experiments saying that she learnt best when she could have the practical experience. However, many practical science experiments are not possible within the confines of a classroom. This may be due to lack of resources or health and safety issues, therefore watching a video or an online demonstration may be the only option. Matt said he enjoyed working on his own, using pen and paper rather than technology for "serious schoolwork". Although Matt had the technical skills to manage on-line editing he preferred a more manual approach.

Kate reported using technology to collaborate with friends via text messages, whilst Marie was happy to use Facebook for working with friends but Marie was not too happy about having teachers as friends on Facebook. Tom was using technology for speed of completion of homework tasks and remarked that he would rather use the computer to follow his own interests than doing schoolwork. He was, however, quite happy to share his computing knowledge and skills with his peers as he considered that this was his strength.

The use of technology outside of school was far less regulated and more accessible to the students, than within the school environment where it is more restricted. The participants accepted that computers were expensive to provide and with limited technical support it was easier to restrict access than repair damage. The students also all reported on how they "needed" the Internet at home in order to complete homework, with all of them acknowledging that they used the Internet, using services such as Google, and Wikipedia to find information.

This use of the Internet for finding information raises an issue for the schools in that they need to teach the students how to conduct effective searches, evaluate the information, and how to use the information in a manner that does not support plagiarism. Tom explained his search strategy thus: "I just type what I want into Google, read the information and then copy and paste what I want. Sometimes I will edit but usually just copy and paste". There is no doubt that using the Internet 
to find out information has benefits for learning but whether the students are understanding the information and using effective search strategies is another issue that requires further investigation. The participants all agreed that they would use the Internet to find information rather than use textbooks or visit a library. These young people had not stopped to consider whether information obtained from the Internet was authentic or reliable. They also showed little understanding of the concepts of copyright and plagiarism, as illustrated by the comment made earlier by Tom, "just copy and paste". It appears from these students that using the Internet at home is the quick fix for finding information.

General discussion with the participants also revealed how they use social media to support their learning. As has been previously mentioned, both in the literature review and by the participants, young people consider they are expert at multi tasking so when working at home they will have a number of windows open so they can communicate with their friends via social media. This enables collaboration on projects and accessing peer support when they have questions about the task. It was interesting to note that Sara was quite horrified that her teachers may communicate via Facebook; she felt strongly that Facebook was her private space and she did not want teachers as friends. She had not considered Facebook as a learning tool.

As illustrated by the participants' comments, technology has had an impact on the way in which they prefer to learn. They are a group of young people who prefer to be able to collaborate and discuss their work, and to participate in authentic learning experiences that involve practical skills as well as seeking out their own information. They freely admit that using technology has enabled them to pursue their own interests and gather information from a wide range of sources. But they are also critical of the way that school does not provide the experiences that they need.

\section{Suggestions for the Future}

What was clear from the data is that the preferred mode for learning by these eight students was using technology in ways that enable them to choose, to some extent, how they manage those aspects of their lives over which they have some degree of control. However, the overall assessment of technology use by the 
students in school and home could be very different than that reported by this small selected group.

The participants had very clear ideas of where they expected technology use to go in the future. Their main priority was to have employment in the future and they were concerned that because the schools were slow in adopting the latest advancement in technology and they would be left behind if they did not access this information for themselves. The students themselves value the ability to be connected to experts, the desire to seek out knowledge that is relevant to their own particular interests as well as being able to contribute their knowledge to the work of others. This illustrates the value of Connectivism, the $21^{\text {st }}$ Century learning theory proposed by Siemens (2004). The participants also identified that the need to address the suggestion of Jukes et al. (2010) that they need to avoid the "infowhelm" by advancing their critical thinking skills, rather than adopting the idea that Google has all the answers and because "it is on the Internet it must be right!"

Throughout the data gathering phase the participants have been very honest and clear about the issues that they feel is impacting on their use of technology for learning at school. They have also been able to identify when their teachers have tried to up skill and enable the participants to incorporate the technology. There were instances when, after the interviews, the students wanted to ask questions and provide additional information. This frequently occurred several days after the initial interview when they had time to reflect on the information they initially shared.

The following chapter draws together this discussion and suggests areas for expanding the integration of technology into the learning environment as identified by this study. It also highlights limitations of the qualitative, interpretive phenomenological methodology. The contributions to the research environment and the personal significance of the study are also discussed. 


\section{Chapter 7: Conclusion and Implications for the Future}

In this final chapter of the thesis I return to the main research question and the four sub questions relating my findings to these questions, and consider how they reflect other research findings both within New Zealand and overseas. I offer some recommendations for supporting pre-service teacher education students as well as professional development for established teachers wishing to up skill in the area of digital technology. I also suggest further opportunities for research as identified in this important area of using technology tools for learning.

This research (albeit a small sample size) indicates that there is considerable diversity of technology use between home and school for this current generation. This diversity cannot be explained based solely on assumptions of generational differences between Digital Natives and Digital Immigrants (Prensky 2001), there are a number of other factors that need to be considered, as identified by the participants: namely access to the digital equipment, teacher knowledge of how to integrate the use of digital materials into the classroom, and the personal motivation of teachers to use the latest technology. This provides some clarity to the issues of exploring the experiences of eight young students' use of technologies in their classroom and how this influenced their learning and preparation for future employment.

The study has provided an insight into the use of technology for learning as experienced by eight secondary aged students from Wellington, New Zealand. Background information also revealed why some schools and teachers have changed considerably and others have been slower to acknowledge any kind of "digital revolution". The value of an interpretive phenomenological study is the detailed rich findings based on data from small number of participants from schools in the Wellington region, however it does not provide an analysis of the current situation for all the Netgen students attending New Zealand schools.

Each of the participants offered details of their personal experiences, although there were common elements that hey had experienced. For example when the participants were asked to define the term "technology", most of them listed the features of technology that had a value of fun and entertainment. It was the entertainment value of computer games that encouraged Tom and Matt to engage 
with a computer. They had not considered the educational value that playing games could offer. Another value that the participants listed for technology was the feature of a tool that makes things easier, for example when Kate reported that using the computer made her writing clearer and easier to read and Tala's example of using the Internet to obtain up to date information. In particular, when the students mentioned communication tools as technology, they emphasised that these tools make their lives simpler and, therefore the process of learning became less demanding and it was preparing them for future work as illustrated by Rashid's example of using email or messaging to contact teachers with a question at any time and from anywhere.

The young people involved in this study have identified areas of concern, and made suggestions for change in their own schools and within their personal learning environments. The responsibility for making changes now rests with the "digital innovators" amongst the teachers, to take up this challenge, making sure that the student voice is not lost, and work towards the future where they can meet some, if not all, of the needs of these young learners. This responsibility lies not only with the classroom practitioners but also with the school management and the Ministry of Education if the teachers are going to implement a strategy that fosters $21^{\text {st }}$ century learning. The young people spoke freely of their frustration at not being able to use the tools with which they were familiar and seemingly proficient in using in order to support their learning.

During the early days of computers in schools, computers were used for administrative tasks and the production of typed worksheets for students to use, and there was little opportunity for the students to have access to computers for general classroom use. When the technology became more widely available the business model of giving a presentation tended to be used by teachers, the presentation tool of PowerPoint being the "go-to" app. This tool offered little interaction between student and learning materials, the students were still in the passive mode of a transmission model of learning content. The teachers are no longer the "holders of the content" and for some of the older generation of teachers this is an uncomfortable feeling. In these early days of Web 1.0 the computer was seen as a tool to deliver content material that was still under strict control of the teachers. 
However, the use of technology has now changed and the students are taking a more active role when using technology in the classroom. Today, students are contributors and producers as well as users of content, the Web has become a more interactive medium, and the move is away from computer labs towards the BYOD arena with wireless connections and mobile access via the tablet, iPad, or cell phone. School management has identified the high cost of upgrading to UFB and wireless networks as a factor that inhibits student use of digital technology but the cost of replacing out dated hard copy books is also increasing at an alarming rate. Thus the schools have to decide where they use their limited funding in order to maximise the benefits for the students.

By interviewing and observing these eight young people who had selfidentified as heavy and persistent users of the latest gadgets and gizmos, I have become very aware of how quickly the learning preferences of the students in some schools are changing. I have, through my research, raised the awareness of how the "Netgen Kids" are using technology in their lives. I have provided an insight into the struggles as well as the achievements that these young people have shared with me. Through observing them from a distance as well as talking to them in the interviews and less formal conversations, I have identified areas where improvements to both the teaching and the learning aspects of every day school can be made.

The following sections identify other important findings from this study by addressing each of the four sub-sections from the main research question.

\section{Sub Question 1}

\section{How, when, and where did the participating students acquire their knowledge and skills in using the new technologies?}

Whilst much of the previous research on the use of technology for learning had focused on the pedagogical benefits of technology (Baytak et al., 2011, Becta, 2008, Harwood, 2007), the conversations that occurred with my participants gave evidence of the issue very clearly from the learners' perspective. Although research on the pedagogical benefits produced valuable information about technology and its use, little research focused on the experiences of students who were attempting to use technology in their learning processes. 
As has been mentioned earlier in this chapter, the participants have acquired most of their technology skills away from the school environment. They learnt their skills through game playing and sought assistance from friends and the online help sites. They struggled to transfer this type of social use of technology into their learning. Their skills were acquired through experiential means and seeking assistance from friends, family and online sources such as YouTube. The students reported that their efforts to bring these skills into the classroom were inhibited by lack of access to computers, old and unreliable machines, and poor Internet connections. The practise of rationing data usage was also contributing to their frustration, as was the blocking of certain websites. Although these management strategies were aimed at controlling the use of the Internet in order to protect the students, a suggestion from the participants was that they could be encouraged to self-regulate their usage.

Through the use of in-depth interviews and the follow up conversations that occurred the young people were able to tell their individual stories of technology use. The use of these guided interviews gave ample opportunity for the student voices to be heard and the information gained helps fill the gap in the earlier literature concerning the use of technology by the Netgen Kids. As evidenced by the statements by Rashid and Kate far more attention is now being given to students' prior learning and knowledge not only on matters of content but also on their use of digital devices. However, in two of the schools involved in the study, progress had been made to enable the students to showcase their talent by allowing them to teach the teacher and to support their peers.

Although the participants indicated that learning how to use computers, tablets, and other portable Internet capable devices was undertaken outside of the classroom, they had the opportunity to explore the technology at their own pace, often driven by their need to access information, entertainment, or communicate with friends. The students discovered the value of online help and support, mainly through YouTube and Google before asking peers, parents, and teachers for any help. They were self-taught in many areas of technology use, and their initial use of technology was predominantly through a gaming environment.

The participants in this study identified that they used home computers for gaming purposes as a popular choice of entertainment. Gaming was an area 
identified as a key introduction to learning computing skills despite the report that parents considered it non-educational. This study also found that some parent's had concerns about Internet safety and their own limited experience with the use of technology for learning could be a barrier for students' use of computers at home. For Matt, there was very little parental influence or control over his use of computers yet Tom received considerable help, support and advice from home, as his father was involved in the IT industry.

It is, therefore, clearly necessary to establish more open communication between teachers and parents in order to increase effectiveness of home computer use for learning purposes. Two of the schools involved in this study were investigating the use of linking parents into the learning management system so they could check in on the work their young person was undertaking. Communication between home and school was also being explored using social media and text messaging. One school in this study was beginning to explore the use of text messaging to contact parents with regards to absences and student progress. It was also evident from the participants' comments that schools and teachers were adapting the types of homework tasks that they set: for example, requiring tasks that demanded technology use such as doing more research, designing digital artefacts, or contributing to online discussions via a class blog. To encourage more educational use of computers at home, teachers need to provide more game type activities that are educational while remaining able to control the content of the games - this will be both educational and enjoyable and, hence, motivational for young people.

$\mathrm{Xu}$ and Meyer (2007) report that teachers who used technology such as email, Internet, and electronic calendaring saw an increase in their overall productivity. My research indicated this was also the experience of the participants. These students discussed using the "extra time" gained through using technology to improve their assignment and project work and they reported spending less time finding information when they could "Google it" than when having to use textbooks. This may be due to their lack of research skills when using textbooks or other reference materials or indeed how to access information from a library. However, the literature also shows that using Google was not always an effective search, the students were using a "copy and paste" method of including information 
in their writing. There was little evidence of deeper processing of content from the students. The students also indicated that they considered their work was presented in a more professional manner when using a computer. They could use spell check and it was easy to edit their work when it was in a digital format. They also stated that they were confident of using the most up to date information when using the Internet.

However, what was lacking in these self-taught skills was the ability to conduct effective research (Jenkins et al., 2007). The students' understanding and use of advanced search tools was poor; they simply used keywords and then utilised the first couple of items without checking for authenticity or reputable source. The attitude tended to be "if it's on the Internet, it must be true". From all these details it appears that the students would like to see schools taking a more active role in teaching them the "how" of using technology in the most efficient manner. They saw that the use of a computer, tablet or other personal device had become an essential tool required by people for working in the global environment.

\section{Sub Question 2}

\section{How can they apply their knowledge and skills to their learning?}

It was interesting to observe how the students applied this technology knowledge to their work in the classroom. The common issue raised by them was the lack of opportunity to use their skills and knowledge. In two schools involved in this study have acknowledged the student experience and technical skills of the students and have implemented support groups that are run by the students to help not only teachers but also their fellow students to up skill. Although there is more research required into the efficacy of this mode of teacher professional development it met the immediate needs of the teacher. There was evidence emerging from the participants that not all teachers were keen on accepting the help that was offered by the students. The students were able to demonstrate to the teacher the basic "how to" skills of using specific software rather than suggesting how the software could support learning. This support ranged from how to plug in a data projector to how to embed a video in a PowerPoint presentation.

However, this approach of having the students teach the teacher was not always best received or appreciated by the adult. For example, in the case of Tom, 
who was a competent user of technology his teachers described his attitude to supporting them as being "arrogant". It may be prudent in this case to help Tom develop his social and communication skills before he is involved in educating the teachers.

This process of students teaching teachers is important to follow up on to ascertain how effective it has been with the teachers. A future study on how teachers have changed their practise after accepting support from students would provide evidence of the learning that occurred. This had been followed up in a Ministry of Education review of the Tech Angels project in 2005. This evidence, of students teaching teachers, also supports the work of Somekh et al. (2008) that teachers' technology literacy and skills, support and training, and personal motivational factors all influenced their adoption of technology in the classroom. Those teachers who had an introductory level of skill were more likely to seek out new technologies that would enhance their teaching, according to Somekh et al. (2008). What was important for teachers, as suggested by the participants in my study, was support from the management and senior teachers within the school. This support and encouragement would motivate the teachers to continue their exploration of technology alongside the support given by the students. This was a recurring theme in the students' narrative: that they wanted their teachers to be effective users of technology as this would enable them (the learners) to be more effective in their use of the devices.

Another suggestion made by Wiremu and supported by Kate and Rashid, was to allow them to use their own devices when in class. Several of the other participants were not sure this was a positive move, they cited disadvantages as inequity of ownership, fear of losing their device, having to use their own data allowance and the cost of having to purchase such a device. The participants reported that using their own devices would be easier for them as it was a tool with which they were familiar but they did acknowledge that this could be a problem for schools. They identified the problems as being lack of technical support for a multitude of different devices and not being able to connect to the school network. Matt and Tom had both explained that they had found "better ways of doing stuff" through their use of online tutorials but teachers were not keen to accept their suggestions. 


\section{Sub Question 3}

\section{How do the students perceive that teachers and schools are meeting their needs for the future?}

The participants' initial response to questions about the schoollearning environment was one of negativity. Main concerns were that technology was difficult to access and out of date, that teachers did not know how to use it, and that searching for current information was made difficult as sites were often blocked. But throughout the course of the study the students began to appreciate the efforts that their teachers and schools were making to try and alleviate these difficulties. The participants indicated that they were aware of professional development opportunities that teachers had attended and in one school the up grading of a wireless network was beginning to have an impact on technology use in the regular classroom. This section links to the next sub-question of the research, about the increasing awareness that the students had observed of those changes that were occurring.

As previously mentioned, the findings by Somekh (2008) on the development of teacher technology skill acquisition indicated that the support and training that was available combined with individual teacher motivation had influenced the extent to which they were integrating this into their teaching. As identified in the literature, those teachers that had acquired a basic level of skill were likely to look for new and different technologies that would enhance their teaching. It is likely that most teachers have never had training or been instructed on how to use Web 2.0 tools, such as Twitter or Google docs or experienced interactive whiteboards during their pre service education, or experienced real-time collaboration with colleagues from across the country (or the world), and yet they are able to learn and take advantage of all these innovations to enhance their teaching. What better way of showing students how to prepare for their unknown future, than having teachers model it? The need for teachers to listen to their learners and allow them to teach and suggest changes to the learning environment is one of the biggest challenges facing educators today. Therefore, the suggestions and recommendations that the participants made would be valuable for developing pre- service teachers' knowledge and skills. 


\section{Sub Question 4}

\section{Are the Netgen students aware of any changes in teaching and learning as a consequence of their immersion in a digital society?}

The participants' awareness of changes taking place in their school was heightened by their inclusion in this study. During my observations of the students in the classroom it became clear that they engaged in discussions with their peers on how changes were taking place around their schools. Other students did not appear to have noticed these changes. The participants were impressed with the efforts that some teachers were making in order to integrate technology into the school day. They appreciated being given the opportunity to share their views and to pass on their skills and knowledge to the teaching staff. They also developed a greater understanding of the difficulties faced by the teachers and schools when trying to implement a digital strategy.

There are many imponderables in education - how can teachers ensure that they prepare students for an unknown future world? Friedman (2007) suggests that the Netgen students should anticipate having multiple careers in industries that don't yet exist. So we need to be asking; is the teaching of today going to be relevant for future careers of tomorrow? Perhaps we should consider that the role of teachers has never been to prepare students for future employment. Although the curriculum being taught may be important, does the way in which we teach need changing? As long as young people understand that learning is constant, that change is useful, and that mistakes are valuable, they will be able to deal with any challenges that come their way. They will be suitably equipped to deal with life. The future will not belong to those people who focus only on the technology, but to those that see the technology as being part of a greater system, but this is in need of further research and development. As teachers of the next generation it is important to remember it is not all about the tools but the way that we use these tools.

\section{Personal Significance of the Findings}

The findings from this qualitative interpretive phenomenological study are also significant on a personal level; they have provided significant insight into the professional aspect of teaching and learning using technology, and will also 
contribute information to the body of available literature on technology and pedagogy. I now have a more thorough understanding of the way in which the young people have adopted new technology and the expectations they have from their teachers to provide high quality technology integration into the classroom. The students have developed their technology skills, not through the formal learning environment provided by schools, but through collaboration with their peers and the use of online tutorials, help pages, and YouTube videos. The young people have shown skills of perseverance, motivation, and problem solving that teachers say are often absent from the classroom environment.

Although I have been working with technology implementation for a number of years and view new technologies as exciting opportunities both for the learner and teacher. However, I had forgotten what it was like for a person not immersed in technology to find, analyse, adopt, and assess a new technology when time is limited and money for purchase of equipment is in short supply. Also, knowing that the students will be far more skilful in using the software frequently undermines the confidence of a teacher to begin to use the technology in the classroom. It is also important to remember here that it is not always about having the latest gadget or tool but how we use these tools to facilitate the learning that is important.

It is also crucial, at this point to reflect on some of the limitations of this research in terms of the findings and methodology with regard to the impact of this study on both initial teacher education and in-service professional development as well as the impact on student learning. But at the heart of this research is the importance of "listening to the student voice" and respecting their views on how and when they wish to incorporate technology into their learning. For me, this is the most significant aspect of the study - priority must be given to what the young people are saying about the issues they consider important to their future learning experiences. These issues, as highlighted in this study are concerned with access to technology and developing skills regarding the use of said technology rather than the teachers' pedagogical approach to technology integration. 


\section{Limitations of the Study}

A number of limitations are acknowledged in relation to this study regarding the methodology, research design, and participants. In the following sections each of these limitations is discussed combined with details of how these have been addressed.

Throughout the course of this study it became evident that there were limitations not only regarding the gathering of data, but also of the validity and reliability of this information in relation to the fast changing digital environment being experienced by the participants. As with any research using an interpretative approach, there is also a range of limitations that relate to the phenomenological method, the research design, and the range of participants concerned. A further perceived limitation of this study is that the research sample is considered to be small; therefore the transferability of the data to a greater population would be limited. However, when comparing my findings with other more recent studies from overseas, there does appear to be some congruence in these details. The young people are raising the same issues three to four years after my initial data collection.

Whilst this phenomenological research is a small-scale study that involved eight participants and the stories that they related were just a small part of a much wider group, they would have valuable stories to tell. Although the initial data gathering phase was conducted over a relatively short time-period, it is reasonable to conclude that given the rapidly changing digital environment other findings may have emerged by re-visiting the students at a later date. Therefore, a study over a longer period of time, to follow up the recommendations made by the participants would be of value and would confirm whether the student voice was really being heard by the school management and policy makers.

As the data produced from interviewing is a verbal report and this information is filtered through the eyes of the participants, it is dependent upon their ability to recall their experiences and to a certain degree their level of articulation. For this reason the participants for this study were selected from Year 12, aged between 15 and 16 years of age. They had been attending secondary school for at least three years and I expected that they would be confident to talk about their experiences with some clarity. Chang (2008) suggests that the memory often reveals partial truth and can sometimes be unreliable, so it was important not only to 
interview these students but also to have the opportunity to observe them in school and have those less structured, informal conversations that enabled the validation of their experiences.

When interviewing adolescents there is also the possibility that the information they supply is what the interviewee expects is wanted rather than reporting on their personal experience. For this reason, it was important that the participants were comfortable that they would be anonymous informants and none of the information provided would enable their identification or the school that they attended. To further protect their identity they were asked to select their own pseudonyms.

Creswell (2007) indicated that reconstructing the details of the interview at a later date is a challenging task for the researcher, and the reliability of the data may be compromised during the process of analysis. To limit the possibility of any such misunderstanding, it was important to check back with the participants as to the correct interpretation of their interview statements. This was undertaken in several ways: firstly the data from the interviews was shared with a colleague who was asked to give their understanding of it, and then when visiting the schools, the participants were asked to confirm their responses to the interview questions. They were offered the opportunity to add further detail as well as to change information if they felt that it had been incorrectly transcribed.

The data was subject to common interviewer issues as well, including the skill level of the interviewer, bias, interaction between the interviewer and interviewee, and the context within which the interview took place. A particular concern was that of interpretive partiality which could arise because of researcher bias. Researcher bias includes assumptions, interests, perceptions, and opinions of the researcher (Bogdan \& Biklen, 2007; Rubin \& Rubin, 2005) as discussed in the earlier methodology section. In this study, the researcher attempted to limit the effect of her biases by setting aside (as far as possible) theories, research presuppositions, and ready-made interpretations; formulating open-ended questions to offset those biases; and by reflecting on her own subjectivity by the use of field notes.

Another issue for consideration when interviewing the participants was the need to create a natural context for the interview. It was important that the participants were comfortable talking about the school-based issues when they were at school. It was important that they could respond to the questions without any fear 
of a negative response or criticism from their teachers. Thus, I was able to gather valuable data from the students during casual conversations that expanded on their responses from the interviews. It was also important that they gave consent for this information to be recorded and included in the study. In some cases this casual information contradicted their interview responses. I believe that the relationship that developed between the researcher and the participants and the change from a formal interview to more casual conversations enabled the students to talk more freely about their experiences. The participants were also encouraged to ask the researcher about the study and to answer any other questions they had.

In school, questions asked of students are usually seeking correct answers. In this study, however, the questions were intentionally designed in a manner that helped prevent students from providing the answers they thought were expected of them - the emphasis was upon what they actually thought, did or felt. The type of questioning that was utilised included unstructured, short, open-ended questions that enabled discussion between the participant and the researcher. The questions that were formulated for the interview can be found in the Appendix, these were guiding questions only and not all were asked in each interview. These questions were used to promote the conversation and to elicit more in depth information.

This study has been presented as a qualitative interpretive phenomenological study and as such presents the student perspective on the impact of using digital technology during their learning. Whilst it cannot be the ultimate statement on the phenomenon, given the nature of interpretative work and the multiple interpretations that exist within and across different people and different learning environments, it does provide another perspective on the use of technology by adolescents. The phenomenological process is filled with times of scrutiny and intuition that are an essential part of the analysis process; van Manen (1990) describes these moments as moments of seeing meaning. The decisions that we make about these meanings can also influence the development of further themes for analysis and reporting of the findings.

A further concern with phenomenological research is the tendency to label themes too soon and, in such a way that the labelling prevents further thinking about the particular feature of the phenomenon. In this way, the intuitive and reflective nature of phenomenological research can be subject to interesting ideas 
that reveal more of the researcher's interest than they do the essence of the participants' experiences of the phenomenon. While, because of the infinite and ever evolving nature of human understanding, it is never completely possible to recognise blind spots, I have worked to do this through discussion with colleagues and other interested parties and have actively sought their interpretation of the participants' comments. It was important for me to have a secondary interpretation from people that were unfamiliar with the technology being discussed.

This phenomenological research gives priority to the participants' lived experience, and by so doing, the methodology limits perspectives that might be gained from a wider ranging group of participants. Similarly, the research approach has limited the gathering of data that would be subjected to contextual influences. One such critique might be that this study has not had explicit concern for the influence of economic factors that influence the access to technology outside of the school environment. While this is acknowledged here, it was beyond the scope of this research to consider all factors that impacted on the student experience. Therefore, consideration in greater detail of the economic factors that influence the access to technology would be a worthwhile study. To attempt to address this the participants were selected from a range of low to high decile rated schools.

As previously stated the participants for this research were Year 12 students from eight different schools in the lower North Island of New Zealand. As the participants were identified through a general ICT survey amongst the schools I made contact with in connection with my work, the spread of participants geographically was limited. In this sense, the research might be deemed to have a regional rather than national focus. Furthermore, there were only four ethnicities identified by the participants among a much broader range that exists in New Zealand society today. However, individual ethnicity or cultural background was not considered important criteria in this study.

\section{Contributions to Theory and Practice}

There is no doubt that there are substantial changes occurring in economies, social structures, cultures, governments and educational environments, driven by globalisation and technological developments. It's easy to talk about educating students for 'jobs that don't exist yet' when arguing for change, but preparing 
students for this changed environment could be seen as a central driver for transformation - and it raises questions that go right to the heart of what education is about. Therefore, we must pay attention to what the young people are saying about how they prefer to learn, using the technology tools with which they are familiar.

This research topic adds to the current field of research in the following areas;

- Validating the use of student voice to gather data

- Suggesting changes to pre- service teacher education

- Supporting the need for in-service professional development in order to facilitate the integration of technology into the regular classroom

- The importance of identifying technology as a tool that can enhance the learning of the young people

- Providing support to master technology skills for future learning or employment.

- Contributing to the body of knowledge about the relevance of interpretive phenomenology in studying lived experience

Contribution to student voice research

Although much of the previous research on the use of technology for learning had focused on the pedagogical benefits of technology, and the factors that influenced the adoption of technology by teachers as perceived by the policy makers, teachers, and budget holders this study provides another perspective - the voice of the students. The research in those aforementioned areas produced valuable information about technology and its adoption by the teachers; however, little research had focused on the experiences of students who were attempting to use digital technologies in their learning processes. However, this study has identified the benefits and drawbacks of using technology for learning, as experienced by the young people and enabled the participants to express their views on how the teachers could adapt their teaching to incorporate some of these suggestions.

For this reason, I used an interpretive phenomenological case study methodology that allowed the young people to tell their "stories" of technology use. The use of in-depth interviews gave ample opportunity for the student voices to be 
heard as they clearly identified and discussed both the positive examples of technology use as well as some of the factors that they considered had hindered their use of technology. The results of these interviews, supplemented by casual conversations and observations, did help to fill the gap in the literature concerning the use of technology by the "Netgen Kids" from their perspective and gave an indication of how a small number of schools were attempting to support student learning by enabling the use of this technology.

This study has reflected and promotes student voice and at its heart is a fundamental conviction that students are not the problems in our schools, they are the potential. We must not only ask the young people for their thoughts and recommendations, but we must truly listen and only then can we learn to be effective educators. We must learn from what they are saying by asking those important questions and trying to discover why they feel as they do. Student voice is being able to be heard, to be listened to, then being able to change things for the better. It is one thing to be able to say what you feel, but to have adults listen and process what you say is totally different (Quaglia, 2014).

Contribution to Pre-service and In- service Teacher Education

As has been identified by the participants they want to see their teachers using the technology within their teaching and delivering an education that acknowledges the prior knowledge of the students and their use of technology to manage their lives. They also understand that as technology is changing rapidly the teachers need the time and opportunity to up skill and become comfortable and confident in their personal use of a variety of devices and software.

Technology integration

However, it is also important to identify the technology as a tool that can enhance the learning of the young people. The students in this study were independent learners when they were observed in their classroom working with computers, they relied on the technology to answer their queries rather than ask the teacher a question. Even though the students have the technology skills to manage their own learning, teachers are still regarded as having content authority. The participants, for example, accepted that certain websites were reliable and trustworthy because the teacher had directed them to the site. In other words, 
students are aware they still need support to develop their use of technology for learning (i.e., developing critical digital literacy skills). Based on the previous studies about teachers' perceptions and the results of this study, it is clear that school management and class teachers need to develop new ways to integrate technology into education for an effective learning environment.

This study also revealed that students are setting the parameters for the integration of technology into education and in some cases they could provide support to their peers and teachers to master technology skills required for future learning or employment. Even though all participants identified the potential of using technological tools for learning, they were mostly conscious about the balance of technology integration into their lessons. They were able to identify potential barriers and enablers of this integration and suggest ideas that would alleviate some of these issues. They pointed out that although there was awareness of the effects and importance of computers for learning, there were few teachers who were willing to accept that this was the way of future learning.

The participants were aware of new technological styles of teaching and learning but expressed concerns that the teachers did not always have the education, encouragement, or facilitative environment to implement this. My participants' experiences with technology integration also support findings that some teachers may not be well prepared or "trained" for using the available technology and this creates barriers between students and teachers. However, a participant of this current study, Tom, made a recommendation that "more teachers should use technology in classrooms, but they have to have backup plans if there might be virus or the network is down". In addition, it was identified in previous studies that teachers had expressed concerns about technical problems and lack of support from management or more skilled colleagues. However, students in this study mentioned those as teachers' problems. The reason for that could be because they do not see the technical problems as their responsibility or they found ways to overcome such problems. For example, based on classroom observation and interviews, students tried to solve technical problems themselves. They had also developed the skills to overcome the "blocked" sites problem that they encountered on a daily basis.

Phenomenology as a research method 
This study also adds to the body of knowledge supporting the use of interpretive phenomenology to investigate the lived experience of the participants. The experience of the participants is subjected to rigorous and reflective process of interpretation by the researcher. These interpretations can be drawn from a range of theoretical perspectives provided that they are developed around the participants' experience. The process of interpretive phenomenology aims to explore the meanings that the participants apply to their experiences. However, the participants are the expert on their own experiences and will offer the researcher an understanding of their thoughts and feelings through the telling of their own stories, in their own words and with as much detail as possible.

\section{Future Research}

Undoubtedly in the future there will be advances in technological teaching aids, from holographic displays to three-dimensional printing that is available now, improving in quality and becoming less expensive with time. There are many choices of delivery, display, and interactive manipulation of the ideas and concepts that teachers strive to convey. Static textbooks and paper-based instruction are no longer the only options teachers have for presenting information to their students. The ability to present information through a variety of different mediums and having the students interact in real time on problems that are relevant to them will only raise the level of engagement and subsequently the learning of new knowledge.

These young learners are adept at manipulating technologies that seem, to them, to be a normal part of their digital landscape. Adult educators, who witnessed the advent of the personal computer, the mobile phone, and the Internet, often see these innovations as newcomers on the educational scene. Whether a teacher will embrace these gadgets as relevant tools or shun them as faddy distractions will depend largely on a willingness to meet the young learner in a new place of learning, on this new digital landscape.

From these research findings, a number of important issues have been identified and there are a number of future research directions that need to be explored. I suggest that the following studies be undertaken: 
- A study focusing on student experiences as they navigate a technology rich learning environment such as a BYOD school or a school that has a 1:1 tablet programme and examining the effect that intensive use of technology has upon learning outcomes

- A study that identifies professional development opportunities for experienced teachers that will enable them to integrate technology into the classroom.

- An investigation of the different expectations and experiences that technology is having on the relationship between students and their teachers and how this important student/teacher relationship develops.

- An investigation into the changing teaching approaches that includes game based learning, blended learning as well as the flipped classroom in order to support the $21^{\text {st }}$ Century learners

I suggest that having a clear understanding of how using digital devices affects the way a person learns and works offers useful information to technology researchers and teachers supporting those less confident learners. The findings of this study will help to prepare teachers and students for the experience of using digital devices for both teaching and learning. The teachers will have to address the changing learning needs of their students. The findings of this study can be considered a chart through the digital oceans of technology, the ebb and flow of the tides and the strong undercurrents that pull the learner in a number of different directions all the while expecting them to master a wide variety of skills and knowledge.

Finally, this study should encourage curriculum and technology designers, and educators to consider these perceptions of the students in future educational plans and policies. This should apply not only to schools but also pre-service education and professional development of experienced teachers. It is a reality that the Net generation enjoys communicating through online means and sharing the things they enjoy. Therefore, age appropriate chat and discussion platforms and information and artefact sharing sites are necessary for these students to productively use technology both at school and at home. The assumptions that have been made about the most suitable type of education for the young people may not match the reality of the world today. It is not acceptable to assume that the needs of 
the Netgen are the same as the educators just because the educators were once young. Times have changed, young people have changed, technology has changed and so must the education system. The young people of today are not only consumers of information but also producers, editors, and designers: thus we need to be "Listening to the student voices". So to conclude in the wise words of John Dewey "If we teach today's students as we taught yesterday's, we rob them of tomorrow." 


\section{References}

Adams, D. (1999). How to stop worrying and learn to love the Internet. Retrieved from http://www.douglasadams.com/dna/19990901-00-a.html

Alton-Lee, A. (2003). Quality teaching for diverse students in schooling: Best evidence synthesis iteration Wellington, New Zealand: Ministry of Education.

Arnett, J. (2013). Adolescence and emerging adulthood: A cultural approach $\left(5^{\text {th }}\right.$ ed.) (pp. 336-361). New Jersey: Pearson Education

Audi, R. (2001). The Cambridge dictionary of philosophy (2nd ed.). New York: Cambridge University Press.

Balanskat, A., Blamire, R., \& Kefaia, S. (2006). The ICT Impact Report: A review of studies of ICT impact on school in Europe. Retrieved from http://colccti.colfinder.org/sites/default/files/ict impact report 0.pdf

Baytak, A., Tarman, B., \& Ayas, C. (2011). Experiencing technology integration in education: Children's perspectives. International Electronic Journal of Elementary Education, 3 (2), 139 -151.

Becta. (2003). What the Research Says About ICT and Motivation. Coventry, UK Becta. Retrieved from http://www.mmiweb.org.uk/publications/ict/Research_Motivation.pdf

Becta. (2008). Harnessing Technology: Next generation learning 2008- 2014. Coventry, UK: Retrieved from http://webarchive.nationalarchives.gov.uk/20101102103654/publications.Becta. org.uk/display.cfm?resID $=37348 \&$ page $=1835$

Beddington, J. (2013). Future Identities: Changing Identities in the UK: The Next 10 Years. London, UK: The Government Office for Science. Retrieved from https://www.gov.uk/government/uploads/system/uploads/attachment_data/file/2 73966/13-523-future-identities-changing-identities-report.pdf

Bennett, S., \& Maton, K. (2010). Beyond the 'digital natives' debate: Towards a more nuanced understanding of students' technology experiences. Journal of Computer Assisted Learning, 26 (5), 321-331. 
Bennett, S., Maton, K., \& Kervin, L. (2008). The 'digital natives' debate: a critical review of the evidence. British Journal of Educational Technology, 39(5), 775 786.

Bereiter, C. (2002). Education and mind in the knowledge age. Mahwah, N.J: Lawrence Erlbaum.

Berg, B.L. (2004) Qualitative research methods for social sciences. Boston:p.15-30 Allyn \& Bacon.

Bogdan, R.C., \& Biklen, S.K. (2007). Qualitative research for education: An introduction to theories and methods. ( $5^{\text {th }}$ ed.). Boston, MA: Pearson Education

Bolstad, R., Gilbert, J., Vaughan, K., Darr, C., \& Cooper, G. (2006). Zooming in on learning in the Digital Age (ZILDA). Wellington: NZCER.

Bolstad, R., Gilbert, J., McDowall, S., Bull, A., Boyd, S., \& Hipkins, R. (2012). Supporting future oriented learning and teaching - A New Zealand perspective. Wellington: NZCER

Bourke, R., \& Loveridge, J. (2014). Student voice(s) as a pedagogical tool. In A. St. George, S. Brown \& J. O’Neill (Eds.), Facing the big questions in teaching: Purpose, power and learning (2nd ed.). Melbourne, Australia: Cengage Learning.

Boyd, D. (2007). The significance of social software. In T. Burg \& J. Schmidt (Eds.), BlogTalks reloaded: Social software research and cases. (p 15-30) Norderstadt, Germany: Books on Demand.

Broadcasting Standards Authority. (2008). Seen and Heard: Childrens' media use, exposure and response. Wellington, New Zealand: BSA.

Brown, M. (2004). The study of wired schools: A study of Internet using teachers. (Doctoral thesis), Massey, Palmerston North. Retrieved from http://muir.massey.ac.nz/handle/10179/1629

Bruner, J. (1966). Towards a Theory of Instruction. Cambridge, MA: Harvard University Press.

Buckingham, D. (2007). Digital media literacies; rethinking media education in the age of the Internet. Research in Comparative and International Education, 2(1), $43-55$. 
Buckingham, D. (Ed.). (2008). Youth identity and Digital Media. Cambridge, MA: MIT Press.

Carr, N. (2010). The Shallows: What the Internet is doing to our Brain. New York: W. W. Norton \& Company Ltd.

Celik, L., \& Keskin, M. (2009). The effects of the primary class teachers' information technology literacy skills on student achievement: The case of Afyonkarahisar. Procedia Social and Behavioural Sciences, 1(1), 1167- 1171.

Chang, H. (2008). Auto-ethnography as method. Walnut Creek, CA: Left Coast Press.

Christensen, R., \& Knezek, G. (2001). Profiling teacher stages of adoption for technology integration. Computers in New Zealand Schools, 13(3), 53-60.

Cilesiz, S. (2009). Educational Computer Use in Leisure Contexts: A Phenomenological Study of Adolescents' Experiences at Internet Cafes. American Educational Research Association, 46(1), 232-274.

Cohen, L., Manion, L., \& Morrison, K. (2000). Research methods in education (5th ed.). London: Routledge Falmer.

Cook-Sather, A. (2002). Authorising students' perspectives: Towards trust, dialogue, and change in education. Educational Researcher, 31(4), 3-14.

Cook-Sather, A. (2003). Listening to students about learning differences. Teaching Exceptional Children, March/April, 22-26.

Cook-Sather, A. (2014). The trajectory of student voice in educational research. New Zealand Journal of Educational Studies, 49, (2), 131-148.

Corrin, L., Lockyer, L., Bennett, S. (2010). Technological diversity: an investigation of students' technology use in everyday life and academic study. Learning, Media and Technology, 35(4), 387-401.

Cowie, B., Jones, A., Harlow, A., McGee, C., Cooper, B., Forret, M., Gardiner, B. (2008). TELA: Laptops for teachers evaluation. Wellington, New Zealand: Ministry of Education. 
Cox, M., Webb, M., Abbott, C., Blakeley, B., Beauchamp, T., \& Rhodes, V. (2004). ICT and pedagogy: A review of the research literature. London: Department for Education and Skills.

Cranmer, S. (2014). Digital Skills and Competencies in Schools. In D. Passey \&A. Tatnall (Eds) Key Competencies in ICT and Informatics. Implications and Issues for Educational Professionals and Management. Vol 444 (pp165-177). Potsdam, Germany.

Creswell, J.W. (1994) Research Design: Qualitative and quantitative approaches. Thousand Oaks, CA: Sage Publications

Creswell, J. (1998). Qualitative inquiry and research design: Choosing among five traditions. Thousand Oaks, CA: Sage.

Creswell, J. (2007). Qualitative Inquiry and Research Design: Choosing Among Five Approaches (2nd ed.). Thousand Oaks: Sage Publications.

Creswell, J. W., \& Clark, V. L. P. (2007). Designing and conducting mixed methods research. Thousand Oaks: Sage.

Crook, C., Cummings, J., Fisher, T., Graber, R., Harrison, C., Lewin, C., Sharples, M. (2008). Web 2.0 technologies for learning: The current landscapeopportunities, challenges and tensions. Nottingham: Becta.

Crothers, C., Gibson, A., Smith, P., Bell, A., Miller, M. (2014). Internet Trends in New Zealand 2007-2013. Auckland, New Zealand: Institute of Culture, Discourse \& Communication, Auckland University of Technology.

Cuban, L. (2001). Oversold and Underused: Reforming Schools Through Technology, 1980- 2000. Cambridge, MA: Harvard University Press.

Davies, C., \& Eynon, R. (2013). Teenagers and Technology. Hove, East Sussex: Routledge.

Denzin, N. K., \& Lincoln, Y. S. (2000). The handbook of qualitative research (2nd ed.). Thousand Oaks, CA: Sage.

Denzin, N. K. \& Lincoln, Y.S. (2003). Collecting and interpreting qualitative materials. Thousand Oaks, Calif., Sage.

Devaney, L. (2008). Gaming helps students hone 21st-Century skills. Retrieved from http://www.eschoolnews.com/ news/top-news/index.cfm?i=53586\&page=1 
Dewey, J. (1915). The school and society (2nd ed.). Chicago: University of Chicago Press.

Docherty, S., \& Sandelowski, M. (1999). Focus on qualitative methods: Interviewing children. Research in Nursing and Health, 22, 177-185

Downes, S. (2005). E-Learning 2.0. eLearn Magazine. Retrieved from http://elearnmag.org/subpage.cfm?section=articles\&article=29-1

Dye, J. (2007). Meet generation C: Creatively Connecting through Content. EContent magazine, 30, 38-43. Retrieved from http://www.econtentmag.com

Eder, D. \& Fingerson, L. (2002) Interviewing Children and Adolescents in Gubrium, J.K. \& Holstein, J.A., Handbook of Interview Research. London: Sage.

Education Review Office. (2005a). E-learning in secondary schools Wellington: Education Review Office.

Education Review Office. (2005b). Voices. Beginning teachers' experience during their first two years of teaching. Wellington: Education Review Office.

Eisner, E. W. (1991). The enlightened eye: Qualitative inquiry and the enhancement of educational practice. New York, NY: Macmillan Publishing Company.

Eveland, J. D. (1986). Diffusion, Technology Transfer, and Implementation:

Thinking and talking about change. Knowledge: Creation. Diffusion. Utilisation, $8(2), 303-332$. Retrieved from http://www.jdeveland.com

Eynon, R. (2009). Mapping the digital divide in Britain: implications for learning and education. Learning Media and Technology, 34(4), 277-290.

Falloon, G. W. (2004). An analysis of the impact of an e-classroom environment on the social, cognitive and affective elements of student work practices. Curtin University of Technology, Perth.

Falloon, G. (2010). Learning Objects and the development of students' key competencies. Australasian Journal of Educational Technology, 26(5), 626-642.

Fielding, M. (2004). 'New wave' student voice and the renewal of civic society. London Review of Education, 2(3), 197-217. 
Fielding, M. (2009). Interrogating student voice. In H. Daniels, H. Lauder \& J. Porter (Eds.), Educational theories, cultures and learning: A critical perspective. London: Routledge.

Fisch. (2007). Did you know? Retrieved from http://thefischbowl.blogspot.co.nz/2007/06/did-you-know-20.html

Fletcher, A. (2003). Unleashing student voice: Research supporting meaningful student involvement. Olympia, WA: The Freechild Project.

Flutter, J., \& Rudduck, J. (2004). Consulting pupils: What's in it for schools? London: Routledge Falmer.

Friedman, T. L. (2006). The world is flat. The globalised world in the twenty-first Century. Victoria: Penguin

Fu, J. S. (2013). ICT in Education: A Critical Review and Its Implications. International Journal of Education and Development using Information and Communication Technology (IJEDICT), 9(1), 112-125.

Fullan, M. (1993). Change Forces; probing the depths of educational reform. London: Falmer.

Garza. (2007). Varieties of phenomenological research at the University of Dallas: An emerging typology. Qualitative Research in Psychology, 4, 313 - 342.

Gee, J. (2007). Confronting the challenges of participatory culture; Media education for the 21st Century. Chicago: Mac Arthur Foundation.

Gibson, A., Miller, M., Smith, P., Bell, A., Crothers, C. (2013). The Internet in New Zealand 2013. Auckland, New Zealand: Institute of Culture, Discourse \& Communication, AUT University.

Gilbert, J. (2005). Catching the knowledge wave? The knowledge society and the future of education. . Wellington: NZCER Press.

Giorgi, A. (1997). The theory, practice, and evaluation of the phenomenological method as a qualitative research procedure. Journal of Phenomenological Psychology, 28, 135-160. 
Glesne, C. ((1999)). Making words fly: Developing understanding through interviewing. In Becoming qualitative researchers: An introduction (2nd ed.). New York: Longman.

Golafshani, N. (2003). Understanding reliability and validity in qualitative research. The Qualitative Report, 8(4), 597-606 Retrieved from .http://www.nova.edu/ssss/QR/QR*_4/golafshani.pdf

Gomez, J. (2007). Print is dead: Books in our Digital Age. New York: Palgrave Macmillan.

Grbich, C. (2007). Qualitative data analysis: an introduction. . London: SAGE Publications.

Green, E., \& Singleton, C. (2009). Mobile connections: an exploration of the place of mobile phones in friendship relations. The Sociological Review, 57(1), 125-144.

Green, H., \& Hannon, C. (2007). Their Space - Education for a digital generation. London: Demos.

Greenfield, S. (2009). How Facebook addiction is damaging children's brains. A leading neuroscientists chilling warning. Daily Mail. Retrieved from http://www.dailymail.co.uk/femail/article-1172690/How-Facebook-addictiondamaging-childs-brain-A-leading-neuroscientists-chilling-warning.html

Greenfield, S. (2014). Mind Change: How Digital Technologies are Leaving Their Mark on Our Brains. London, UK: Rider Books

Halsey K., Murfield, J., Harland, J., \& Lord, P. (2007). The voice of young people: an engine for improvement. Slough: National Foundation for Education Research.

Harwood, P.G. \& Asal, V. (2007). Educating the first Digital Generation. Maryland, USA: Rowman \& Littlefield education.

Heppell, S. (1999). Computers, creativity, curriculum and children. . Times Educational Supplement. London

Hernández-Ramos, P. (2005). If not here, where? Understanding teachers' use of technology in Silicon Valley schools. Journal of Research on Technology in Education, 38(1), 39. 
Hoepfl, M. C. (1997). Choosing qualitative research: A primer for technology education researchers. Journal of Technology Education, 9(1), 47-63. Retrieved from http://scholar.lib.vt.edu/ejournals/JTE/v9n1/pdf/hoepfl.pdf

Hood, D. (1998). Our Secondary schools don't work anymore. Auckland: Profile Books.

Hopwood, N. (2004). Research design and methods of data collection and analysis: researching students' conceptions in a multiple-method case study. Journal of Geography in Higher Education, 28(2), 347-353.

Howard, T. (2003). Theory into practice: Culturally relevant pedagogy: Ingredients for critical teacher reflection. Columbus, $\mathrm{OH}$ : The Ohio State University.

Howe, N., \& Strauss, W. (2000). Millennials Rising: The Next Great Generation. United States: Vintage Books.

Illeris, K. (2003). Learning, Identity and self-orientation in youth. Young, 11(4), $357-376$.

Illich, I. (1971). Deschooling Society. Retrieved from http://www.preservenet.com/theory/Illich/Deschooling/intro.html

Ito, M., Baumer, S., Bittanti, M., boyd, d., Cody, R., Herr-Stephenson, B., L, T. (2010). Hanging out, Messing around and Geeking out. Cambridge, MA: MIT Press.

Ito, M., Horst, H., Bittanti, M., boyd, d., Herr-Stephenson, B., Lange, P. G., Robinson, L. (2009). Living and Learning with New Media: Summary of Findings from Digital Youth Project. Cambridge, Mass.: MIT.

Janesick, V. J. (2000). Strategies of Inquiry. In N. K. Denzin \& Y. S. Lincoln (Eds.), Handbook of Qualitative Research (2nd edition) (2nd ed., pp. 371-389). Thousand Oaks: Sage Publications.

Jenkins, H., Clinton, K., Purushotma, R., Robinson, A. J., \& Weigel, M. (2007). Confronting the challenges of participatory culture: media education for the 21st Century. Chicago: The MacArthur Foundation. 
Johnson, K., (2004), Children's Voices: pupil leadership in primary schools, National College for School Leadership. Retrieved from http://dera.ioe.ac.uk/5067/1/randd-pupil-1ship-johnson.pdf

Johnson, S. (2005). Everything bad is good for you: How today's popular culture is actually making us smarter. New York: Riverhead Books.

Johnson, M., Kazakov, D., \& Švehla, M. (2005). ICT in schools report 2005. Wellington: 2020 Communications Trust.

Johnson, M., Lynch, C., \& Kazakov, D. (2008). ICT in Schools Report 2007: Information \& Communications Technology in New Zealand schools 19932007. Wellington, New Zealand.

Jonassen, D., Peck, K., \& Wilson, B. (2000). Learning with technology: A constructivist approach. . Upper Saddle River, NJ: Prentice Hall.

Jonassen, D. H. (2000). Toward a design theory of problem solving. Educational Technology Research and Development, 48(4), 63-85

Jukes, I., \& Dosaj, A. (2004). Understanding Digital Kids: teaching and learning in the new Digital landscape. Retrieved from http://www.infosavvygroup.com

Jukes, I., McCain, T., \& Crockett, L. (2010). Living on the Future Edge: Windows on tomorrow. Kelowna, BC Canada: Corwin.

Keogh, B. K. (1999). Reflections on a research career: One thing leads to another. Exceptional Children, 65(3), 295-300.

Kitchen, S., Finch, S., \& Sinclair, R. (2007). Harnessing Technology School Survey. Coventry, UK: Becta.

Knezek, G., \& Christensen, R. (1999). Stages of adoption for technology in education. Computers in New Zealand Schools.

Kvale, S. (1996). Interviews: An introduction to qualitative research. London: Sage.

Lai, K.W. (2005). E-Learning Communities: Teaching and learning with the Web. Dunedin: University of Otago Press.

Lankshear, C. (1997). Changing Literacies. Buckingham: Open University Press. Lauer, Quentin. (1965). Phenomenology: Its genesis and Prospect. New York: Harper Torchbooks. 
Leadbeater, C. (2008). We-think: the power of mass creativity. London: Profile.

Leander, K. M., Phillips, N. C., \& Headrick Taylor, K. H. (2010). The changing social spaces of learning; mapping new mobilities. Review of Research in Education, 34(1), 329-394.

Lenhart, A., and Madden, M. (2005). Teen content creators and consumers. Washington DC. Retrieved from http://www.pewInternet.org/files/old$\underline{\text { media/Files/Reports/2005/PIP Teens Content_Creation.pdf.pdf }}$

Lenhart, A., Madden, M., \& Hitlin, P. (2005). Teens and technology: Youth are leading the transition to a fully wired and mobile nation. Washington DC. Pew Internet and American Life Project.

Lenhart, A., Madden, M., Macgill, A.R., \& Smith, A. (2007). Teen Content Creators. Washington DC: Pew Internet and American Life Project.

Lenhart, A., and Madden, M. (2007a). Social networking websites and teens: An overview. Retrieved from http://www.pewInternet.org/PPF/r/198/report_display.asp

Lenhart, A., and Madden, M. (2007b). Teens, privacy and online social networks: How teens manage their online identities and personal information in the age of MySpace. Washington DC: Pew Internet and American Life Project.

Levin, D., Arafeh, S., Lenhart, A., \& Rainie, L. (2002). The digital disconnect: The widening gap between Internet-savvy students and their schools. Washington DC: Pew Internet and American Life project.

Lincoln, Y.S., \& Guba, E.G. (1985). Naturalistic inquiry. Newbury Park, CA: Sage.

Livingstone, S., and Helsper E.J., (2007) Gradations in digital inclusion: Children, young people and the digital divide. New Media \& Society 9 (4): 671- 696.

Lodge, C. (2008). Student Voice and Learning-focused School Improvement Research Matters (Vol. 32). London: INSI.

Loveless, A. (2002). Literature review in creativity, new technologies and learning. Report 4: A report for NESTA Futurelab. Retrieved from www.nestafuturelab.org/research/reviews/cr01.htm 
Lowther, D.L., Inan, F.A., Strahl, J.D., Ross, S.M. (2008). Does technology integration "work" when key barriers are removed? Educational Media International, 45(3), 195-206.

Luckin, R., Clark, W., Grabner, R., Logan, K., Mee, A., \& Oliver, M. (2009). Do web 2.0 tool really open the door to learning? Practices, perceptions and profiles of 11- 16 year old students. Learning Media and Technology, 34(2), 87- 104.

Madden, M., Lenhart, A., Duggan, M., Cortesi, S. \& Gasser, U. (2013). Teens and Technology 2013. Retrieved from http://www.pewinternet.org/Reports/2013/Teensand-Tech.aspx

McLeod, Scott, Lehmann, C., (2011). What school leaders need to know about digital technologies and social media. San Francisco, CA: Jossey - Bass

McNeely, G. (2005). Using technology as a learning tool, not just the cool new thing. In Oblinger, D. G. \& Oblinger, J.L (Ed.) Retrieved from http://www.educause.edu/books/educatingtheNetgen

Merriam, S. B. (1998). Case study research in education: A qualitative approach. San Francisco: Jossey- Bass.

Miles, M.B. \& Huberman, A.M. (1994). Qualitative data analysis: an expanded sourcebook. Thousand Oaks: SAGE Publications.

Miller, M., Gibson, A., Smith, P., Bell, A., \& Crothers, C. (2013). The Internet in New Zealand 2013. Auckland, New Zealand: Institute of Culture, Discourse \& Communication AUT University.

Ministry of Education. (2005). DigiOps project - Tech Angels. Retrieved from http://www.minedu.govt.nz/NZEducation/EducationPolicies/Schools/SchoolOpe $\underline{\text { rations/Resourcing/ResourcingHandbook/Chapter1/DecileRatings.aspx }}$

Ministry of Education. (2006). ICT Strategic Framework for Education: Ministry of Education. Wellington, New Zealand.

Ministry of Education. (2007). The New Zealand Curriculum. Wellington: Learning Media. 
Ministry of Education (2013). New Zealand Education. Retrieved from http://www.minedu.govt.nz/NZEducation/EducationPolicies/Schools/SchoolOpe rations/Resourcing/ResourcingHandbook/Chapter1/DecileRatings.aspx

Ministry of Education (2014). Future -focused learning in connected communities. Retrievedfromhttp://www.education.govt.nz/assets/Documents/Ministry/Initiativ es/FutureFocusedLearning30May2014.pdf

Ministry of Education (2014). New Zealand Education in 2025. Retrieved from http://www.education.govt.nz/assets/Documents/Ministry/Initiatives/Lifelonglea $\underline{\text { rners.pdf }}$

Ministry of Education (2010). M learning capability pilot project: Research report for the Ministry of Education. University of Waikato

Moser, F.Z. (2007). Faculty Adoption of Educational Technology. Educause Quarterly, 1, 66-69. Retrieved from http://www.er.educause.edu

Moss, G., Jewitt, C., Levacic, R., Armstrong, V., Cardini, A., \& Castle, F. (2002). The interactive whiteboards, pedagogy and pupil performance evaluation: An evaluation of the schools whiteboard expansion (SWE). London: DfES.

Moustakas, C. (1994). Phenomenological Research Methods. Thousand Oaks: SAGE Publications.

Muir-Herzig, R. G. (2004). Technology and its impact in the classroom. Computers and Education, 42(2), 111-131.

Neal, G. (2005). Student Reflections of the effectiveness of ICT as a learning resource. Paper presented at the AARE Conference, Parramatta. Retrieved from http://www.aare.edu.au/data/publications/2005/nea05582.pdf

New Zealand Government. (2004). Digital strategy: A draft New Zealand strategy for consultation .Wellington, NZ: New Zealand Government.

New Zealand Government. (2005). The digital strategy: Creating our digital future. Wellington, NZ: New Zealand Government.

Oblinger, D., \& Oblinger, J. L. (2005). Educating the Net generation. Retrieved from www.educause.edu/educatingtheNetgen/ 
Oblinger, D., (2008). Emerging technologies for learning- Volume 3, Coventry, UK. Becta

Ofsted. (2005). Embedding ICT in schools - a dual evaluation exercise. Retrieved from, www.ofsted.gov.uk/Ofstedhome/Publications-andresearch/Education/Curriculum/Information- andcommunicationtechnology/Secondary/Embedding-ICT-in-schools-a-dualevaluation-exercise

Owen, S., \& Moyle, K. (2008). Students'voices learning with technologies. Students' expectations about learning with technologies: A literature review. Canberra: University of Canberra.

Papert, S. (1980). Mindstorms: Children, computers and powerful ideas. New York: Basic Books.

Passey, D., Rogers, C., Machell, J., \& McHugh, G. (2004). Passey, D., Rogers, C., Machell, J., \& McHugh, G. (2004). The motivational effect of ICT on pupils Lancaster: DfES.

Patton, M. Q. (Ed.). (2001). Analysis, interpretation, and reporting. In Qualitative research and evaluation methods (3rd ed.). Thousand Oaks, CA: Sage.

Pedretti, E., Mayer-Smith, J., \& Woodrow, J. (1998). Technology, text and talk. Students' perspectives on teaching and learning in a technology enhanced secondary classroom. Science Education, 82(5), 569- 589.

Pietersen, C. (2002). Research as a learning experience: A phenomenological explication. . The Qualitative Report, 7(2). http://www.nova.edu/ssss/QR/QR72/pietersen.html

Pivec, M. (2007). Play and learn: Potentials of game based learning. . British Journal of Educational Technology, 38(3), 387-393.

Poole, D.A., \& White, L. (1991). Effects of question repetition on the eye witness testimony of children and adults. Developmental Psychology, 27, 975-986.

Prasad, P. (2005). Crafting qualitative research: Working in post-positivist traditions. New York: M.E. Sharpe Inc.

Prensky, M. (2001). Digital Natives, Digital Immigrants. On the Horizon, 9(5), 1-6. 
Prensky, M. (2005 (a). "Engage me or enrage me" - what today's learners demand? Educause Review, 40(5), 60-65

Prensky, M. (2005 (b)). Listen to the Natives. Educational Leadership, 63(4), 8-13.

Prensky, M. (2009). H.Sapiens Digital: From Digital Immigrants and Digital Natives to Digital Wisdom. Innovate: Journal of Online Education. Retrieved from http://www.wisdompage.com/Prensky01.html.

Purcell, K., Buchanan, J., \& Friedrich, L. (2013). The impact of Digital tools on student writing and how writing is taught in schools. Retrieved from http://pewinternet.org/Reports/2013/Teachers-technology-and-writing

Puttnam, D. (2007, Tuesday 8 May). In class I have to power down. The Guardian. Manchester.

Quaglia, Russell, J., Corso, Michael, J. (2014) Student Voice. The Instrument of Change. Corwin, Thousand Oaks, CA.

Raymond, L. (2001). Student involvement in school improvement. Forum, 43(2), $58-61$.

Reid, K., Flowers, P., \& Larkin, M. (2005, 01). Exploring lived experience. Psychologist, 18, 20-23. Retrieved from http://search.proquest.com/docview/211749955?accountid=14782

Roberts, D. F., \& Foehr, U. G. (2005). Trends in Media Use. Children and Electronic Media 18(1), 11-37. Retrieved from http://futureofchildren.org/publications/journals/journal details/index.xml?journ $\underline{\text { alid }=32}$

Roberts, D. F., Foehr, U. G., \& Rideout, V. (2010). Generation M: Media in the lives of 8- 18 year olds. Washington, DC: Kaiser Family Foundation.

Robinson, C., \& Taylor, C. (2007). Theorising student voice: values and perspectives. Improving Schools, 10(1), 5-17.

Rogers, E. M. (1995). Diffusion of innovations (4 ed.). New York: Simon \& Schuster.

Rogers, E. M. (2003). Diffusions of innovations (5th ed.). New York: Free. 
Roschelle, J. M., Pea, R., Hoadley, C. M., Gordin, D. N., \& Means, B. M. (2000). Changing how and what children learn in school with computer-based technologies. The Future of Children, 10(2), 76-101.

Rosen, L. D., Carrier, L. M., \& Cheever, N. A. (2010). Rewired: Understanding the iGeneration and the way they learn. New York: Palgrave Macmillan.

Rowlands, I., Nicholas, D., Huntington, P., Gunter, B., Withey, R., Dobrowolski, T., et al. (2008). Information behaviour of the researcher of the future. Retrieved from

http://www.jisc.ac.uk/whatwedo/programmes/resourcediscovery/googlegen.aspx

Rubin, H.J., \& Rubin, I.S. (2005). Qualitative interviewing: The art of hearing data. $\left(2^{\text {nd }}\right.$ ed). Thousand Oaks, CA: Sage

Rudd, T., Colligan, F., Naik, R. (2007). Learner Voice: A Handbook. Bristol: Futurelab

Ruddock J., \& Flutter J. (2004). How to Improve your School: Giving Pupils a Voice. London: Continuum.

Rudduck, J., Chaplain, R., \& Wallace, G. (Eds.). (1996). School improvement: What can pupils tell us? London, United Kingdom: Fulton.

Rudduck, J., \& Flutter, J. (1996). Consulting young people in schools. Cambridge: Homerton College, University of Cambridge, Economic and Social Research Council.

Sandt, C. (1999). Interviewing children just got easier. ABA Child Law Practice 18(8), 126-127. Retrieved from http://www.kidscounsel.org

Schwandt, T. A. (1997). Qualitative inquiry: A dictionary of terms. Thousand Oaks, CA: Sage.

Seidman, I. E. (1991). Interviewing as qualitative research: A guide for researchers in education and the social sciences. New York: Teachers College Press.

Selwyn, N. (2006). Exploring the digital disconnect between net savvy students and their schools. Learning, Media and Technology, 31, 5-17.

Selwyn, N. (2012). Making sense of young people, education and digital technology: the role of sociological theory. Oxford Review of Education, 38(1), 81-96. 
Selwyn, N., \& Grant, L. (2009). Researching the realities of social software use - an introduction. Learning, Media and Technology, 34(2), 79 -86.

Shapley, K., Sheehan, D., Maloney, C., \& Caranikas-Walker, F. (2011). Effects of technology immersion on middle schools students' learning opportunities and achievement. The Journal of Educational Research, 104(5), 299-315.

Sheehan, M., \& Nillas, L. A. (2010). Technology integration in secondary mathematics classrooms: Effect on students' understanding Journal of Technology Integration in the Classroom, 2(3), p. 67

Siemens, G. (2004). Connectivism: A learning theory for the Digital Age. http://www.elearnspace.org/Articles/connectivism.htm

Siemens, G. (2006, November 18). Knowing Knowledge. http://ltc.umanitoba.ca/KnowingKnowledge/index.php/Main_Page

Sime, D., Priestley, M. (2005). Student teachers' first reflections on information and communications technology and classroom learning: Implications for initial teacher education Journal of Computer Assisted Learning, 21(2), 130-142.

Smith, J.A. (2010). Evaluating the contribution of interpretative phenomenological analysis. Health Psychology Review, 5, (1), 9 - 27.

Smith, D. W. (2013). Phenomenology. In E. N. Zalta (Ed.), The Stanford Encyclopedia of Philosophy (Winter ed.).

Smith, P., Gibson, A., Crothers, C., Billot, J., \& Bell, A. (2011). The Internet in New Zealand. Auckland, New Zealand: Institute of Culture, Discourse \& Communication, AUT University.

Somekh, B., Underwood, J., Convery, A., Dillon, G., Jarvis, J., \& Lewin, C. (2007). Evaluation of the ICT Test Bed project (Final). Centre for ICT, Pedagogy and Learning Education and Social Research Institute, Manchester Metropolitan University. Retrieved from http://dera.ioe.ac.uk/1584/1/Becta 2006 icttestbed annualreport report.pdf

Spitzer, M., (2015) Bottom of the class. New Scientist 228 (3043). 28-29

Stake, R. E. (2006). Multiple case study analysis. New York: Guilford Press.

Starkey, L. (2012). Teaching and Learning in the Digital Age: Routledge. 
Statistics New Zealand. (2004). The Digital Divide - Examining the main characteristics that influence household Internet connection in New Zealand. Retrieved from www.stats.govt.nz

Statistics New Zealand. (2007). Information and communication technology in New Zealand: 2006 Wellington: Statistics New Zealand.

Statistics New Zealand. (2013). Household use of Information and Communication Technology: 2012: Wellington: Statistics New Zealand Retrieved from http://www.stats.govt.nz/ /media/Statistics/Browse\%20for\%20stats/Househo ldUseofICT/HOTP2012/HouseholdUseofICT2012HOTP.pdf

Steele, J. R., \& Brown, J. D. (1995). Adolescent room culture: Studying media in the context of everyday life. Journal of Youth and Adolescence, 25(5), 551.

Stenbacka, C. (1999). Qualitative research requires quality concepts of its own. Management Decision, 39(7), 551-555.

Stones, C. R. (1988). Research: Toward a phenomenological praxis. In D. Kruger (Ed.), An introduction to phenomenological psychology (2nd ed., pp. 141-156). Cape Town, South Africa: Juta.

Strauss, A., \& Corbin, J. (1990). Basics of qualitative research: Grounded theory procedures and techniques. Newbury Park, CA: Sage Publications, Inc.

Tapscott, D. (1998). Growing up Digital: The rise of the Net generation. New York: McGraw Hill.

Tapscott, D. (2009). Grown up digital: How the Net Generation is changing your world. New York: McGraw Hill.

Tapscott, D., \& Williams. (2006). Wikinomics: How Mass Collaboration Changes Everything. New York: Portfolio.

Terre Blanche, M. \& Durrheim, K. (2002). Research in Practice. Applied Methods for the Social Sciences. ( $2^{\text {nd }}$ ed.) Capetown, UCT Press

Thomson, P. (2011). Coming to terms with 'voice'. In G. Czerniawski \& W. Kidd (Eds.), The student voice handbook: Bridging the academic/practitioner divide (pp. 19-30). Bingley, United Kingdom: Emerald.

Trochim, William M. (2001). The Research Methods Knowledge Base, 2nd Edition. Retrieved from http://www.socialresearchmethods.net/kb/ 
Trochim, W. M. K. (2006). Qualitative validity. Web Center for Social Research Methods. Retrieved from http://www.socialresearchmethods.net/kb/qualval.php

Tuttle, H. V. (2012). The lived experiences of faculty who use instructional technology: A phenomenological study. (PhD), University of Nebraska, Lincoln, Nebraska.

Underwood, J. (2009). The impact of digital technology: A review of the evidence of the impact of digital technologies on formal education. Coventry, UK: Becta.

Valentine, P., \& Holloway, S. L. (2002). Cyber kids? Exploring children's identities and social networks in online and off-line worlds. Association of American Geographers, 92, 301-319.

van Manen, M. (1990). Researching lived experience: Human science for an action sensitive pedagogy. . London, Ontario, Canada: The State University of New York.

Vincent, J. (2004). 1116 Mobile: examining mobile phone and ICT use amongst children aged 11 to 16 . Retrieved from http://www.dwrc.surrey.ac.uk/Portals/0/11-16Mobiles.pdf

Vygotsky, L. (1986). Thought and Language. Cambridge, Mass: The MIT Press. Wenglinski, H. (1998). Does it compute? The relationship between educational technology and student achievement in mathematics. Princeton, NJ: ETS.

Williamson, B., (2013). The future of the Curriculum. School Knowledge in the Digital Age. Cambridge, MA; MIT Press

Willis, J. W. (2007). Foundations of qualitative research: interpretive and critical approaches. Thousand Oaks: SAGE Publications.

Windham, C. (2005). Father Google and Mother IM: Confessions of a Net Gen Learner. Educause Review, 40(5), 43-58.

Windschitle, M. (1998). The WWW and classroom research: What path should we take? Educational researcher, 27(1), 28 -33.

Wolcott, H.F. (1994). Transforming qualitative data: description, analysis and interpretation. Thousand Oaks: SAGE Publications. 
Wright, N. (2010). E-Learning and implications for New Zealand schools: a literature review. Wellington: Ministry of Education.

Wurman, R. S. (1989). Information anxiety. New York; Doubleday.

Xu, Y, \& Meyer K (2007). Factors explaining faculty technology use and productivity. The Internet and Higher Education, 10 (1), 41-52.

Yin, Robert K., (1994) Case Study Research: Design and Methods. Thousand Oaks. Sage Publications 
Appendices 


\section{Appendix A}

\section{Initial Information Technology survey.}

I am Judy Lymbery, Lecturer at Victoria University of Wellington, School of Educational Psychology and Pedagogy. I am carrying out a research project for my $\mathrm{PhD}$ examining how secondary students use technology for learning. I want to find out how students in New Zealand are using current technologies and how it may be influencing the way that they learn. This information will be used to inform my research and may be used to inform teachers how they can best meet the learning needs of the "Netgen" students.

This survey is designed to determine the ways in which secondary school students use ICT both at school and at home. Your response to this survey will add valuable information to this research. Your responses will be treated as confidential; you and your school will not be identified in the final report. The information that you supply will only be used for this research and will not be shared with any other organisation.

The survey is divided into three sections, general information, ICT at school and ICT at home. Please ensure that you answer all questions to the best of your ability.

Thank you for taking the time to complete this survey and if you have additional comments to make please add them to the final page of the survey.

Please read the next section carefully and then sign your name at the bottom of the form.

I understand that by completing this form I am giving my consent to participate in this part of the research project only.

Signed:

Date: 


\section{Section A: General Information}

Please supply the following background information.

1. Gender: Male/Female

2. Age in years:

3. Year Level:

4. How many years have you been using computers? Circle your answer.

Less than a year

$1-2$ years

$3-4$ years

$5-6$ years

More than 6 years

5. How would you rate your skills in using the following applications?

\begin{tabular}{|l|l|l|l|l|l|}
\hline & Excellent & Very Good & Average & Poor & Never Used \\
\hline $\begin{array}{l}\text { Word Processing } \\
\text { Spread sheets }\end{array}$ & & & & & \\
\hline Power point & & & & & \\
\hline e-mail & & & & & \\
\hline $\begin{array}{l}\text { Internet } \\
\text { browsing }\end{array}$ & & & & & \\
\hline Graphics & & & & & \\
\hline $\begin{array}{l}\text { Web page } \\
\text { design }\end{array}$ & & & & & \\
\hline $\begin{array}{l}\text { Chat (msn) } \\
\text { or other }\end{array}$ & & & & & \\
\hline $\begin{array}{l}\text { Social } \\
\text { networking } \\
\text { Bebo etc.) }\end{array}$ & & & & \\
\hline
\end{tabular}




\begin{tabular}{|l|l|l|l|l|l|}
\hline $\begin{array}{l}\text { On Line } \\
\text { Shopping }\end{array}$ & & & & & \\
\hline $\begin{array}{l}\text { Interactive } \\
\text { whiteboard }\end{array}$ & & & & & \\
\hline
\end{tabular}

6. Who taught you about computers? Please tick as many as necessary.

Myself

$\square$ Training Course

$\square$ Teachers

$\square$ On-line help

$\square$ Friends

$\square$ Family

$\square$ Other (please list) 


\section{Section B: At School}

1. Do you use computers at school?

$\mathrm{Yes} / \mathrm{No}$

2. What type of computers does your school have for student use?

Laptop

Desktop PC

Both

3. How often do you use computers at school?

Daily

Weekly

Monthly

4. At school what do you use a computer for? Please tick as many as you use

\begin{tabular}{|l|l|}
\hline e-mail & Internet \\
\hline Chat & Web design \\
\hline Games & Research \\
\hline Word processing & Animation \\
\hline Drawing/painting & Databases \\
\hline Multimedia production & Spread sheets \\
\hline Music production & Programming \\
\hline Other Uses: & \\
\hline
\end{tabular}

5. What do you most like using the computer for at school? 
6. List all the subjects in which you use computers:

7. What, if anything, do you find frustrating about using computers at school?

8. Which of the following do your teachers use in their teaching?

\begin{tabular}{|l|l|}
\hline Overhead Projector & TV \\
\hline Video player & DVD \\
\hline Digital camera & $\begin{array}{l}\text { Multimedia } \\
\text { projector }\end{array}$ \\
\hline Laptop computer & Desktop computer \\
\hline Printer & Scanner \\
\hline CD writer & Cell phone \\
\hline Interactive whiteboard & Any other technology device: \\
& \\
\hline
\end{tabular}




\section{Section C: Technology at Home}

1. Do you have a computer at home?

Yes/No

If you do not have a computer at home, please answer the questions based on where you mostly use a computer outside of school.

2. If you do not have a computer at home where else can you use a computer?

3. Do you have Internet at home? Yes/No

4. Do you have a personal e-mail address? Yes/No

5. Do you have your own web site? Yes/No

6. How often do you use your home computer?

Every day

2-3 times a week

Less than once a week

7. Do you have?

\begin{tabular}{|l|l|}
\hline Printer & Scanner \\
\hline Digital camera & Webcam \\
\hline Computer speakers & Cd writer/burner \\
\hline DVD player & Cell phone \\
\hline Other items/ peripherals: & \\
& \\
\hline
\end{tabular}

8. What do you mostly use your computer for at home?

Thank you for completing the survey, if you wish to add any other comments please do so here. 
Appendix B

Participant Information sheet and Consent Form 


\section{Information Sheet}

\section{Research project: A phenomenological investigation of secondary students experiences of using technology for learning.}

\section{$\underline{\text { Participant Information Sheet }}$}

I am Judy Lymbery, Lecturer at Victoria University of Wellington, School of Educational Psychology and Pedagogy. I am carrying out a research project for my $\mathrm{PhD}$ examining how secondary students use technology for learning.

I am inviting thirty secondary students to participate in this project by completing an initial general survey and then following up some of the issues from the survey with in-depth interviews and focus group discussions. I will be asking you about your experiences of using technology in your learning. As this research is about using technology there will be the opportunity to communicate your thoughts and ideas via a blog and wiki. The blog and the wiki will only be available to the project participants, so all information will remain confidential.

If you choose to participate in this project it will take approximately 20 minutes of your time to complete the survey and then 1-2 individual interviews to be held at a mutually convenient time and place. These interviews will be spread over a period of 4 months. There will also be the opportunity to participate in a focus group discussion if you consent to this. The contribution to the blog and wiki will be on going throughout the research period on an as and when required basis.

You will be required to sign a form giving your consent to be a voluntary participant in this project.

Your rights as a participant include the following:

- To decline to participate in the research project

- To refuse to answer any questions

- To withdraw from the research at any time without question

- To ask any questions about the research at any time

- Your responses will remain confidential, and you will not be identified in any way

- To be provided with a copy of all information that you have provided upon request

- To have access to the final report

- To have a support person present during the interviews. 
The information gathered during this project will be used to contribute to my $\mathrm{PhD}$ and also in my work at the University in Teacher education.

If you have any questions about this research please contact me at judy.lymbery@vuw.ac.nz or contact my supervisors Dr Lex McDonald and Dr Stephen Marshall.

\author{
Dr L McDonald \\ Head of School \\ School of Educational Psychology and Pedagogy \\ Victoria University of Wellington \\ Donald St \\ Karori \\ Tel 044635173 \\ lex.mcdonald@,vuw.ac.nz \\ Dr Stephen Marshall \\ Acting Director UTDC \\ Victoria University of Wellington \\ Kelburn \\ Tel 044635205 \\ stephen.marshall@vuw.ac.nz
}




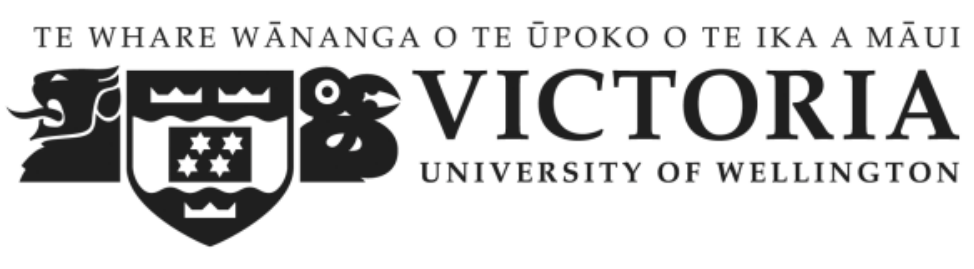

Consent Form.

I am Judy Lymbery from Victoria University of Wellington, School of Psychology and Pedagogy and I am conducting a research project on,

"A phenomenological investigation of secondary students experiences of using technology for learning."

If you would like to take part in this research project you must read the following and then sign the form to say that you are a willing participant in this study.

\section{Contract}

I have read and understand the details of the study as explained on the Information sheet. All my questions have been answered to my satisfaction, and I understand that I may ask for further clarification at any time.

I understand that I have the right to withdraw from the research project at any time and decline to answer any questions.

I agree to provide the researcher with information on the understanding that my name will not be used and my school and I will not be identified in any way.

The information that I give will only be used for this research project and publications arising from it.

I agree to any interview being recorded and that I can ask for this to be stopped at any time. At the end of the research the recordings will be destroyed and all other material returned to participant if requested.

If requested, I agree to participate in an individual interview and/or a focus group.

I agree to participate in this research project as set out above.

Signed.

Name. Date 


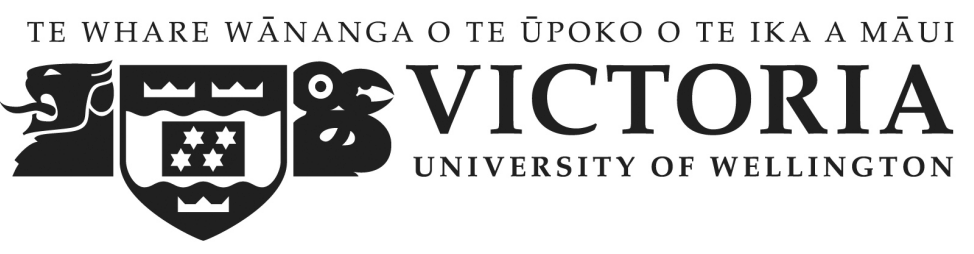

Date

Dear

I am Judy Lymbery, Lecturer at Victoria University of Wellington. At the current time I am carrying out a research project as part of my $\mathrm{PhD}$ looking at how students are using technology for learning and whether this use has changed the way in which they prefer to learn.

I am seeking your permission to approach students at your school who would be willing to take part in this project. They would be asked to complete a general questionnaire about their technology usage and skills. I would like to approach 20 students in year 12 of mixed gender and ethnicity who are not taking a specific IT course at this level. I would also then like to follow up with a focus group meeting or an individual interview with a small number of these students. I would like to interview 30 students from a variety of secondary schools in the Wellington region, so this interview may only involve two or three student from your school.

The confidentiality and privacy of the students will be maintained at all times and no individual or school will be identified in the final report. All participants will be asked if they wish to participate and will be given an information sheet about the project. They will be asked to sign a consent form that clearly outlines their role as a participant in the project. They will be able to leave the project at any time and all information they have given will be destroyed at the conclusion of the project.

If you are happy for me to undertake this project with your students can you please sign and return the enclosed consent form. 
If you have any questions about this project please contact me or my supervisors using the details below.

Judy Lymbery — judy.lymbery@vuw.ac.nz

Dr L.McDonald 044635173 lex.mcdonald@,vuw.ac.nz

Dr S Marshall 04-463 5205 stephen.marshall@vuw.ac.nz

Yours sincerely

Judy Lymbery 


\section{Appendix C}

\section{Consent form for Principals}

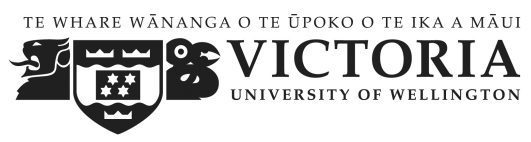

\section{Consent Form for Principals}

I am Judy Lymbery from Victoria University of Wellington, School of Psychology and Pedagogy and I am conducting a research project on,

"A phenomenological investigation of secondary students experiences of using technology for learning."

\section{Contract}

I have read and understand the details of the study as explained on the Information sheet. All my questions have been answered to my satisfaction, and I understand that I may ask for further clarification at any time.

I understand that I have the right to withdraw my permission to participate in this research project at any time and decline to answer any questions.

I understand that the researcher does not foresee any potential physical, psychological, social, legal, or other risks to the participants, my school or themselves during this research.

The information that is gathered will be stored securely on the Victoria University site for at least five years and will be destroyed when no longer required.

I agree that research data may be published provided that my identity and that of the school and students will not be disclosed.

I agree to allow this research project to contact the students at my school and that I may withdraw my permission at any time.

Signed:

Name:

Date:

School:

Please return this signed form in the enclosed envelope. 


\section{Appendix D}

\section{Information for Focus groups}

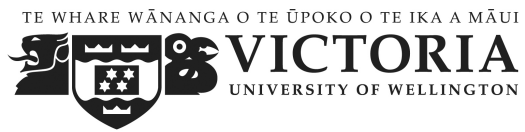

\section{Information Sheet for Focus Group}

Research project: A phenomenological investigation of secondary students experiences of using technology for learning.

\section{$\underline{\text { Participant Information Sheet }}$}

I am Judy Lymbery, Lecturer at Victoria University of Wellington, School of Educational Psychology and Pedagogy. I am carrying out a research project for my $\mathrm{PhD}$ examining how secondary students use technology for learning.

As part of this research I would like to offer you the opportunity to discuss your thoughts and ideas with other students. This is not a compulsory element of the project and you do not have to become involved if you do not want to. However if you choose to take part then there are some ground rules for the group that you must agree to follow. I have listed your rights as a participant in the project below and added on to this rules for engagement in the focus group. You will be asked to sign this letter to agree to follow these rules.

Your rights as a participant in this project include the following;

- To decline to participate in the research project

- To refuse to answer any questions

- To withdraw from the research at any time without question

- To ask any questions about the research at any time

- Your responses will remain confidential, and you will not be identified in any way

- To be provided with a copy of all information that you have provided upon request

- To have access to the final report.

For the focus group:

- You must agree to not use names of your school or give any information that could lead to other participant identifying your school 
- All information that is shared within the group must not be revealed to any person who is not part of the project

- The sharing of information is voluntary within the group

- All comments and opinions are to be treated with respect.

At the first meeting of the group there will be an opportunity to discuss these rules and make any changes that will ensure confidentiality and safety of all participants. You will have the opportunity to withdraw from the group at any time.

If you have any questions about this research project or the focus group please contact me at judy.lymbery@vuw.ac.nz or contact my supervisors Dr Lex McDonald and

Dr Stephen Marshall

\author{
Dr L McDonald \\ Head of School \\ School of Educational Psychology and Pedagogy \\ Victoria University of Wellington \\ Donald St \\ Karori \\ Tel 044635173 \\ lex.mcdonald@vuw.ac.nz
}

Dr Stephen Marshall

Acting Director UTDC

Victoria University of Wellington

Kelburn

Tel 044635205

stephen.marshall@vuw.ac.nz

Consent to participate in the Focus group.

I have had the information about the focus group explained to me and my questions answered.

I agree to be a willing participant in the survey and acknowledge my rights as stated above and agree to follow the rules for the focus group.

Signed:

Date: 


\section{Appendix E}

\section{Interview Questions}

These questions are used as a starting point for the individual interviews, other questions will be generated during the discussion between the researcher and the participant. These questions will form a follow up to the general questionnaire.

1. Tell me about the kinds of technology that are available for you to use when you are at school.

2. Tell me about how you learned how to use this technology.

3. Tell me how you have used technology in places other than school, what other technology is available to you?

4. How do teachers use technology with their students?

5. What is most important about having technology available for you to use?

6. What difference in learning do you think this technology will make for you?

7. What do you use technology for in your classroom?

8. Did you have any successful experiences with using computers for your learning? What were they and what made them successful?

9. Do you have any difficulty with technology in the classroom? Why?

10. What impact do you hope technology will have on your learning?

11. What does technology integration mean to you?

12. What skills and knowledge do you find important to draw on in using technology in your classroom?

13. What do you think prevents teachers using technology in the classroom?

14. Is there anything that can be to help teachers use technology for teaching?

15. Can you think of anything that the school should know about how you use technology and how it should be used in school? 


\section{Appendix F Ethics Approval}

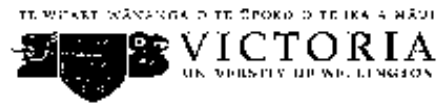

25 March 2010

Judy Lynbery

Lectures

Victoria University of Wallington Faculty of Education

Ci- School of Educational Psychology and Pedagogy

Donald Street

Metlington

Dear Judy

RE: Ethics application SEPP/20D9/40: RU 16731

I am pleased to advise you that your ethics application 'A phenominologlcal investigation of secondary students' experiences of using technology for loarning', with the required changes, has been approved by the Victoria University of Wellingtcr Faculcy of Education Eth.cs Committee. Flease note that the approval for your research to commence is from the date $o^{-}$-his lelter.

Good luck with your research.

Youss Sincerely

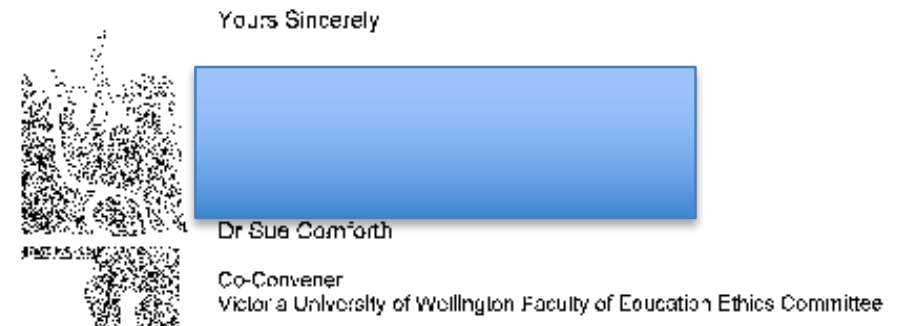

Victor a Unilvergly of Wellng lon Faculty of Eoucation Ethics Comınitte 